\title{
Aperfeiçoamento de uma arquitetura para robótica social
}

\author{
Renato Ramos da Silva
}




\title{
Aperfeiçoamento de uma arquitetura para robótica social
}

\author{
Renato Ramos da Silva
}

Orientadora: Profa. Dra. Roseli Aparecida Francelin Romero

Tese apresentada ao Instituto de Ciências Matemáticas e de Computação - ICMC-USP, como parte dos requisitos para obtenção do título de Doutor em Ciências - Ciências de Computação e Matemática Computacional. VERSÃO REVISADA

USP - São Carlos

Março de 2013 
Ficha catalográfica elaborada pela Biblioteca Prof. Achille Bassi e Seção Técnica de Informática, ICMC/USP, com os dados fornecidos pelo(a) autor(a)

Ramos da Silva, Renato
Aperfeiçoamento de uma Arquitetura para Robótica
Social / Renato Ramos da Silva; orientadora Roseli
Aparecida Francelin Romero. -- São Carlos, 2012.
126 p.
Tese (Doutorado - Programa de Pós-Graduação em
Ciências de Computação e Matemática Computacional) --
Instituto de Ciências Matemáticas e de Computação,
Universidade de São Paulo, 2012.
1. Robótica. I. Aparecida Francelin Romero,
Roseli, orient. II. Título.


Dedico este trabalho a Deus 



\section{Agradecimentos}

À minha noiva, que esteve comigo durante todo o processo deste trabalho. Em todo momento me apoiando e sendo paciente em momentos difíceis.

Aos meu pais, que são exemplo de vida e amor aos filhos. Por estarem sempre comigo, dando todo apoio suporte e amor.

À minha orientadora, prof. Dra. Roseli Francelin Romero, por tornar possível esse trabalho.

Ao meus orientadores em Pittsburgh, o prof. Dr. Reid Simmons e profa. Dra. Judith Matthews, pela oportunidade e exemplo de dedicação ao orientandos.

Minha gratidão aos amigos e colegas que ganhei como graça de Deus durante esse período. Em especial, ao pessoal do Ministério Universidade Renovadas que mesmo na distância sempre estaram perto. Ao pessoal do laboratório BIOCOM e LAR pela amizade e tempos de descontração. Ao Gustavo Almeida, Maxim Makatchev e Zachary Kurtz, colegas que conheci em Pittsburgh.

Agradecimentos especiais à Fundação de Amparo à Pesquisa do Estado de São Paulo (FAPESP) pelo contínuo apoio por meio de auxílios científico-financeiros e à Coordenadoria de Aperfeiçoamento de Pessoal de Nível Superior (CAPES) pelo auxílio financeiro recebido no primeiro semestre e pelo Conselho Nacional de Desenvolvimento Científico e Tecnológico (CNPq) pelo apoio para a realização de um estágio de doutorado no exterior. 



\section{Abstract}

One important aspect of human interaction is the shared attention. It is a communication process where one person redirect his or her attention to an object or event and the other person or people follow gaze to the same place. This process end with a pointing and a comment about the situation by the person that follows the attention. This important ability was learned by us during the childhood and some roboticist are trying to develop robotics architectures to learn this ability in robots. In this way, the Learning Lab Robotics has been working on a robotic architecture used with this proposed. It is composed by three modules, stimulus perception, consequence control and response emission. This robotic architecture was evaluated to control a robotic head and it was capable to learn to follow gaze and identify some objects. However, all of these modules have some limitations. In order to take a better interaction between a robot and a human and reduce the effects of limitations, some improvements were developed. They include a new head pose classification algorithm using histogram of oriented gradient, increase the capability of consequence control with new reflexes and new learning algorithms to select the best action. All modification reduce the limitations and it can improve the interactions between a robot and a human being. 



\section{Resumo}

Um aspecto importante da interação humana é a atenção compartilhada. Ela é um processo de comunicação onde uma pessoa redireciona a sua atenção para um objeto ou evento e a outra pessoa ou pessoas seguem o seu olhar para o mesmo lugar. $\mathrm{O}$ processo é finalizado com a pessoa que segue a atenção realizando um apontamento sobre o objeto e um comentário sobre a situação. Esta habilidade importante é aprendida por nós durante o período da infância e hoje, alguns pesquisadores em robótica estão tentando desenvolver arquiteturas robóticas para aprender essa habilidade em robôs. Deste modo, o laboratório de aprendizado de robôs está trabalhando em uma arquitetura robótica para esse fim. Ela é composta por três módulos, percepção de estímulo, controle de consequência e emissão de resposta. Esta arquitetura robótica foi avaliada no controle de uma cabeça robótica e foi capaz de aprender a seguir o olhar e identificar alguns objetos. No entanto, todos esses módulos têm algumas limitações. A fim de ter uma melhor interação entre um robô e um humano e reduzir os efeitos das limitações, algumas melhorias foram desenvolvidas. Entre elas incluem um novo algoritmo de classificação das posições da cabeça através do histograma de gradiente orientado, inserir novas funcionalidades (definidas como reflexos) ao módulo de controle de consequência e novos algoritmos de aprendizado para selecionar a melhor ação. Todas as modificações realizadas reduziram as limitações e pode melhorar as interações entre um robô e um ser humano. 

Lista de Figuras $\quad$ ix

Lista de Tabelas $\quad$ xi

Lista de Algoritmos $\quad$ xiii

\begin{tabular}{ll} 
Lista de Símbolos & Xv \\
\hline
\end{tabular}

Glossário xviii

1 Introducão 1

1.1 Contextualizacão . . . . . . . . . . . . . . . . . . . . . 1

1.2 Objetivos e Contribuicões . . . . . . . . . . . . . . . . . . 3

1.3 Organização do Trabalho . . . . . . . . . . . . . . . . . . 4

2 Atencão Compartilhada 5

2.1 Conceito . . . . . . . . . . . . . . . . . . . . . 5

2.2 Métodos de Aprendizado . . . . . . . . . . . . . . . . . . 10

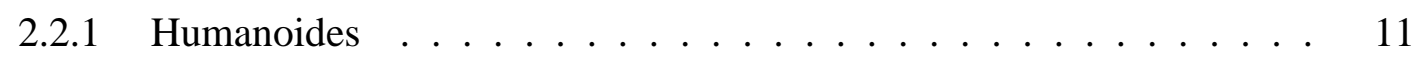

2.2 .2 Tronco Superior . . . . . . . . . . . . . . . . . 13

2.2 .3 Simulacão . . . . . . . . . . . . . . . . . . . . . . . . . . . . . . . . .

2.2.4 Robôs com Aparência não humana . . . . . . . . . . . . . . . . . . 17

2.3 Considerações Finais . . . . . . . . . . . . . . . . . . . . . . . 19

3 Arquitetura Robótica Social 21

3.1 Arquitetura Inspirada na Análise do Comportamento . . . . . . . . . . . . 21

3.1.1 Módulo de Percepcão de Estímulos . . . . . . . . . . . . . . . . 22

3.1.2 Módulo de Controle de Consequências . . . . . . . . . . . . . . 27

3.1.3 Módulo de Emissão de Resposta . . . . . . . . . . . . . . . . . . . 27

3.2 Simulador de Interações Sociais f . . . . . . . . . . . . . . . 28 


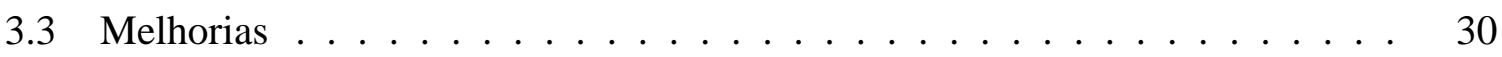

3.3 .1 Módulo de Emissão de Resposta . . . . . . . . . . . . . . . . . . 30

3.4 Funcionamento da Arquitetura $\ldots \ldots \ldots$. . . . . . . . . . . . . . . . 33

3.5 Análise de Complexidade do Algoritmo de Aprendizado . . . . . . . . . . . 37

3.6 Análise de Resultados . . . . . . . . . . . . . . . . . . . . . . . 38

3.6 .1 Métricas . . . . . . . . . . . . . . . . . . . . 38

3.6 .2 Avaliacão . . . . . . . . . . . . . . . . . . 39

3.6.3 Configuracões para os Experimentos . . . . . . . . . . . . . . . 40

3.6 .4 Simulacão . . . . . . . . . . . . . . . . . . . 41

3.6 .5 Cabeça Robótica . . . . . . . . . . . . . . . . . 43

3.7 Limitacões . . . . . . . . . . . . . . . . . . . . . . . . . 45

3.8 Considerações Finais $\ldots \ldots \ldots \ldots$. . . . . . . . . . . . . 47

4 Estimativa de Posição da Face 49

4.1 Introducão . . . . . . . . . . . . . . . . . . . . . . . . . . 49

4.2 Trabalhos Relacionados ...................... 50

4.2.1 Um Modelo Híbrido para Estimativa de Posição da Face . . . . . . . 52

4.2.2 Estimativa da Posicão da Cabeça Utilizando Histograma de Gradientes Orientados com OpenCv . . . . . . . . . . . . . . 55

4.2 .3 Resultados . . . . . . . . . . . . . . . 60

4.3 Considerações Finais . . . . . . . . . . . . . . . . . 62

5 Identidade pessoal $\quad 65$

5.1 Teoria Psico-evolucionária de Emoções $\ldots \ldots$. . . . . . . . . . . 65

5.2 Modulo de Identidade Pessoal $\ldots \ldots \ldots$. . . . . . . . . . . . 66

5.3 Algoritmo de Processamento . . . . . . . . . . . . . . . . . 70

5.4 Experimentos . . . . . . . . . . . . . . . . . . . . 70

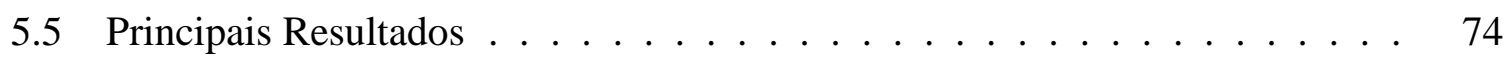

$5.5 .1 \quad$ Experimento $1 \ldots \ldots \ldots \ldots 75$

5.5 .2 Experimento $2 \ldots \ldots \ldots \ldots \ldots$

5.6 Considerações Finais $\ldots \ldots \ldots \ldots$. . . . . . . . . . . . 80

6 Emissão de Resposta $\quad 81$

6.1 Introducão . . . . . . . . . . . . . . . . . . . . . . . 81

6.2 Algoritmos de Aprendizado . . . . . . . . . . . . . . . . . . 82

6.2 .1 Sem Informacão Adicional . . . . . . . . . . . . . . . . . . . . . . . . . . . . . . 82

6.2 .2 Redes Neurais Recorentes . . . . . . . . . . . . . . . 83

6.2 .3 Sem Informacão Adicional Versão 2 . . . . . . . . . . . . . . . . . . 89

6.2 .4 Experimentos Realizados . . . . . . . . . . . . . . . . . . . 90

6.3 Considerações Finais . . . . . . . . . . . . . . . . . . . 94

7 Conclusões e Trabalhos Futuros 97

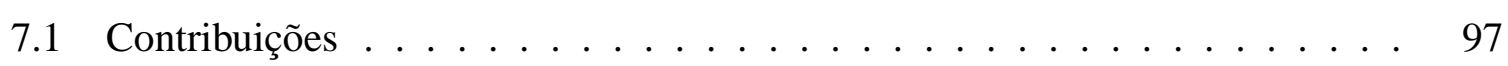

7.2 Trabalhos Futuros . . . . . . . . . . . . . . . . . . 100 
Referências

\begin{tabular}{|l|l|l|l|l}
\hline Apêndice A & 113
\end{tabular}

A.1 Resultado dos testes sobre o módulo de identidade pessoal . . . . . . . . . 113

A.1.1 Experimento $1 \ldots \ldots \ldots \ldots \ldots \ldots \ldots$

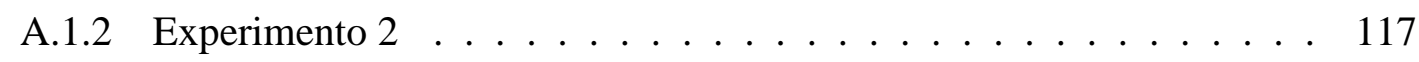





\section{Lista de Figuras}

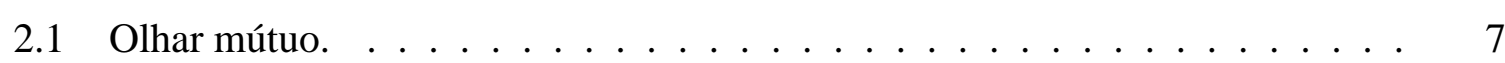

2.2 Seguir à atencão $\ldots \ldots \ldots \ldots$

2.3 Apontamento Imperativo $\ldots \ldots \ldots \ldots$

2.4 Apontamento Declarativo. . . . . . . . . . . . . . . . . . . 9

2.5 Atencão Compartilhada segundo Kaplan. . . . . . . . . . . . . 9

2.6 Atencão Compartilhada segundo Nagay. . . . . . . . . . . . . . . . . 9

2.7 Humanoid Robots. . . . . . . . . . . . . . . . . . . . . . . . 13

2.8 Robôs de tronco superior. . . . . . . . . . . . . . . . . . . . . . 15

2.9 Robôs não humanoides. . . . . . . . . . . . . . . . . . . . . . . . 18

3.1 Organizacão geral da arquitetura. . . . . . . . . . . . . . . . . . 22

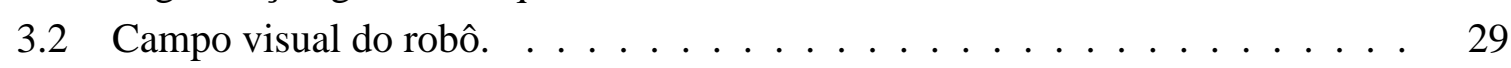

3.3 Controle de posicionamento . . . . . . . . . . . . . . . . . . . . . . . . . . 29

3.4 Modelo geral de funcionamento . . . . . . . . . . . . . . . . . . . . 33

3.5 Representacão dos estados e ações. . . . . . . . . . . . . . . . . 34

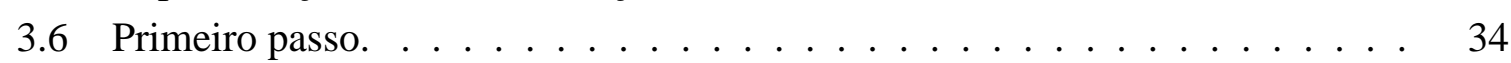

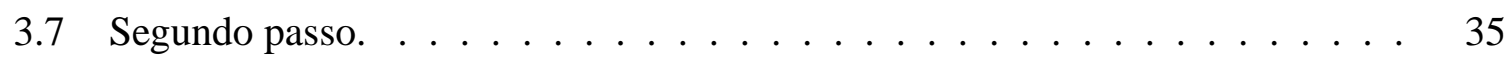

3.8 Terceira etapa. $\ldots \ldots \ldots \ldots \ldots \ldots$

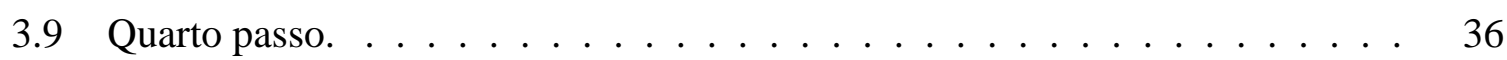

3.10 Ouinto passo . . . . . . . . . . . . . . . . . . . . 37

3.11 Evolucão do aprendizado durante os experimentos. . . . . . . . . . . . 42

3.12 Evolucão do aprendizado durante os experimentos. . . . . . . . . . 42

3.13 Evolucão do aprendizado durante os experimentos. . . . . . . . . . . 44

3.14 Evolução do aprendizado durante os experimentos. . . . . . . . . . . . . 46

4.1 Fluxograma do funcionamento do sistema de estimativa da face. . . . . . . . 52

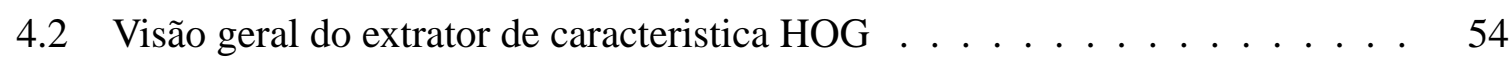

4.3 Fluxograma do funcionamento do sistema de estimativa da face . . . . . . . 56

4.4 Estados analisados para classificação . . . . . . . . . . . . . . . . . . 57 
$4.5 \quad$ Tracking da posicão da cabeca no centro da imagem . . . . . . . . . . . . . . 59

4.6 Tracking da posicão da cabeca no lado esquerdo da imagem . . . . . . . . . . 59

4.7 Tracking da posição da cabeça no lado direito da imagem . . . . . . . . . . . 59

5.1 Representacão de teoria psico-evolucionaria de emocões. . . . . . . . . . . . 67

5.2 Representacão de teoria psico-evolucionaria de emoções. . . . . . . . . . . . 68

5.3 Experimento 1 - Resultado energia humor $1 \ldots \ldots$. . . . . . . . . 75

5.4 Experimento 1 - Resultado atencão diversão 1 . . . . . . . . . . . . . 76

5.5 Experimento 1 - Resultado emocões $1 \ldots \ldots$. . . . . . . . . 77

5.6 Experimento 1 - Resultado emocões $3 \ldots \ldots$. . . . . . . . . . . 77

5.7 Experimento 2 - Resultado energia humor $1 \ldots \ldots$. . . . . . . 78

5.8 Experimento 2 - Resultado energia humor $1 \ldots \ldots \ldots$. . . . . . . 78

5.9 Experimento 2 - Resultado emocões $1 \ldots \ldots$. . . . . . . . . 79

5.10 Experimento 1 - Resultado emoções $3 \ldots \ldots$. . . . . . . . . . 80

6.1 Problema do mundo da grade de luz. . . . . . . . . . . . . . . 85

6.2 Célula de memória. . . . . . . . . . . . . . . . . . . 86

6.3 Topologia básica de uma LSTM . . . . . . . . . . . . . . . . . 87

6.4 Comparativo da atencão obtida 1. . . . . . . . . . . . . . . . . . 91

6.5 CGI durante o experimento $1 . \ldots \ldots \ldots$. . . . . . . . . . . . . . . . 92

6.6 Comparativo da atenção obtida $2 . \ldots \ldots \ldots$. . . . . . . . . . . . . . . . . . . . . . . .

6.7 Comparativo da atencão obtida 2. . . . . . . . . . . . . . . . . 93

6.8 CGI durante o experimento $2 . \ldots \ldots \ldots$. . . . . . . . . . . . . . . . . 94

6.9 CGI durante o experimento $2 \ldots \ldots \ldots$. . . . . . . . . . . . . . . 94

A.1 Experimento 1 - Resultado da barra de antecipacão e surpresa 1 . . . . . . . . 114

A.2 Experimento 1 - Resultado da barra de medo e raiva 1 . . . . . . . . . . . . . 114

A.3 Experimento 1 - Resultado da barra de alegria e tristeza 1 . . . . . . . . . . . 114

A.4 Experimento 1 - Resultado da barra de confiança e desgosto $1 \ldots$. . . . . . 115

A.5 Experimento 1 - Resultado energia humor 2 . . . . . . . . . . . . . 115

A.6 Experimento 1 - Resultado atencão diversão 2 . . . . . . . . . . . . . . . 116

A.7 Experimento 1 - Resultado emocões 2 . . . . . . . . . . . . . . . . 116

A.8 Experimento 1 - Resultado da barra de antecipacão e surpresa 2 . . . . . . . . 117

A.9 Experimento 1 - Resultado da barra de medo e raiva 2 . . . . . . . . . . . 117

A.10 Experimento 1 - Resultado da barra de alegria e tristeza 2 . . . . . . . . . . 118

A.11 Experimento 1 - Resultado da barra de confiança e desgosto $2 \ldots . . . . .118$

A.12 Experimento 1 - Resultado energia humor 3 . . . . . . . . . . . . . . . . 119

A.13 Experimento 1 - Resultado atencão diversão 3 . . . . . . . . . . . . . . . . . 119

A.14 Experimento 1 - Resultado da barra de antecipacão e surpresa 3 . . . . . . . . 119

A.15 Experimento 1 - Resultado da barra de medo e raiva 3 . . . . . . . . . . 120

A.16 Experimento 1 - Resultado da barra de alegria e tristeza 3 . . . . . . . . . . 120

A.17 Experimento 1 - Resultado da barra de confianca e desgosto 3 . . . . . . . . 120

A.18 Experimento 2 - Resultado da barra de antecipacão e surpresa 1 . . . . . . . . 121

A.19 Experimento 2 - Resultado da barra de medo e raiva 1 . . . . . . . . . . . 121 
A.20 Experimento 2 - Resultado da barra de alegria e tristeza 1 . . . . . . . . . . . 121

A.21 Experimento 2 - Resultado da barra de confiança e desgosto 1 . . . . . . . . 122

A.22 Experimento 2 - Resultado energia humor $2 \ldots \ldots$. . . . . . . . . 122

A.23 Experimento 2 - Resultado atencão diversão 2 . . . . . . . . . . . . . . . . . 122

A.24 Experimento 2 - Resultado emocões 2 . . . . . . . . . . . . . . . . 123

A.25 Experimento 2 - Resultado da barra de antecipacão e surpresa 2 . . . . . . . . 123

A.26 Experimento 2 - Resultado da barra de medo e raiva 2 . . . . . . . . . . . 123

A.27 Experimento 2 - Resultado da barra de alegria e tristeza 2 . . . . . . . . . . 124

A.28 Experimento 2 - Resultado da barra de confiança e desgosto 2 . . . . . . . . 124

A.29 Experimento 2 - Resultado energia humor 3 . . . . . . . . . . . . . . 125

A.30 Experimento 2 - Resultado atencão diversão 3 . . . . . . . . . . . . . . 125

A.31 Experimento 1 - Resultado da barra de antecipacão e surpresa 3 . . . . . . . . 125

A.32 Experimento 2 - Resultado da barra de medo e raiva 3 . . . . . . . . . . . . 126

A.33 Experimento 2 - Resultado da barra de alegria e tristeza 3 . . . . . . . . . 126

A.34 Experimento 2 - Resultado da barra de confiança e desgosto 3 . . . . . . . 126 



\section{Lista de Tabelas}

3.1 Resultados obtidos após as 5 corridas de sessão de aprendizado por tutelagem.(Silva et. al., 2008) . . . . . . . . . . . . . . . . 45

4.1 Validacão cruzada com 10 amostras . . . . . . . . . . . . . . 61

4.2 Média e desvio padrão da validacão cruzada com 10 amostras _. . . . . . . 61

4.3 Acurácia na classificacão utilizando uma amostra de 10 elementos . . . . . . 63

4.4 Acurácia na classificação utilizando todos os dados . . . . . . . . . . . . . . 64

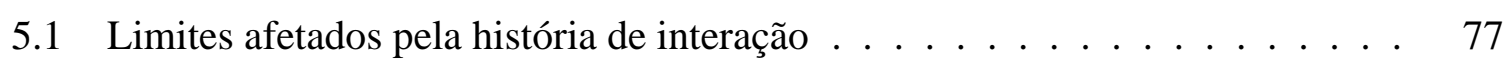

5.2 Limites afetados pela história de interação . . . . . . . . . . . . . . . 80 



\section{Lista de Algoritmos}

$1 \quad$ ETG Algoritmo . . . . . . . . . . . . . . . . . . . . . . . 32

2 Árvore-mecanismo de armazenamento . . . . . . . . . . . . . . 33

$3 \quad$ Módulo de Identidade Pessoal . . . . . . . . . . . . . . . . . . . . 71

$4 \quad$ Algoritmo FAIETGO . . . . . . . . . . . . . . . . . 83

5 Algoritmo FAIETGO - Mecanismo de armazenamento . . . . . . . . . 84

6 Algoritmo FAIETG . . . . . . . . . . . . . . . . . . . . . 84

7 Algoritmo FAIETG - Mecanismo de armazenamento . . . . . . . . . . . 85 

emoção "Uma emoção é um programa com alto grau de ordenação com funções que direcionam as atividade e interações de subprogramas responsaveis pela percepção, atenção, inferência, aprendizado, memória, escolha de objetivos, prioridades motivacionais e reações psicologicas, entre outras" Cosmides \& Tobby (2000). 2, 66

filogenética Campo da biologia que estuda a relação evolutiva entre os organismo por meios de dados genéticos. 2

homeostase Homeostasia (ou Homeostase) é a propriedade de um sistema aberto, seres vivos especialmente, de regular o seu ambiente interno para manter uma condição estável, mediante múltiplos ajustes de equilíbrio dinâmico controlados por mecanismos de regulação inter-relacionados.. 67, 70, 71, 75

humanoide Robô com estrutura corporal semelhante ao do ser humano. 1, 11

pitch é o movimento em torno do eixo horizontal, perpendicular ao eixo longitudinal. Também é chamado de arfagem, é o popular "levantar e abaixar o nariz". 52, 55

pixel Elemento de imagem. O pixal é o menor elemento num dispositivo de exibição, ao qual é possivel atribuir-se uma cor. Em outras palavras, o pixel é o menor ponto que forma uma imagem.. 57

reflexo $\mathrm{O}$ comportamento de reflexo foi definida como uma resposta a um estímulo involuntário; uma resposta instintiva ou sem aprendizado a um estímulo.. 2

roll é o movimento em torno do eixo horizontal, na direção do eixo logitudinal. Também chamado de rolagem.. 52, 55

yaw é o movimento em torno do eixo vertical, perpendicular ao eixo longitudinal. Também chamado de guinada.. 50, 52, 55 
$\alpha$ taxa de aprendizagem. 31,41

$\epsilon$ constante de exploração. 41

$\gamma$ parâmetro de desconto. 31, 41

AR Aprendizado por reforço. 31

AS antecipação-surpresa. 69, 72, 75, 77, 81, 83, 85

AT alegria-tristeza. 68, 72, 76, 77, 81, 83

CD confiança-desgosto. 69, 72, 73, 76, 78, 81, 83, 85

CGI Correct Gaze Index. 38, 39, 44, 98

DOF graus de liberdade. 51

ETG Economic TG. 31, 32, 38

GAC garantir a atenção conjunta. 16

GAVAM Generalized Adaptive View-based Appearance Model. 51

hog histograma de orientação de gradientes. 52 54

IAC iniciar a atenção conjunta. 16

IHR Interação Humano Robô. 11

ISA iniciar a atenção compartilhada. 10

JA atenção conjunta. 6, 10,13, 15,19 
LAR Laboratório de Aprendizado de Robôs. 21

lgo histograma de orientação de gradientes locais. 52, 54, 55

LSTM long short term memory. 89, 92, 94, 95

MIP Módulo de Identidade Pessoal. 67, 70, 71, 74, 80, 104

MLP multilayer perceptron. 50

MR medo-raiva. 69, 72, 75, 78, 81, 83, 85

MSE erro quadrático mínimo. 50

RAC responder à atenção conjunta. 16

RNN rede neural recorrente. 88, 91, 94

RSA responder à atenção compartilhada. 10

SA atenção compartilhada. 2,7, 10, 12, 20

SECS Specialized Egocentrically Coordinated Spaces. 13

SIFT Scale-invariant feature transform. 52, 54

SVM Support Vector Machine. 19, 50, 55, 56, 59, 60, 103

WTA Winner-Takes-All. 13 


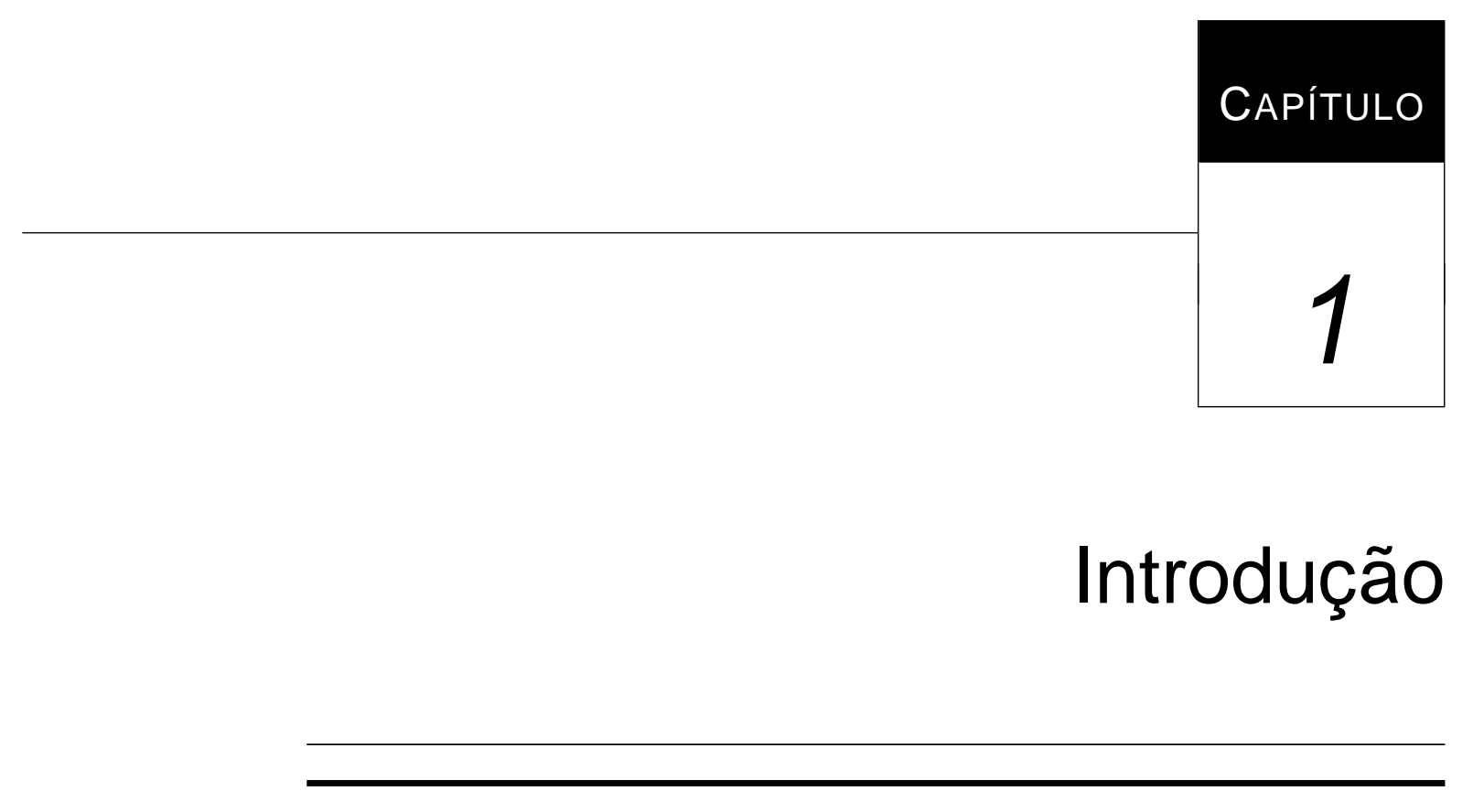

\subsection{Contextualização}

A robótica social é a área de estudo que tem o seu foco na construção de robôs sociais, que podem ser definidos por Bartneck \& Forlizzi (2004) como:

"Um Robô Social é um dispositivo autônomo movél equipado com sensores, atuadores e interfaces (robô) que interage e se comunica com os seres humanos seguindo algumas regras de comportamento esperados, que são fundadas sobre as propriedades físicas do robô e do ambiente onde ele está incorporado, principalmente tendo em conta as necessidades das pessoas com quem se está interagindo"

A definicão acima é adotada perante varias outras existentes Breazeal (2002); Fong et al. (2003), pois a que reune as condições mais proxima da visão contemporânea sobre o assunto. Ele define robô como elemento físico existente no ambiente Duffy (2000); Mataric (2007), enquanto outros assumem que robôs virtuais podem ser considerados como robôs Fong et al. (2003); ?. Além disso, o robô é considerado autônomo, o que significa que ele escolhe as ações sem supervisão, admitindo somente que o comportamento deve estar de acordo com as regras seguidas na sociedade Moral et al. (2009). Ainda assim, para ser considerado social o 
robô deve nos entender e nós, por sua vez, devemos ser capazes de compreende-lo nos mesmos termos sociais Hegel et al. (2008).

O ponto importante na criação de robôs sociais, explanada até o momento, é a comunicação entre os individuos. A interação entre individuos pode ser considerada bem sucedida se o entendimento da comunicação verbal e não verbal é de fato entendida por ambos. Entre as diversas habilidades que exercemos durante a interação, existe uma que é por nós seres humanos aprendida durante a infância que nos auxilia a entender o nosso semelhante durante a interação e é conhecida como atenção compartilhada (AC).

$\mathrm{A} A \mathrm{AC}$ é termo usado para se referir a um fenômeno que acontece quando duas pessoas ou mais estão interagindo. O processo de $\mathrm{AC}$ acontece com duas ou mais pessoas que “ compartilham" suas opiniões, alterando o foco da atenção, de forma intencional por uma das pessoas, para um mesmo ponto de referência. Esse processo pode ser dividido em quatro etapas, que será detalhado no posteriormente. O especial interesse por esse mecanismo está relacionado com a possibilidade de ser um precursor central da linguagem e da comunicação (Deák et al., 2001).

Outro fator importante na comunicação a ser considerado é a emoção. Ela é considerada um reflexo que supostamente é moldada através de uma longa história filogenética. $\mathrm{O}$ interesse na emoção vai além do simples fato da aparência, onde a expressão em determinados momentos reforça o comportamento de uma pessoa durante a interação, tornando a interação mais amistosa, amigavél, prazerosa. Além disso, a emoção influência no processamento de informação, na tomada de decisão, na seleção de ações, no aprendizado ou na organização da memória (Perez et al., 2012).

Todas as habilidades possíveis de serem executadas por um robô são planejadas e estruturadas em arquiteturas robóticas, que são constituídas por módulos, com funções específicas, para a atuação do robô em um ambiente específico. Policastro (2008) desenvolveu uma arquitetura robótica composta por três grandes módulos que podem ser identificados como: módulo de percepção de estímulos, módulo de emissão de respostas e módulo de controle de consequências. Essa arquitetura robótica foi utilizada para controlar uma cabeça robótica em um ambiente controlado sendo capaz de realizar três etapas de todo o processo de $\mathrm{AC}$. Apesar do avanço atingido, algumas limitações ainda dificultam a interação com um ser humano e o desenvolvimento da própria arquitetura robótica.

As limitações relativas a esta arquitetura robótica que serão abordadas nessa tese compreendem os três módulos citados anteriormente. O sistema de percepção de estímulos possui limitação no modelo de estimativa de posição da cabeça que necessita de uma câmera exclusiva e fixa. Além disso, o sistema é sensível ao posicionamento da cabeça da pessoa com quem se interage no ambiente. O módulo de controle de consequências que foi desenvolvido sem a possibilidade de inserção de fatores internos e forma de gerar ações proativas. Finalmente, o 
módulo de emissão de resposta foi desenvolvido com uma dependência do módulo de controle de consequência na seleção de uma ação.

\subsection{Objetivos e Contribuições}

Diante do que foi exposto anteriormente, esta tese tem como principal objetivo melhorar a interação e execução do processo da $\mathrm{AC}$ por um robô através do aperfeiçoamento da arquitetura robótica previamente citada. Desse modo, os seguintes objetivos para cada módulo da arquitetura foram definidos:

- estado da arte: apresentar o estado da arte dos modelos computacionais utilizados para capacitar um robô ou um agente com partes da habilidade da $\mathrm{AC}$,

- visão computacional: desenvolver um método capaz de realizar a estimatição de posição da cabeça que seja mais robusto às variações do ambiente. Além disso o método deve ser capaz de ser utilizado com a(s) câmera(s) do robô;

- identidade pessoal: utilizar métodos que possibilitem emular alguns processos internos, como emoções, e capacitar uma personificação do robô de acordo com a interação realizada pelo mesmo;

- emissão de resposta: capacitar a arquitetura robótica em aprender a $\mathrm{AC}$ ou parte dela, sem utilizar informação adicional de outro módulo.

Com os objetivos definidos acima a ser alcançados, as seguintes contribuções foram atingidas:

- estado da arte: foi realizado o estado da arte dos modelos computacionais utilizados para capacitar um robô ou um agente com partes da habilidade da $\mathrm{AC}$, sendo formalizado em um artigo para revista;

- visão computacional: o algoritmo proposto baseado em histograma de orientação pode ser usado como entrada de dados em uma cabeça robótica, além de minizar as limitações existentes na implementação anterior;

- identidade pessoal: um modelo baseado na psicologia evolutiva que emula alguns processos internos, como emoções, e capacita uma personificação do robô de acordo com a interação realizada pelo mesmo;

- emissão de resposta: desenvolvido um algoritmo de aprendizado por reforço que não segue uma política, mas descobre qual dependência existente entre o estado e a ação anteriormente executada que gera um reforço positivo na selação de ações. 


\subsection{Organização do Trabalho}

Esta tese de doutorado está organizada da seguinte forma:

- Capítulo2-Atenção Compartilhada. Nesse capítulo, é apresentado o estado da arte sobre $\mathrm{AC}$ aplicada à robótica, incluindo os sistemas que utilizam apenas parte do processo $\mathrm{de} \mathrm{AC}$,

- Capítulo 3 - Arquitetura Robótica. Nesse capítulo, é descrito a arquitetura robótica utilizada para interações sociais, com a execução de três etapas da habilidade da $\mathrm{AC}$,

- Capítulo 4 - Visão Computacional. Esse capítulo é dedicado aos estudos realizados para o desenvolvimento de um sistema de visão computacional capaz de classificar as posições da cabeça de uma pessoa e se a mesma está presente no ambiente;

- Capítulo 5-Identidade Pessoal. Esse capítulo contém estudos relacionados à area da psicologia, com foco na psicologia evolutiva das emoções, para a criação de um módulo capaz de emular alguns reflexos humanos;

- Capítulo 6 - Emissão de Respostas. Nesse capítulo, são apresentados métodos de aprendizado baseados em reforço, que capacite um robô a exercer a $\mathrm{AC}$ utilizando somente as informações da interação;

- Capítulo 7 - Conclusões e Trabalhos Futuros. Nesse capítulo, são apresentadas as conclusões desta tese, suas contribuições, limitações e propostas para trabalhos futuros. 


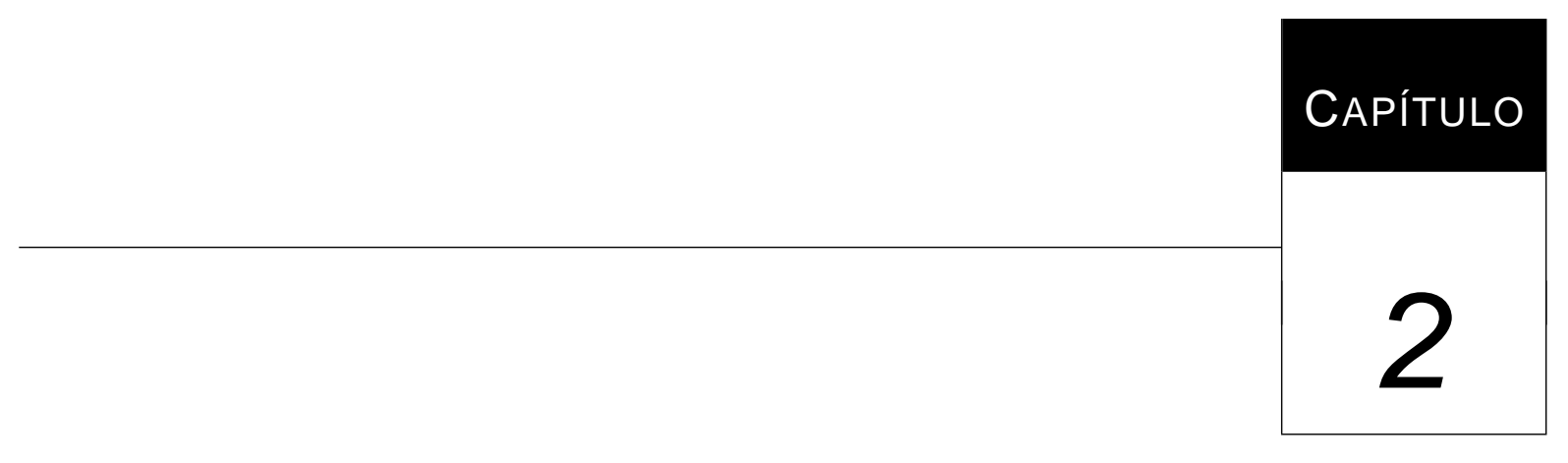

\section{Atenção Compartilhada}

A atenção compartilhada (AC) é termo usado para se referir a um fenômeno que acontece quando duas pessoas ou mais estão interagindo. Ela pressupõe um maior nível de interatividade pela coordenação de ações e percepções para atingir um objetivo comum ou dividir uma experiência (Staudte \& Crocker, 2011). O especial interesse por esse mecanismo está relacionado com a possibilidade de ser um precursor central da linguagem e da comunicação (Deák et al., 2001).

O principal foco desse capítulo é apresentar o conceito da $\mathrm{AC}$ e analisar os trabalhos que estão envolvidos no seu aprendizado ou em parte dela. Além disso, algumas aplicações que utilizam esse fenômeno em diferentes plataformas robóticas serão apresentadas.

\subsection{Conceito}

O termo "atenção" é o processo pelo qual um agente exclui todas as características do ambiente, exceto algumas do seu interesse e se concentra somente nelas. Esse processo pode ocorrer quando o agente dispara automaticamente a atenção a um objeto saliente ou a um evento (atenção passiva), ou quando o agente está envolvido em um processo intencionalmente dirigido ao recurso especial (atenção ativa) (Kaplan \& Hafner, 2004). Além disso, se o 
processo de atenção acontece com duas ou mais pessoas que "compartilham" suas opiniões, alterando o foco da atenção, de forma intencional por uma das pessoas, para um mesmo ponto de referência, então, todo esse processo é denominado "atenção compartilhada".

Outra definição sobre AC pode ser considerada como os comportamentos observáveis de um indivíduo em relação a um objeto ou evento que é fonte da alteração da atenção do indivíduo com o qual se interage, e cada um tem o conhecimento da intenção do outro para esse objeto (Triesch et al., 2006).

E, finalmente, de acordo com Kaplan \& Hafner (2004), uma definição formal pode ser feita por uma sequência de quatro processos:

1. olhar mútuo - ocorre quando o estabelecimento de contato visual entre duas pessoas acontece, onde há uma atenção entre ambos.

2. seguir a atenção - ocorre quando uma pessoa intencionalmente olha para um objeto de interesse ou de algum evento, para o qual outra pessoa está olhando.

3. apontamento imperativo - apontando para um objeto ou evento, independentemente se a outra pessoa está com a atenção nele.

4. apontamento declarativo - fazer alguma suposição sobre a cena em um contexto social adequado.

Esta definição é a que será adotada no presente trabalho. Caso uma interação entre agentes envolva alguns dos 4 quatro processos, será denominada Atenção Compartilhada Parcial.

Além disso, existe o termo 'atenção conjunta (AJ)]', que causa alguma confusão com a AC. Um processo pode ser considerado $\mathrm{AJ}$ quando ele é composto apenas da sequência dos dois primeiros processos, segundo definição adotada, i.e., olhar mútuo e seguir à atenção. Böckler et al. (2011) define AJ, a um nível funcional, como

"a direção do olhar de uma pessoa fornecendo pistas para um observador a respeito do local da sua atenção. Isso provoca no observador uma mudança rápida de atenção para aquele local, sendo a rápida alteração considerada benéfica em diversas situações, como de perigo. Dessa forma, a $\mathrm{AJ}$ fornece uma percepção conjunta pelas pessoas que interagem, pela coordenação de ações interpessoais e o componente central na percepção da outra pessoa."

A maior parte das pesquisas se concentram no processo da $\mathrm{AJ}$ ou seguir o olhar por serem mais simples que a $\mathrm{AC}$. 


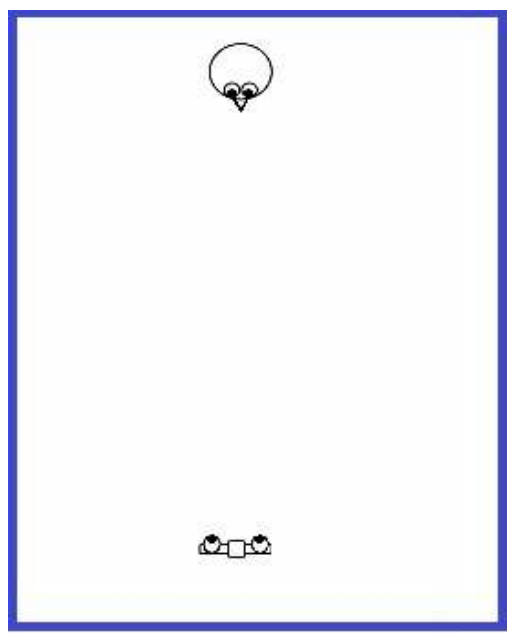

Figura 2.1: Processo do olhar mútuo. Circunstância onde a atenção do robô está no ser humano e vice-versa.

A Figura 2.1 mostra a primeira etapa do processo de $\mathrm{AC}$, o olhar mútuo entre um robô (parte inferior) e um ser humano (parte superior). A atenção mútua permanece durante algum período de tempo (pelo menos alguns segundos). Durante este período, eles podem estar falando sobre alguma coisa. A comunicação verbal neste momento é muito comum, mas não é uma obrigação, é apenas uma maneira que ajuda a manter a atenção.

O segundo passo, seguir a atenção, pode ser definida como o redirecionamento da atenção para o local onde outra pessoa está com o foco, como representado na Figura 2.2. Aqui, um objeto chama a atenção da pessoa no ambiente, fazendo-o redirecionar a atenção, como é apresentado na Figura 2.2 a. Em seguida, o robô direciona a sua atenção para o mesmo objeto, como demonstrado na Figura 2.2 b. Este processo é rápido, mas não é simultâneo. Quando um processo simultâneo acontece, ele não é mais considerado como "seguir a atenção".

O próximo passo está representado na Figura 2.3, apontamento imperativo, é uma confirmação, apontando para um objeto ou evento de interesse usando o braço e mão ou algo similar. Essa etapa aumenta a precisão do observador em focar o objeto correto que é o centro da atenção da outra pessoa.

Finalmente, o último estágio é o momento em que o agente faz alguma comunicação verbal sobre o objeto ou evento. No entanto, eles precisam compartilhar o mesmo aspecto do que está em foco. Podemos exemplificar com a seguinte situação, ao observar uma maçã, a outra pessoa (no nosso caso o robô) poderia perguntar se ela está com fome. Esse é um exemplo geral, mas a ideia chave é ter o mesmo contexto sobre o objeto ou evento.

A sequência de Figuras 2.1, 2.2, 2.3 e 2.4 mostra como o processo da AC acontece. Kaplan \& Hafner (2004) demonstram todos os passos da AC com dois robôs animais, como pode ser visto na Figura 2.5

Outro exemplo de definição da AC é apresentado por Nagai (2004) e está representado 


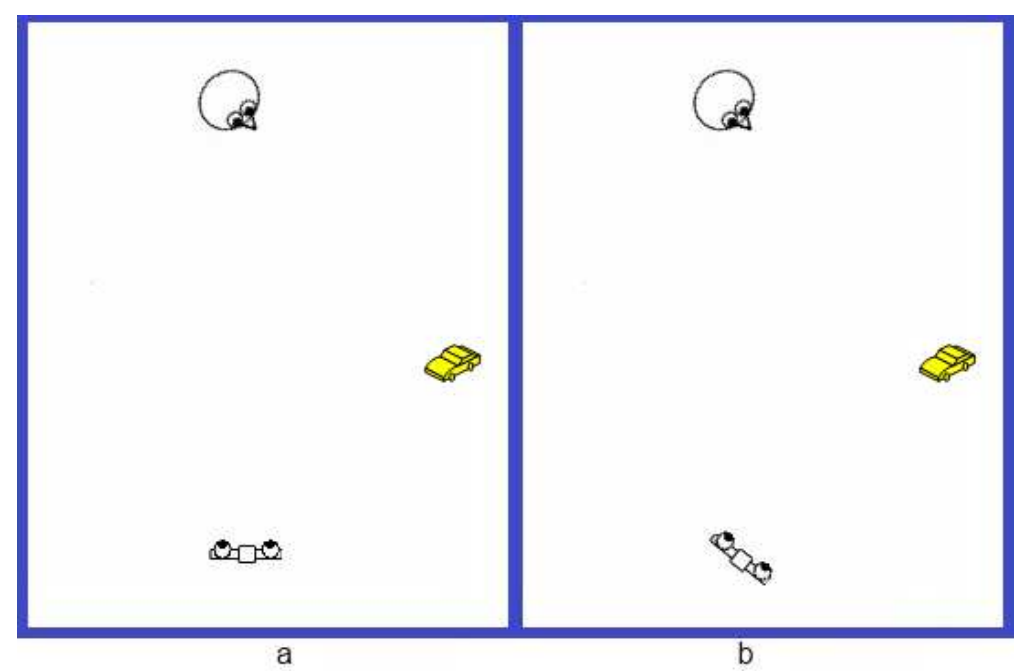

Figura 2.2: Imagem que representa o processo de seguir à atenção. Um objeto chama a atenção da pessoa que muda o foco da sua atenção a. O robô segue a atenção da pessoa para o mesmo objeto $\mathbf{b}$

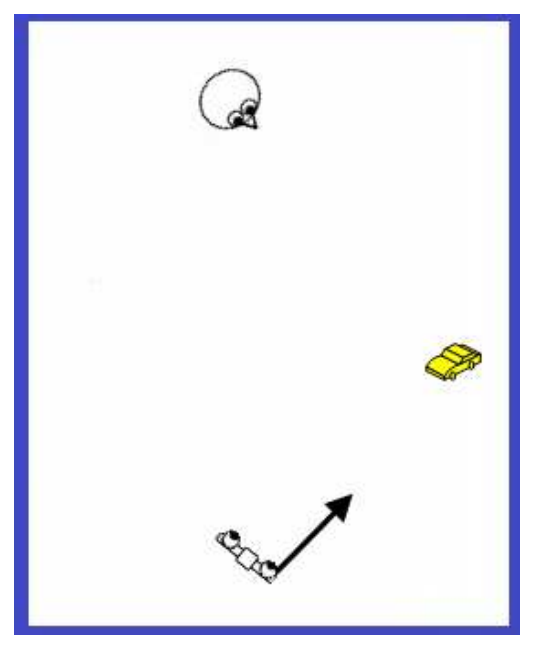

Figura 2.3: Processo de apontamento imperativo, o robô aponta para o objeto que foi visualmente detectado.

na Figura 2.6. Em sua definição de $\mathrm{AC}$ é adicionada a teoria da mente no final do processo. Teoria da mente é uma habilidade baseada na atenção social e permite um indivíduo X entender o que indivíduo Y está pensando sobre um objeto que eles estão olhando (Nagai, 2004). A definição utilizada por Nagai difere no fato de não adotar o processo de apontamento imperativo (terceiro passo na definição de Kaplan \& Hafner (2004)) e na etapa de seguir o olhar não é considerado a atenção no objeto ou evento, só acontecendo na etapa da AJ.

Durante o processo da $\mathrm{AC}$, os envolvidos, seja por iniciar a atenção compartilhada (ISA) ou responder à atenção compartilhada (RSA), processam informações sobre o objeto ou evento e do comportamento da outra pessoa relativo ao objeto, podendo fazer inferências sobre a situação. Além disso, as pessoas processam informações sobre as próprias ações executadas 


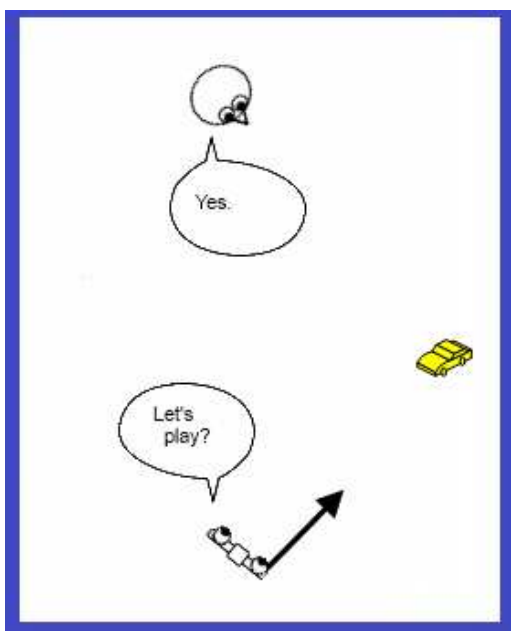

Figura 2.4: Processo de apontamento declarativo, o robô faz uma observação sobre o fato

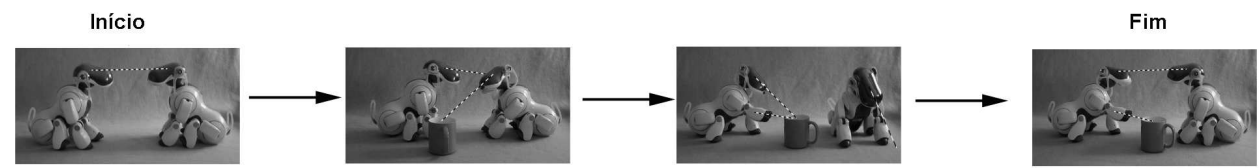

Figura 2.5: O processo da atenção compartilhada sendo realizado por dois robôs com estrutura de cães. Figura adaptada de Kaplan \& Hafner (2004).

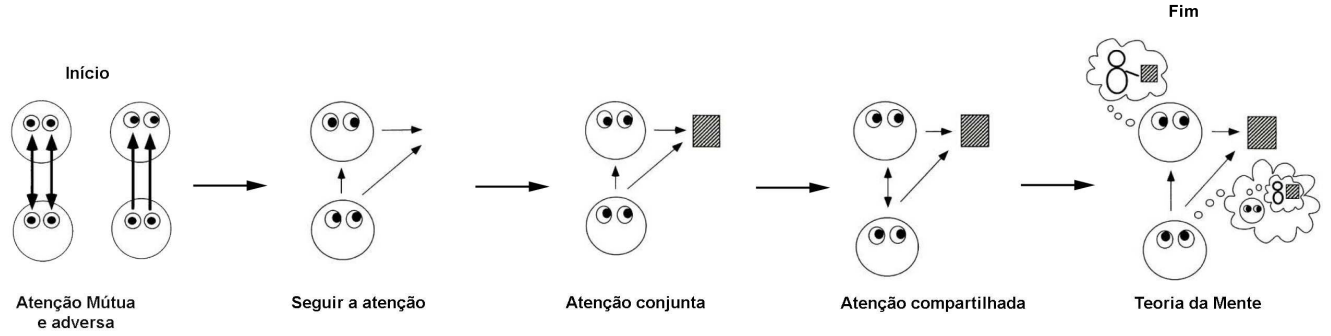

Figura 2.6: O processo da atenção compartilhada que utiliza o conceito da teoria da mente. Figura adaptada de Nagai (2004)

e sobre o estado interno. Toda informação é integrada com o objeto ou evento comumente referenciado (Mundy \& Jarrold, 2010).

É evidente que este processo é pré-requisito de uma comunicação de sucesso entre os seres humanos. Especialmente na infância, quando começar a fazer a conexão do que é apresentado e falado. Esta tendência pode desempenhar um papel crucial no desenvolvimento de capacidades como imitação e linguagem (Böckler et al., 2011; Mundy \& Jarrold, 2010).

Além disso, este processo ou parte dele não é exclusivo dos seres humanos. Alguns organismos com campos direcionais visuais limitados podem se beneficiar em adquirir recursos e evitar o perigo usando todo ou parte do processo de $\mathrm{AC}$. Por exemplo, tem sido demonstrado que o processo de seguir o olhar ocorre em várias grupo de seres vivos, incluindo 
corvos (Bugnyar et al., 2004), cabras (Kaminski et al., 2001), macacos (Ferrari et al., 2000), e grandes macacos (Bräuer et al., 2005). Essas habilidades também revelam uma capacidade de aprender associações secundárias ou fazer inferências sobre os comportamentos dos outros e eventos no ambiente. Como a expressão emocional utilizada pelo ser humano em direção a um objeto para modelar o seu comportamento.

Alguns trabalhos sobre a análise teórica da $\widehat{\mathrm{AC}}$ podem ser encontrados em Moore \& Dunham (1995); Tomasello (1995); Baldwin (1995); Carpenter et al. (1998); Brooks \& Meltzoff (2005); Tomasello et al. (2005); Kwisthout et al. (2008); Mundy \& Jarrold (2010); Shepherd et al. (2010); Schilbach et al. (2010). Existem outros que focam no estudo da relação entre a $\mathrm{AC}$ e algumas desordens no comportamento do ser humano, como o autismo (Delinicolas \& Young, 2007; Clifford \& Dissanayake, 2008).

\subsection{Métodos de Aprendizado}

O mecanismo da $\mathrm{AC}$ se desenvolve nos seres humanos durante o início da vida, antes do primeiro ano de vida (Böckler et al., 2011).

Para o desenvolvimento de um mecanismo de aprendizado da $\mathrm{AC}$ em robôs, esses necessitam ser um humanoide ou robôs que tenham a parte superior do tronco. No entanto, devido ao alto custo desses robôs, vários pesquisadores de Interação Humano Robô (IHR) trabalham com o comportamento da $\mathrm{AJ}$ utilizando robôs com estrutura corporal não humana ou um simulador computacional.

O simulador computacional é utilizado também como uma etapa prévia para avaliar os modelos antes de serem inseridos nos robôs. Essa opção reduz a complexidade e os custos associados com a construção de robôs, embora exista o risco de simplificar o fenômeno de interesse.

$\mathrm{Na}$ literatura, existem duas diferentes formas de aplicar $\mathrm{AC}$ em robôs: nativista e concepcionista. A forma nativista está focada na utilização de um sistema de $\mathrm{AC}$ em robôs e a forma concepcionista se preocupa no desenvolvimento de um mecanismo que torne o robô capaz de aprender. A forma nativista tem a forma mais refinada do comportamento, evitando suposições. Por outro lado, a forma concepcionista demonstra como o aprendizado pode ser responsável pelo desenvolvimento do comportamento. Ele também ajuda a explicar a progressão na aquisição da habilidade, e a existência de um desenvolvimento de uma maneira diferente, ou ainda, de não se desenvolver (Jasso, 2007).

A fim de permitir uma melhor compreensão sobre como o aprendizado da $\mathrm{AC}$ se realiza, este capítulo será dividido de acordo com a estrutura robótica utilizada: humanoide, tronco superior, cabeça robótica, software simulador e robôs com aparência não humana. 


\subsubsection{Humanoides}

Um dos primeiros trabalhos relacionados do aprendizado da $\mathrm{AC}$ com robôs humanoides foi realizado por Yukie Nagai. Ela desenvolveu um modelo de aprendizado fundamentado no desenvolvimento e outro baseado no aprendizado por experiência, sendo ambos utilizam redes neurais multi-camadas com o algoritmo backpropagation. O modelo baseado no desenvolvimento é composto por dois módulos. O primeiro módulo faz a avaliação do estado do ambiente, que utiliza uma rede neural para processar a informação do objeto e do rosto, e assim, atualiza os pesos da rede neural do segundo módulo. O segundo módulo, por sua vez, decodifica a imagem, que é processada por uma rede neural para a seleção da ação a ser executada. O segundo modelo é constituído de uma rede neural e um avaliador interno para os objetos direcionados pelo ser humano. $\mathrm{O}$ avaliador tem o papel de ativar o processamento das informações pela rede neural quando um objeto está dentro de um campo de visão, sendo validado por um limiar de distância relativa ao centro do foco. Os modelos são considerados importantes na construção de modelos para seguir a atenção, pois utilizam um mecanismo interno para indicar que o objetivo da atenção do ser humano foi atingido, como um reforço. No entanto, em ambos os modelos não foi considerado o valor do olhar mútuo e o mecanismo permite um robô aprender utilizando um meio off-line, em outras palavras, um robô aprende AJ off-line utilizando dados que foram adquiridos em um ambiente real com antecedência (Nagai et al., 2003; Nagai, 2004, 2005).

Em seguida, Shon et al. (2005) propôs um algoritmo probabilístico para seguir a atenção de um ser humano e identificar objetos salientes em uma cena empregando inferência Bayesiana. Para isso, vetores com as posições da cabeça da pessoa em conjunto com os mapas da projeção das cenas visuais foram usados para calcular a probabilidade de máximo a posteriori das estimativas dos objetos observados pelo instrutor. A distribuição resultante constituiu a representação intermodal do objetivo comum do robô e do ser humano. A contribuição relevante está na utilização de mapas de saliência e o fato do sistema ser utilizado em um estudo para demonstrar o mecanismo de aprendizagem diante uma interação social comunicativa, com papel fundamental na mediacão entre seguir a atencão de um bebê por um robô (Meltzoff et al., 2010).

Em uma primeira aplicação em humanoides, Mutlu et al. (2006) implementaram um algoritmo de $\mathrm{AJ}$ de forma nativista para alterar a atenção e realizar gesto para o robô humanoide ASIMO, da Honda, que conta histórias. O estudo está focado na influência da alteração da atenção durante a narração de uma história, com a participação de um robô e dois seres humanos. Para isso, com base na frequência da atenção que receberam do robô, o algoritmo probabilístico foi utilizado. Nos resultados, eles descobriram que os participantes tiveram um desempenho significativamente melhor em recordar a história contadas pelo robô ASIMO, quando o robô olhou mais para eles. 
Em uma outra aplicação, Yoshikawa et al. (2006) desenvolveram um sistema para controlar um robô de comunicação (Robovie-R2, ATR Robotics), com capacidade de resposta não verbal, chamada habilidade responsiva, sendo composta pelos mecanismo de seguir e evitar a atenção. O sistema foi controlado por um dispositivo portátil para detecção da atenção e seus efeitos foram avaliados sobre o parceiro ao ser olhado pelo robô. Esse sistema foi comparado sem a capacidade de resposta não verbal, chamada habilidade não-responsiva, sendo composta pelos mecanismo de atenção independente e sem deslocamento da atenção. $\mathrm{O}$ primeiro altera a direção da sua atenção de forma independente do parceiro e o segundo não a altera durante toda a interação. Por fim, o trabalho demonstrou que o mecanismo de resposta não verbal gera uma melhor interação entre um robô e humanos.

No robô HRP2, um sistema de raciocínio geométrico envolvendo rotação mental e capacidade de tomada de perspectiva para fornecer a capacidade de AJ/foi utilizado (Marin-Urias et al., 2009). Esse método utiliza uma matriz de probabilidade de um objeto para saber se ele é projetado no meio ambiente. Além disso, os elementos que não são projetados, objetos considerados como obstrução e sem a projeção, também são calculados. Para que tudo isso seja possível, o robô utiliza quatro câmeras para realizar a projeção e a pessoa que o robô se destina a interagir é equipada com um capacete especial com sistema de captura de movimento, sendo capaz de localizar e rastrear a posição e orientação da cabeça humana. Por meio desse processo, o robô pode compartilhar ou influenciar a atenção humana.

No próximo trabalho, Yucel et al. (2009) construíram um robô de interação social para ser utilizado para fins de serviço e orientação utilizando o humanoide Nao da Aldebaran, FESTO Robotino e um computador portátil. Eles usaram uma combinação de estimativa de posição da cabeça (usando o modelo de cabeça cilíndrica e representação de vetores), a estimativa de direção do olhar (usando duas redes neural) e computação da saliência (usando o método de saliência bottom-up e uma rede neural Winner-Takes-All (WTA). Esta combinação proporciona ao robô a capacidade da $\mathrm{AJ}$ durante a interação com um ser humano. Além disso, o robô é capaz de determinar o objeto de interesse, com um alguma distração no ambiente.

O robô Mobile-Dexterous-Social (MDS) foi utilizado por Trafton et al. (2009) com o modelo ACT-R/E para capacita-lo com a habilidade de seguir a atenção. O modelo é baseado em fatos e regras utilizando cinco componentes básicos:

- Componente reativo - mecanismo não direcionado a objetivo,

- Habituação - tempo de permanência para identificar o ambiente, o sistema utiliza extração de informação na memória do ACT-R como um modelo habituação,

- Componente espacial - utiliza a teoria espacial: Specialized Egocentrically Coordinated Spaces (SECS)

- Componente para seguir à atenção - busca visual dirigido a partir de um ponto de partida 


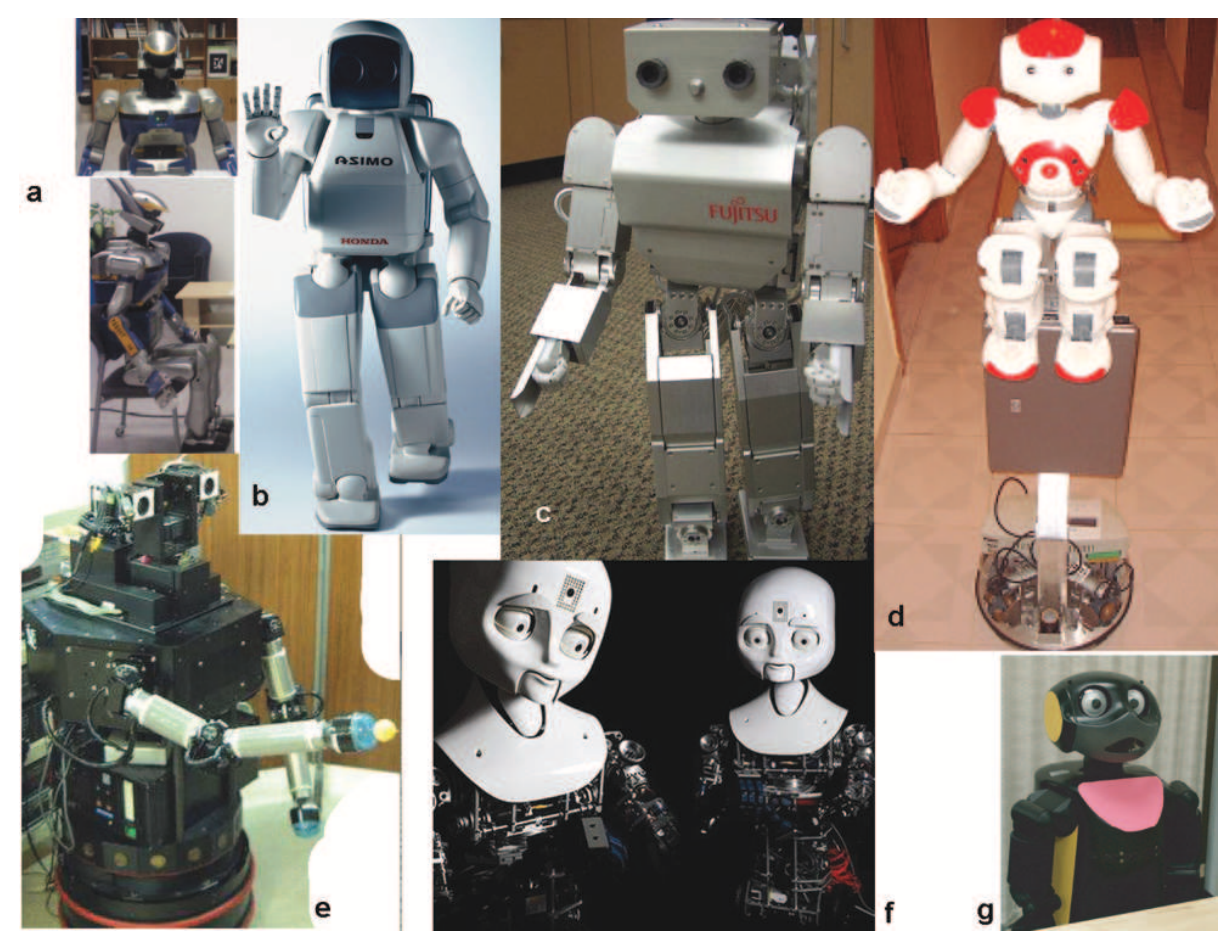

Figura 2.7: Na parte superior temos: a)robô HRP2. Figura adaptada de (Marin-Urias et al., 2009); b)Asimo. Figura adaptada de (Mutlu et al., 2006); c)robô HOAP-2. Figura adaptada de (Shon et al., 2005); d)robô de Yücel. Figura adaptada de Yucel et al. (2009), na sequência. Na parte inferior: e)humanoide de Nagai, Figura adaptada de (Nagai, 2005); f) Mobile-Dexterous-Social. Figura adaptada de (Trafton et al., 2009) e g) Robovie-R2. Figura adaptada de (Yoshikawa et al., 2006) na sequência.

e um ângulo ou um ponto final. A busca visual vai retornar a localização de um objeto ao longo dessa linha com certa tolerância.

- Componente útil de aprendizado - através de um algoritmo de diferença temporal é responsável por disparar uma regra.

Além disso, segundo Trafton este trabalho tem um alto grau de plausibilidade cognitiva (Trafton et al., 2009).

A Figura 2.7 apresenta todos os robôs humanoides utilizados nos trabalhos citados.

\subsubsection{Tronco Superior}

Robôs de tronco superior são aqueles que possuem ao menos uma cabeça e um suporte. No entanto, esses robôs podem ter braços e a parte acima do abdômen igual aos seres humanos.

Um dos primeiros trabalhos na literatura sobre como capacitar um robô com tronco superior com a habilidade de atenção compartilhada foi proposto por Scassellati (1996). Seu grupo construiu um robô com a parte superior do tronco, chamado Gog. Um sistema nativista 
foi desenvolvido com um sistema de visão para detecção de rosto humano, tratamento de imagem dos olhos e apontamento imperativo. O processo consiste em extrair o ângulo do olhar do humano e extrapolá-lo para serem utilizado como rotinas dos motores para alternar o olhar entre o rosto e o objeto. Finalmente, o mapeamento das coordenadas da imagem da câmera são enviadas para os motores do braço, realizando o apontamento (Scassellati, 1999). Um processo semelhante foi feita por Kosima com o robô de tronco superior Infanoid (Kozima \& Yano, 2001; Kozima, 2002; Jasso, 2007).

Por um outro ponto de vista, Doniec et al. (2006) desenvolveram um sistema para orientar a atenção de uma pessoa a uma terceira entidade (objeto) por um robô que tem a parte superior do tronco, chamado Nico. Eles utilizam a busca e apontamento dos braços para melhorar o processo de aprendizagem da AJ por uma rede neural. Na primeira etapa, o robô aprende a encontrar e apontar para um objeto, entre seis opções existentes. Então, o robô usa sua habilidade de apontando para guiar a atenção do instrutor para um objeto específico no ambiente. A ambiguidade pode ocorrer quando um objeto está longe. Além disso, o modelo não aborda as questões como: mudança de localização do objeto e o que ocorre quando o instrutor não segue a atenção do robô durante o processo de aprendizagem.

Com base no trabalho de Shon et al. (2005), Hoffman et al. (2006) utilizaram um processo de aprendizagem por imitação como forma de melhorar todo o processo. Então, seu modelo Bayesiano combina imitação da posição da cabeça com modelos da projeção para localizar objetos de interesse mútuo entre o instrutor e o observador. Essa melhoria aumentou a velocidade do aprendizado com relação a sua versão anterior.

Sumioka et al. (2010) desenvolveram um modelo que é composto por um filtro de saliência para extrair informações do ambiente, a partir da câmera. Essa informação foi transmitida para o módulo seletor de atenção, com informações de movimento (como a posição da cabeça humana ou de movimentos de objetos manipulados pelo homem), para decidir onde e quando olhar. Ao mesmo tempo, uma saída da rede neural de mapas de auto-organização (SOM), que continha padrões pré-classificados de face, é ativada por semelhanças com o padrão de rosto capturado. Ambos os comandos são recebidos pelo módulo de seleção, que seleciona uma ação a ser executada.

Outro trabalho que utiliza uma base estruturada é visto em Kim et al. (2008). Com base no modelo proposto por Triesch et al. (2006), ele realiza algumas melhorias para ser inserida em uma cabeça de robótica. Para isso, foram necessárias modificações no sistema de visão computacional para processar os objetos salientes e posição da cabeça. Harris corner detectors, K-means e transformada de Hough são métodos usados no processo para encontrar o objeto saliente. O processamento para encontrar a posição, para a qual a cabeça está apontando, é dividido em três fases: a detecção, discriminação da posição e estimativa de profundidade para distinguir uma postura da outra. Todo este processo foi feito por uma abordagem semi-autônoma. O resultado dessa combinação, chamada de área visual, é um 


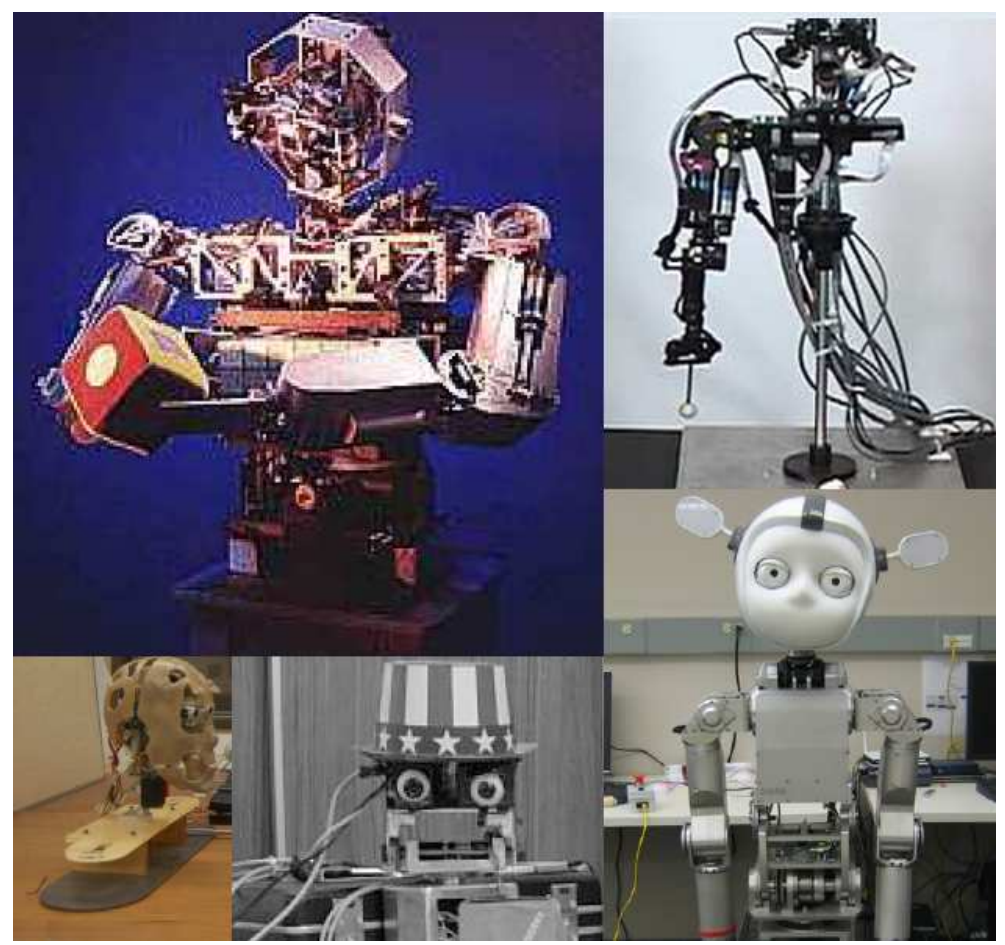

Figura 2.8: Robôs de tronco superior. Na parte superior: Cog e o robô desenvolvido por Doniec. Figura adaptada de (Scassellati, 1999) e (Doniec et al., 2006), respectivamente. Na parte inferior está: robô desenvolvido por Kim, Sumioka e o robô Simon, na sequência. Figura adaptada de Kim et al. (2008). Sumioka et al. (2010) e (C. Huang \& Thomaz, 2010), respectivamente

vetor de estado $\mathbf{u}$, que compreende um mapa de saliência do centro do corpo $\mathbf{s}$ e o mapa da posição da cabeça $\mathbf{h}$ do instrutor. Outra modificação foi feita no módulo de aprendizado por reforço. Nesse caso, eles usaram o aprendizado por reforço com ator crítico. Então, com estas modificações, Kim et al. (2008) mostraram a viabilidade de seu modelo em um ambiente do mundo real controlado.

Os robôs de tronco superior apresentados até aqui são apresentados na Figura 2.8.

Além dos robôs apresentados até o momento, mais dois trabalhos se destacam. O foco do modelo de Huang é baseado em responder e iniciar a $\mathrm{AJ}$ durante a interação de um robô com um ser humano, e isto é o que difere dos outros trabalhos (C. Huang \& Thomaz, 2010). Para isso, ele propôs um modelo de $\mathrm{AJ}$ que consiste em três componentes:

- responder à atenção conjunta (RAC)- habilita o robô a seguir a atenção do ser humano

- iniciar a atenção conjunta (IAC) - habilita o robô a manipular a atenção do ser humano para uma posição de interesse.

- garantir a atenção conjunta (GAC) - garante que a atenção ao objeto é seguida corretamente 
No entanto, o modelo de Huang não aprende a atenção compartilhada, ou seja, é uma forma nativista.

Por fim, Boucenna et al. (2011) desenvolveram um modelo para combinar AJ e o reconhecimento da expressão facial em relação a um objeto. O modelo é baseado na aquisição de dados por sensores-motores e no aprendizado da atenção compartilhada de forma supervisionada, considerado como imitação, utilizando vários tipos de redes neurais.

\subsubsection{Simulação}

O primeiro registro na literatura sobre simulação do aprendizado de alguma das partes da atenção compartilhada está em Matsuda \& Omori (2001). Eles desenvolveram um modelo usando uma rede neural e diferença temporal (TD) para aprender a $\mathrm{AJ}$. Além disso, eles aplicaram uma modificação no algoritmo de divisão com base adaptativa (ABD) para a divisão do espaço de estado para simulação computacional. O simulador é composto por um ser humano, um robô, uma mesa, alguns objetos e alguns brinquedos. O humano e o robô estão frente a frente em cada lado da mesa. Além disso, todos os objetos estão na mesa, mas apenas objetos familiares estão na área de visão do robô e alguns brinquedos estão fora. O processo de simulação da $\mathrm{AJ}$ inicia-se por um contato ocular entre o humano e o robô. Depois, o ser humano muda o seu olhar em direção a algum brinquedo. Se o robô segue a atenção do humano corretamente, o humano movimenta o brinquedo como forma de recompensa para o robô. O fato de só receber recompensa do objeto em movimento e a atenção de um ser humano não levar a qualquer recompensa é considerado como fator limitante.

Em seguida, Ikegami \& Iizuka (2003) combinaram reconhecedores dinâmicos para fornecer ao robô a capacidade da $\mathrm{AJ}$, O sistema foi composto por uma rede neural recorrente que é usado para selecionar as ações e com um algoritmo genético para atualizar os pesos da rede de acordo com o desempenho. O problema do sistema é que o algoritmo genético necessita de milhares de gerações para resolver o problema.

Um modelo que associa a posição da cabeça do humano e a posição de um objeto no espaço utilizando percepção de profundidade para solucionar ambiguidade espacial, foi desenvolvido por Lau \& Triesch (2004). Para isso, o modelo utilizou a combinação de um mapa de saliência dos objetos e outro mapa de estimativa da posição da cabeça. O resultado é um mapa de interesse que é utilizado por uma rede neural com aprendizado hebbiano para capacitar um robô a aprender a $\mathrm{AJ}$.

Triesch et al. (2006) desenvolveram um conjunto básico de estruturas e mecanismos para proporcionar a agentes a capacidade de seguir a atenção. Este conjunto inclui habilidades perceptivas e preferências, dispositivo de recompensa como forma de aprendizagem, habituação e um ambiente social estruturado (Fasel et al., 2002). O ambiente de simulação é 
composto por um robô, um instrutor e um espaço hexagonal, onde uma entidade (robô, objeto ou instrutor) pode ocupar. O robô e o instrutor estão frente a frente e permanecem na mesma posição durante a interação. $\mathrm{O}$ espaço é discretizado em $\mathrm{N}$ regiões distintas. $\mathrm{O}$ instrutor pode olhar para qualquer uma dessas regiões ou para o robô. Essa proposta foi bem sucedida na aprendizagem em um ambiente devidamente estruturado, onde o instrutor ao olhar para os objetos, o robô responde corretamente (Triesch et al., 2006).

Finalmente, o último trabalho relacionado a simulação destacado nessa tese é o proposto por Sumioka et al. (2008). Eles investigaram como a transferência de entropia (Mitchell, 1997), uma medida da teoria da informação, é utilizada para quantificar a causalidade inerente da interação face a face. Eles usaram a entropia de transferência para quantificar, através de recompensa, a causalidade entre uma percepção e uma ação. Em simulações computacionais de interação humano-robô, examinaram qual par de percepção/ação é selecionado como o par causa-efeito e mostraram que os pares selecionados podem ser usados para a aprendizagem de um mapa sensor-motor para a AJ (Sumioka et al., 2008).

Embora alguns simuladores tenham sido desenvolvidos e usados como premissa na implantação de sistemas de aprendizado da atenção compartilha em robôs, não há um simulador que contém os detalhes de uma interação real. Em geral, o propósito dos simuladores é executar de forma simples as interações mais complexas, o que pode dificultar a realização de experimentos com robôs reais.

\subsubsection{Robôs com Aparência não humana}

Thomaz et al. (2005) desenvolveram um modelo de referência social para o robô Leonardo. A referência social é a tendência de utilizar a reação emocional da outra pessoa para ajudar na própria avaliação de uma nova situação, que é então utilizado para guiar o comportamento subsequente. A atenção social é parte de referência social. Para isso, três aspectos foram considerados: o foco da atenção do robô, o foco da atenção humana e o foco referencial compartilhado pelos dois. O foco da atenção é calculado pela concorrência em níveis de saliência dos objetos e eventos perceptíveis. O objeto que apresentar a maior saliência torna-se o foco de atenção do robô. $\mathrm{O}$ foco da atenção humana, o robô Leonardo determina como sendo o ponto para o qual a pessoa está olhando, utilizando monitoramento da posição da cabeça. O último aspecto foi coberto por um mecanismo simples de votação para acompanhar o tempo relativo de atenção dos objetos no ambiente compartilhado pelo robô e pelo humano.

Um outro robô interessante que merece destaque é o Keepon. Ele é um robô pequeno e simples projetado para a interação natural, não-verbal com crianças. Kozima et al. (2009) desenvolveram esse robô para ajudá-los a compreender e elaborar modelos psicológicos do desenvolvimento da inteligência social, utilizando como foco as crianças pré-escolares e crianças 


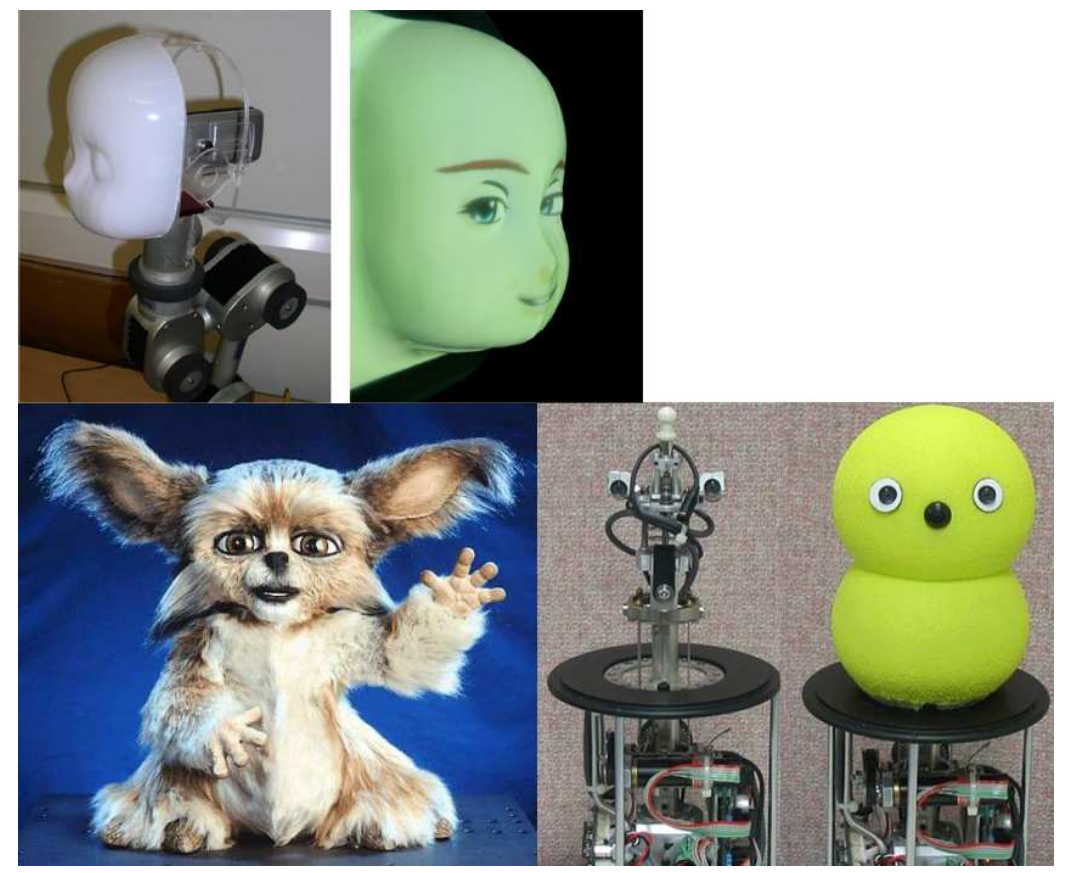

Figura 2.9: Robôs não humanoides. Na parte superior: robô de Delaunay. Figura adaptada de Delaunay et al. (2010). Inferior esquerdo: Leonardo. Figura adaptada de Thomaz et al. (2005). Na parte inferior direito: Keepon. Figura adaptada de Kozima et al. (2009)

com distúrbios de desenvolvimento, particularmente, com distúrbios autistas. Os resultados mostraram que as interações mudam qualitativamente com a idade e esse robô ajudou essas crianças na interação com seus instrutores (Kozima et al., 2009).

Delaunay utilizou quatro diferentes tipos de rosto (humano real, duas máscaras diferentes e tela plana) para verificar como as pessoas são boas em leitura da direção do olhar. A ideia do experimento foi avaliar a capacidade do usuário de ler a direção do olhar para uma seleção de diferentes modelos robóticos de rosto, usando uma face humana como base. Para isso, os experimentos foram compostos por um ser humano (participante), uma grade de numeração e um display no qual foram projetados o rosto. O resultado mostrou que o rosto humano real é mais fácil e mais preciso do que os outros (Delaunay et al., 2010).

Um trabalho que não possui uma estrutura robótica foi proposto por H. Huang et al. (2002). Eles desenvolveram um sistema que faz a detecção e tracking do rosto usando uma versão modificada do Multi-CamShift(G. R. Bradski, 1998). Em seguida, as informações da face são processadas para detectar a orientação utilizando detector de borda e fluxo óptico. Cada um desses metódos envia o resultado para uma Support Vector Machine (SVM) Cortes \& Vapnik (1995). O resultado das SVMS são combinados para gerar o controle motor e resolver a AJ, Os experimentos foram feitos usando esse sistema em um computador e uma webcam.

Finalizando esta seção, uma cabeça virtual com alguns movimentos não verbais com intuito de informar sobre determinados objetos no ambiente foi utilizada em testes para verificar a aceitação desse assistente durante uma terapia com pacientes com problemas de 
osteoartrose (Matthews et al., 2012b,a). A cabeça virtual guia a atenção do paciente para determinados objetos durante a interação, que auxilia na interpretação dos comandos a serem realizados pelo paciente.

\subsection{Considerações Finais}

Um progresso significativo vem sendo realizado no desenvolvimento de mecanismos de atenção compartilhada durante os últimos anos. Existem vários trabalhos que podem fornecer ou capacitar um robô a aprender a atenção compartilhada, ou parte dela, em tempo real ou em cenários simples. No entanto, é evidente que há muito a ser feito ainda para tornar o processo de $\mathrm{AC}$ mais natural possível.

O presente capítulo apresentou a definição de atenção compartilhada, além de várias técnicas e estruturas utilizadas no desenvolvimento de robôs sociais. Além disso, algumas aplicações foram mostradas, o que demonstra que esse mecanismo é um importante fator na interação com os seres humanos. 



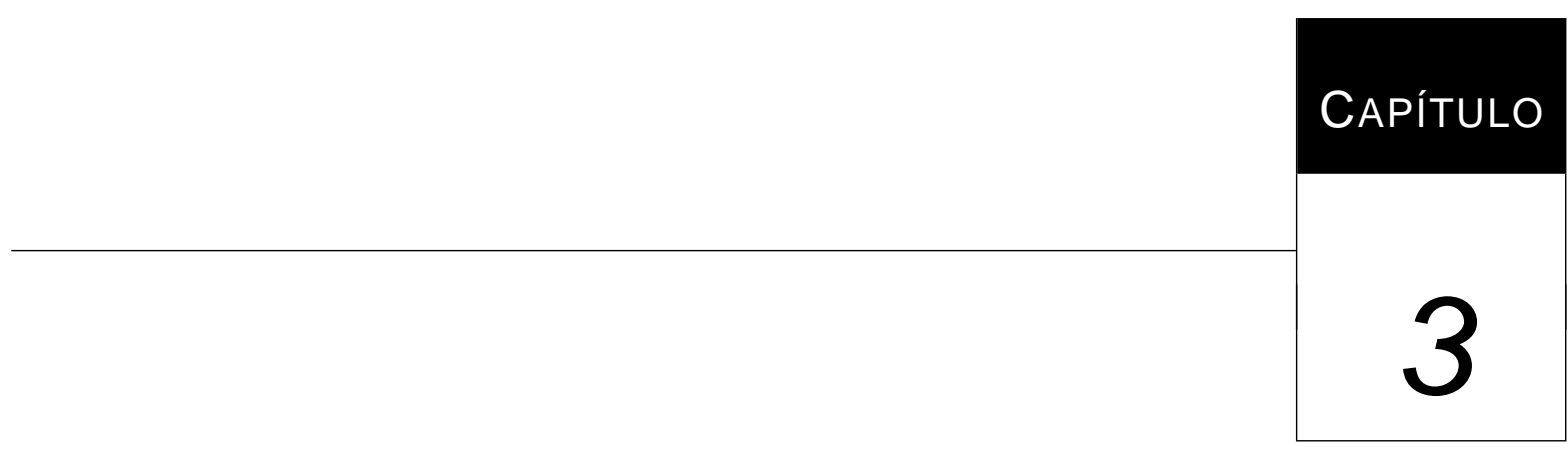

\section{Arquitetura Robótica Social}

Uma arquitetura robótica é um conjunto de componentes, em nível de software, que se

comunicam para selecionar ações a partir da percepção do ambiente (Policastro, 2008). Uma arquitetura torna-se social à medida que as ações escolhidas são consideradas adequadas em uma interação entre um ser humano, o robô e o ambiente. Dessa forma, o robô está apto a ser inserido em um ambiente social.

Neste capítulo, é apresentada a concepção da arquitetura robótica que está em desenvolvimento no Laboratório de Aprendizado de Robôs (LAR) do ICMC-USP, o funcionamento de cada parte constituinte e os sistemas utilizados para avaliar o aprendizado do comportamento da atenção compartilhada parcial.

\subsection{Arquitetura Inspirada na Análise do Comportamento}

A arquitetura robótica utilizada foi proposta por Policastro (2008) com base nas teorias do Controle de Estímulos (Serio et al., 2004), que envolve o aprendizado em emitir respostas (ações) diferenciadas na presença de determinados contextos do ambiente (estímulos discriminativos). A arquitetura é composta por três grandes módulos que podem ser identificados como: módulo de percepção de estímulos, módulo de controle de consequências e módulo de 


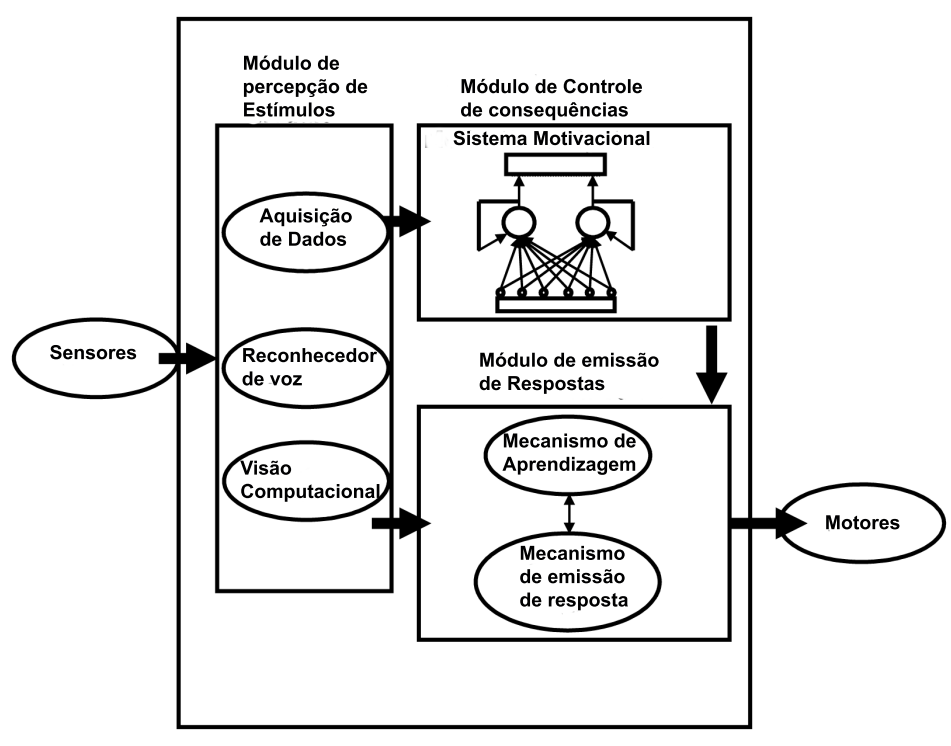

Figura 3.1: Organização geral da arquitetura. As setas indicam o fluxo de informações entre os três módulos da arquitetura. Os círculos indicam os métodos e estruturas componente dos módulos (Policastro, 2008).

emissão de respostas, conforme é representada na Figura 3.1 .

O módulo de percepção de estímulos captura os estímulos do ambiente e codifica as informações importantes para uma representação a ser utilizada pelos outros módulos. O módulo de controle de consequências processa a informação, através de uma rede neural, para informar o tipo de necessidade existente do sistema. Ao final da etapa, o módulo de emissão de resposta seleciona a melhor ação a ser executada de acordo com as informações recebidas pelos outros dois módulos. Posteriormente, o controle da arquitetura entra em um ciclo de iterações que pode ser executado até o robô alcançar sua meta, ou enquanto durar um episódio de aprendizado.

\subsubsection{Módulo de Percepção de Estímulos}

O módulo de percepção de estímulos é responsável por capturar o que acontece no ambiente e filtrar o que é relevante para o processamento de todo o sistema. Assim, ele é composto por algoritmos de aquisição de dados utilizando sensores (como câmeras e laser), sistema auditivo e através do tato, dependentes da parte constituinte do robô.

A cabeça robótica utilizada neste trabalho possui duas câmeras. A primeira está posicionada no entre os olhos do robô com a função de prover atenção visual ao robô. Para isso, é utilizado o mecanismo de atenção visual baseado em um modelo de saliência proposto por Itti (2000), empregando as funções de saliência da biblioteca Lti-Lib. A segunda câmera está fixada sobre o robô com o mecanismo para reconhecimento da face com estimativa de posição 
da cabeça através do modelo da aparência adaptativa proposto por L.-P. Morency et al. (2003), empregando as funções de detecção da biblioteca Watson. Dessa forma, os mecanismos empregados captam as informações do ambiente que são processadas e convertidas em uma representação relacional para ser utilizada pelos outros módulos.

Além disso, um sistema de reconhecimento de fala capaz de reconhecer frases completas em português, utilizando a biblioteca Nuance (2001), foi utilizada como parte do processo da atenção compartilhada.

\section{Mecanismo de Atenção Visual}

O mecanismo de atenção visual utiliza uma abordagem bottom-up que constrói um mapa bidimensional para representar a saliência visual dos objetos. Ele é composto por vários mapas de características que tratam de propriedades elementares da imagem, como cor, intensidade e orientação. Separados, as características semelhantes buscam destacar-se no mapa, enquanto as diferentes características entre mapas contribui na criação do mapa de saliência.

O primeiro passo do processo, conhecido como extração de características, consiste em decompor a imagem de entrada em um conjunto distinto de "canais", como cor (vermelho (r), verde (g), azul (b) e amarelo (y)). Com os canais é possível criar determinar a intensidade (I) e criar quatro novos canais de cores (R, G, B e Y), diretamente relacionados aos canais originais. Além disso, é determinado a orientação local $\left(0^{\circ}, 45^{\circ}, 90^{\circ}, 135^{\circ}\right)$, utilizando filtros lineares (Itti, 2000; Policastro, 2008).

Os canais de cores (R, G, B e Y) e intensidade (I) segundo Itti (2000), são representados por:

$$
\begin{gathered}
R=r-\frac{(g+b)}{2}, \\
G=g-\frac{(r+b)}{2}, \\
B=b-\frac{(r+g)}{2}, \\
Y=\frac{(r+g)}{2}-\|r-g\|-b, \\
I=\frac{(r+g+b)}{3} .
\end{gathered}
$$

A informação sobre orientação local é obtida pela aplicação do método de pirâmides orientada de Gabor $O(\sigma, \theta)$, onde $\sigma \in[0,8]$ representa a escala e $\theta \in\left\{0^{\circ}, 45^{\circ}, 90^{\circ}, 135^{\circ}\right\}$ representa a orientação (Itti, 2000). 
A segunda etapa, filtragem linear, consiste da utilização progressiva de filtro passa baixa e reescalonamento da imagem original, onde cada nível subsequente é reduzido pela metade. O resultado desse processamento é uma estrutura piramidal com nove imagens.

Em seguida, é realizado o cálculo das diferenças centro-vizinhanças da pirâmide para obter os mapas de características, através da subtração dos níveis centrais $(c \in\{2,3,4\})$ pela sua vizinhança ( $s=c+\delta, \delta \in\{3,4\}$ ). Então, computam-se seis mapas de características para cada tipo de característica (nas escalas 2-5, 2-6, 3-6, 3-7, 4-7, 4-8). Desta forma, obtém-se sete tipos de características: uma para intensidade da imagem, duas que codificam as diferenças Vermelho-Verde e Azul-Amarelo, e mais quatro para contraste local da orientação $\left(0^{\circ}, 45^{\circ}\right.$, $90^{\circ}, 135^{\circ}$ ). Ao final do processo, 24 mapas de características são criados (Itti, 2000: Breazeal et al., 2001; Policastro, 2008).

Cada característica gerada é combinada para formar três mapas de notoriedade (intensidade, cor e orientação) na escala $4(\sigma=4)$ Itti (2000).

Após normalização, os três mapas de notoriedade são somados para gerar o mapa de saliência. O mapa é uma forma detalhada das saliências de uma imagem, que são consideradas como entrada em um sistema de rede neural . No trabalho de Itti (2000) foi utilizado um rede neural integra-e-dispara com duas camadas.

\section{Mecanismo de Estimativa da Posição da Face}

O mecanismo de estimativa da posição da face (ângulos pan e tilt) é baseado em intensidade e em profundidade de auto-vetores, construído através de várias diferentes perspectivas do objeto exemplo.

Uma vez detectada uma face em uma imagem, pode-se proceder a detecção da posição da mesma. Esta detecção pode ser dividida em duas partes (L.-P. Morency et al., 2003):

1. Criação do modelo a priori dado um frame inicial;

2. Cálculo das mudanças de posições usando um Modelo Baseado em Aparência.

A criação do modelo a priori, utilizando a biblioteca Watson, foi implementada empregando o método PCA para 28 diferentes posições de 14 diferentes pessoas. Inicialmente o sistema procura uma reconstrução com menor erro para a posição inicial e a partir dos coeficientes de correspondência, dados pela técnicas PCA, reconstrói a imagem para todas as outras posições. Isso equivale a procurar a melhor representação da imagem para todas as posições. O propósito de reconstruir um modelo a priori é generalizar um grupo de posições que é utilizado no cálculo da posições relativa entre dois frames. Dado um frame próximo e a posições do modelo, é possível reconstruir todos as outras possíveis posições nos frames 
subsequentes. O modelo a priori construído é então utilizado para estimar a pose absoluta de um novo frame por meio de duas etapas:

- Cálculo da pose relativa da face entre o novo frame e cada posição da face do modelo $a$ priori usando o algoritmo iterativo AVAM.

- Integrar a pose mensurada (pose relativa) usando o Filtro de Kalman para produzir a pose absoluta.

O modelo AVAM, proposto por L.-P. Morency et al. (2003), mantém as diversas poses de um objeto em frames-chaves. O método armazena um frame atual, um frame anterior e todos os frames-chaves. O modelo pode ser atualizado e ajustado, isto é, frames-chaves podem ser modificados, adicionados ou removidos durante a busca. O modelo AVAM consiste em uma coleção de poses armazenadas em frames-chaves adquiridos durante a detecção e cálculo das poses. Para cada frame-chave o modelo armazena a seguinte informação:

$$
M_{s}=\left\{I_{s}, Z_{s}, x_{s}\right\}
$$

no qual, $I_{s}$ e $Z_{s}$ são as imagens de intensidade e de profundidade associadas ao frame-chave s. O modelo, portanto, pode ser definido pelo conjunto $\left\{M_{1}, M_{2}, \ldots, M_{k}\right\}$ onde $k$ é o número de frames-chaves. Segundo L.-P. Morency et al. (2003) a pose de cada frame-chave é bem representado por uma variável aleatória com distribuição gaussiana, sendo representada por um vetor de seis dimensões $x_{s}=\left\{T^{x}, T^{y}, T^{z}, w^{x}, w^{y}, w^{z}\right\}$ (com a translação $(T$ ) e rotação $(w)$ através dos três eixos de coordenadas).

A detecção da pose e o ajuste do modelo são executados simultaneamente, assim, quando se adquire um novo frame, todos os frames-chaves são utilizados para estimar a pose do novo frame e o ajuste do modelo é alcançado aproximando a densidade a posteriori:

$$
p\left(x_{t}, x_{M} \mid y_{1 . . t}\right)
$$

na qual, $x_{t}$ é a pose do frame atual, $y_{1 . . t}$ é o conjunto de todas as poses calculadas até o momento anterior a $t$ e $x_{M}$ contêm todos os frames-chaves utilizados até o momento, ou seja, $x_{M}=\left\{x_{1}, \ldots, x_{k}\right\}$.

\section{Reconhecimento de Fala}

O sistema de reconhecimento de fala construído é capaz de reconhecer frases completas em português utilizando a biblioteca Nuance de reconhecimento de fala (Nuance, 2001). A biblioteca Nuance é baseada em uma arquitetura cliente/servidor, composta por um módulo cliente de reconhecimento responsável pela aquisição de fala (incluindo o pré-processamento 
da mesma), por um servidor de reconhecimento responsável pelo reconhecimento de fala, por um gerenciador de recursos responsável pela distribuição eficiente de tarefas de reconhecimento (Policastro, 2008).

O processo de reconhecimento da biblioteca Nuance inicia-se com o pré-processamento dos dados de áudio para otimizar o reconhecimento. Uma das principais operações é a distinção do ruído do fundo da própria expressão vocal. Em seguida, o servidor analisa as características da mesma para produzir uma transcrição da expressão vocal para texto utilizando modelos acústicos, arquivos de dicionário e gramática de reconhecimento para executar o reconhecimento (Nuance, 2001; Policastro, 2008).

\section{Conversão dos Dados}

A arquitetura é embasada na técnica de representação do conhecimento conhecida como representação relacional de primeira ordem. Todos os estímulos definidos possuem diversas propriedades como forma, cor, tamanho, posicionamento em relação ao foco do robô e, no caso de seres humanos, a postura da cabeça. Os estímulos percebidos no ambiente deverão ser codificados em átomos no tipo: see(X), smell(X), hear(X), at(X), nos quais $X$ representa um fato sobre um estímulo percebido no ambiente. Por exemplo: see(frontal(face)), tem-se que see() é um átomo, face é um estímulo percebido e frontal() é um fato sobre face, definido de acordo com as propriedades desse estímulo (Silva et al., 2009; Policastro, 2008).

Para facilitar a comunicação entre os módulos e o processamento das informações, essa representação é transformada em um número binário através do processo de binarização pela conversão de um atributo categórico em um número binário assimétrico (Tan et al., 2005). A transformação é feita pela função, $\mathrm{f}=2^{x}$, onde $x$ varia de 0 a $n-1$, e $n$ é o número total de estímulos e fatos. A função permite a representação dos estados do ambiente por uma soma binária e a possibilidade da decomposição dos bits sem perda de informação.

Além disso, a troca de informação entre os três módulos principais da arquitetura é feita por uma memória de trabalho. Esta memória é usada para manter informações sobre estímulos, últimas respostas emitidas, necessidades internas ativas e reforços detectados. Cada elemento inserido na memória de trabalho possui um contador que confere a noção de tempo. Quando um novo elemento é inserido na memória, seu contador de tempo é inicializado com valor igual a zero. Adicionalmente, este contador é incrementado de uma unidade sempre que novos elementos são inseridos subsequentemente na memória. Assim, os elementos persistem por vários passos de tempo na memória até que um limiar seja atingido. 


\subsubsection{Módulo de Controle de Consequências}

O módulo de controle de consequências é composto por um mecanismo que simula as necessidades de um indivíduo, baseado no sistema proposto por Breazeal (2003). Esse mecanismo é constituído de unidades de necessidade que são implementadas de maneira similar a um perceptron simples com uma conexão recorrente (Haykin, 1999). A função de ativação da unidade de necessidade é dada por: $y=\sum w_{j} \cdot i_{j}$, na qual $i_{j}$ são sinais de entrada que indicam a presença ou não das propriedades dos estímulos percebidos no ambiente e $w_{j}$ são os pesos (que podem ser positivos ou negativos) pré-definidos de acordo com a unidade de processamento. Essas unidades de necessidade simulam a homeostase dos organismos vivos. Elas possuem um ponto de equilíbrio e variam entre um valor máximo e mínimo, empiricamente determinados. Um valor positivo em uma unidade de necessidade, acima do ponto de equilíbrio, indica a privação do robô a um determinado estímulo reforçador. Por exemplo, na ausência de um estímulo no ambiente que indica a presença de uma pessoa (cor de pele), uma unidade que simule a necessidade de interagir com pessoas por ter seu valor aumentado no tempo, levando o robô a precisar estabelecer contato e interagir com um ser humano. Uma vez que o robô estabeleça contato, essa unidade tem seu valor de ativação reduzido gradativamente até o ponto de equilíbrio (Policastro, 2008).

Dessa forma, a arquitetura fornece mecanismos para simular estados de privação e satisfação de necessidades, permitindo que uma resposta emitida tenha uma consequência reforçadora ou punitiva e permitindo que o algoritmo de aprendizado possa receber informações sobre as consequências das respostas por ele selecionadas na presença de determinados estímulos discriminativos (Policastro, 2008).

\subsubsection{Módulo de Emissão de Resposta}

A aprendizagem é efetuada por meio de um algoritmo de aprendizado por reforço não determinístico Sutton \& Barto (1998) Mitchell (1997), pela construção e armazenagem de novas regras de comportamento, assim como pela atualização da probabilidade de execução das regras existentes.

Em cada ciclo, o módulo de emissão de respostas utiliza o estado e a informação das necessidades ativas para selecionar uma resposta a ser emitida pelo robô. A seleção de respostas é efetuada de uma maneira estocástica, baseada em uma roda de roleta Goldberg (1989). O algoritmo de seleção da roleta possibilita um bias nulo e a probabilidade de seleção de uma regra é proporcional ao valor de aptidão da mesma. A distribuição das probabilidades de seleção das regras de comportamento e respostas inatas, proposta nesta tese, é dada por: 


$$
p_{i}=\frac{f_{i} \pm I}{\sum_{j=1}^{n} f_{j}}
$$

na qual $f_{i}$ e $f_{j}$ são valores de aptidão de cada resposta ou regra de comportamento. Para tanto, todas as respostas do repertório do robô possuem um valor padrão de aptidão $\left(f_{d}\right)$ e este valor é pré-definido como um parâmetro na arquitetura. Este valor padrão de aptidão, assim como os valores de aptidão das regras de comportamento, são empregados para construir a roleta de seleção. Após a seleção da resposta mais apropriada, essa é emitida pela execução de uma rotina de motor.

Mais detalhes do funcionamento desse algoritmo, que é conhecido como aprendizagem de contingência é detalhado em Policastro (2008).

\subsection{Simulador de Interações Sociais}

Essa arquitetura robótica foi testada em um simulador de interação social projetado sobre uma importante habilidade social: a atenção compartilhada, referenciado no Capítulo 2 .

A primeira versão do simulador de interações sociais foi desenvolvido por Policastro (2008) e é apresentada na Figura 3.2. No lado esquerdo do simulador possui elementos de configuração e no lado direito está o espaço de simulação onde foram definidas três entidades que podem ser manipuladas por funções do simulador: um humano, um robô e um brinquedo. Nesse simulador, o ser humano e o robô foram posicionados frente a frente a uma distância fixa. Além do ser humano e do robô, o simulador possibilita posicionar até dois brinquedos simultaneamente no ambiente social. Essa funcionalidade é útil para se simular um objeto distrator enquanto se posiciona um objeto que é foco de atenção do ser humano. Isso permite verificar se o robô direciona o olhar para o brinquedo correto, mesmo na presença de outros objetos no ambiente. Um brinquedo pode ser posicionado em qualquer lugar vazio do ambiente social, a qualquer momento durante uma simulação.

O ambiente social foi modelado da seguinte maneira. Tanto o robô como o ser humano podem girar suas cabeças para a esquerda ou para a direita, em um ângulo de até $90^{\circ}$. O robô tem seu foco central em $0^{\circ}$ e tem seu campo visual limitado por um parâmetro de fóvea $\lambda^{\circ}$, permitindo que o robô visualize objetos em um campo visual formado por um cone de abertura dada por: $\left[-\lambda^{\circ},+\lambda^{\circ}\right]$, com centro em $0^{\circ}$. Na Figura 3.2, é ilustrada esta modelagem do campo visual do robô.

A posição da cabeça do robô é determinada por $\theta_{r}$, que pode assumir valores entre $\left[-90^{\circ},+90^{\circ}\right]$. A posição da cabeça do ser humano é determinada por $\theta_{a}$, que também pode assumir valores entre $\left[-90^{\circ},+90^{\circ}\right]$. Quando um objeto $i$ é posicionado no ambiente 


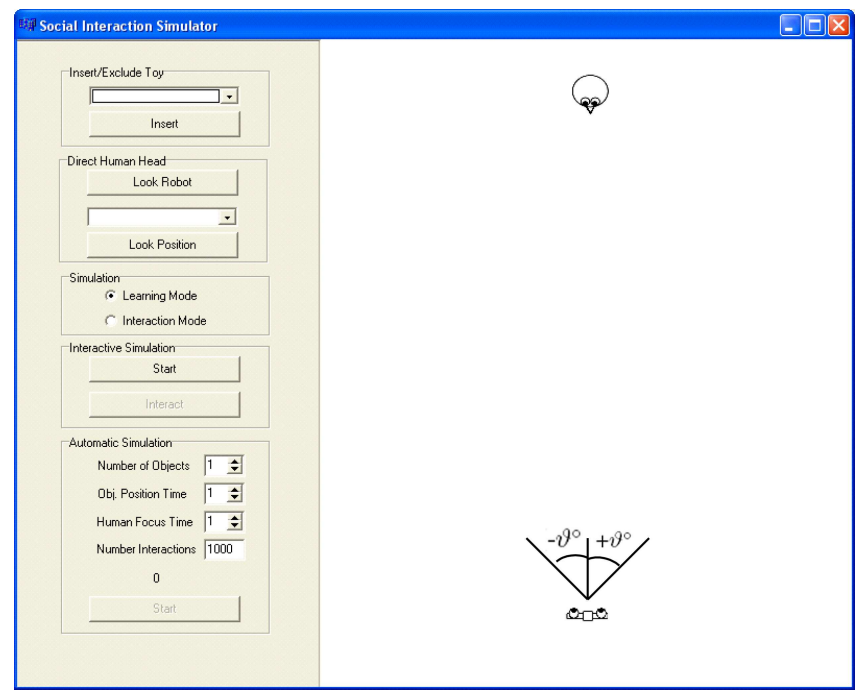

Figura 3.2: Campo visual do robô. As linhas representam os limites do campo visual do robô, com abertura dada por: $\left[-\lambda^{\circ},+\lambda^{\circ}\right]$, com centro em $0^{\circ}$.

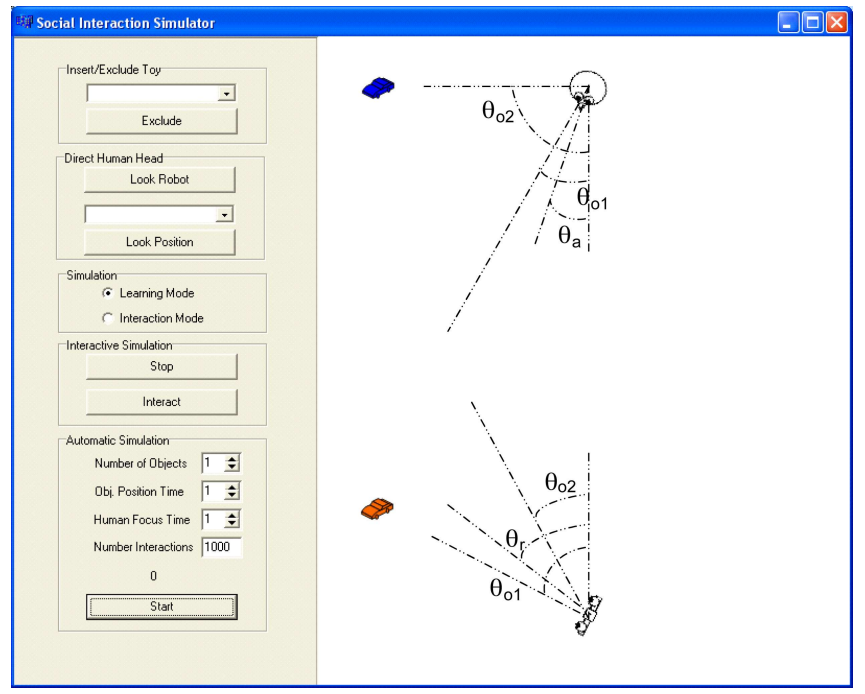

Figura 3.3: Controle de posicionamento. As linhas representam as distâncias entre o foco do robô e os objetos posicionados no ambiente social, assim como a posição da cabeça do robô e da cabeça do ser humano. Nesta figura é mostrada uma interação na qual o ser humano está olhando para um objeto posicionado no ambiente e o robô acompanha seu olhar para o objeto correto, apesar da existência de um objeto distrator.

social, o simulador traça o ângulo entre este objeto e o foco do robô, ou seja, ele determina o deslocamento da cabeça do robô necessário para focalizar o objeto posicionado no ambiente. Esta mapeamento é dado por $\theta_{o i}$, que pode assumir valores entre $\left[-90^{\circ},+90^{\circ}\right]$. Desta maneira, se um objeto é posicionado no ambiente, o simulador verifica se o mesmo está dentro do campo visual do robô, comparando sua posição em relação ao foco da visão do robô, considerando o campo de visão do mesmo. Na Figura 3.3 , são ilustrados os parâmetros de posicionamento dos objetos e do ser humano em relação ao campo visual do robô. 
Durante uma simulação, o simulador é capaz de executar interações continuamente e cada interação toma aproximadamente 1 segundo. O simulador pode posicionar até dois objetos simultâneos no ambiente social, em posições estocasticamente selecionadas com probabilidade $\rho_{o}$. Estes objetos são posicionados nos respectivos lugares durante um tempo determinado pelo usuário (determinado em segundos ou ciclos de interações no painel de controle). Adicionalmente, o simulador pode direcionar a cabeça do ser humano para focar um objeto presente no ambiente ou para focar o robô. O objeto que recebe o foco do olhar do ser humano é estocasticamente selecionado com probabilidade $\rho_{a}$. Após focar um objeto, o humano permanece com o seu foco no mesmo durante um tempo determinado pelo usuário (determinado em segundos ou ciclos de interações no painel de controle), antes de direcionar a sua cabeça para focar outro objeto ou para focar o robô.

\subsection{Melhorias}

Nesta seção serão apresentados algumas melhorias realizadas na arquitetura previamente apresentada.

\subsubsection{Módulo de Emissão de Resposta}

O módulo de emissão de respostas é composto por um mecanismo de aprendizado e um mecanismo de emissão de respostas. O mecanismo de aprendizado utiliza uma abordagem considerada biologicamente plausível para o problema da atenção compartilhada, o processo de aprendizagem por reforço (Triesch et al., 2006). No funcionamento geral da arquitetura, esse mecanismo recebe as informações dos outros módulos e as processa para selecionar a ação a ser executada pelo sistema. Ao final, ele envia a ação para o mecanismo de emissão de respostas que a converte para ser executada pelos atuadores.

$\mathrm{O}$ Aprendizado por reforço (AR), também conhecido como programação dinâmica adaptativa, é um processo através do qual um agente melhora o seu comportamento através de interação direta com o ambiente. Ele emergiu como poderosa ferramenta para resolver complexos problemas de decisão sequencial na área de teoria do controle, em particular os problemas de decisão de Markov e suas variantes (Gosavi, 2009).

Inicialmente, o algoritmo não possui conhecimento sobre o problema e na presença dos estímulos percebidos no ambiente o mecanismo de aprendizado emite respostas por um processo estocástico. Uma determinada resposta, emitida na presença de um conjunto de estímulos, apresenta efeito de reforço positivo ou negativo que será de uma forma associada à ação e/ou estado. O objetivo do algoritmo é construir uma política de ações que condicione o agente a atingir o objetivo da melhor forma. Entre vários algoritmos proposto na literatura, o 
$Q$-learning é o mais utilizado por sua simplicidade.

O Algoritmo Q-learning, uma técnica proposta por Watkins (1989), utiliza uma função ação-valor, ou função Q, para ponderar a qualidade da ação selecionada em um estado seguindo uma politica (Kaelbling et al., 1996). Dessa forma, em um momento $t$ da interação do agente com o ambiente, a função Q calcula o valor da ação executada sobre o estado, valor $Q$, de acordo com:

$$
\Delta Q\left(s_{t}, a_{t}\right)=\alpha\left[r_{t+1}+\gamma \max _{a_{t+1}} Q\left(s_{t+1}, a_{t+1}\right)-Q\left(s_{t}, a_{t}\right)\right]
$$

na qual taxa de aprendizagem $(\alpha)$ e parâmetro de desconto $(\gamma)$ estão no intervalo $(0<\alpha<1)$ $\mathrm{e}(0<\gamma<1)$.

Assim, após um período de treinamento o agente constroi uma base de conhecimento que armazenará o conjunto $(s, a$, valor $Q)$ em sua estrutura. A partir desse momento o número de consultas a sua base de informações será maior que o número de processos randômicos para a seleção de uma ação.

Baseado no algoritmo Q-learning, o algoritmo TG (Driessens, 2004) foi desenvolvido para tratamento de dados relacionais em larga escala. Para utilizar o algoritmo como mecanismo de aprendizado na arquitetura proposta por Policastro, algumas modificações foram proposta no algoritmo TG, dando origem ao algoritmo Economic TG $(E T G)$ e são apresentadas a seguir.

\section{Algoritmo ETG}

A primeira alteração está na forma de atualizar o mecanismo de armazenamento. No algoritmo TG, o sistema interage com o ambiente até encontrar o estado desejado. Dessa forma, todo conjunto obtido pelo processo e as métricas de avaliação do conjunto são armazenadas em uma estrutura auxiliar. Em seguida, cada conjunto é avaliado e apenas os exemplos considerados bons são inseridos na estrutura principal, uma árvore de regressão binária. Por outro, lado o ETG insere os exemplos, sem distinção, na estrutura principal a cada iteração sem realizar uma avaliação do conjunto, se valendo apenas do valor $Q$. Além disso, o algoritmo ETG não utiliza nenhuma função do sistema TILDE (Blockeel \& De Raedt, 1998).

A segunda está na ordenação das melhores ações em cada nós folhas, a serem executadas em ordem crescente do valor Q.

Além disso, o sistema utiliza a variável necessidade para auxiliar na escolha da ação. O atributo fornecido pelo módulo de consequência é utilizado como apoio na seleção da ação a ser executada. De acordo com a necessidade do agente, o módulo de consequência atribui o valor, 0 ou 1 , ao evento ocorrido, adicionando um elemento necessidade ao conjunto 
(s, a, valor $Q$, necessidade).

Dessa forma, os algoritmos 1 e 2 mostram o funcionamento, passo a passo, do mecanismo de aprendizado. Todo o processo se inicia com o algoritmo 1 recebendo o valor do estado do ambiente e da necessidade do agente. Com os valores obtidos, o algoritmo busca por uma melhor ação na estrutura de armazenamento ou faz uma busca aleatória (tendo uma probabilidade fixa de $5 \%$ na fase de aprendizado). A ação selecionada é executada sobre o ambiente, resultando em um reforço e um novo estado que é observado pelo agente. Caso o agente não esteja em fase de aprendizado, o processo se repete até o fim da interação. Caso contrário, o algoritmo atualiza o valor $\mathrm{Q}$ e insere o conjunto (s, a, valor $Q$, necessidade) na estrutura de armazenamento.

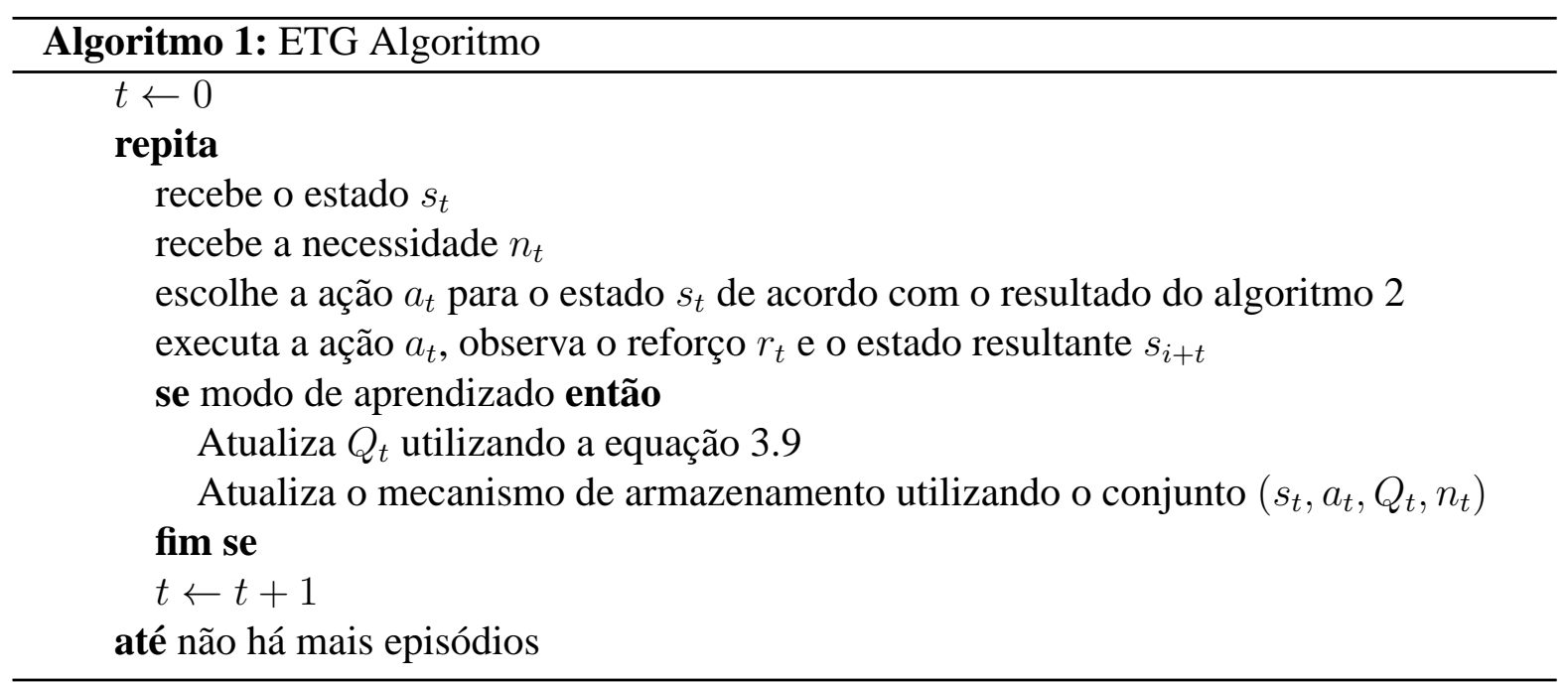

O mecanismo utilizado como estrutura de armazenamento é apresentado pelo algoritmo 2. No processo de atualização dos dados, o estado $s$ é comparado, pelos elementos que o constituem com cada nó entre a raiz e o nó folha. Caso o elemento armazenado se encontre presente como elemento do estado, o algoritmo segue a esquerda da estrutura da árvore, caso contrário, a direita. Um nó é inserido na falta do mesmo ou quando o algoritmo atinge o nó folha mas todos os elementos do estado ainda não foram verificados. No último caso, se faz necessário organizar a disposição dos mesmos.

Ao atingir um nó folha, é verificada a existência da ação no mesmo. Caso exista, o valor Q é atualizado, caso contrário, a ação com os valores da necessidade e valor Q são inseridos. Para finalizar o processo, caso seja necessário, ordenar as ações após a atualização para que o maior valor Q seja sempre o primeiro.

No processo de seleção, o estado é comparado da mesma forma que a da atualização. No entanto, se o algoritmo encontrar o nó folha a ação é retornada, caso contrário, um valor definido é retornado para que seja feita uma seleção aleatória. 

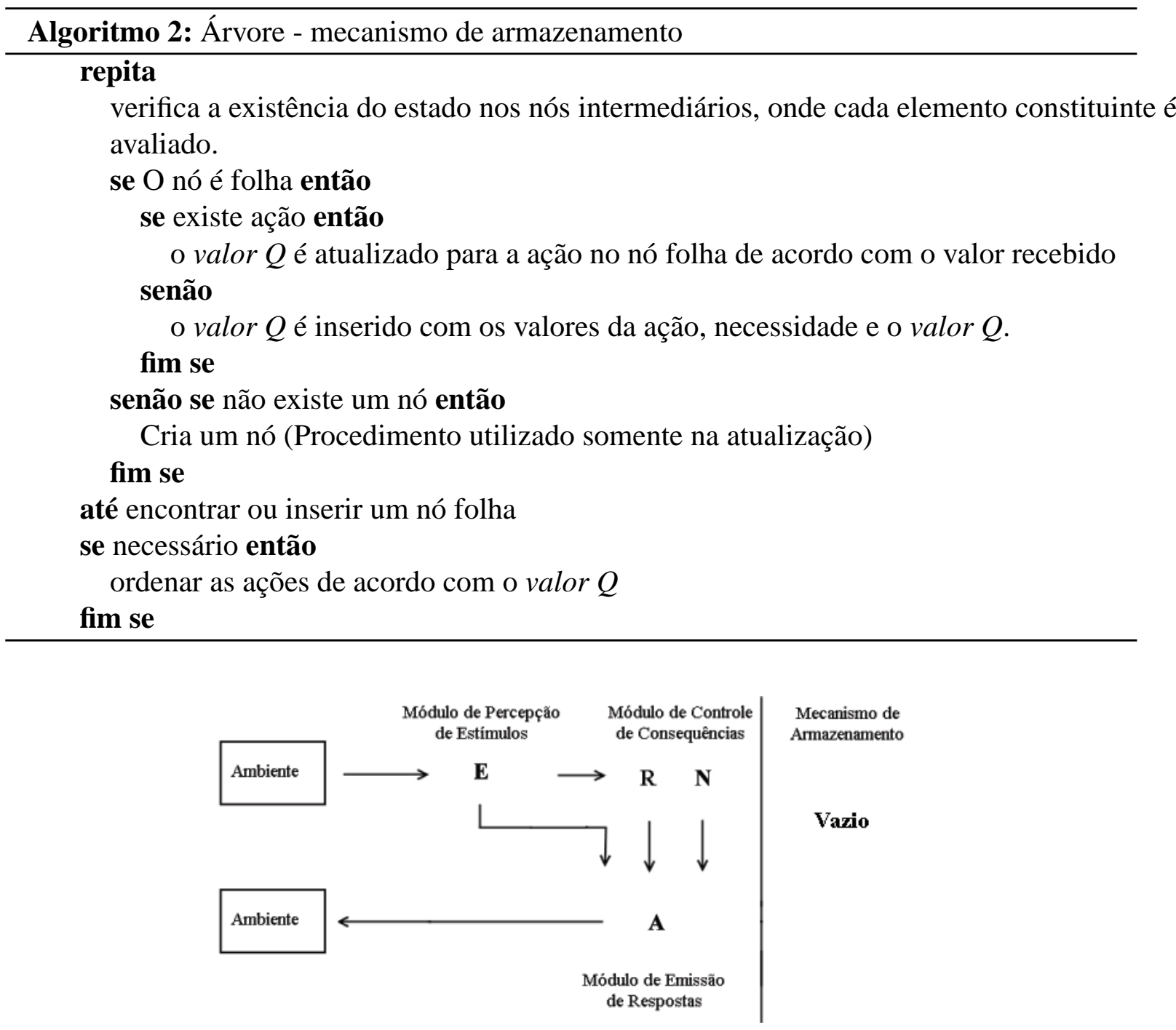

Figura 3.4: Funcionamento geral da arquitetura robótica

\subsection{Funcionamento da Arquitetura}

Após apresentar cada parte do sistema, as Figuras 3.6, 3.7, 3.8, 3.9 e 3.10 mostram, através de exemplos, cada parte do processo e o comportamento da estrutura de aprendizado. Na exemplificação é considerado a presença do robô, do instrutor e de objetos no ambiente.

Uma visão geral desse funcionamento é apresentado na Figura 3.4. O estado do ambiente é capturado pelo módulo de percepção de estímulos e codificado em uma representação para ser utilizado pelos outros módulos (E). O módulo de controle de consequência utiliza a informação do ambiente para gerar a necessidade $(\mathbf{N})$ do robô e do reforço $(\mathbf{R})$ da ação previamente executada. Com todas essas informações geradas, o módulo de emissão de resposta verifica no mecanismo de armazenamento a ação a ser executada (A) sobre o ambiente.

Os estados e as ações foram definidas para esse exemplo como: $X, Y$ e $Z$ (estados) e $a$, 


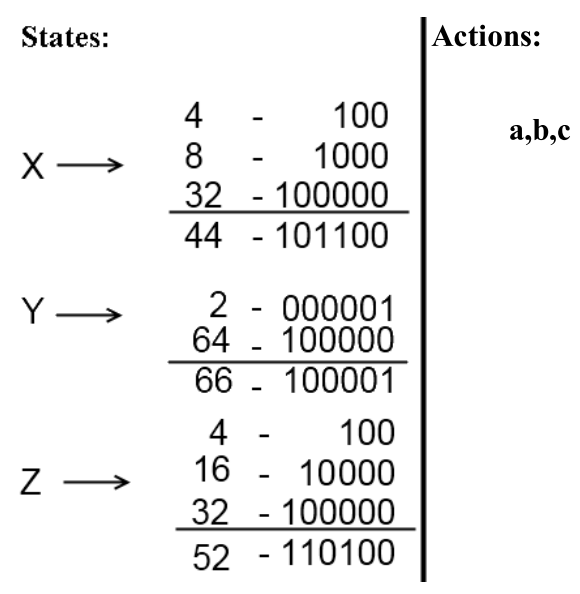

Figura 3.5: Estados, com suas específicas conversões, e ações utilizadas

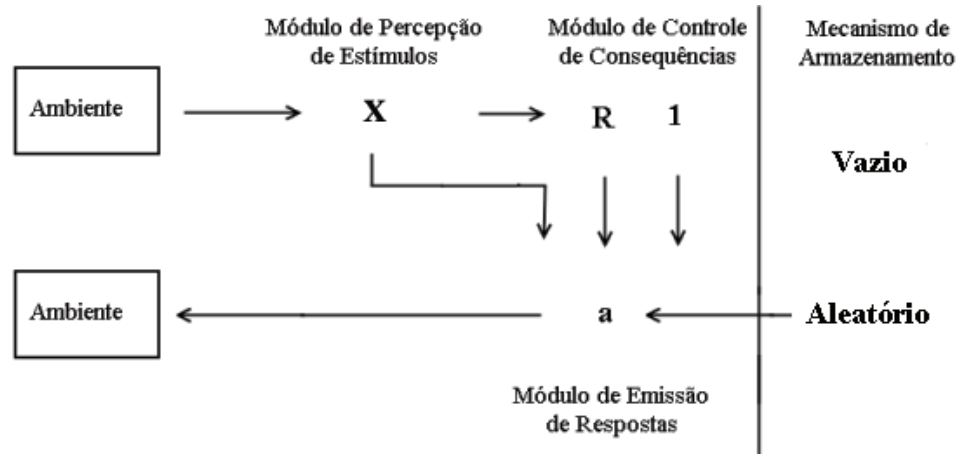

Figura 3.6: Exemplo de um primeiro passo de uma determinada iteração

$b$ e $c$ (ações). Na Figura 3.5, as ações e os estados são apresentados. Além disso, as conversões dos estados utilizados são apresentados. Dessa forma, toda vez que o texto se referenciar ao estado $X$, está implícito que a arquitetura utilizará o valor binário 101100.

O início de todo o processo está representado na Figura 3.6 O robô reconhece o ambiente, que é representado por " $\mathrm{X}$ ". $\mathrm{O}$ valor resultante é armazenado na memória de trabalho para ser utilizado pelos outros módulos.

O modulo de controle de consequências acessa a informação sobre o ambiente. O valor é processado e a necessidade do robô é informada. O sistema ainda faz uma estimativa do reforço recebido, positivo (1) ou negativo (0). Na Figura 3.6 a necessidade é positiva (1) e o reforço não é informado por ser a primeira interação. No final toda informação gerada pelo modulo é inserida na memória de trabalho.

O modulo de emissão de resposta acessa as informações geradas pelos outros módulos na memória de trabalho para selecionar a melhor ação a ser executada. Primeiro, o algoritmo verifica se existe uma ação para o estado recebido na estrutura de armazenamento. Na Figura 3.6. a estrutura está vazia. Em casos onde o estado não está na árvore, o algoritmo faz uma escolha aleatória da ação a ser executada pelo agente. Figura 3.6. este processo está 

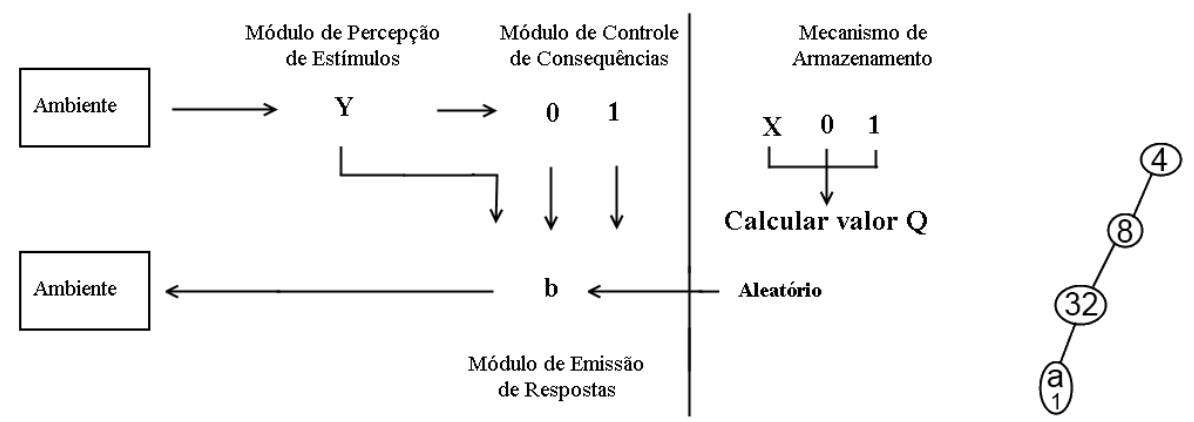

Figura 3.7: Etapa subsequente que mostar a atualização da estrutura de armazenamento

exemplificado pela letra "a". A ação é executada e o estado do ambiente pode alterar. Além disso, o estado, a ação e o reforço são armazenados na memória.

Ao fim da primeira iteração, o estado do ambiente se alterou e agora é representado pela letra "Y", como mostra a Figura 3.7 De modo semelhante o módulo de controle de consequências analisa o estado e retorna o valor da necessidade positiva (1) e o reforço negativo (0). Vale ressaltar que o reforço é relativo ao par (estado,ação) do turno anterior.

O módulo de emissão de resposta busca a melhor ação na estrutura de armazenamento que ainda está vazia. Dessa forma, o algoritmo seleciona de forma aleatória a ação b. Como a primeira iteração já foi toda processada é possível o cálculo do valor Q pelo algoritmo. Esse valor será associado ao estado, ação e necessidade para atualizar a estrutura de armazenamento, como mostra a parte esquerda da Figura 3.7

O processo de atualização da estrutura de armazenamento se inicia tentando encontrar o estado $\mathbf{X}$ na árvore comparando cada característica (número binário) nos nós intermediários. Se o valor encontrado no nó é parte constituinte do estado, o algoritmo busca o próximo nó a esquerda, caso contrário, o nó a direita é selecionado. Quando um nó não é encontrado, o algoritmo insere um novo nó. Na Figura 3.6, a estrutura de armazenamento está vazia, assim, o estado é inserido, como mostra na Figura 3.7.

A Figura 3.8 mostra o que acontece quando a estrutura de armazenamento não está vazia e, nesse caso, todas as iterações subsequentes, seguirá esta sequência. O módulo de emissão de resposta utiliza todas as informações para encontrar a melhor ação na estrutura de armazenamento. Cada elemento constituinte do estado é comparado na estrutura intermediária para identificar a presença do estado. Em primeiro lugar, o nó representado pelo valor 4 é comparado com o estado atual, sendo representado na Figura 3.8 pelo número vermelho 1 . A resposta positiva faz o algoritmo seguir para o próximo nó pelo seu lado esquerdo. A linha vermelha representa o caminho que foi realizado (juntamente com os números vermelho 2, 3 e 4). Em cada nó a resposta foi positiva, mas ao chegar no nó de folha ou ao número 4 em vermelho, o valor da necessidade é diferente. Nesse caso, a ação foi escolhido aleatoriamente. A ação é executada no ambiente e o valor Q é calculado. A estrutura de armazenamento 


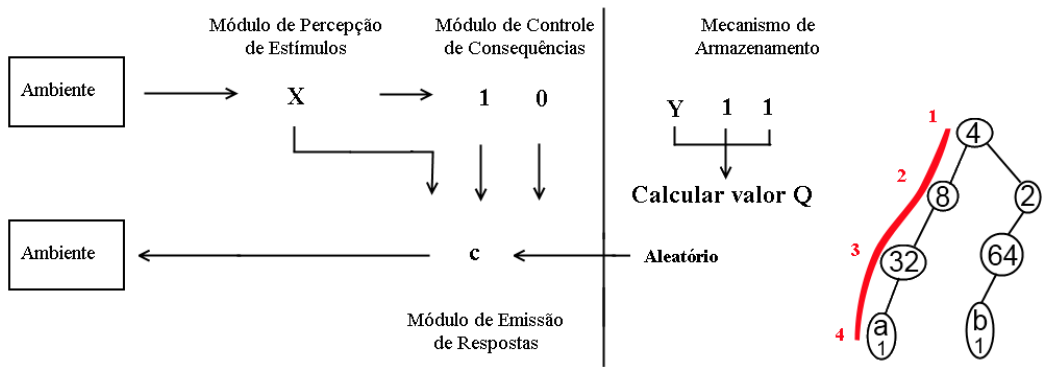

Figura 3.8: Terceira etapa do processo de iteração.

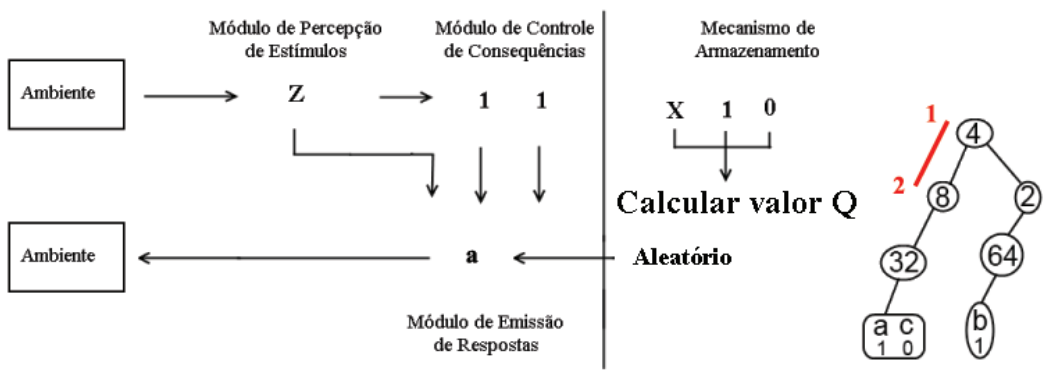

Figura 3.9: Quarto passo do processo de iteração

é atualizada com as informações sobre a última iteração. Para isso, a comparação com o primeiro nó (com o valor 4) foi feita com resposta negativa. Dessa forma, o algoritmo segue pelo lado direito e não encontra um nó. O novo estado é inserido no lado direito do primeiro nó da estrutura. Os outros nós são inseridos na estrutura de forma semelhante ao realizado na primeira atualização.

A Figura 3.9 e 3.10 são apresentados para mostrar algumas possibilidades. Na Figura 3.9, o novo estado tem alguns elementos de outro estado já inseridos na árvore e mostra o que acontece em um procedimento de atualização para um estado existente com ação diferente. No primeiro caso, o algoritmo fez uma comparação na estrutura de armazenamento. No primeiro nó, com o número de vermelho 1 , o resultado é positivo e o algoritmo segue pelo lado esquerdo. Mas, no segundo nó, com o número 2 vermelho, o resultado é negativo e o algoritmo segue para o lado direito. Aqui, o algoritmo não encontrar um nó e chama a função aleatório para escolher uma ação, a. Para atualizar a estrutura de armazenamento, o algoritmo compara os elementos existentes no nó intermediaro com os elementos do estado antecessor X. Ao atingir o nó folha, a ação, necessidade e valor Q são inseridos.

Na Figura 3.10, é apresentado o caso quando uma ação é selecionada utilizando a estrutura de armazenamento. O estado atual é comparado em cada nó e sempre segue pelo lado esquerdo, como é mostrado na Figura 3.8, com os números vermelhos. No nó folha, a ação que possue o mesmo valor de necessidade com maior valor Q é selecionada.

Esse exemplo usa um estado simplificado para uma melhor compreensão. Outro ponto a lembrar, cada ação armazenada no estrutura de armazenamento tem o seu valor Q associado. 


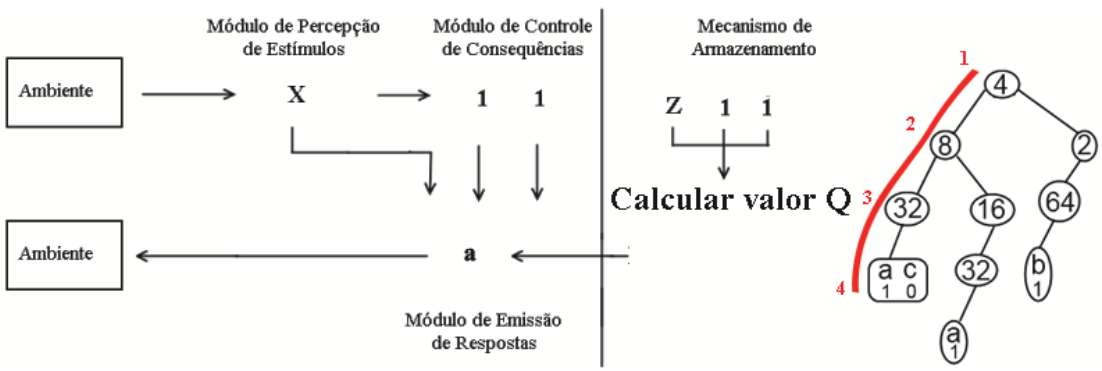

Figura 3.10: Último passo do processo de iteração

\subsection{Análise de Complexidade do Algoritmo de Aprendizado}

Após sua descrição, a análise de complexidade do algoritmo ETG, relativos a quantidade de memória requerida e acesso de memória, será apresentada.

O algoritmo armazena toda a informação em uma árvore binária. Além disso, em todo nó folha pode estar armazenada mais de uma ação. Desta forma, é necessário uma outra estrutura, no caso utilizamos um vetor, para armazena-las. No entanto, esse vetor tem dimensão limitada pelo número de ações, $n$, considerado para o problema da atenção compartilhada. Assim, considerando que $h>1$ denota a profundidade da árvore binaria, tem-se um total de:

$$
\sum_{i=0}^{h-2} 2^{i}+2^{h-1} \times n<\frac{1}{2(h-1)}[(h-1) 1]+n<n+1
$$

nós a serem armazenados.

O algoritmo ETG faz um tratamento para que o acesso a ação mais adequada seja realizada de forma simples possível. Assim, as ações estão armazenadas em ordem decrescente do valor $\mathrm{Q}$ e o total de tempo consumido está na ordem de

$$
O\left(\log _{2} m\right)
$$

sendo utilizado uma árvore binaria.

Mais detalhes do modelo ETG pode ser encontrados em (Silva \& Romero, n.d.).

\section{Simulador de Interações Sociais}

Na segunda versão, o simulador define o tipo de situação que está acontecendo. Dessa forma, é possível ter diferentes formas de interação, mesmo não tendo modificações na forma que é feita. Assim, ficou definido três tipos de situações: atenção, diversão e sozinho. Os duas primeiras são consideradas situações positivas e a terceira é negativa, essa classificação é uma 
forma de indicar a interação. Os dois primeiros são identicos e onde o processo de atenção conjunta é executado. Na terceira forma, o humano é retirado e não existe interação, o robô fica sozinho no ambiente. Essa alteração realizada na senguda versão foi desenvolvida para avaliar o modulo de identidade pessoal que será apresentado no Capítulo 5 .

\subsection{Análise de Resultados}

Para uma melhor análise dos resultados essa seção apresenta, primeiro as métricas utilizadas. Em um segundo momento, a forma de avaliação utilizada e em seguida as configuração de algumas constantes utilizadas nos módulos de controle de consequência e no de emissão de resposta. Por fim, os resultados obtidos nos testes com o simulador e com a cabeça robótica.

\subsubsection{Métricas}

Para os experimentos sobre a atenção compartilhada, a capacidade de aprendizado da arquitetura foi analisada pela observação da interação do robô com o humano e o ambiente, e pela computação de uma métrica denominada índice de olhar correto ou Correct Gaze Index (CGI). Essa métrica é baseada nos trabalhos apresentado por Whalen \& Schreibman (2003) e é definida como a frequência de direcionamento da atenção para o local correto, o qual o humano está olhando e definido pela Equação 3.12 .

$$
C G I=\frac{\text { direcionamento do foco para o local correto }}{\text { direcionamento do foco para qualquer local }}
$$

Além disso, a média e o desvio padrão é dado, respectivamente, pelas equações:

$$
\begin{gathered}
\overline{C G I}=\frac{1}{k} \sum_{i=1}^{k} C G I_{i} \\
d=\frac{1}{k}\left[\frac{1}{k-1} \sum_{i=1}^{k}\left(C G I_{i}-\overline{C G I}\right)^{2}\right]
\end{gathered}
$$

onde $k$ é o número de ciclos de interações.

Além disso, outra métrica considerada nesse trabalho é o contato ocular, que identifica a quantidade de vezes que ocorreu olhar mútuo. Esse fator nos ajuda na avaliação de cada sistema de aprendizado, pois não basta ter uma alta média de CGI se o contato ocular foi baixo, ou seja, isso significa que o agente conseguiu realizar bem o foco no qual o ser humano está observando, mas não conseguiu manter contato ocular. A quantidade de vezes que o 
agente manteve o contato ocular indica o número de possibilidades de realização da atenção compartilhada. Assim, quanto mais contato ocular mais vezes o agente tem para interagir com a pessoa.

\subsubsection{Avaliação}

Os experimentos foram compostos por uma fase de aprendizagem de $\mathrm{NrCiclos}$ ciclos de interação. Durante a fase de aprendizagem, o ser humano mantinha o foco inicialmente no robô até que este estabelecesse o contato ocular. Então, uma objeto era posicionado no ambiente e o ser humano direcionava o seu olhar o mesma. O ser humano mantinha o seu olhar no objeto selecionado até o robô emitir uma resposta (execução de uma ação motora). Depois, o objeto era removido e o ser humano voltava a olhar para o robô, aguardando que este estabelece novamente o contato ocular. Este procedimento foi executado para simular uma interação social na qual dois agentes estão mantendo contato ocular e então um deles direciona o olhar para um evento ou objeto interessante no ambiente.

Para quantificar o aprendizado da arquitetura durante os experimentos, a fase de aprendizado foi interrompida em pontos específicos, a cada unTem unidades de tempo. Então, uma fase de validação do conhecimento adquirido foi iniciada para avaliar o comportamento da arquitetura. Essa avaliação foi executada por nrmExe execuções de unTem unidades de tempo ou unTem ciclos de interação. Para cada execução, o valor do CGI foi computado, dado pela Equação 3.12. Depois das nrmExe execuções, a média e desvio padrão das nrmExe medidas foram calculados, de acordo com as Equações (3.13) e (3.14), respectivamente.

Durante a fase de aprendizagem, o ser humano mantinha o foco inicialmente no robô até que este estabelecesse o contato ocular, sendo esse considerado pela permanência por 3 unidades de tempo. Então, dois objetos eram posicionados no ambiente e o ser humano direcionava o seu olhar para um destes objetos, obedecendo as probabilidades definidas no simulador de interações sociais. O humano mantinha o seu olhar no objeto selecionado por 5 unidades de tempo. Depois, os objetos eram removidos do ambiente social e o ser humano voltava a olhar para o robô, aguardando que este estabelecesse contato ocular novamente. Este procedimento foi executado para simular uma interação social na qual dois agentes mantêm contato ocular e então um deles direciona o olhar para um evento ou objeto interessante no ambiente.

Nas primeiras prmTime unidades de tempo da fase aprendizagem, nenhum objeto foi posicionado no ambiente e o ser humano manteve o seu foco no robô ao longo de todo este período de tempo. Nestas primeiras prmTime unidades, o robô aprendeu que estabelecer o contato ocular com ser humano produz alguns estímulos reforçadores de atenção do mesmo, satisfazendo sua necessidade de socialização (unidade de necessidade socialize configurada 
no sistema motivacional). Este procedimento foi executado para modelar o comportamento do robô de procurar por um ser humano e manter contato ocular sempre que sente necessidades de socialização. Depois das prmTime primeiras unidades de tempo, a fase de aprendizagem prosseguiu empregando uma fruta como declarado acima. A partir deste ponto da aprendizagem, o robô sempre olhava para o ser humano quando queria interagir socialmente (unidade de necessidade socialize estava ativa). Entretanto, quando um objeto era posicionado no ambiente e o ser humano direcionava seu olhar para este objeto, o robô perde a atenção do humano e começava a procurar por qualquer estímulo no ambiente que pudesse satisfazer seus estados internos (unidades de necessidade socialize). Quando o robô olhava para um objeto definido como uma fruta na base de conhecimento da arquitetura, este satisfazia suas necessidades. Adicionalmente, se o robô focasse uma fruta que também era o foco de atenção do ser humano, este último voltava a dar atenção ao robô, em relação ao objeto a qual ambos estavam focando.

\subsubsection{Configurações para os Experimentos}

O sistema motivacional foi configurado como segue. Foi criada uma unidade de necessidade: "socialize". O limiar de ativação do sistema motivacional foi fixado em 0,70 no simulador e 0,50 para a cabeça robótica. A inclinação da função sigmoide das unidades de necessidade (parâmetro $\delta$ ) foi configurada com valor igual a 0,20. Para a unidade socialize, o bias foi configurado com valor igual a 1,00 e o peso de sua conexão foi configurado com valor igual a 0,5 . O peso da conexão recorrente foi configurado com valor igual a 1,00. Os pesos das conexões das unidades de entrada hear(attention), see(frontal(face)), see(toy(object)), see(looking oy $\left.\left._{\text {object }}\right)\right)$ foram configurados, respectivamente, com valores iguais a $-1,00$, 0,05, 0,05 e 0,00. Durante o processo de configuração da arquitetura, verificou-se empiricamente que estes valores produziram os melhores resultados.

O módulo de emissão de respostas foi configurado como a seguir. A constante de aprendizado $\propto$ foi determinada com o valor acronimo taxaAprendizagem $=0,2$. O reforço positivo foi configurado com valor 10 e o reforço negativo com valor -1 . A constante de exploração constante de exploração $(\epsilon)$ foi configurado com o valor de $5 \%$ ou 0,05 . O valor do fator de desconto $\emptyset$ foi colocada somo sendo igual a 0,1 para a simulação e 0,9 para a cabeça robótica. Para discretizar o ambiente em regiões de interesse, foram definidas quatorze respostas de forma que o robô pudesse olhar para o ser humano ou procurar objetos em seis regiões definidas ao girar sua cabeça para a esquerda e seis regiões definidas ao girar a sua cabeça para a direita no simulador. No caso da cabeça robótica, sete respostas foram definidas para que o robô consiga olhar o ser humano e encontrar a fruta em cinco regiões definidas (esquerda, direita, abaixo, abaixo à esquerda e abaixo à direita). 


\subsubsection{Simulação}

Nesta Seção, são apresentados os principais resultados dos experimentos executados para a avaliação da arquitetura no contexto do aprendizado da atenção conjunta, empregando-se o simulador de interações sociais apresentado anteriormente. O propósito destes experimentos foi a determinação da capacidade de exibição de comportamentos apropriados e de aprendizagem da arquitetura com o algoritmo TGE durante o controle do robô simulado em um ambiente social controlado. Foi realizado também uma avaliação comparativa entre três técnicas de aprendizado: aprendizado por contingência, $Q$-learning tradicional (utilizando uma matriz) e TGE.

Para este conjunto de experimentos, as variáveis foram definidas da seguinte forma:

- NrCiclos - 10.000

- unTem - 500

- prmTime - 100

- $n r m E x e-20$

Além disso, o conhecimento de arquitetura foi configurado da seguinte maneira. Quatro estímulos foram declarados: face, object, attention e environment, no qual attention é um estímulo reforçador gerado com a atenção do ser humano. Foram declarados dois fatos para definir que objetos vermelhos e azuis são brinquedos. Também foram declarados treze fatos para diferenciar a pose da cabeça do ser humano como frontal, além de seis poses de perfil esquerdo e seis poses de perfil direito. Adicionalmente, foram declarados mais fatos para definir quando o robô está focalizando o ser humano ou um objeto.

Na Figura 3.11, é apresentada a curva da atenção obtida pelo agente do robô, ou seja, quando o agente consegue manter contato ocular com o ser humano, para três mecanismos de aprendizado (aprendizado de contingência, Q-learning tradicional e ETG). Ela contém também o valor do desvio padrão do intervalo.

Considerando que são realizados 500 ciclos e que para ser validado como contato ocular a necessidade de 3 ciclos, o valor máximo de contatos oculares são 166.

E neste ponto o algoritmo de aprendizado por contingência foi bem melhor que os outros dois algoritmos.

O comparativo entre os três mecanismos de aprendizado é representado na Figura 3.12 através da média do $C G I$ e do valor do desvio padrão no intervalo. As curvas de aprendizado demonstram o progresso da aprendizagem durante os experimentos de simulação para cada mecanismo. O resultado obtido demonstra que o ETG tem desempenho similar ao Q-learning 


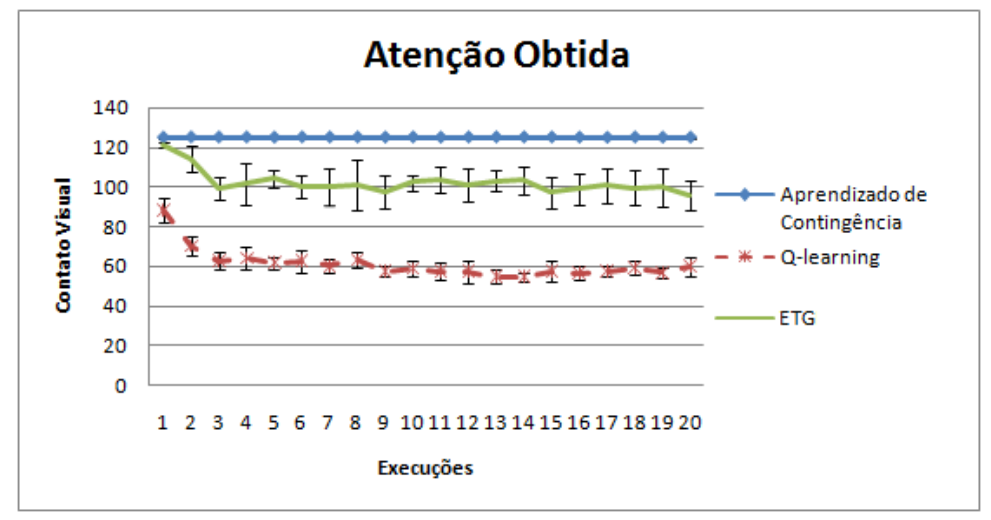

Figura 3.11: Quantidade de contato visual que o robô manteve com o ser humano

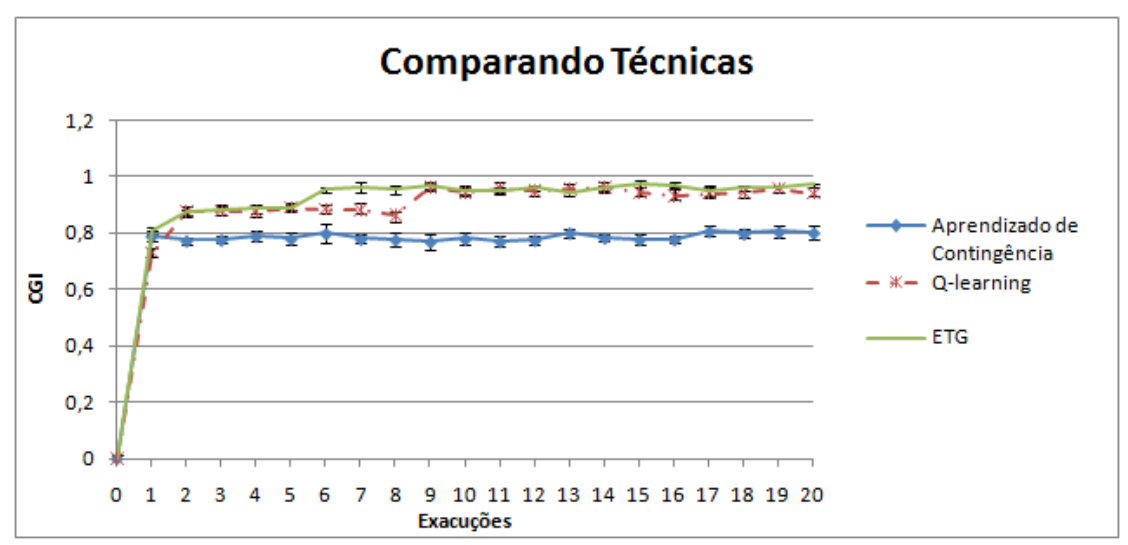

Figura 3.12: Comparação entre as técnicas utilizando o intervalo de confiança

tradicional, apesar do fato que em alguns momentos o TGE seja superior. A figura apresentou ainda que ambos são melhores que o aprendizado por contingência.

Na Figura 3.12 o valor máximo é 1 e esse ponto indica que o agente conseguiu $100 \%$ de aproveitamento.

Uma análise mais profunda pode ser feita considerando as Figuras 3.11 e 3.12, Considerando os fatores de aprendizado e contato ocular, pode-se afirmar que o algoritmo ETG consegue melhores resultados. Essa afirmação é feita pois o algoritmo obteve o melhor valor relativo ao aprendizado (junto com o algoritmo Q-learning), conseguindo manter um bom contato visual. Os outros métodos atingiram índices baixo do algoritmo ETG em um dos testes.

De fato, para estes experimentos, o Q-Learning empregou como mecanismo de representação do conhecimento uma Tabela $Q$ de 3150 posições. Já o TGE utilizou 68 nós, sendo que 29 são nós folhas que contribuem com 328 posições para o armazenamento das ações. 


\subsubsection{Cabeça Robótica}

Após a realização dos experimentos sobre o aprendizado da atenção conjunta, empregando o simulador de interações sociais, foram realizados os experimentos e estudos empregando a cabeça robótica interativa. Estes experimentos foram realizados no contexto do aprendizado da atenção compartilhada com o propósito de se avaliar a capacidade de aprendizagem da arquitetura proposta em um ambiente social real e controlado.

No cenario experimental, o robô deve ser capaz de aprender três partes da atenção compartilhada, sendo o de apontamento declarativo relativo ao aprendizado dos nomes dos objeto (uma maça, limão ou laranja) que alteraram o foco da atenção do ser humano.

Para realizar o experimento as seguintes configurações foram utilizadas:

- NrCiclos - 500

- unTem - 100

- prmTime - 30

- nrmExe-5

Além disso, o conhecimento de arquitetura foi configurado da seguinte maneira. Quatro estímulos foram declarados: face, objeto, atenção e ambiente, onde atenção foi configurado como um estímulo reforçador. Três fatos foram declarados como vermelho, laranja e verde, para definir o objeto fruta. Seis fatos foram declarados para diferenciar a posição da cabeça do ser humano: posição frontal, duas para direita, duas para a esquerda e uma para baixo. Além disso, mais dois fatos foram declarados para definir quando o robô está com o foco no ser humano ou no robô.

Como as frutas eram posicionadas no ambiente somente quando o ser humano direcionava seu foco para as mesmas, depois de uma história de reforçamento o robô aprendeu seguir o olhar do ser humano para receber a atenção dele e satisfazer suas necessidades de brincar e socializar.

A capacidade de aprendizagem da arquitetura foi analisada observando-se a interação do robô com o ser humano e com o ambiente e pela computação da métrica CGI, dada pela Equação (3.12).

Na Figura 3.13, é apresentada a curva de aprendizado que demonstra o progresso da aprendizagem durante os experimentos. Esta figura mostra um gráfico que apresenta o valor da média do CGI para cada fase de avaliação, em pontos específicos durante a fase de aprendizagem. Os resultados obtidos mostram que o valor do CGI é crescente no decorrer da fase de aprendizagem, demonstrando as capacidades de aprendizagem da arquitetura. 


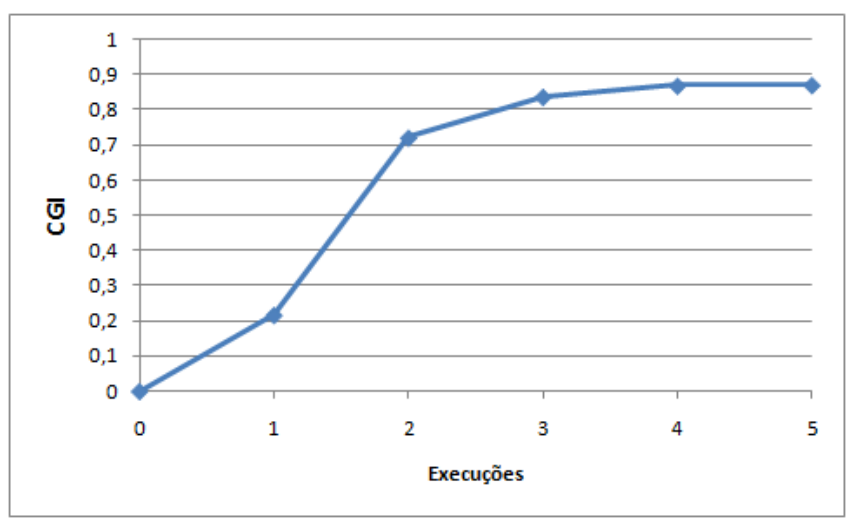

Figura 3.13: Evolução do aprendizado durante os experimentos. A curva apresenta a avaliação do conhecimento adquirido pela arquitetura com o passar do tempo. Em pontos específicos do processo de aprendizagem, este era temporariamente interrompido e uma fase de avaliação do comportamento do robô era executada por 5 corridas de 100 unidades de tempo. Para cada corrida, era computado o valor do CGI e depois das 5 corridas era calculada a média e desvio padrão das 5 corridas.

Estes resultados mostram que a arquitetura é capaz de exibir comportamentos apropriados durante uma interação social real e controlada. Adicionalmente, os resultados confirmam os resultados dos experimentos anteriores, mostrando que a arquitetura pode aprender a partir de uma interação social. Os resultados mostram ainda que a arquitetura suporta a modelagem de comportamentos, isso é, ela possibilita que o comportamento do robô seja modelado por meio de aproximações sucessivas, por meio do reforço e encadeamento de comportamentos inatos para a implantação de um comportamento mais complexo. Nestes experimentos, isto foi realizado pela modelagem do comportamento de procurar por um ser humano e, após isso, pela modelagem do comportamento de seguir o olhar deste.

Finalmente, um exame dos resultados obtidos mostram que a arquitetura proposta é capaz de adquirir habilidades sociais básicas a partir de comportamentos inatos existentes no repertório do robô e da interação com o ambiente. Os resultados evidenciam também que a arquitetura constitui uma contribuição para a área de pesquisa sobre o aprendizado da atenção compartilhada, por representar um modelo de aprendizado desta habilidade tida como um dos grandes desafios da robótica sociável. Adicionalmente, pode-se afirmar que os resultados obtidos estão de acordo com a literatura existente na área (Fasel et al., 2002; Carlson \& Triesch, 2003; Nagai et al., 2003; Lau \& Triesch, 2004; Deák \& Triesch, 2005; Dube et al., 2004).

Portanto, os resultados mostram que a arquitetura é uma ferramenta potencial para controlar robôs sociáveis durante interações em um ambiente social.

Para avaliar a habilidade da cabeça robótica de fazer apontamento declarativo, o ser humano ensinou ao robô a reconhecer os objetos (maça vermelha, limão amarelo e laranja) através do aprendizado por tutelagem. Uma rede neural ART2 foi utilizada como mecanismo de aprendizado dos nomes do objetos sendo configurado da seguinte maneira. O limiar 
de confiança $\left(\phi_{c}\right)$ foi configurado com valor igual a 2 e o limiar de conhecimento $\left(\phi_{k}\right)$ foi configurado com valor igual 6. A rede neural de ART2 foi configurada como a seguir. O parâmetro de vigilância $(\lambda)$ foi configurado com valor igual 0,999 . Os parâmetros $a, b, c$ e $d$ foram configurados respectivamente com valores iguais $10,10,0,1$ e 0,9 . Durante o processo de configuração do mecanismo, verificou-se empiricamente que estes valores produziram os melhores resultados.

$\mathrm{Na}$ fase de teste da atenção compartilhada, no momento em que o robô percebe um objeto, o ser humano requisita ao robô o reconhecimento do objeto, sendo feita por um conhecimento prévio Policastro (2008). Para avaliar o mecanismo de aprendizagem proposto, foram calculadas 5 métricas durante os experimentos: taxa de desconhecimento, taxa de suposições corretas, taxa de suposições incorretas, taxa de erros e taxa de acertos. As métricas mostram desconhecimento, incerteza com suposição correta ou incorreta, e conhecimento incorreto ou correto, respectivemente.

Na Tabela 3.1 são mostrados os valores das médias e desvios padrão das 5 métricas para as 5 corridas executadas durante os experimentos Silva et al. (2008).

Tabela 3.1: Resultados obtidos após as 5 corridas de sessão de aprendizado por tutelagem.(Silva et. al., 2008)

\begin{tabular}{lc}
\hline Métrica & Média $(\%)$ \\
\hline \hline Taxa de desconhecimento & $7.23 \pm 0.58$ \\
Taxa de suposições corretas & $17.47 \pm 1.28$ \\
Taxa de suposições incorretas & $1.8 \pm 0.44$ \\
Taxa de erros & $0.6 \pm 0.2$ \\
Taxa de acertos & $72.89 \pm 2.19$ \\
\hline
\end{tabular}

A arquitetura com a rede neural ART2, de acordo com a tabela acima, conseguiu classificar os padrões com $73 \%$ de acerto e realizando o passo de apontamento declarativo da atenção compartilhada. Além disso, os resultados da Tabela 3.1 mostram a boa capacidade do sistema de aprendizado por tutelagem.

\subsection{Limitações}

Apesar do bom funcionamento do robô em interações simples algumas limitações dessa arquitetura impede o desenvolvimento de mais habilidades do robô. A visão computacional é limitada no reconhecimento do ambiente. Pode ser citada como exemplo de limitação a dificuldade de adaptação a iluminação, modelo que reconhece os movimentos da cabeça com reconhecimento do padrão da face não estável e que não possibilita uma livre movimentação do ser humano que está interagindo. Esse problema será abordado no Capítulo 4 


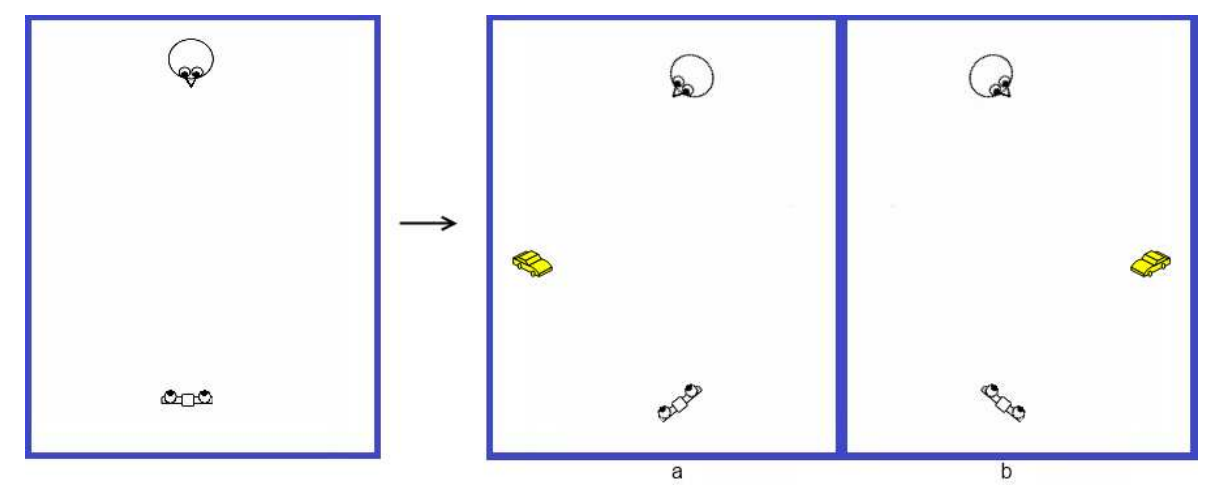

Figura 3.14: Problema ao utilizar somente aprendizado por reforço para capacitar um agente com atenção compartilhada. Inicialmente o agente tem o contato ocular com o ser humano. No momento em que um evento acontece no ambiente o humano muda a sua atenção ao evento. $\mathrm{O}$ agente acompanha a atenção do humano. O evento pode acontecer em qualquer posição do ambiente. Ao dar atenção ao evento, independente da posição, o estado percebido pelo agente é a mesma.

Além disso, o modulo motivacional que deveria exercer a função de pró-atividade e, no entanto só auxilia o modulo de emissão de resposta a aprender a atenção compartilhada. $\mathrm{O}$ problema é que essa interferência dificulta a criação de outros módulos. Esse problema será abordado no Capítulo 5

A adição de uma informação para auxiliar o algoritmo a resolver o problema de aprender a atenção compartilhada se deve ao fato de determinados estados acontecerem em situações diferentes. A Figura 3.14ilustra esse fato. $\mathrm{O}$ agente tem a atenção do robô, caracterizado pelo contato ocular durante um período de tempo. Um evento acontece no ambiente, no caso da figura um objeto aparece, e a atenção do agente é deslocada e focaliza o objeto. Em seguida o robô volta a sua atenção ao mesmo objeto, esse movimento não é simultâneo. O objeto pode aparecer em qualquer posição do ambiente. Sendo assim, em diferentes posições em que o objeto se situar o estado percebido pelo agente é o mesmo.

O problema está em escolher uma ação para retomar o contato ocular, pois dependendo da posição aonde o objeto se encontra a ação necessária para tal é diferente. Assim, a informação adicional auxilia o robô a entender a posição aonde ele se encontra.

Existem outros problemas ao utilizar aprendizado por reforço para capacitar um robô a executar a atenção compartilhada. Uma das situações conflitantes é no momento que o foco do robô está no evento e o robô tenta voltar o foco ao ser humano. Caso o ser humano tenha voltado o foco e já esteja olhando para o robô, ao voltar o foco para o ser humano o robô recebe reforço positivo, mas se o foco do ser humano estiver no evento, o robô receberá reforço negativo. Outra situação acontece no momento em que o robô percebe que o agente continua olhando para o evento, ao voltar o foco no local que o evento se encontrava, o agente percebe que o evento não se encontra mais lá. Quando o objeto estava lá o robô recebe reforço 
positivo, mas ao perceber que o evento não se encontra lá o reforço é negativo. Além disso, o agente recebe reforço positivo quando está focado no ser humano, quando o ser humano muda o foco o agente recebe reforço negativo pois está olhando o ser humano. Esse problema será abordado no Capítulo 6 .

\subsection{Considerações Finais}

O capítulo apresentou a concepção da nossa arquitetura robótica e os dispositivos (simulador e cabeça robótica) utilizados para validar o aprendizado da atenção compartilhada. Os resultados apresentados mostram que a arquitetura é capaz de aprender a dar atenção e a acompanhar o foco da atenção do ser humano a um objeto. E com a ajuda de um sistema de aprendizado por tutelagem, o robô foi capaz de inferir sobre alguns objetos. Dessa forma, a arquitetura é capaz de realizar três etapas das quatro que fazem parte da atenção compartilhada, segunda a definição adotada.

Tais resultados também mostram que a potencialidade do algoritmo como mecanismo de aprendizado da arquitetura. Os resultados obtidos mostram que a arquitetura é capaz de exibir comportamentos apropriados e é capaz de aprender a partir de interações sociais. Além disso, a utilização de diferentes domínios de aplicação demonstra a portabilidade da arquitetura.

Apesar do bom desempenho no aprendizado da atenção compartilhada algumas limitações impedem o desenvolvimento da arquitetura. Entre elas, a visão computacional com uma limitação no modelo de estimativa de posição da cabeça, o modulo de controle de consequências que foi desenvolvido sem a possibilidade de inserção de fatores internos e gera uma dependência do modulo de emissão de resposta para selecionar uma ação. 



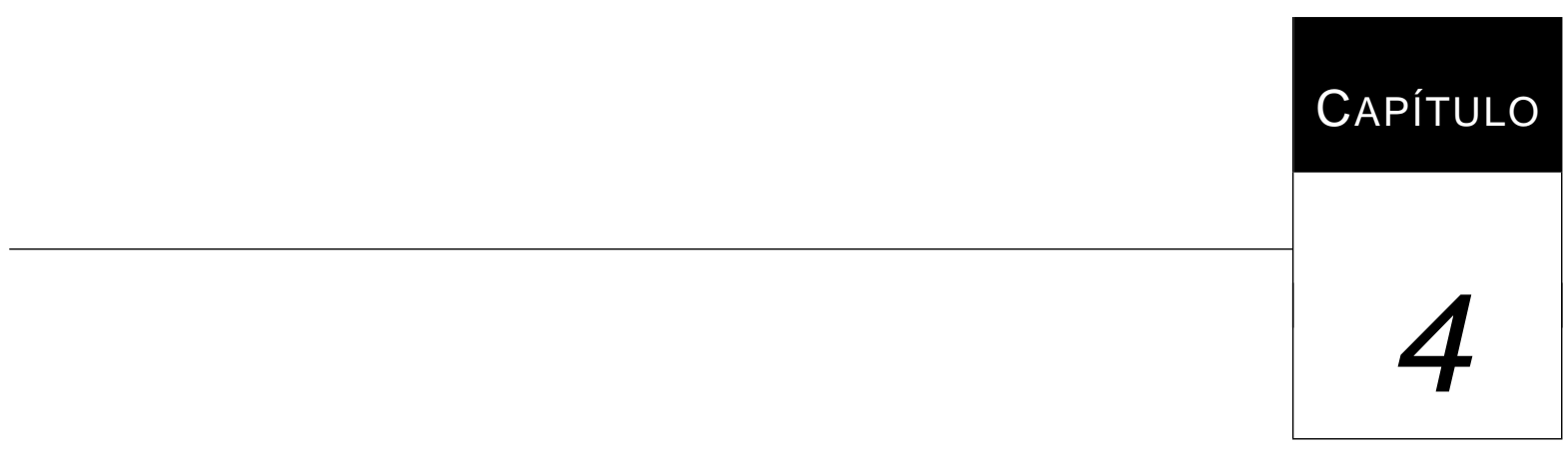

\section{Estimativa de Posição da Face}

Estimar a posição da face da pessoa com quem está interagindo é uma habilidade comum nos seres humanos e importante para entendermos a outra pessoa. Esse gesto é uma forma não verbal de indicar que algo ou um evento importante está ocorrendo. Além disso, é um importante passo para simular o comportamento da atenção compartilhada em um robô.

Neste capítulo são apresentadas as técnicas utilizadas no desenvolvimento de um algoritmo de estimativa de posição da face que também seja capaz de identificar a presença de uma pessoa. Note que, segundo a pesquisa bibliográfica realizada nesta tese, atualmente nenhum algoritmo é capaz de identificar tal presença, atuando erroneamente quando não há uma pessoa na imagem.

\subsection{Introdução}

Os seres humanos tem uma extraordinária habilidade de não apenas ser capaz de estimar a posição da cabeça de outra pessoa, mas também de utiliza-la para inferir sobre algo. A posição da cabeça fornece uma pista sobre o foco da atenção das pessoas, que é essencial para sistemas robóticos autônomos inteligente interagirem com os humanos. Um robô capaz de determinar a posição da cabeça beneficiar-se-ia em muitos aspectos da percepção dos 
acontecimentos ao redor do ser humano. O conhecimento da posição da cabeça da pessoa e da direção do seu apontamento permitiria o robô a deduzir quais pessoas interessadas na sua presença, e para prever movimentos futuros das pessoas, para um melhor planejamento das ações a serem tomadas. Para fazer tais inferências, o algoritmo para estimar a posição da cabeça requer uma combinação de vários fatores, tais como identidade, aparência, posição da cabeça, e iluminação (Ivanov et al., 2009).

Dessa forma, realizar a estimativa da posição da face é um problema complexo. Além de garantir os fatores citados acima, a obtenção da pose em imagens de duas dimensões (2D) é difícil porque muitos fatores aparecem interligados, não sendo linearmente separáveis, como as variações rígidas (posição da face) e as não rígidas (expressões) (Jimenez et al., 2009). A partir desse ponto, inúmeros métodos tem sido propostos e serão apresentados na próxima seção.

\subsection{Trabalhos Relacionados}

Na literatura, Murphy-Chutorian \& Trivedi (2009) classificaram os métodos de estimativa de posição da cabeça em oito categorias:

- Modelo de aparência: compara uma nova imagem da cabeça com um conjunto de exemplos rotulados até encontrar o mais similar. Os dois sistemas mais simples, a imagem consultada é atribuída a imagem mais próxima dos valores armazenados utilizando cross-correlation em resoluções de imagem múltiplas (Beymer, 1994) and erro quadrático mínimo (MSE) através da janela deslizante (Niyogi \& Freeman, 1996).

- Métodos de detector de vetor: treinamento de uma serie de detectores para cada posição especifica da cabeça e atribui uma pose ao detector com maior semelhança. Um dos primeiros exemplos da utilização de detectores de vetor usa três SVMs para três valores discretos de yaws (J. Huang et al., 1998). Um sistema mais recente utiliza cinco classificadores FloatBoost utilizando quatro câmeras (Zhang et al., 2007).

- Métodos de regressão não linear: utiliza ferramentas de regressão não linear para desenvolver um mapa funcional da imagem ou dados característicos para cálculo da estimativa da posição da cabeça. Das ferramentas de regressão não linear utilizada para estimativa de pose cabeça, as redes neurais têm sido o amplamente utilizadas na literatura. Um exemplo é o multilayer perceptron $(M L P)$ utilizando o treinamento backpropagation (Brown 
\& Tran, 2002; Zhao et al., 2002; Voit et al., 2007).

- Metodo Manifold embedding: busca baixa dimensão dos manifolds que modelam a variação continua da posição da cabeça. Novas imagens podem ser adicionadas nos manifolds e então ser usadas por comparação de exemplos ou regressão. As técnicas de Manifold embedding tem mostrando-se promissoras. Entre elas estão o mapeamento de características isométricas (Ravtchev et al., 2004; Tenenbaum et al., 2000), Locally Linear Embedding (Roweis \& Saul, 2000) e Laplacian Eigenmaps(Belkin \& Niyogi, 2003).

- Modelos flexíveis: cria um modelo não rígido para uma estrutura facial de cada indivíduo em uma imagem plana. A posição da cabeça é estimada através de comparações de níveis de características ou por representações de parâmetros do modelo. A técnica mais recente que utiliza esse modelo baseia-se em um estrutura probabilística chamada Generalized Adaptive View-based Appearance Model (GAVAM) L. Morency et al. (2010).

- Modelos geométricos: utiliza a localização de características, como olhos, boca, e nariz para determinar a posição de uma configuração relativa. Abordagens iniciais focam sobre a estimativa da cabeça a partir de um conjunto de características locais da fac. Supõe-se que estas características já são conhecidas, e a posição pode ser estimada diretamente a partir da configuração destes pontos. Utilizando-se cinco pontos faciais (os cantos externos de cada olho, os cantos exteriores da boca, e a ponta do nariz), o eixo de simetria facial é encontrado através da ligação de uma linha entre o ponto médio dos olhos e ponto médio da boca (Gee \& Cipolla, 1994). Outra estimativa de pose podem ser obtidos utilizando um conjunto diferente de cinco pontos (os cantos interiores e exteriores de cada olho, e na ponta do nariz) (Horprasert et al., 1996). Um outro método foi recentemente proposto utilizando os cantos interiores e exteriores de cada um dos olhos e os cantos da boca, que são automaticamente detectados na imagem (Wang \& Sung, 2007).

- Método de posicionamento: recupera a mudança da posição global da cabeça de movimentos observados entre frames. Continuidade temporal e restrições de movimento suaves são utilizados para fornecer uma estimativa visualmente atraente de posição da cabeça ao longo do tempo. Uma abordagem mais sofisticada assume que a face humana é uma superfície planar no espaço ortogonal. Nesse caso, dois graus de liberdade (DOF) pode ser recuperado usando mínimos quadrados ponderados para determinar a melhor transformação entre dois frames. O problema é reduzido a uma ambiguidade de rotação, que é capaz de identificar a direção da cabeça (Yao et al., 2001).

- Métodos híbridos: combina um ou mais métodos citados para superar as 


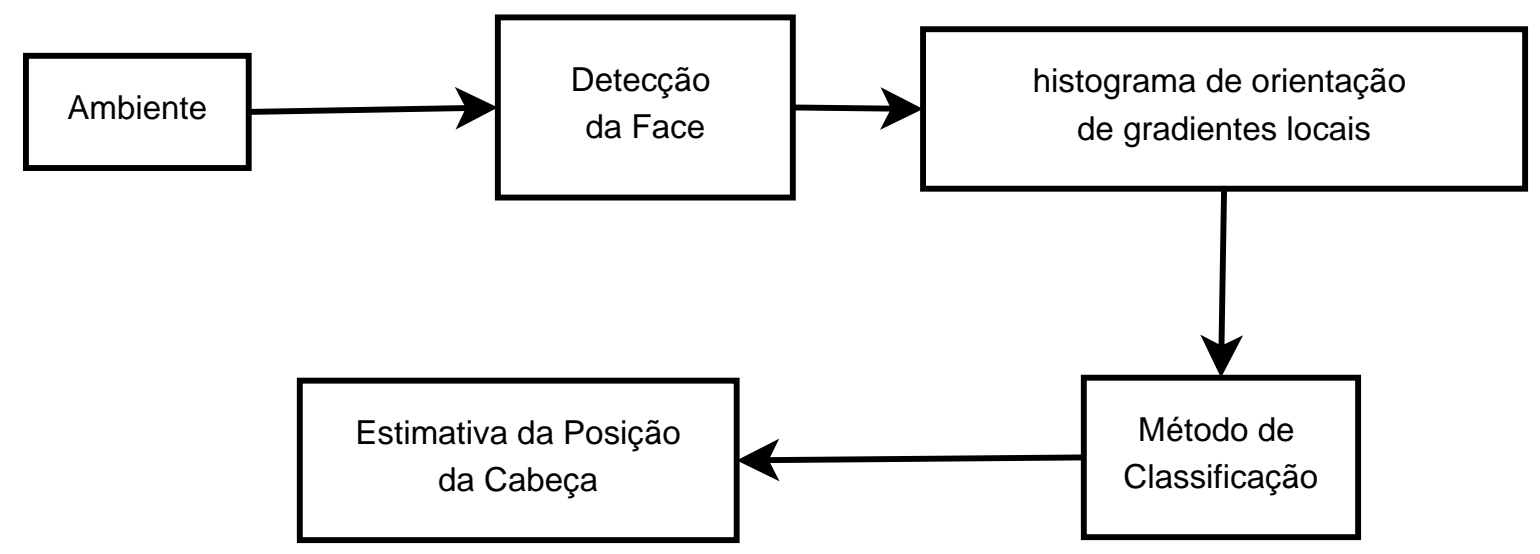

Figura 4.1: Fluxograma do funcionamento do sistema de estimativa da face.

limitações de uma proposta. Um das mais recentes abordagens utiliza um esquema híbrido estimativa pose através de um método de regressão não linear e método de posicionamento. O primeiro é responsável por inicializar o sistema e o segundo por manter a estimativa da posição da cabeça. Esse método combina as propriedades de inicialização e estabilidade do método de regressão não linear com a alta precisão e recursos em tempo real de uma abordagem de monitoramento (Murphy-Chutorian \& Trivedi, 2008).

Para um sistema de estimativa de posição de cabeça ser considerado de uso geral, ele deve ser invariante na identificação, ser estável para permitir movimentação da outra pessoa, ser automático e de fácil integração com o hardware. Com base nessas características, foi escolhido como base para ser desenvolvido nesta tese, o método hibrido de estimativa de posição da cabeça utilizando histograma de gradientes localmente orientados proposto por Murphy-Chutorian \& Trivedi (2009).

\subsubsection{Um Modelo Híbrido para Estimativa de Posição da Face}

O método proposto por Murphy-Chutorian \& Trivedi (2009) é uma forma automática de detecção da face de uma pessoa e subsequentemente estima a posição da cabeça da pessoa de forma instantânea. Para realização do processo, este é dividido em três etapas (detecção da face, cálculo de gradiente e aprendizado), como apresentado na Figura 4.1 .

A detecção da face é feita através do processamento do método Adaboost cascades (Viola \& Jones, 2001; Lienhart \& Maydt, 2002). Este método é executado três vezes, em paralelo, sendo que um para a detecção do lado esquerdo, outro para a detecção do lado direito e outro para detectar a posição frontal da face. Cada detector é capaz de reconhecer a cabeça com desvio suficiente para caracterizar a posição. A possível variação da posição da cabeça 
está ente $-30^{\circ}$ a $30^{\circ}$ no pitch e roll, e $-90^{\circ}$ a $90^{\circ}$ no yaw Foram utilizadas imagens em tons de cinzas com tamanho fixo da imagem de $34 \times 34$ (Murphy-Chutorian \& Trivedi, 2009).

A região da face detectada é utilizada pelo histograma de orientação de gradientes locais $(l g o)$ para prover a descrição da orientação da face. Esse método foi desenvolvido utilizando outros dois métodos como base, o Scale-invariant feature transform (SIFT) e o histograma de orientação de gradientes (hog), O algoritmo SIFT foi proposto por Lowe (2004) para descritor características locais em uma imagem. O seu processo consiste em quatro etapas:

1. Detecção de pontos: O primeiro passo consiste em identificar potenciais pontos de interesse em uma imagem que são invariantes em relação a escala e orientação utilizando diferença de gaussianas.

2. Localização dos pontos chaves: Em cada ponto candidato, o modelo é redimensionado para determinar a localização e escala. Os pontos chaves são selecionados com base em medidas de sua estabilidade.

3. Atribuição de orientação: Uma ou mais orientações são atribuídas a cada ponto chave com base na direção do gradiente local da imagem.

4. Keypoint descritor: Os gradientes locais da imagem são calculados na escala selecionada na região em torno de cada ponto chave.

Ohog é um descritor de características que considera as ocorrências da orientação do gradiente me porções localizadas da imagem. Segundo Dalal (2006), o processo para gerar os descritores se divide em cinco partes.

Na primeira etapa é aplicado uma normalização na imagem projetada para reduzir a influência de efeitos de iluminação. Essa fase, segundo o autor é opcional e pode utilizar as técnicas de compressão gama, o cálculo da raiz quadrada ou o registo de cada canal de cor.

Na segunda etapa é calculado os gradientes de imagem de primeira ordem. Essa etapa captura o contorno, a silhueta e algumas informações de textura, proporcionando uma maior resistência a variações de iluminação.

Na terceira etapa, o objetivo é produzir uma codificação que é sensível ao nível de imagem local, permanecendo resistente a pequenas alterações na postura ou aparência. A janela de imagem é dividida em pequenas regiões espaciais, chamados de "células". Para cada célula é calculado o gradiente local ou linhas de orientações sobre todos os pixels na célula. O conjunto de células constituem a representação do "histograma orientado". Cada histograma orientado divide o intervalo de ângulo de inclinação para um número fixo de posições pré-determinadas. As magnitudes de gradiente de pixels na célula são usadas para selecionar a orientação do histograma através do processo de eleição. 


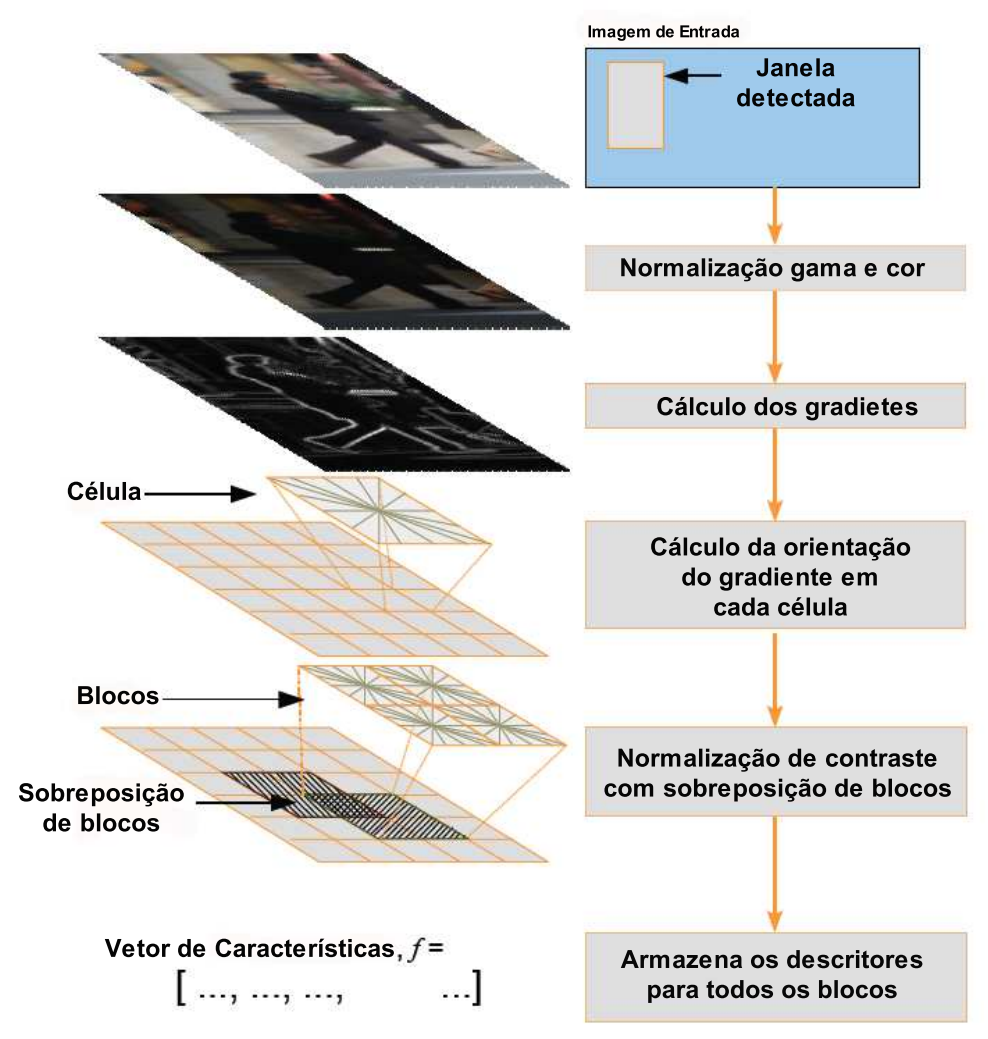

Figura 4.2: Visão geral do extrator de caracteristica HOG. Figura adaptada de Dalal (2006).

Na quarta fase é calculada a normalização, que considera grupos locais de células e de contraste a ser normalizado antes de passar para a próxima fase. A normalização apresenta melhor invariância à iluminação, sombra, contraste e borda. O cálculo é feito pelas medidas de "energia" local sobre os grupos de células chamadas de "blocos". O resultado é usado para normalizar cada célula no bloco. Tipicamente cada célula individual é partilhada entre vários blocos (tal como mostrado na Figura 4.2), mas cada processo de normalização é dependente do bloco e, assim, diferentes. No processo final de normalização, os blocos normalizados são definidos como descritores do hog.

No último passo, os descritores de todos os blocos são armazenados em um único vetor de característica para ser utilizado pelo classificador.

A Figura 4.2 mostra o funcionamento do extrator de características hog.

Dessa forma, o algoritmo $\lg$ utiliza as duas primeiras etapas do algoritmo SIFT, afim de encontrar os pontos chaves, e depois executa o algoritmo hog com as seguintes modificações. O descritor consiste em um histograma de três dimensões, onde as duas primeiras dimensões correspondem a posição vertical e horizontal da imagem, e a terceira contém o gradiente orientado. Os gradientes horizontais e verticais da imagem, $X_{x}(x, y)$ e $Y_{y}(x, y)$, são aproximados utilizando um filtro de sobel $3 \times 3$. A imagem é dividida em $M \times N$ blocos, e para cada pixel $(x, y)$ no $(m, n)$ bloco, o gradiente de orientação absoluto $o(x, y)$ é obtido 
através da equação:

$$
o_{x, y}=\left[O \times\left(\frac{1}{2 \pi} \operatorname{atan} 2\left(X_{y}(x, y), X_{x}(x, y)\right)+05\right)\right]
$$

Após calcular o histograma, ele é suavizado com um kernel $(3 \times 3 \times 3)$,

$$
K(m, n, o)=\left(1-\frac{g(m)}{M}\right)\left(1-\frac{g(n)}{N}\right)\left(1-\frac{g(o)}{O}\right)
$$

e para prevenir distorções, onde $m, n, o \in \beta$ para $\beta=-1,0,1$, e $g\left({ }^{\cdot}\right)$ é o complemento da função impulso dada por:

$$
g(\lambda)= \begin{cases}0 & \text { se } \lambda=0 \\ 1 & \text { se } \lambda \neq 0\end{cases}
$$

Depois do processo, o histograma resultante é reformulado e normalizado para cada unidade do vetor. Finalizado, qualquer componente que seja superior ao valor 02 é truncada nesse valor e o processo de normalização é refeito, se necessário. Esse sistema utiliza um vetor com 128 posições onde $M=4, N=4$ e $O=8$.

A última etapa do processo consiste em estimar a posição da cabeça utilizando o regressor SVM (Cortes \& Vapnik, 1995) sobre o histograma.

Para o sistema proposto foi utilizada uma função kernel não linear com base radial,

$$
\kappa_{R B F}(a, b)=\exp \left(-\gamma\|a-b\|^{2}\right)
$$

O sistema utiliza três $S V M$ s treinadas para as propriedades da posição da cabeça, conhecidas como pitch, yaw e roll. Para encontrar os valores ótimo para parâmetros de otimização $\epsilon, \gamma$ e $c$, o sistema normaliza cada componente dos dados no limite $[-1,1]$ e então realiza um validação cruzada sobre os dados.

\subsubsection{Estimativa da Posição da Cabeça Utilizando Histograma de Gradi- entes Orientados com OpenCv}

Utilizando como base a estimativa de posição da cabeça obtida pelo modelo híbrido lgo foram propostas algumas modificações para classificar os estados de acordo com a posição da cabeça e também identificar a presença do ser humano. O modelo proposto constituinte de três fases permanece o mesmo, mas a forma como é desenvolvido foi alterada.

O processo de estimativa de pose e identificação do ser humano no ambiente é apre- 


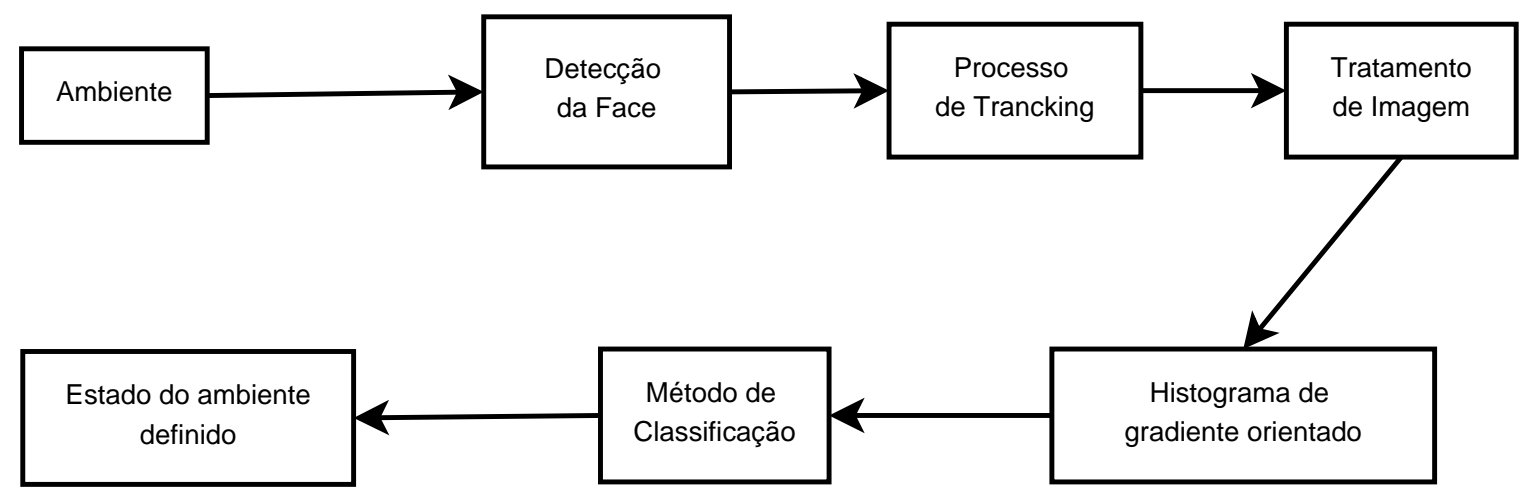

Figura 4.3: Fluxograma do funcionamento do sistema de estimativa da face.

sentado na Figura 4.3 . Ele constituído pelas seguintes etapas:

1. Detecção da face - Utiliza Adaboost cascades para detectar regiões frontais da face.

2. Processo de tracking - Aplicar o método Camshift (utilizando cor) sobre a região detectada anteriormente;

3. Tratamento de imagem - Normalização da região em um tamanho fixo e conversão para escala em tons de cinza;

4. Histograma de gradiente orientado - A região selecionada é processada e o descritor é gerado;

5. Método de aprendizado- $O$ descritor é informado a uma sequência de $S V M$ s que define o estado do ambiente, pelo processo de classificação.

Para diagnosticar o estado do ambiente, as $\underline{S V M S}$ necessitam ser treinada com alguns exemplos. Assim, tornou-se parte do processo a criação de uma base de dados com as posições que eram de interesse utilizando a sequência de etapas 1 à 4 enumerados acima. Os descritores gerados eram utilizados como base de treinamento das $S V M \mathrm{~s}$,

Além disso, os estados definidos para classificação estão representados na Figure 4.4 e descritos abaixo:

- Frontal - quando o robô está frente a frente com o ser humano

- Direita min (R-MIN) - quando o ser humano está olhando para a direita do robô em uma posição em torno de $45^{\circ}$

- Direita max (R-MAX) - quando o ser humano está olhando para a direita do robô em uma posição de $90^{\circ}$ 


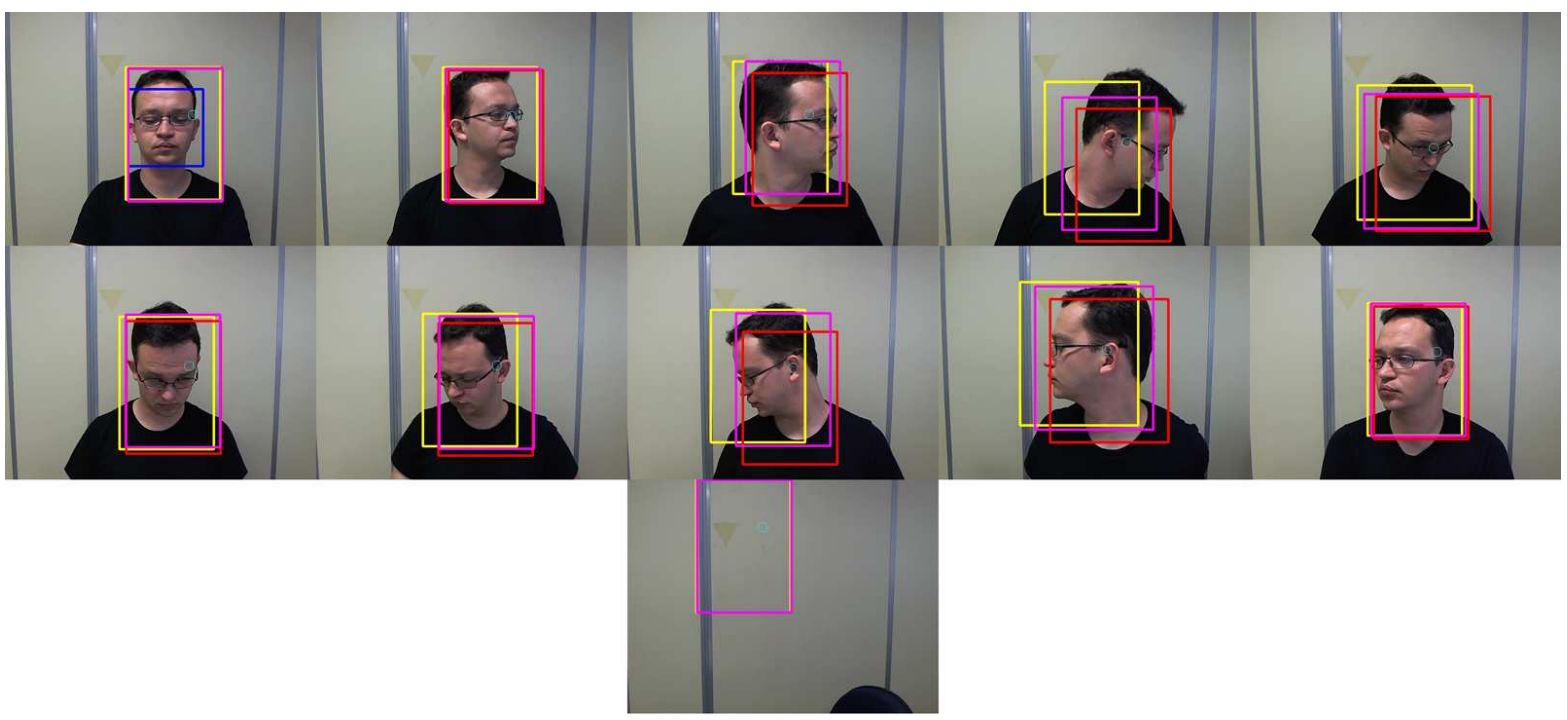

Figura 4.4: Estados definidos para classificação. Primeira linha: frontal, direita min, direita max, direita abaixo max, direita abaixo min. Segunda linha: frontal abaixo, esquerda abaixo min, esquerda abaixo max, esquerda max, esquerda min. Ultimo estado: sozinho

- Direita abaixo max (D R-MAX) - quando o ser humano está olhando para a direita do robô e para baixo em uma posição de $90^{\circ}$

- Direita abaixo min (D R-MIN) - quando o ser humano está olhando para a direita do robô e para baixo em uma posição em torno de $45^{\circ}$

- Frontal abaixo (D FRONTAL) - quando o robô está frente a frente com o ser humano e olhando para baixo

- Esquerda abaixo min (D L-MIN)- quando o ser humano está olhando para a esquerda do robô e para baixo em uma posição em torno de $45^{\circ}$

- Esquerda abaixo max (D L-MAX) - quando o ser humano está olhando para a esquerda do robô e para baixo em uma posição de $90^{\circ}$

- Esquerda max (L-MAX)- quando o ser humano está olhando para a esquerda do robô em uma posição de $90^{\circ}$

- Esquerda min (L-MIN)- quando o ser humano está olhando para a esquerda do robô em uma posição em torno de $45^{\circ}$

- Sozinho (OUT) - momento que o robô não encontra o ser humano

Todas as etapas constituintes do processo serão descritas em detalhes a seguir. 


\section{Detecção da Face}

Para detectar a cabeça da pessoa com o qual se está interagindo, foi utilizado o método de Adaboost cascades para encontrar o perfil da face frontal (Viola \& Jones. 2001: Lienhart \& Maydt, 2002). O método utiliza Haar-like features retangulares que codificam a existência de contrastes orientados entre as regiões da imagem. O método Haar-like features considera regiões retângulares adjacentes em um local específico dentro de uma janela de detecção, sendo calculadas pela soma das intensidades dos pixels em cada região e a diferença entre as somas. Um conjunto desses recursos podem ser usados para codificar os contrastes exibidos por um rosto humano e suas relações espaciais (G. Bradski \& Kaehler, 2008).

O processo para detectar a face inicia-se com o treinamento do classificador através de parâmetros previamente encontrados e utilizados pela biblioteca OPENCV. Após o classificador ser treinado, a imagem é aplicada a uma região de interesse (do mesmo tamanho como usado durante a fase de treinamento) de uma imagem de entrada. O classificador gera " 1 " se a região provavelmente contém o obieto (ou seia, face), e "0" caso contrário (G. Bradski \& Kaehler, 2008). Neste ponto, além de encontrar a face de uma pessoa na imagem, o algoritmo é responsável para definir o retângulo contendo a face, isto é, definir a distribuição de característica (baseada na cor) que serão utilizadas pelo algoritmo CamShift.

O algoritmo CamShift é um método robusto para encontrar o local extremo na distribuição de densidade de um conjunto de dados. O algoritmo funciona da seguinte forma. Em primeiro lugar, a distribuição de característica para representar um objecto é escolhido (por exemplo, utilizando a cor). Em seguida, é iniciada a janela onde a distribuição de características relativa ao objeto for compativel. E finalizando, a distribuição característica escolhida sobre o quadro seguinte é computado. A partir da localização atual janela, o algoritmo irá encontrar ponto da nova distribuição de características na imagem, que (presumivelmente) está centrada sobre o objeto que produziu a cor. Deste modo, a janela de CamShift acompanha o movimento do objeto quadro a quadro (G. Bradski \& Kaehler, 2008).

Todo o processo descrito acima é responsável por realizar o tracking da face em diferentes posições, como apresentado nas Figuras 4.5, 4.6 e 4.7.

\section{Tratamento de Imagem}

O processo de detecção da face resulta em dois retângulos. A primeira é relativa a janela originada pelo algoritmo Camshift e a outra janela é calculada pelo subtração no ponto de referência da janela original e pela adição nas medidas das dimensões pela equação 4.5, dada por:

$$
r=(M I N(\text { cols }, \text { rows })+5) / 6
$$




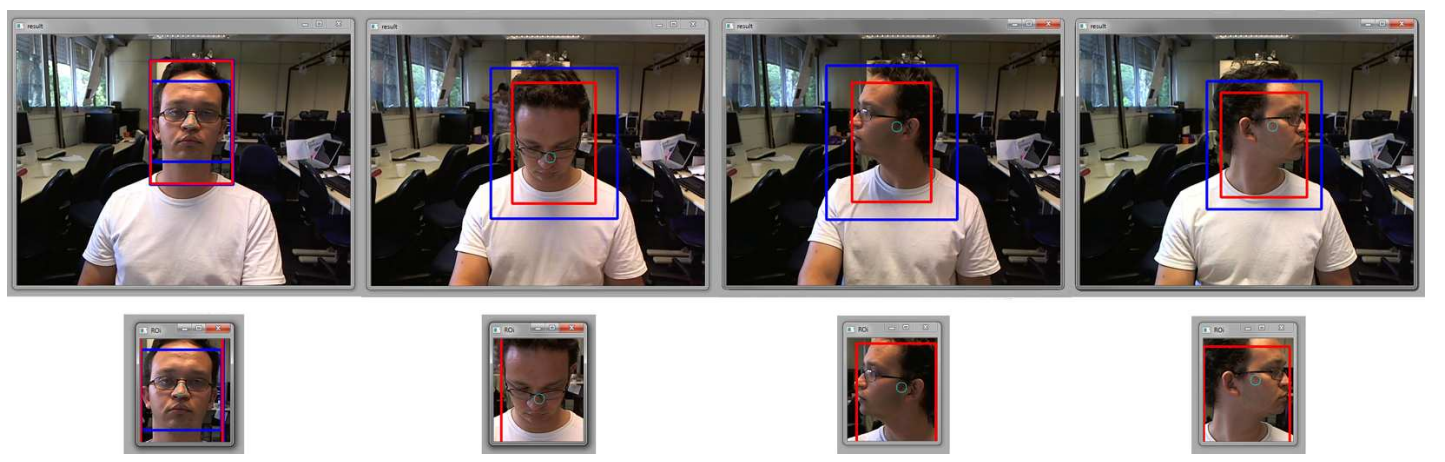

Figura 4.5: Tratamento da imagem para diferentes posições da cabeça do ser humano que está no centro da imagem original. Na parte superior da figura é mostrado o modelo proposto sobre a imagem capturada e na inferior a imagem a ser utilizada no tratamento do histograma.

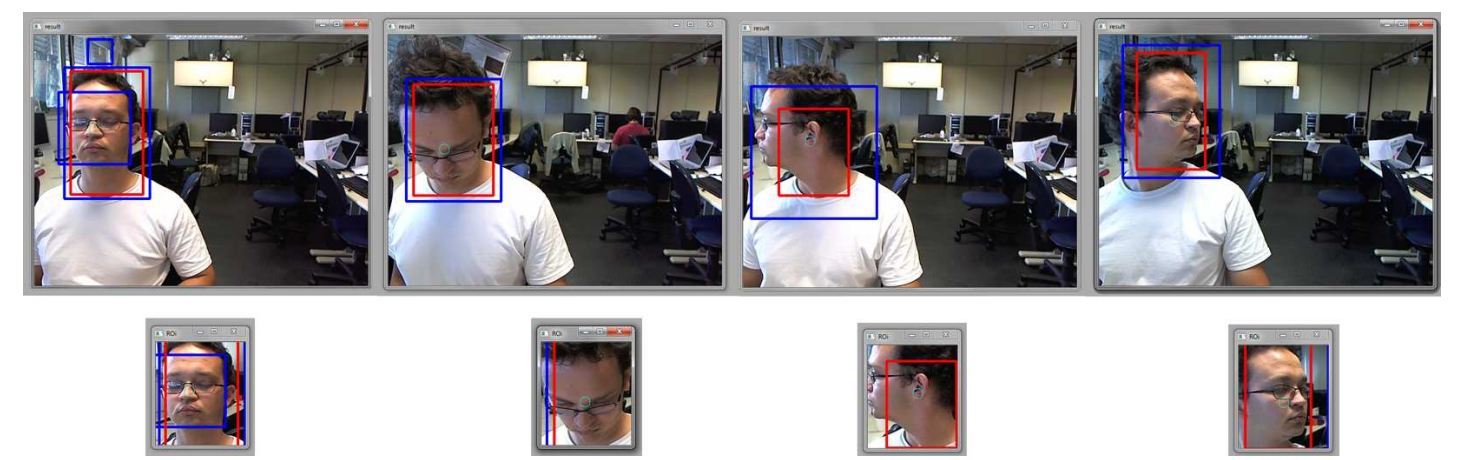

Figura 4.6: Tratamento da imagem para diferentes posições da cabeça do ser humano que está à esquerda da imagem original. Na parte superior da figura mostra o modelo proposto sobre a imagem capturada e na inferior a imagem a ser utilizada no tratamento do histograma.

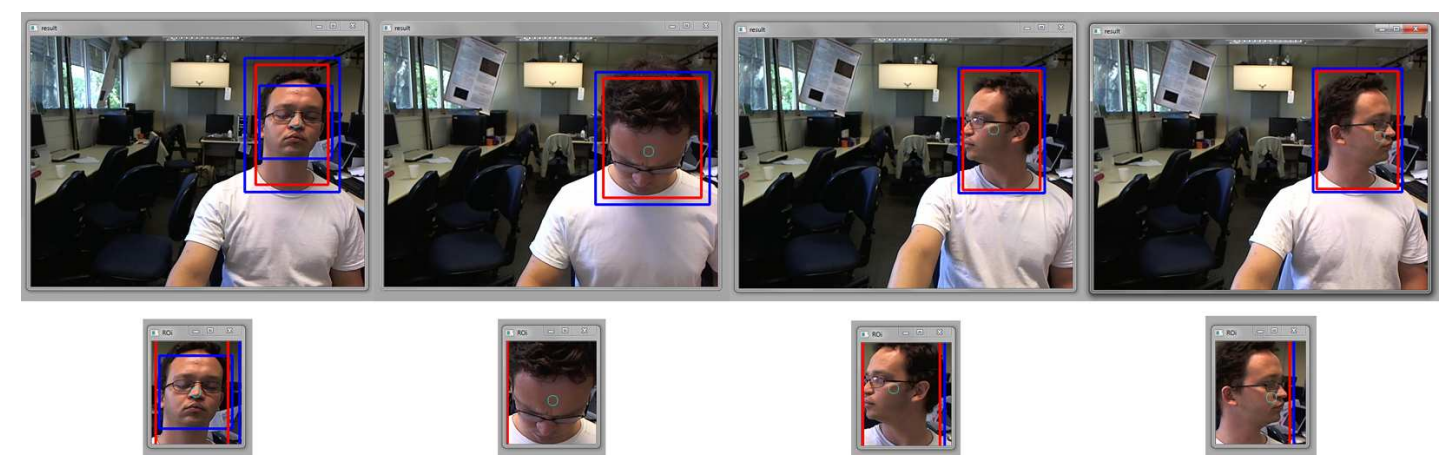

Figura 4.7: Tratamento da imagem para diferentes posições da cabeça do ser humano que está à direita da imagem original. Na parte superior da figura mostra o modelo proposto sobre a imagem capturada e na inferior a imagem a ser utilizada no tratamento do histograma.

onde cols e rows identificam o número de colunas e linhas da matriz que representa a janela original.

Além disso, o algoritmo Camshift possui a propriedade de redimensionamento da distribuição da densidade. Por isso, ao unir as janelas que identificam a face, um tratamento de 
limitação do tamanho da altura e largura é feito com os valores obtidos na primeira detecção.

O resultado da união é utilizado criando uma região de interesse, ou seja, uma nova imagem somente com a janela resultante. Essa nova imagem é reduzida a um tamanho fixo de $32 \times 32$ pixels, para assegurar que o sistema é invariante em escala. Além disso, a imagem é convertida em tons de cinza.

\section{Histograma de Gradiente Orientado}

Para fornecer uma descrição robusta de cada região facial, um histograma de orientação gradiente é calculado. Esse método foi explicado anteriormente.

\section{Método de Aprendizado}

O método utilizado para analise dos descritores é o SVM Apesar de ser o mesmo método utilizado por Murphy-Chutorian \& Trivedi (2009), a forma de utiliza-lo é diferente, sendo considerado a forma de classificação. Além disso, durante os testes iniciais verificou-se que o kernel polinomial, representado na equação (4.6), apresentou melhor resultado.

$$
\kappa_{\text {polynomial }}(a, b)=\left(\text { gamma } * a^{\prime} * b+\text { coef } 0\right)^{\text {degree }}
$$

onde gamma, coef0 e degree são constantes e são empiricamente definidas por 0,00308642, 0 e 3 , respectivamente.

Para classificar o estado do ambiente foi utilizado dez SVMs, Inicialmente, o sistema classifica se existe uma pessoa no meio ambiente ou se o robô está sozinho. Caso exista uma pessoa no foco do robô, o sistema verifica se a cabeça da pessoa está no mesmo nível do robô ou se a pessoa está olhando para baixo. Na sequência, o sistema avalia se a face é frontal ou perfil da face está a esquerda ou a direita. Caso a face não esteja frontal, o sistema avalia se o perfil da face está a esquerda ou a direita. Se estiver a esquerda, outra svm classifica se está à esquerda com $90^{\circ}$ ou com $45^{\circ}$ de perfil da face. Senão, outra svm avalia se o perfil da face é direito com $90^{\circ}$ ou com $45^{\circ}$.

Para a implementacão do sistema proposto, foi utilizada a biblioteca OpenCV (G. Bradski \& Kaehler, 2008) e um pacote de software otimizado para SVM (Chang \& Lin, 2011).

\subsubsection{Resultados}

Para validar o sistema proposto, primeiro foi analisado o desempenho dos descritores sobre as SVMS utilizando o software R (Team, 2012). Para isso, usamos validação cruzada 
Tabela 4.1: Validação cruzada com 10 amostras

\begin{tabular}{|c|c|c|c|c|c|c|c|c|c|c|}
\hline & 1 & 2 & 3 & 4 & 5 & 6 & 7 & 8 & 9 & 10 \\
\hline Out-In & 89,72 & 86,96 & 86,56 & 89,72 & 88,93 & 90,51 & 91,30 & 88,14 & 90,91 & 88,54 \\
\hline Up-Down & 88,54 & 88,78 & 92,60 & 89,26 & 90,45 & 89,26 & 90,21 & 87,35 & 88,54 & 89,02 \\
\hline Frontal-LR & 92,59 & 90,37 & 89,63 & 91,85 & 90,37 & 94,07 & 93,33 & 93,33 & 95,56 & 93,33 \\
\hline Left-Right & 95,23 & 100 & 95,24 & 97,62 & 100 & 97,62 & 97,62 & 98,81 & 96,43 & 98,81 \\
\hline Left Max-Min & 97,37 & 97,37 & 94,74 & 92,10 & 100 & 97,37 & 100 & 97,37 & 97,37 & 97,37 \\
\hline Right Max-Min & 97,82 & 100 & 89,13 & 97,83 & 86,96 & 91,30 & 95,65 & 97,83 & 95,65 & 93,48 \\
\hline D Frontal - LR & 78,12 & 84,38 & 90,625 & 82,29 & 79,17 & 86,46 & 84,375 & 87,5 & 82,29 & 87,5 \\
\hline D Left-Right & 91,03 & 84,61 & 92,31 & 93,59 & 84,61 & 89,74 & 91,03 & 91,03 & 91,03 & 88,46 \\
\hline D Left Max-Min & 95,56 & 91,11 & 88,89 & 86,67 & 88,89 & 91,11 & 88,89 & 95,56 & 91,11 & 95,56 \\
\hline D Right Max-Min & 96,97 & 93,94 & 87,88 & 87,88 & 84,85 & 87,88 & 93,94 & 87,88 & 87,88 & 84,85 \\
\hline
\end{tabular}

Tabela 4.2: Média e desvio padrão da validação cruzada com 10 amostras

\begin{tabular}{rrrrrr}
\hline & Mean & S. D. & & Mean & S. D. \\
\hline Out-In & 89,13 & 1,60 & Right Max-Min & 94,56 & 4,26 \\
Up-Down & 89,70 & 1,42 & D Frontal - LR & 84,27 & 3,91 \\
Frontal - LR & 92,44 & 1,87 & D Left-Right & 89,74 & 3,02 \\
Left-Right & 97,74 & 1,72 & D Left Max-Min & 91,33 & 3,22 \\
Left Max-Min & 97,10 & 2,30 & D Right Max-Min & 89,39 & 4,10 \\
\hline
\end{tabular}

com $\mathbf{k}=10$, onde $\mathbf{k}$ é o número de amostras. Na Tabela 4.1 é mostrado o resultado de cada partição e a média e desvio padrão (SD) é mostrada na Tabela 4.2 .

A Tabela 4.1 é composto pelas acuracias de cada classificador $S V M$ em cada partição. Em geral, o uso do kernel polinomial obteve uma nível de classificação bem acima do esperado, com o menor valor atingido de 78,12. Além disso, essa tabela mostra também a importância da base de dados para esse problema. Essa hipótese é corroborada pela diferença de 12,51 entre os resultados do pior classificador, que no caso foi o D Frontal - LR.

Os resultados obtidos nas Tabelas 4.1 e 4.2 demonstram que o sistema proposto é apropriado para classificar o estado do ambiente para uma simples forma de interação entre uma pessoa e o ser humano.

Após esta avaliação offline, o sistema foi avaliado em uma situação real onde o sistema adquiria informação por uma camera e uma pessoa intencionalmente alternava os estados para o sistema classificar. Para isso, quatro avaliações foram executados em frente da câmera, onde a seqüência de estados foram: frontal, direita min, direita max, direita abaixo max, direita abaixo min, frontal abaixo, esquerda abaixo min, esquerda abaixo max, esquerda max, esquerda min, e sozinho. O tempo gasto em cada posição não foi considerado. Dessa forma, a Tabela 4.3 mostra os resultados da média de dez imagens analisadas em cada avaliação. Em outras palavras, isso significa que, para o teste com trinta imagens em uma determinada classe foram analisadas imagens que estavam compreendidas entre a décima e a vigésima primeira posições. A Tabela 4.4 apresenta todas as imagens analisadas pelo valor da média.

Os resultados da Tabela 4.3 mostraram que os melhores elementos classificados foram 
FRONTAL, R-MIN, R-MAX e OUT. Apesar de obter valores expressivos nesta tabela, o resultado do lado direito não segue os valores dos testes realizados previamente no software R. Além disso, o perfil abaixo para a direita não segue as precisões de perfil da mesma altura. O perfil à esquerda os resultados são contrários ao perfil a direita, isso se deve ao fato da maior precisão na classificação dos perfis abaixo do que os da mesma altura. Se considerados os dois piores resultados de ambos os lados, o perfil esquerdo tem um resultado pior. Para alcançar esses resultados, um total de dois mil oitocentos e vinte cinco imagens foram analisadas.

Os valores observados na Tabela 4.4 confirmou o que foi apresentado na Tabela 4.3, A diagonal que contém a classificação correta obteve resultado satisfatório (com menor valor de 21,61) com algumas deturpações (três resultados abaixo 21,61), sendo dois valores do perfil esquerdo, o que pode ser considerado como um bom ponto de partida no estudo na área de visão computacional com foco na interação entre seres humanos e robôs.

\subsection{Considerações Finais}

O capítulo apresentou o desenvolvimento de um sistema de visão computacional baseado no histograma de orientação de gradientes para o problema de estimativa da posição da cabeça e da presença do ser humano utilizando a biblioteca OPENCV. O sistema foi desenvolvido para ser responsavel por classifiacr o ambiente e posterior envio para a arquitetura robótica. Os resultados obtidos mostram a capacidade

Os resultados obtidos mostram que o algoritmo pode ser considerado como um bom ponto de partida no estudo na área de visão computacional com foco na interação entre seres humanos e robôs. 
Tabela 4.3: Acurácia na classificação utilizando uma amostra de 10 elementos

\begin{tabular}{|c|c|c|c|c|c|c|c|c|c|c|c|}
\hline & FRONTAL & R-MIN & R-MAX & D R-MAX & D R-MIN & D FRONTAL & D L-MIN & D L-MAX & L-MAX & L-MIN & OUT \\
\hline FRONTAL & 5,50 & 0,50 & 0,00 & 0,75 & 0,25 & 0,50 & 0,50 & 1,00 & 0,00 & 0,75 & 0,25 \\
\hline R-MIN & 1,75 & 5,00 & 0,75 & 0,00 & 0,25 & 0,75 & 0,75 & 0,75 & 0,00 & 0,00 & 0,00 \\
\hline R-MAX & 0,75 & 0,75 & 5,00 & 0,50 & 0,75 & 0,25 & 0,75 & 0,25 & 0,00 & 0,00 & 1,00 \\
\hline D R-MAX & 1,00 & 1,00 & 0,00 & 2,50 & 0,25 & 1,00 & 0,25 & 2,75 & 0,00 & 0,25 & 1,00 \\
\hline D R-MIN & 0,75 & 1,25 & 0,50 & 1,00 & 0,75 & 1,50 & 0,50 & 1,50 & 0,50 & 0,00 & 1,75 \\
\hline D FRONTAL & 2,25 & 1,75 & 0,00 & 0,75 & 0,25 & 2,75 & 0,75 & 1,00 & 0,00 & 0,00 & 0,50 \\
\hline D L-MIN & 2,25 & 0,50 & 0,00 & 0,25 & 0,50 & 2,00 & 2,75 & 1,25 & 0,00 & 0,00 & 0,50 \\
\hline D L-MAX & 1,50 & 0,50 & 0,00 & 0,25 & 0,00 & 1,50 & 0,75 & 4,50 & 0,50 & 0,25 & 0,25 \\
\hline L-MAX & 3,00 & 1,25 & 0,25 & 0,50 & 0,50 & 0,75 & 0,25 & 1,25 & 0,00 & 0,50 & 1,75 \\
\hline L-MIN & 4,25 & 0,75 & 0,00 & 0,00 & 0,25 & 1,50 & 0,25 & 1,25 & 0,25 & 0,25 & 1,25 \\
\hline OUT & 0,75 & 0,25 & 0,25 & 0,50 & 0,00 & 1,25 & 1,25 & 0,75 & 0,00 & 0,00 & 5,00 \\
\hline
\end{tabular}


Tabela 4.4: Acurácia na classificação utilizando todos os dados

\begin{tabular}{|c|c|c|c|c|c|c|c|c|c|c|c|}
\hline & FRONTAL & R-MIN & R-MAX & D R-MAX & D R-MIN & D FRONTAL & D L-MIN & D L-MAX & L-MAX & L-MIN & OUT \\
\hline FRONTAL & 54,59 & 3,87 & 0,00 & 8,08 & 6,68 & 3,26 & 2,46 & 9,74 & 0,00 & 1,69 & 9,62 \\
\hline R-MIN & 17,88 & 34,81 & 7,22 & 2,86 & 3,54 & 10,66 & 3,55 & 13,86 & 1,72 & 0,23 & 3,67 \\
\hline R-MAX & 20,04 & 6,70 & 40,41 & 3,87 & 3,02 & 5,40 & 6,00 & 7,40 & 0,66 & 1,10 & 5,40 \\
\hline D R-MAX & 8,15 & 7,77 & 1,00 & 21,61 & 3,62 & 10,58 & 3,95 & 19,62 & 0,00 & 5,27 & 18,43 \\
\hline D R-MIN & 8,36 & 7,22 & 4,80 & 11,08 & 9,25 & 13,13 & 9,23 & 20,21 & 3,00 & 0,37 & 13,35 \\
\hline D FRONTAL & 15,77 & 7,91 & 1,57 & 4,06 & 1,82 & 32,85 & 6,05 & 15,86 & 1,74 & 1,21 & 11,16 \\
\hline D L-MIN & 15,94 & 3,33 & 0,00 & 0,76 & 2,57 & 17,83 & 26,49 & 17,72 & 0,68 & 3,22 & 11,47 \\
\hline D L-MAX & 13,34 & 3,26 & 0,00 & 1,09 & 0,83 & 15,73 & 5,89 & 49,55 & 4,61 & 2,56 & 3,14 \\
\hline L-MAX & 22,03 & 8,26 & 1,48 & 3,28 & 1,88 & 3,44 & 10,40 & 22,63 & 5,35 & 6,05 & 15,18 \\
\hline L-MIN & 33,89 & 11,07 & 1,32 & 1,77 & 4,78 & 16,52 & 4,54 & 9,88 & 1,97 & 7,15 & 7,11 \\
\hline OUT & 8,83 & 4,46 & 2,40 & 0,56 & 0,69 & 10,73 & 7,30 & 14,67 & 1,81 & 1,87 & 46,69 \\
\hline
\end{tabular}




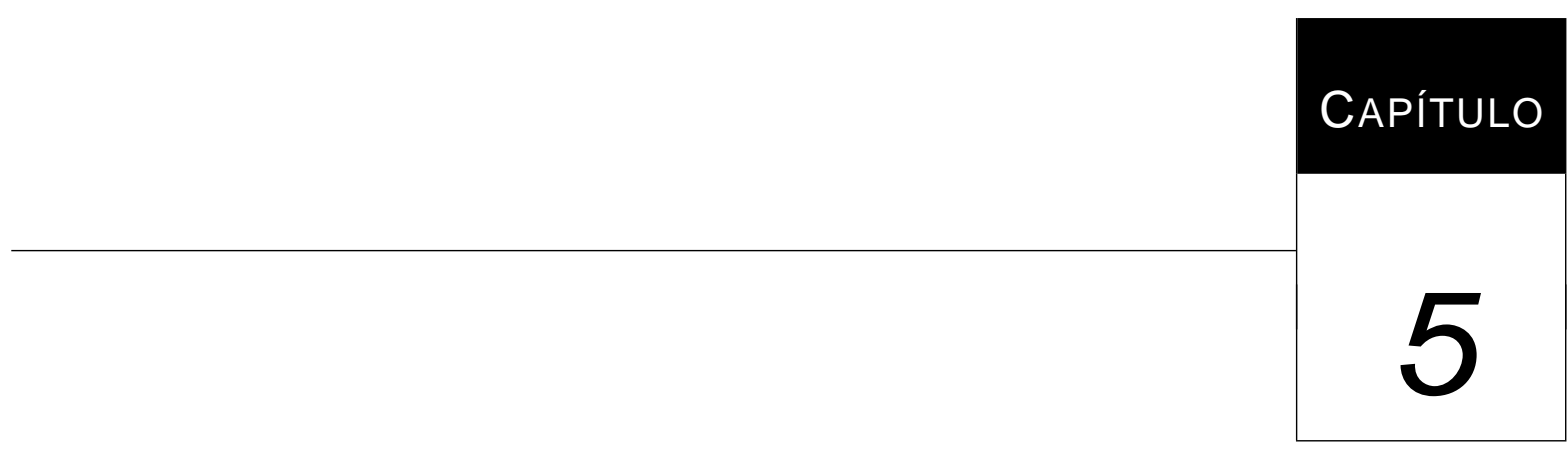

\section{Identidade pessoal}

Os robôs autônomos são capazes de influenciar no ambiente através de ações para atingir um determinado objetivo previamente estabelecido. Durante uma interação social, vários aspectos devem ser considerados e diversas ações podem chegar a tal objetivo. Em robôs sociais, as ações e os efeitos causados no ambiente influenciam em elementos internos ao robô, responsáveis por moldá-lo de forma única durante sua história de vida. Isso ocorre mesmo em robôs com software e hardware idênticos.

O capítulo apresenta a base teórica da psicologia evolucionária das emoções utilizada no desenvolvimento do módulo de identidade pessoal e os resultados obtido em simulação.

\subsection{Teoria Psico-evolucionária de Emoções}

A psicologia evolucionária, ou psico-evolucionária, é uma área de estudo da psicologia que tem foco nas adaptações do ser humano perante as mudanças físicas e sociais do seu ambiente, especialmente as mudanças nas estruturas cerebrais, mecanismos cognitivos, e diferentes comportamentos entre indivíduos (Houghton, 2001). A introdução de ideias evolucionárias no estudo do comportamento do ser humano foi realizado por psicólogos que estudaram a natureza da emoção (Plutcking, 2002). 
Plutchik define a teoria psico-evolucionária das emoções em três partes. A primeira está relacionada com a organização e pelas propriedades que cada emoção possui, ela é chamada de componente estrutural. A segunda está focada no evento temporal das emoções e as suas mudanças psicológicas, nomeado como componente sequencial. A última tem como principal objetivo a relação sistemática de cada emoção em todas as ordens, definido como componente derivativo (Plutcking, 2002).

O componente estrutural pode ser representado como uma estrutura geométrica de três dimensões como um cone com oito segmentos onde cada um representa uma emoção básica. Em cada uma das oito famílias de emoções é chamada como raiva, antecipação, alegria, confiança, medo, surpresa, tristeza e desgosto. A escolha da estrutura foi feita pelas características encontradas nas famílias: intensidade, similaridade e polaridade. Cada família os elementos são ordenados segundo um nível representando a intensidade. As emoções possuem um grau de similaridade entre elas e de oposição. Além disso, por causa das similaridades entre a estrutura e a roda de cores, essa foi adicionada à estrutura. Dessa forma, duas ou mais emoções podem ser combinadas, segundo o padrão utilizado em cor e pesquisa. Um exemplo pode ser mostrado pela combinação de alegria e confiança que produz amor. A Figura 5.1 mostra a estrutura proposta por Plutcking (2002).

O componente sequencial tem o foco na sequência dos eventos de emoção, sem uma resposta encontrada até o momento. A dificuldade desse problema pode ser explicada pela propriedade não linear das emoções. No entanto, um consenso existe desse componente durante a interação que pode ser comprovado no processo de equilíbrio das emoções. Estas podem flutuar moderadamente dentro de um limite, o processo é conhecido como homeostase. Todo o processo é inserido em um complexo sistema de feedback circular onde os estímulos interpretados, tanto externo quanto interno, agem como um ativador primário que inicia o processo emocional.

O componente derivativo é a mais importante ideia. Ele é baseado na evolução do comportamento humano de animais simples, outros comportamentos vistos na infância e outros conceitos são derivados de outras pessoas, através da sociedade.

\subsection{Modulo de Identidade Pessoal}

O Módulo de Identidade Pessoal (MIP) foi desenvolvido para modelar as características humanas para prover o robô da capacidade de interagir socialmente com o ambiente de acordo com as suas necessidades, emoções, diferentes personalidades, expectativa humana e as situações do ambiente. Este modelo segue a ideia do modelo motivacional de Breazeal (2002), mas utilizando como base as características da teoria evolucionaria: intensidade, similaridade e polaridade. 


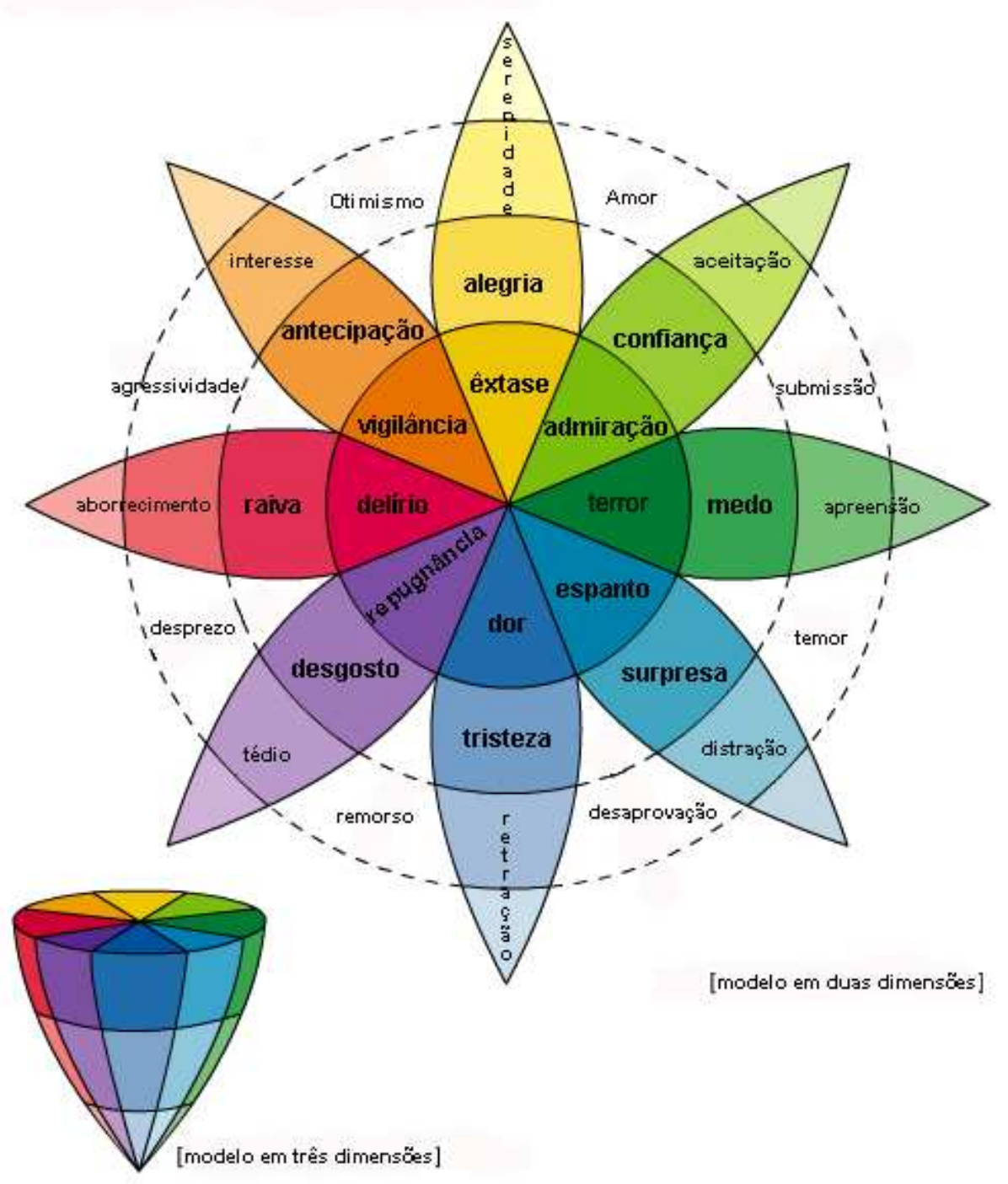

Figura 5.1: Representação de teoria psico-evolucionária de emoções (modelo de cone com círculo de cores). A dimensão vertical representa a intensidade da emoção, qualquer corte seccional representa a similaridade e a bipolaridade é vista nos pontos opostos do circulo. Figura adaptada de Plutcking (2002); Gallery (2012).

O MIP é composto por reflexos adaptativos, reflexos não adaptativos e o mecanismo de emoções. Cada componente citado possui elementos representativos do ser humano, sendo representados por uma barra de medição, onde o nível informa a localização na barra. A escolha por representar os elementos dessa forma está na facilidade de caracterizar o sistema com intensidade e polaridade. A similaridade é realizada através das variáveis escolhidas que afetam cada elemento. Além disso, todos os elementos tentam manter uma situação de homeostase, representada na tendência do nível em permanecer no meio da barra de medição (valor intermediário). Os elementos estão representados na Figura 5.2.

A barra dos elementos do mecanismo de emoção diferem das demais por possuírem significado em cada uma das suas extremidades. Dessa forma, na barra alegria-tristeza (AT), 


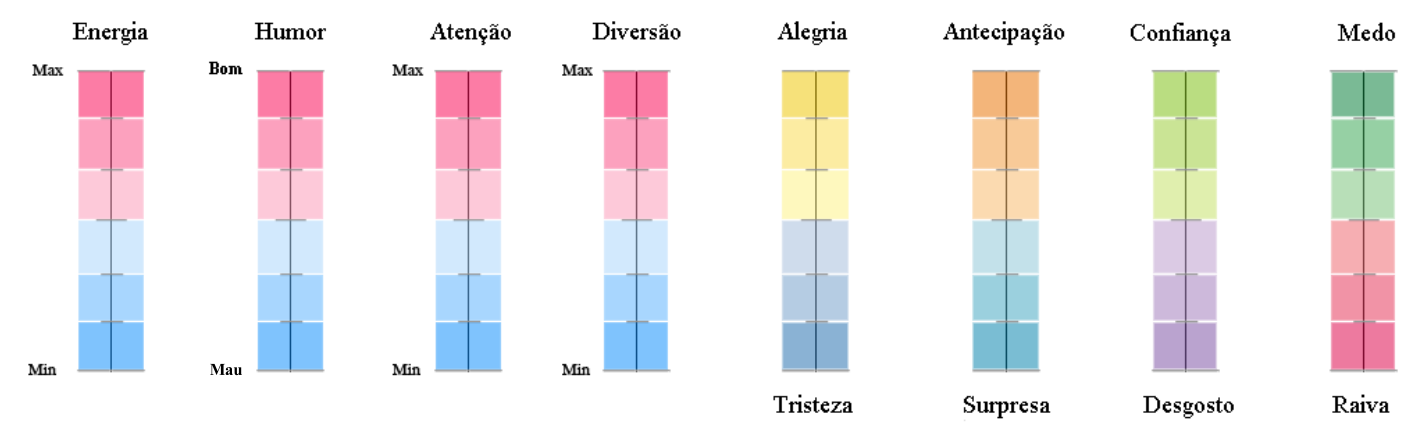

Figura 5.2: Representação de barras utilizada para reproduzir o modelo de cone de roda de cores.

tem um lado para alegria e outro para tristeza, como se duas barras (alegria e tristeza) se unissem. Assim, no momento que referenciar o nível da barra está no lado da alegria, significa que o nível está entre o valor intermediário e valor máximo que alegria representa.

Os reflexos adaptativos ajudam o sistema na manutenção da vida e persiste durante toda a vida. O mecanismo que está sendo proposto é composto por características humanas que não mudam o seu significado durante a vida, como energia e humor. O elemento energia foi desenvolvido seguindo o senso comum da necessidade de descanso de uma pessoa, em torno de oito horas diariamente e consequentemente restando outras catorze horas de atividades. A escolha foi feita segundo pesquisas em sono que mostra que uma pessoa não possui um "número mágico", mas diferentes fatores influenciam na quantidade ótima de horas de descanso (Ferrara \& Gennaro, 2001).

O outro elemento do reflexo adaptativo é o humor. Segundo Kirby et al. (2006), o humor é um elemento que agrega vários eventos na sua formação, em outras palavras, o humor não está ligado a um simples antecedente. Eles são tipicamente de menor intensidade do que as emoções e têm variância relativamente baixa ao longo de um único dia. Humor pode ser causado por uma série de coisas, incluindo mudanças no estado fisiológico (como a falta de sono ou doença), que ocorrem rapidamente respostas emocionais, ou cognição complexa em relação a eventos da vida emocional.

Assim, o elemento humor foi modelado para ser influenciado pela intensidade da atenção dada ao robô. Isso se deve ao fato de que esse elemento é influenciado pelos três tipos de situações. As situações na qual o robô pode encontrar estão definidas na seção 3.5 .

O nível da barra humor pode variar em profundidade (mudança rápida ou lenta de humor) e largura (tempo do efeito da alteração de humor). Durante a interação, profundidade e largura são calculadas pelas alterações durante um breve histórico da intensidade da atenção sobre os acontecimentos, enquanto um fator modificação altera o nível da barra humor durante um determinado número de ciclos. O impacto de um evento é definida por dois limiares que estão relacionados a quantidade da interação. Dessa forma, antes de atingir o primeiro limiar, 
onde a quantidade de interação é baixa, a profundidade e largura computam valores médios. Após atingir o primeiro limiar e antes de atingir o segundo, a profundidade e largura computam os maiores valores assumidos. E por fim, ao ultrapassar limite superior, a profundidade e largura computam os menores valores. Adicionalmente, no início do tempo de descanso, o valor do fator de modificação e o número de ciclos afetados é atualizado.

Os reflexos não adaptativos, caracterizado por elementos que não persistem durante toda a vida, foram planejados com elementos que mudam de significado durante o tempo de vida do ser humano. Dessa forma, os elementos atenção e diversão foram utilizados como reflexos não adaptativos. Ambos são afetados diretamente pelas situações do ambiente. Quando o robô está sozinho o valor do nível da barra atenção e diversão diminuem, com o tempo isso causa necessidade dos mesmos. Mas quando a interação com o humano acontece, o nível da barra atenção aumenta em diferentes proporções quando ocorre somente a situação de atenção ou diversão. Ainda assim, a situação de diversão é o único fator responsável de aumento do nível da barra de diversão.

As emoções também podem ser vistas como reflexos adaptativos, mas nós separamos os reflexos que sofrem influencia do sistema visual e aqueles que são afetados somente por mecanismos internos. Dessa forma, cada elemento do mecanismo de emoção é afetado pela relação existente com os elementos do reflexos adaptativo e não adaptativos. Essa relação define a forma que cada elemento influenciará nas emoções. Em todas elas a posição na barra onde o nível encontra-se é importante, pois os elementos do mecanismo de emoções somente tem acesso as faixas que o nível pode estar em um determinado momento. Assim, um elemento sabe se a quantidade de atenção recebida está baixa ou alta, se a energia está muito baixa ou alta, etc.

O primeiro elemento a ser analisado será a antecipação-surpresa (AS), Um dos fatores que influência na antecipação é o conhecimento da situação, que é contrario a surpresa. Outro fator é a disposição, caso o nível da barra energia tenha valor alto, ela influência o nível da barra AS ao lado da antecipação, de outra forma, o nível da barra tende a ir para o lado da surpresa.

O elemento medo-raiva (MR) está ligado de certa forma ao desconhecido e a situações consideradas negativas. Nesse caso, o nível da barra tende ao lado do medo quando valores baixos de atenção, diversão e/ou humor acontecem. Caso a energia esteja baixa, nivel da barra atenção ou diversão estejam extremamentes baixos ou se o agente olha para um lugar e não encontra objeto ou ser humano durante a diversão, o nível da barra tende ao lado da raiva.

O elemento é influenciado pelas situações positivas e negativas vivenciadas pelo robô. Assim, se os níveis da barra atenção, diversão e humor forem positivos o nível da barra estará no lado da alegria, caso os níveis forem negativos o nível da barra estará no lado da tristeza.

Por fim, o elemento confiança-desgosto (CD) está relacionado ao tempo. Dessa forma, 
um modificador é utilizado para armazenar as situações e então infuênciar no nível da barra CD, O modificador só é atualizado quando contador de confiança, desgosto, ou a diferença entre ambos obter um limite.

Além disso, o histórico de interações influenciam nos valores dos limites de todos os elementos, exceto a energia. O elemento energia não teve seus limites influenciados pois na sua modelagem não possuem variações. Esses valores são atualizados quando o contador do histórico atinge um limiar.

O funcionamento de todos os elementos apresentados acima será apresentado na próxima seção.

\subsection{Algoritmo de Processamento}

O algoritmo inicia definindo que tipo de situação está acontecendo. Esse situação acontecerá por um tempo predeterminado, sendo substituída por outra situação já definida.

Antes de iniciar a interação é verificado se o robô está acordado (fase de atividades), caso contrario, é iniciado o processo de recuperação de energia, ou fase de descanso. Nessa fase, o MIP realiza o processo de homeostase nos elementos do módulo.

Quando o robô está na fase de atividades, o estado do ambiente é informado ao MIP. O módulo interpreta as informações recebidas e codifica o que está acontecendo para os elementos. Nessa codificação o módulo verifica de acordo com a situação vigente o que o robô está observando no ambiente. Dessa forma, o robô pode estar em uma situação de atenção e o estado indica que ele está olhando para nada.

Com essas informações o módulo atualiza os elementos do reflexo adaptativo, não adaptativo e emoções, utilizando essa sequência.

No final o algoritmo verifica se a energia do robô é suficiente para mais uma rodada ou se entra na fase de descanso.

\subsection{Experimentos}

Para quantizar de forma automática a evolução de todos os elementos internos na qual o robô pode encontrar durante as situações vivenciadas com o ser humano, emuladas no simulador, os elementos foram configurados da seguinte forma. Vale ressaltar que os valores foram obtidos empiricamente.

No caso do elemento energia, o sistema reduz em um fator ao nível da barra energia durante a atividade de robô (valor de 0,5 ) e aumenta quando está em descanso (valor de 1 ). É 


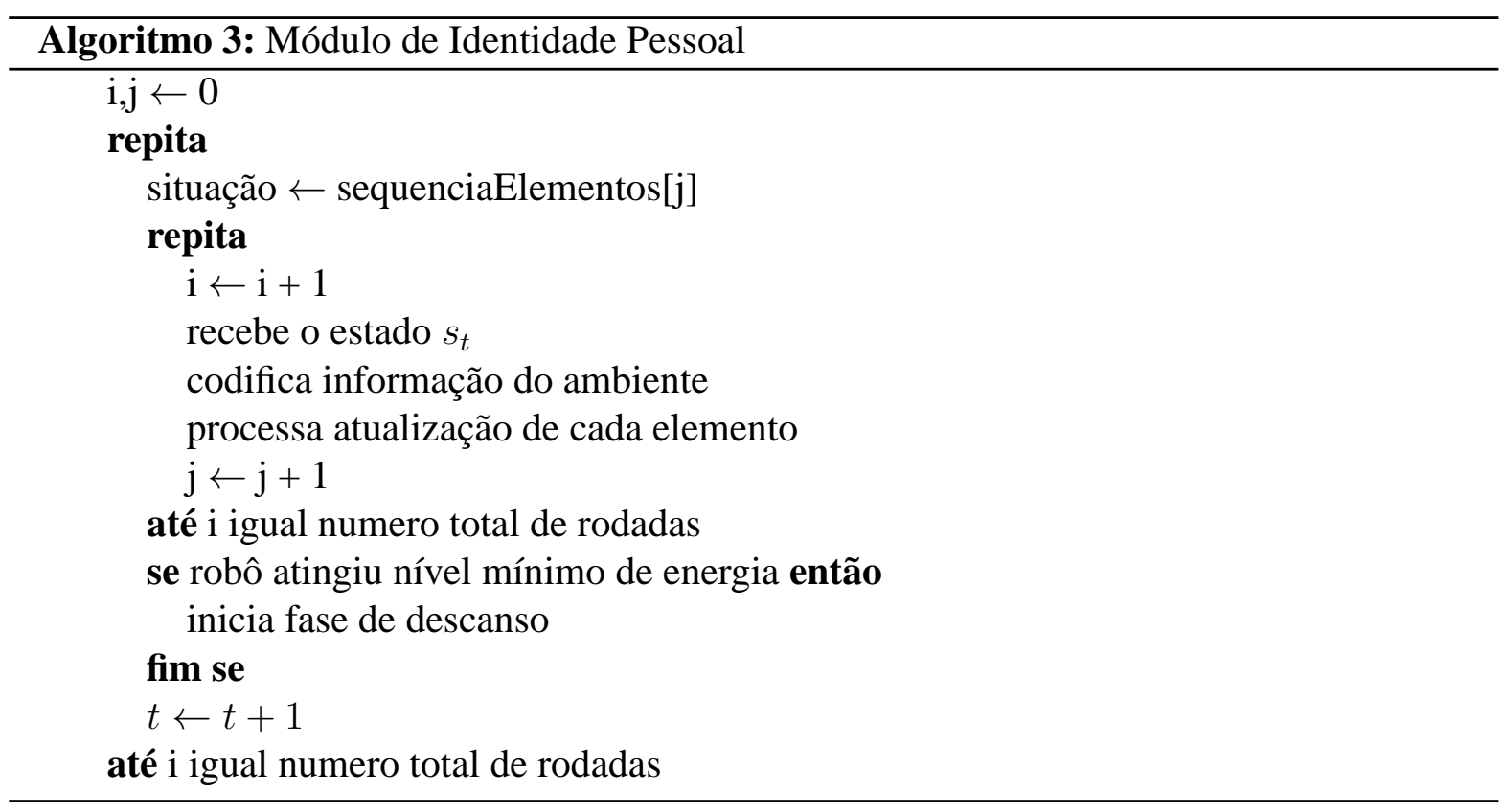

nesse período de descanso que o processo de homeostase acontece em outros elementos. Além disso, a barra de energia tem sete marcadores para qualificar o nível de energia que pode ser acessado por outros elementos do MIP. Os marcadores são colocados nos seguintes pontos: $[0-10),[10-20),[20-30),[30-70),[70-80),[80-90),[90-100]$. Além dos marcadores, a operação de informar quando o nível de ficar extremamente baixo ou alto, definida pelos valores 2 e 98, respectivamente. Essa função é importante para informar o módulo de MIP para mudar a situação do robô de sono ou acordado quando o limiar é ultrapassado.

No elemento humor, o primeiro limiar foi definido com o valor 25 e o segundo com valor 75. Dessa forma, os valores de profundidade e largura podem assumir valores entre -2 e 2 dependendo dos limiares atingidos. Os outros elementos do módulo MIP podem acessar três valores: bom $((75100])$, ruim $([0,25))$ ou humor neutro $([25,75])$.

Para os reflexos não adaptativos, a nível da barra atenção da seguinte forma. Se o valor da intensidade da atenção é maior do que um, o valor do nível da barra atenção é aumentada em 1, de outro modo, o valor é reduzido em 1. Além disso, outra variável foi adicionada para aumentar o tempo de satisfação das atenções. Considerando um limite $l$, a variável é aumentada em 1 até terminar a influência positiva ou negativa no nível da atenção. Quando a influencia no nível é alterado, a variável é reduzida pelo mesmo valor de aumento, até atingir o valor 0. A partir daí o nível de atenção é alterado. Os outros elementos podem acessar as seguintes informações: bom $((75,100])$, ruim $([0,25))$, neutro de atenção $([25,75])$, alta positiva $((92,100])$ e alto negativo de atenção $([0,7))$.

O outro elemento do reflexos não adaptativos, o nível da barra diversão é influenciada da seguinte forma. No momento em que o robô está sozinho, o valor real é subtraído pelo modificador, que é calculado pela subtração do valor real por min e dividido por $n$. Onde min poder ser o valor mínimo da barra de diversão ou valor intermediário do mesmo, dependendo 
se o nível atual está abaixo ou acima do valor intermediário, respectivamente. O valor de $n$ pode assumir 100,50,20,10,8, dependendo do número de interações $(20,50,100,250)$. Quando o tipo de interação é a de atenção, o algoritmo calcula o modificador para subtrair o valor real pelo valor intermediário de nível diversão e dividi-lo por 10 . O valor real é adicionado ou subtraído pelo modificador dependendo da posição do nível, abaixo ou acima da linha intermediaria. A última possibilidade, quando o tipo de interação é de diversão, utiliza a mesma ideia de quando o robô está sozinho, mas os parâmetros são diferentes. Nesse caso, substitui-se min por max, valor máximo da barra de diversão, e o valor é adicionado ao modificador.

O nível da barra $\mathrm{AS}$ é afetado pelos níveis da barra de energia, atenção, diversão e um evento extra, como apresentado na equação 5.1 .

nível AS $=$ nível AS + fator energia + fator atenção $* 2+$ fator diversão $* 2+$ evento extra

A fim de atualizar o nível da barra de $\mathrm{AS}$, a variável fator de energia pode assumir valores entre -6 e 6 , distintos por duas unidades, de acordo com o nível da barra de energia. Os fators atenção e a diversão podem adotar os valores $-4,0$ ou 4 , se o valor do nível da barra de atenção ou diversão é de 0,1 ou 2 , respectivamente. Evento extra é um fator que aumenta a surpresa, mas nesta primeira versão não é utilizado.

No caso do nível da barra MR, a raiva é aumentada quando o nível de atenção ou diversão está em nível negativo alto. Além disso, se o nível de energia está na quarta ou terceira marca inferior, a raiva é aumentada de um, abaixo desses marcadores o valor é dobrado. Além disso, a equação seguinte é usada se a intensidade da atenção é baixa:

$$
\text { nível MR = nível MR }+(\text { nível MR }- \text { valor min }) / 2
$$

onde valor min é o menor valor na barra.

O medo é afetado por duas unidades quando o nível de atenção ou diversão estão no nível ruim. A posição do nível de humor com classificação ruim também aumenta o nível de medo em uma unidade e se o robô encontrou uma situação negativa (não encontrar o objeto ou ser humano) durante a atenção ou diversão, o nível de medo é aumentado em três unidades.

O nível da barra alegria-tristeza (AT) é influenciada para o lado da alegria da seguinte forma. O nível da barra é aumentada de uma unidade quando o humor é bom ou quando o 
robô recebeu uma situação positiva (encontrar o objeto ou ser humano) durante a situação de atenção ou diversão, ou ainda quando o nível de atenção ou diversão é positivo. Por outro lado, a tristeza é ligada quando o humor é ruim, o robô encontrou uma situação negativa durante a situação de atenção ou diversão, ou quando o nível de atenção ou diversão é negativo.

Por fim, o nível da barra CD é afetado em um tempo delimitado por um modificador. O modificador é atualizado quando o contador de confiança, desgosto, ou a diferença entre ambos obter um limite (que foi definido como 30 para os dois primeiro e 20 para o último). $\mathrm{O}$ contador de confiança e desgosto é calculado pelo o número de vezes em que os limiares de alto positivo ou alta negativo de atenção ou diversão são superados.

modifier $=\left\{\begin{aligned}(\text { difTD }+ \text { contador confiança }+(\text { nível atual }- \text { intermTD })) / \text { número de turnos, } & \text { se contador confiança }>\text { contador disgosto } \\ ((\text { nível atual }- \text { intermTD })-(\text { difTD }+ \text { contador disgosto })) / \text { número de turnos, } & \text { caso contrário }\end{aligned}\right.$

onde difTD é a diferença entre os contadores da confiança e do desgosto. intermTD é o valor intermediário da barra $\mathrm{CD}$.

Após contabilizar o valor do modificador, o contador utilizado é atualizado para 0 .

O nível da barra de CD é atualizado pelo valor total acumulado durante o histórico de confiança e de desgosto, em outras palavras, é representado pelo número de execuções.

Para calcular o valor da história, a variável $X$ é inicializada com valor 0 e ageTime com 1. A cada vez que o nível atual de um elemento supera um limite inicial próximo ao nível intermediário, nos diferentes sentidos dos nível (max ou min), a equação 5.4 é calculada com a variável differ $=10$.

$$
x=(x+1) /(\text { ageTime } * \text { differ })
$$

A mesma equação é usada quando o nível atual de um elemento supera de um segundo limiar, mais próximo dos limites max ou min, mas o valor de differ é 1.

Quando o nível atual chegar ao limite do nível max ou min, é calculado o número de vezes que o nível permanece no limite (contador) e quando o nível sai da posição de limite, a equação 5.5 é executada.

$$
x=(\text { counter }+1) /(\text { ageTime } * \text { differ }) ;
$$


onde differ é igual a 10000

\subsection{Principais Resultados}

Nesta Seção, são apresentados os principais resultados dos experimentos executados para a avaliação da arquitetura proposta com foco no desempenho do MIP, empregando o simulador de interações sociais apresentado na seção 3.5 do Capítulo 3. O propósito destes experimentos foi determinar a evolução dos elementos constituintes do MIP durante o controle do robô simulado em um ambiente social controlado. Vale resaltar que os resultados obtidos tem o caráter qualitativo.

A primeira etapa nos experimentos constituem do processo de aprendizagem de atenção conjunta pelo robô. Nesta etapa, o robô aprende a receber a atenção do humano e quando um objeto é posicionado no meio ambiente, ele aprende a seguir a atenção do ser humano para o objeto. Depois, os experimentos são conduzidos a fim de mostrar como o modelo desenvolvido capacita o robô com alguns reflexos humanos usando a teoria da psicologia evolucionaria .

Na segunda etapa, o número de interações foi ajustada para 24900 ciclos, onde a cada 100 ciclos, o tipo de interação foi alterado usando a seguinte sequência de interação: atenção, diversão e sozinho.

O tipo de interação definido como atenção é descrito como o momento em que o humano interage com o robô e objetos, utilizando uma conotação de conversa interessante entre ambos. A situação diversão, eles estão interagindo durante um jogo usando a atenção conjunta para procurar os objetos. A última situação, sozinho, o simulador remove o humano do meio ambiente e o robô permanece sozinho. Este fato é importante uma situação que pode acontecer com o robô.

Um evento em particular acontece quando o robô está com falta de energia, ou seja, energia muito baixa. Nesse momento, o robô descansa para recuperar a energia e a interação é interrompida até que sua energia seja recarregada. A partir desse ponto a interação começa novamente do ponto onde foi interrompida. Contando os dois períodos, o número final de ciclos foi 37316. Para facilitar a apresentação dos resultados, que são apresentados a cada 3000 ciclos, foi considerado 36000 ciclos. 


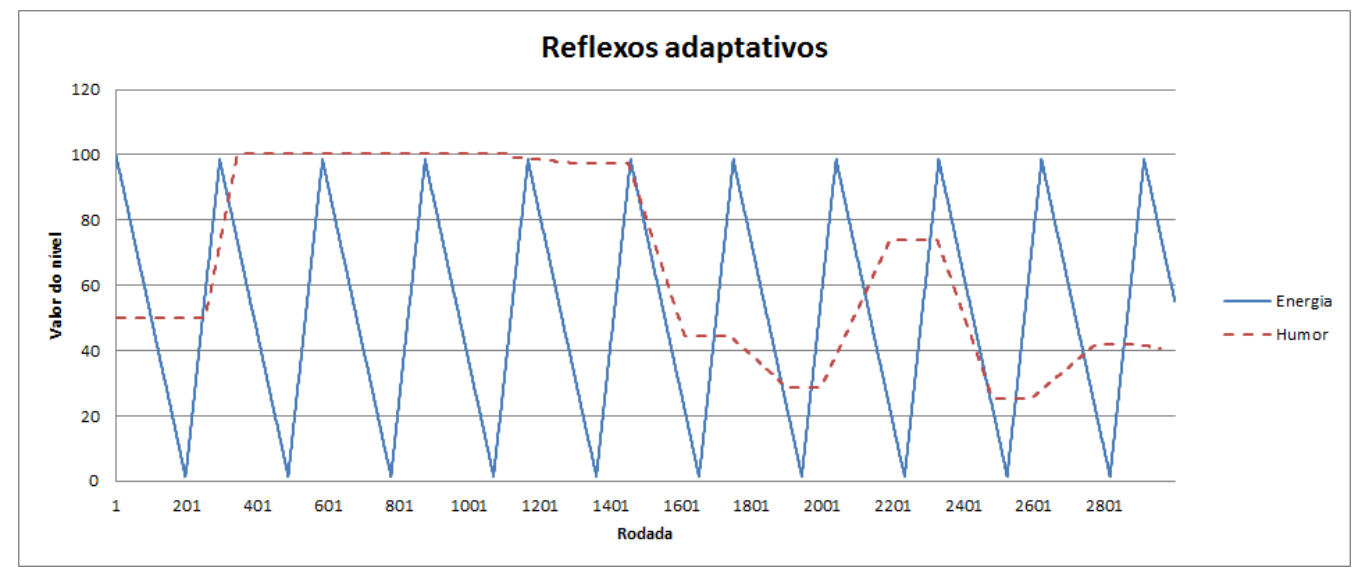

Figura 5.3: Resultado obtido das primeiras 3000 rodadas dos elementos energia e humor. Ele representa a variação do nível da barra dos elementos a cada rodada.

Além disso, a fim de mostrar a importância da interação, os experimentos estão divididos em duas partes, em que a diferença entre os dois é a configuração das situação. No experimento 1, usamos a sequência de interação com 100 turnos em cada um e no segundo, acrescentamos 300 ciclos na situação sozinho, mantendo o número total de ciclos. Dessa forma, no experimento 2 , o número de interações da situação de atenção e diversão é definido como 100 e a de sozinho como 400.

Em cada um dos experimentos é apresentado os resultados mais importantes e no Aé apresentos os resultados complementares e graficos auxiliares para o melhor entendimento do leitor.

\subsubsection{Experimento 1}

As Figuras 5.35.4 e 5.5 apresenta os resultados obtidos nos primeiros 3.000 ciclos.

A Figura 5.3 mostra o resultado da variação do nível da barra de energia e humor. O robô começa a interagir no ambiente com energia completa e decresce de forma constante. Após exceder o limite mínimo, o robô inicia o processo de descanso. O tempo de descanso é $1 / 3$ do tempo total (300 ciclos). O humor inicia em uma posição neutra e após algumas interações positivas o humor do robô é aumentado e atinge um ponto máximo de bom humor. No entanto, o efeito passa após o tempo devido ao mecanismo de homeostase e experiências em situações negativas.

Os níveis da barra de atenção e diversão acompanham o evento que está acontecendo no ambiente. Na Figura 5.4, é comprovado este fato, quando o robô está interagindo o valor 


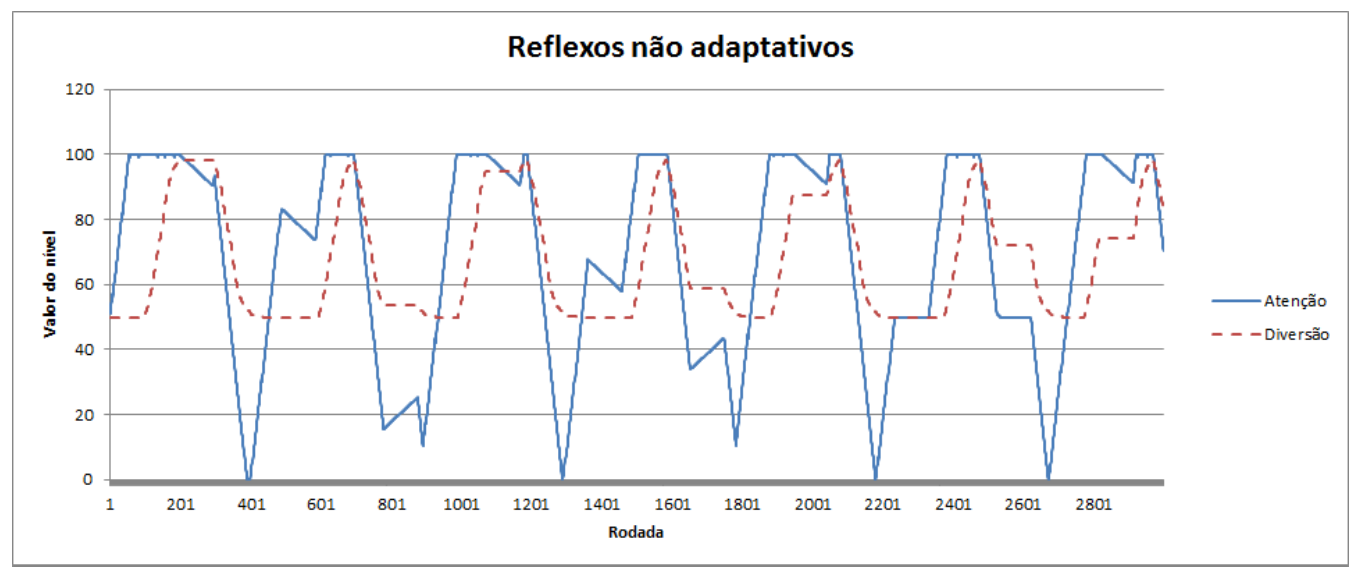

Figura 5.4: Resultado obtido das primeiras 3000 rodadas dos elementos atenção e diversão. Ele representa a variação do nível da barra dos elementos a cada rodada.

aumenta através do tempo, de acordo com cada especificidade. Quando o robô está sozinho, ambos os valores sofrem redução.

Na Figura 5.5, é mostrada a evolução dos elementos da emoção durante as 300 rodadas iniciais no processo de interação. O nível da barra $\mathrm{AS}$ durante a maior parte do tempo do experimento, permanece no valor máximo de antecipação e em alguns momentos o valor do nível desta barra tende, com pequena variação em relação à posição central, em direção a surpresa. O nível da barra MR é mais equilibrado que a variável citada anteriormente. Nesse caso, o robô tem mais medo, alcançando o valor máximo várias vezes, tendo passagens pelo valor intermediário e outros momentos com pequenas variações ao valor máximo de raiva. $\mathrm{O}$ nível da barra AT permanece a maior parte do tempo na parte da alegria, em alguns momentos atingindo o valor máximo, e outras o valor intermediário. O nível da barra $\mathrm{CD}$ permanece a maior parte da interação na parte de desgosto e em somente cinco ocasiões ele ultrapassa o nível intermediário, permanecendo perto desse nível que separa as duas emoções.

Uma análise feita das primeiras 3000 rodadas iniciais mostram uma sobreposição de comportamentos das emoções caracterizadas por antecipação, alegria, medo e desgosto devido a experiência vivida pelo robô.

No caso das emoções, na Figura 5.6, os últimos 3000 ciclos, mostram apenas uma pequena mudança no nível da barra $\overline{C D}$, que permanece a maioria do tempo em desgosto e alguns picos próximos do valor máximo de confiança. Os outros níveis apresentam apenas flutuações verificadas em nos figuras das emoções mostradas anteriormente.

Na Tabela 5.1, apresentou-se o ciclo em que o valor máximo (max) foi atingido. 


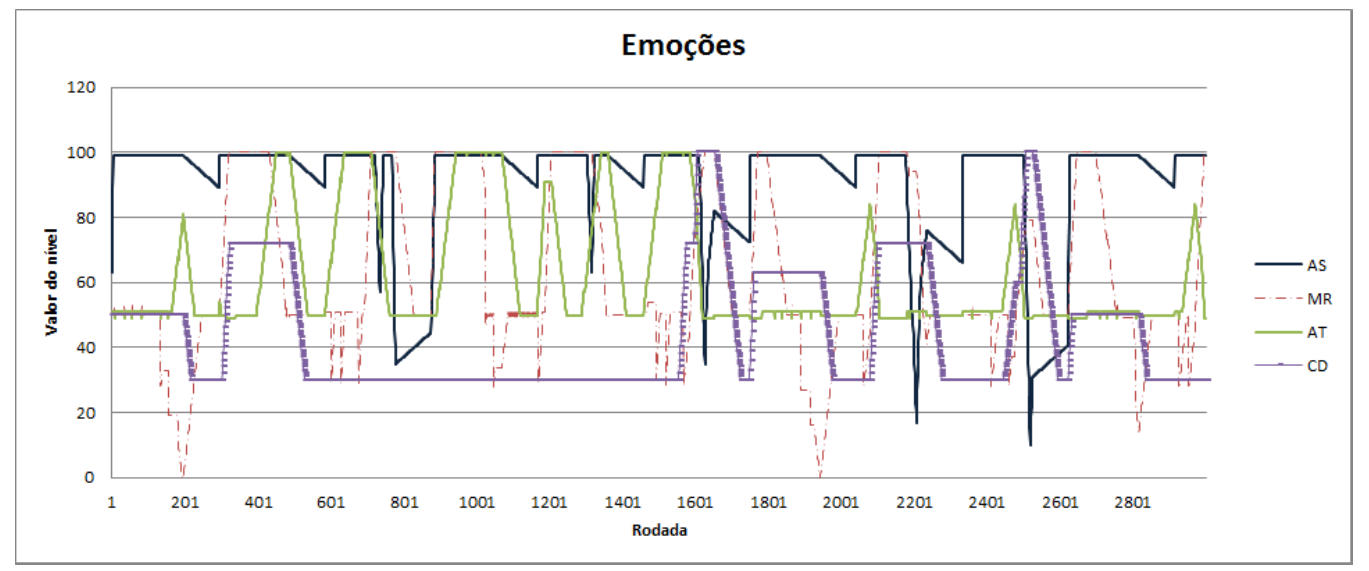

Figura 5.5: Resultado obtido das primeiras 3000 rodadas dos elementos de emoção. Ele representa a variação do nível da barra dos elementos a cada rodada.

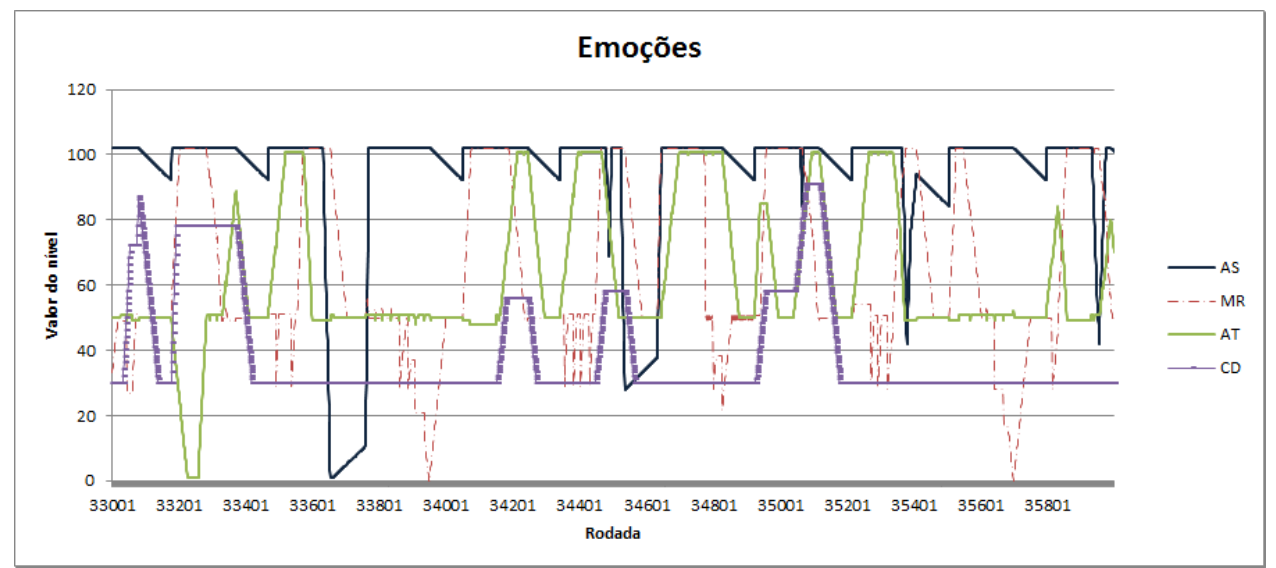

Figura 5.6: Resultado das últimas 3000 rodadas do elemento emoção.

Os valores alcançados pelo limite max foi de 101, 102 e 103, dependendo dos elementos constituintes do MIP.

Tabela 5.1: Limites afetados pela história de interação

\begin{tabular}{|l|c|c|c|}
\hline & 101 & 102 & 103 \\
\hline Humor & 11423 & - & - \\
\hline Atenção & 9171 & 28053 & - \\
\hline Diversão & 24096 & - & - \\
\hline AS & 3329 & 10064 & 30150 \\
\hline MR & 9378 & 27740 & - \\
\hline AT & 19961 & - & - \\
\hline CD & - & - & - \\
\hline
\end{tabular}

Um fato importante a ser mencionado é que não houve alteração do limite mínimo (min) nesse experimento. Isso significa que a experiencia do robô se baseou mais em situações positivas. 


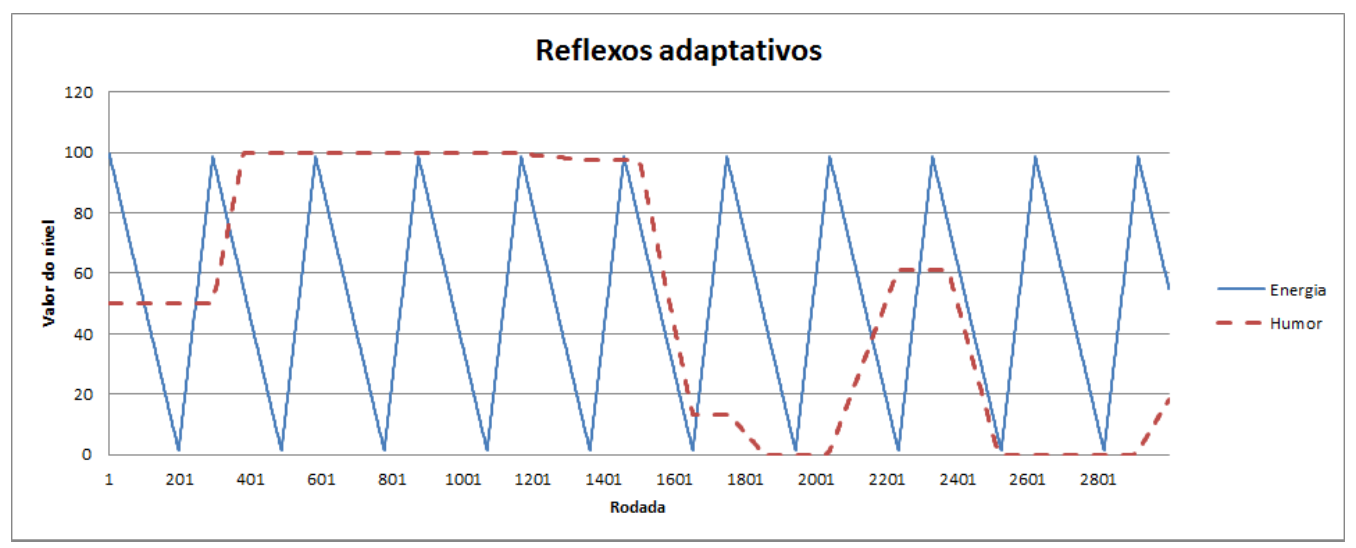

Figura 5.7: Resultado dos primeiros três mil ciclos dos elementos energia e humor. Ele representa a situação dos elementos a cada ciclo.

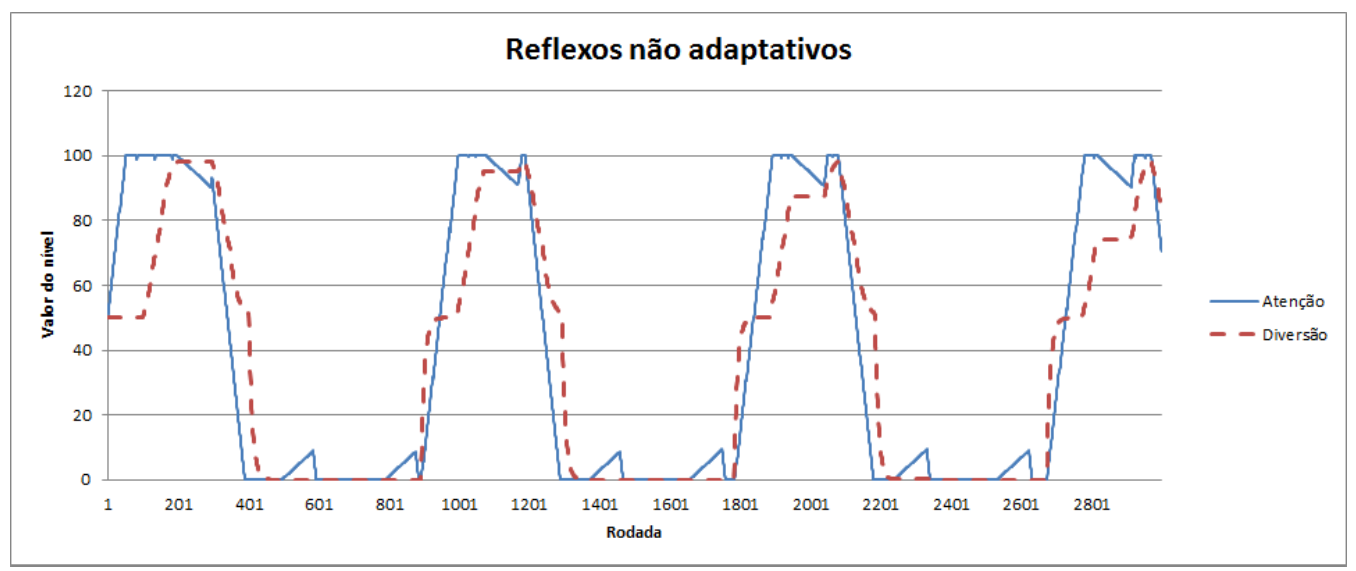

Figura 5.8: Resultado dos primeiros três mil ciclos dos elementos atenção e diversão. Ele representa a situação dos elementos a cada ciclo.

\subsubsection{Experimento 2}

A analise dos resultados do experimento 2 inicia-se no primeiros três mil ciclos. $\mathrm{O}$ nível da barra energia se comporta de forma semelhante ao do último experimento. Isso é apresentado na Figura 5.7, que também mostra a variação do nível da barra humor. A variação do nível da barra humor é muito parecido com o primeiro, mas com um período maior sozinho. O robô conseguiu atingir um nível menor de humor que o experimento anterior e, além disso, permanece mais tempo sob o valor intermediário.

Os elementos pertencentes ao reflexo não adaptativo oscilam entre o valor alto e baixo nas suas respectivas barras. O fato pode ser atribuído no contexto da permanência do robô no tipo de interação sozinho mais tempo. Dessa forma, o nível da barra atenção e diversão foi reduzido. A Figura 5.8 mostrar essa oscilação. 


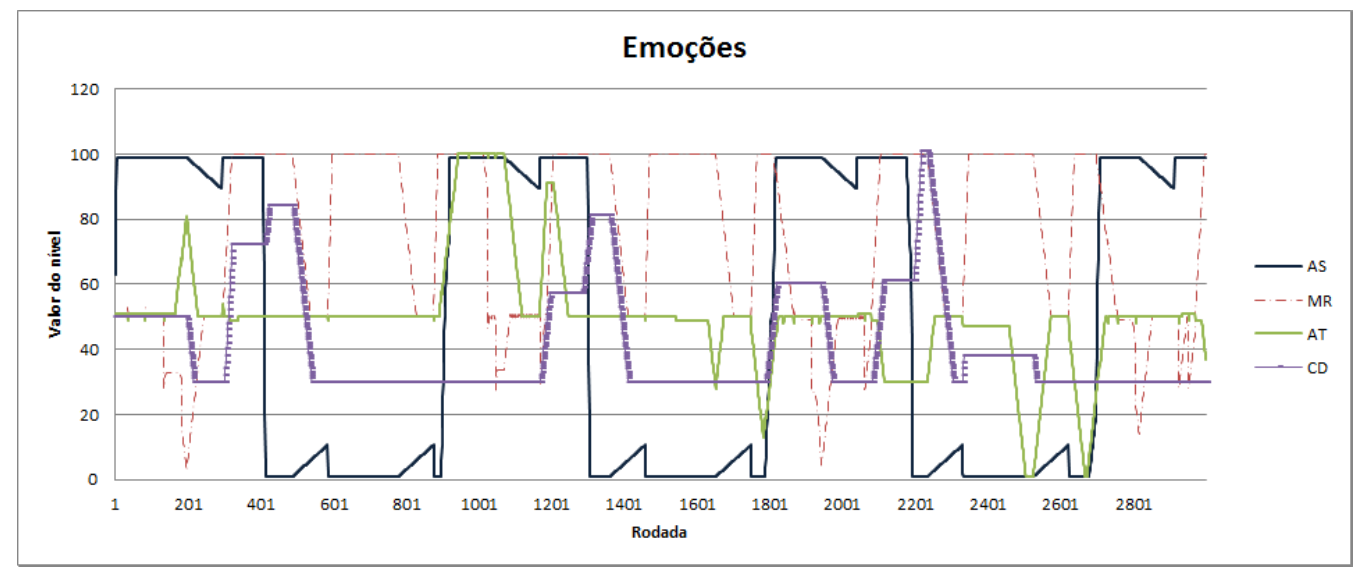

Figura 5.9: Resultado das primeiras 3000 rodadas dos elementos de emoção. Ele representa a situação dos elementos a cada rodada.

A Figura 5.9 apresenta-se o comportamento dos elementos que fazem parte das emoções. Ao compararmos essa figura com a reciproca do primeiro experimento, algumas alterações podem ser percebidas. O nível da barra $\mathrm{AS}$, oscila entre o valor máximo de antecipação e surpresa, com um tempo de permanência um pouco maior no valor máximo de surpresa. No caso do nível da barra MR, os resultados são semelhantes aos do primeiro experimento. Nesse caso, o nível permanece por mais tempo na parte do medo, atingindo várias vezes o valor máximo, com algumas passagens na parte da raiva. O nível da barra AT, inicialmente, até 1500 rodadas, fica apenas no valor intermediário flutuando em alguns momentos na parte da alegria, atingindo o topo uma única vez. Depois desse número de rodadas, o nível fica perto da parte intermediária com oscilações no nível tristeza atingindo o valor máximo em duas ocasiões. Por fim, os resultados relativos ao nível da barra $\mathrm{CD}$ mostram que o nível ficou quase todo tempo na parte do desgosto perto do valor intermediário. Mas ao mesmo tempo, o nível foi alterado, em alguns momentos, para a parte da confiança e atinge o valor máximo uma única vez.

Os últimos ciclos referentes a emoção, que são apresentados na Figura 5.10, mostram uma acentuação no nível de tristeza, atingindo o valor mínimo com uma frequência maior. Nos demais casos, a flutuação segue o determinado padrão dos dois resultados anteriores, como no caso do nível da barra $\mathrm{MR}$, ou de apenas um resultado, como apresenta o nível da barra $\mathrm{CD}$ quando comparamos as Figuras 5.9 e 5.10, apresentados nos ciclos anteriores.

Na Tabela 5.2, são apresentados as rodadas nas quais o limite máximo (max) e mínimo (min) foram atingidos. Os valores alcançados para o limite máximo foi de 102 para o nível de medo e raiva e para o limite mínimo foi de -2 para outros elementos. Além desses, os níveis 


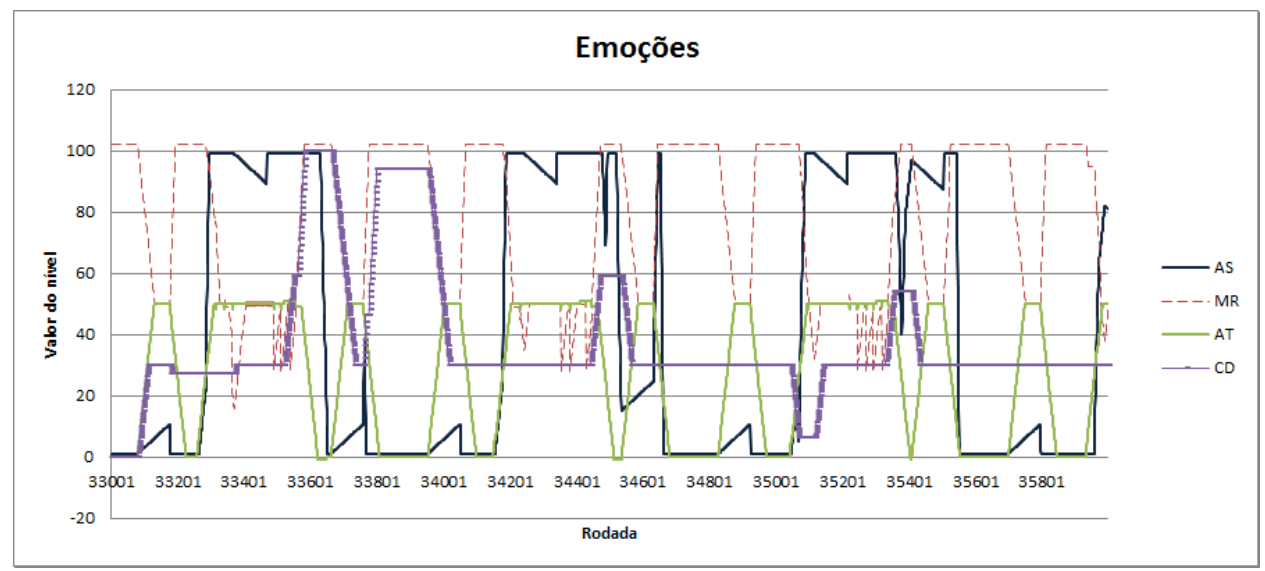

Figura 5.10: Resultado das últimas 3000 rodadas do elemento emoção..

de $\mathrm{AS}$ e $\mathrm{CD}$ não atingiram os seus limites máximo e/ou mínimo durante o Experimento 2.

Tabela 5.2: Limites afetados pela história de interação

\begin{tabular}{|l|c|c|c|c|}
\hline & 102 & 101 & -1 & -2 \\
\hline Humor & - & - & 7292 & 19878 \\
\hline Atenção & - & - & 8900 & 26834 \\
\hline Diversão & - & - & 7863 & 23032 \\
\hline AS & - & - & - & - \\
\hline MR & 14145 & 4462 & - & - \\
\hline AT & - & - & 14923 & 36780 \\
\hline CD & - & - & - & - \\
\hline
\end{tabular}

Os resultados obtidos demonstram que é viável a utilização da teoria psico-evolucionária de emoções para criar diferentes robôs, com personalidades diferentes, de acordo com a história de interação de cada um.

\subsection{Considerações Finais}

Neste capítulo foi apresentado a base teórica da psicologia evolucionária das emoções utilizada no desenvolvimento do módulo de identidade pessoal. O módulo é composto por reflexos adaptativos, não adaptativos e emoções. A arquitetura robótica foi avaliada com o novo módulo sobre o simulador de interações sociais.

Os resultados mostraram uma foma de utilizar os conceitos da psicologia evolucionária das emoções na criação de um módulo de controle interno. Além disso, as diferentes interações com o ambiente modelaram diferentes resultados, sendo considerado um possível elemento para criação de robôs com personalidade diferentes. 


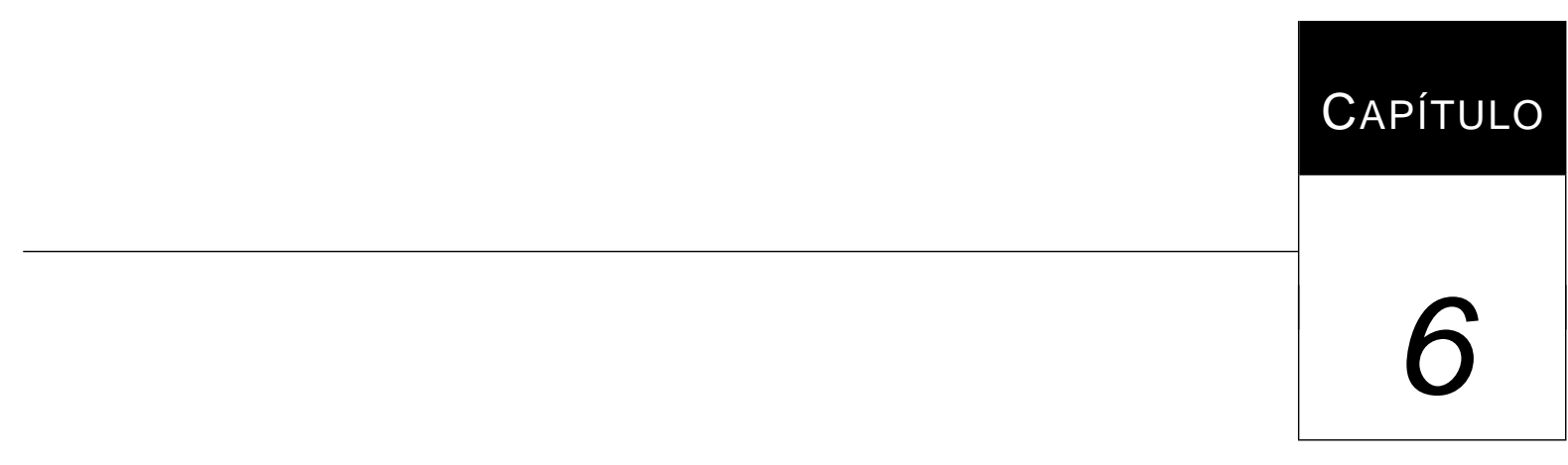

\section{Emissão de Resposta}

Com a finalidade de tornar a arquitetura robótica flexível a inserção de novos módulos, algumas modificações no mecanismo de aprendizado da arquitetura foram propostas e avaliadas para permitir que o robô aprenda a atenção conjunta sem a necessidade de informação adicional.

Neste capítulo são apresentadas as duas concepções utilizadas no desenvolvimento de três algoritmos de aprendizado, bem como a descrição dos mesmos e a análise comparativa de seus desempenhos.

\subsection{Introdução}

Em um ambiente dinâmico podem existir situações onde um agente ao exercer uma ação a sobre o estado corrente $\mathbf{s}$ em um tempo $\mathbf{t}_{x}$ receba um reforço positivo. Na mesma situação, em um tempo $\mathbf{t}_{y}$, o agente recebe um reforço negativo, onde $x \neq y$. Dessa forma, o robô não consegue construir uma política para atingir um objetivo. Esse problema foi explicitado na seção 3.7 do Capítulo 3, demonstrando que em alguns momentos a situação 
citada acima acontece.

Para resolver o problema, duas formas de armazenar informações anteriormente processadas foram utilizadas como forma de auxílio na decisão. A primeira está relacionada a criação da dependência a uma ação realizada anteriormente na seleção da ação a ser executada, pois a política para atingir o objetivo no problema da atenção conjunta está nessa dependência e não no histórico de interações. A segunda forma utiliza uma rede neural recorrente (RNN) com memória para atualizar o valor Q dos estados-ações que acontecem no problema citado. Esse método foi baseado no trabalho apresentado por Dung et al. (2008).

\subsection{Algoritmos de Aprendizado}

Nesta seção são descritas às técnicas para resolução do problema da atenção conjunta. Os dois primeiros trabalhos mostram a criação da dependência em relação a ação previamente executada na escolha de uma ação. Posteriormente, a proposta que aborda a $\mathrm{RNN}$ será apresentada.

\subsubsection{Sem Informação Adicional}

A dependência do módulo de aprendizado de informação adicional produzida pelo módulo de controle de consequência para capacitar o robô a realizar o processo de tem dificultado o desenvolvimento da arquitetura robótica social, apresentada no Capítulo 3 , Por isso, foi explorada uma abordagem onde a solução utiliza somente informação do ambiente. Assim, encontrou-se a possibilidade de utilizar a ação que originou o estado com reforço positivo como opção de informação para a seleção de uma ação.

A ideia principal é o fato do problema da atenção conjunta não precisar definir uma política de um estado inicial ao um estado final. Esse problema é considerado Markoviano, isto é, possui uma dependência somente da ação executada anteriormente, sendo esse o ponto a ser solucionado. Assim, a política de aprendizado precisa saber qual ação executar em um determinado estado de acordo com a ação previamente executada sobre o estado que gerou um reforço positivo.

A proposta foi modelada sobre o algoritmo ETG, sendo realizadas duas modificações. A primeira é a substituição da informação adicional, necessidade, que o módulo de controle de 
consequência transmitia ao modulo de emissão de resposta pela ação previamente executada. Esse algoritmo recebeu o nome de ETG livre de informação adicional com valor Q, do inglês Free Additional Information ETG with $Q$-value(FAIETGQ). Na segunda etapa foi retirado o valor-Q para verificar a influência desse fator. Dessa forma, esse algoritmo recebeu o nome de ETG livre de informação adicional, do inglês Free Additional Information ETG(FAIETG).

O Algoritmo 4 mostra o processamento do algoritmo FAIETGQ ressaltando a modificações realizadas em relação ao algoritmo 1. Destaca-se a retirada da informação necessidade e também a inserção da ação que gera um reforço positivo. Comparandos-se os algoritmos 2 e 5. nota-se as alterações feitas no mecanismo de armazenamento.

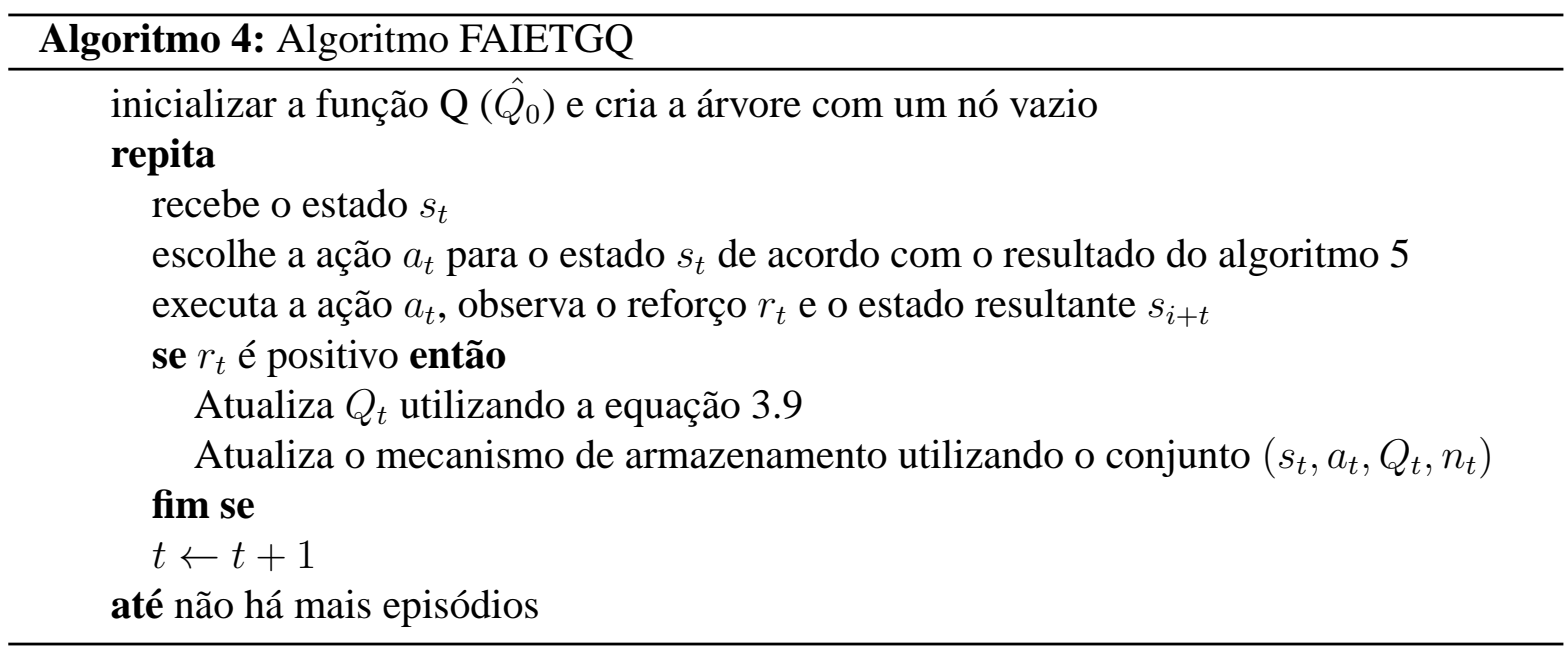

Os algoritmos 6 e 7 contem as modificações realizadas em relação a versão original do ETG, apresentada na seção 3.3.1, do Capítulo 3. Nesses algoritmos além de se substituir a informação adicional, o valor-Q foi removido para analisarmos a sua influência na solução do problema.

\subsubsection{Redes Neurais Recorentes}

Dung et al. (2008) propuseram um método baseado em utilizando memória, conhecida como long short term memory (LSTM). Essa proposta foi nomeada como RLSSAC. O método consegue resolver o problema do mundo da grade de luz, em inglês (The Lighting Grid World Problem). Nesse problema existem duas câmeras e uma parede no meio com duas portas como forma de passagem entre as câmaras. Uma das câmeras possui o estado de partida do agente e a outra, o objetivo, uma lâmpada que deve ser acionada. A questão é que apenas uma porta pode estar aberta e em determinados períodos elas trocam de posição, ou seja, a porta que 

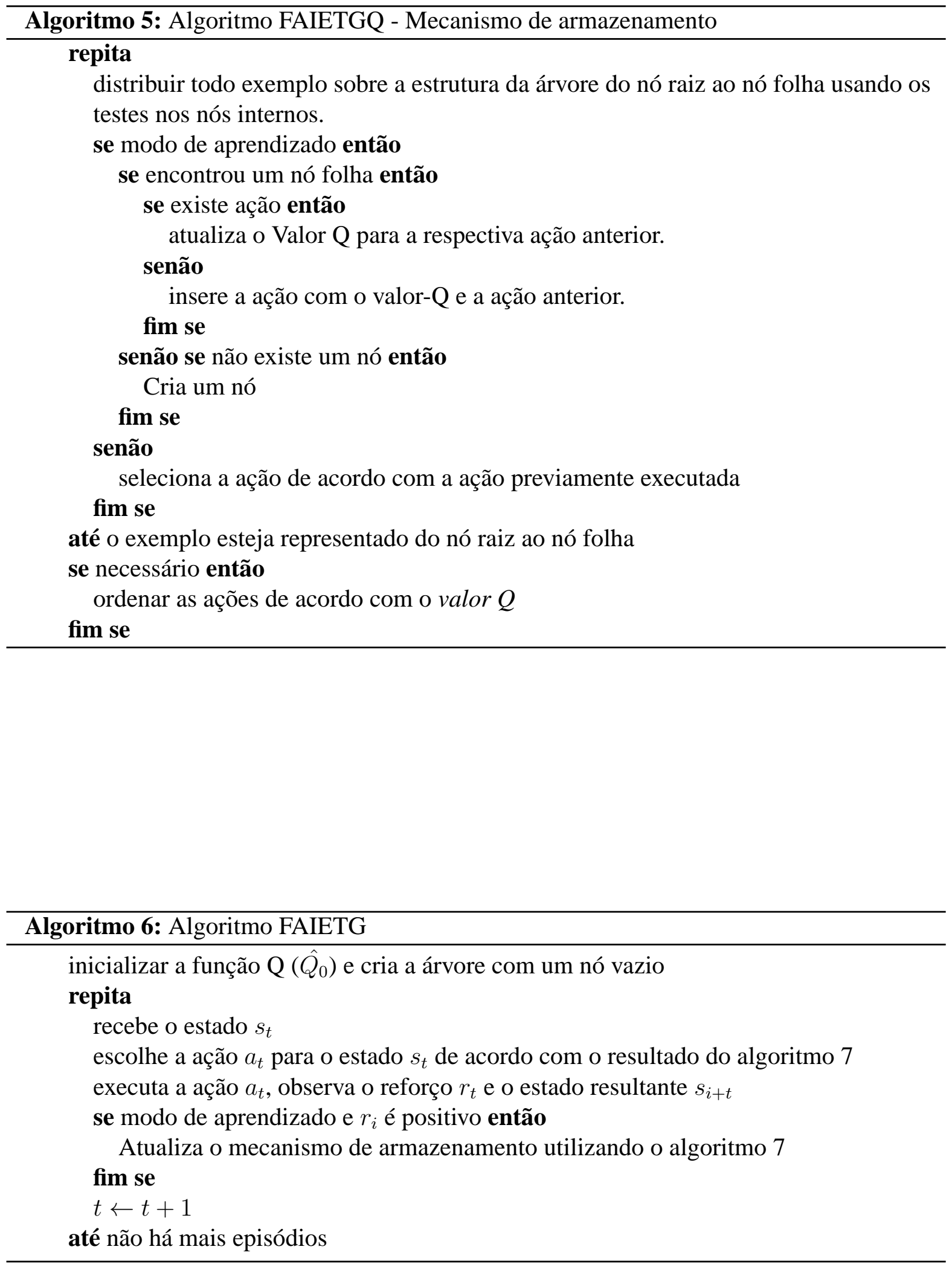

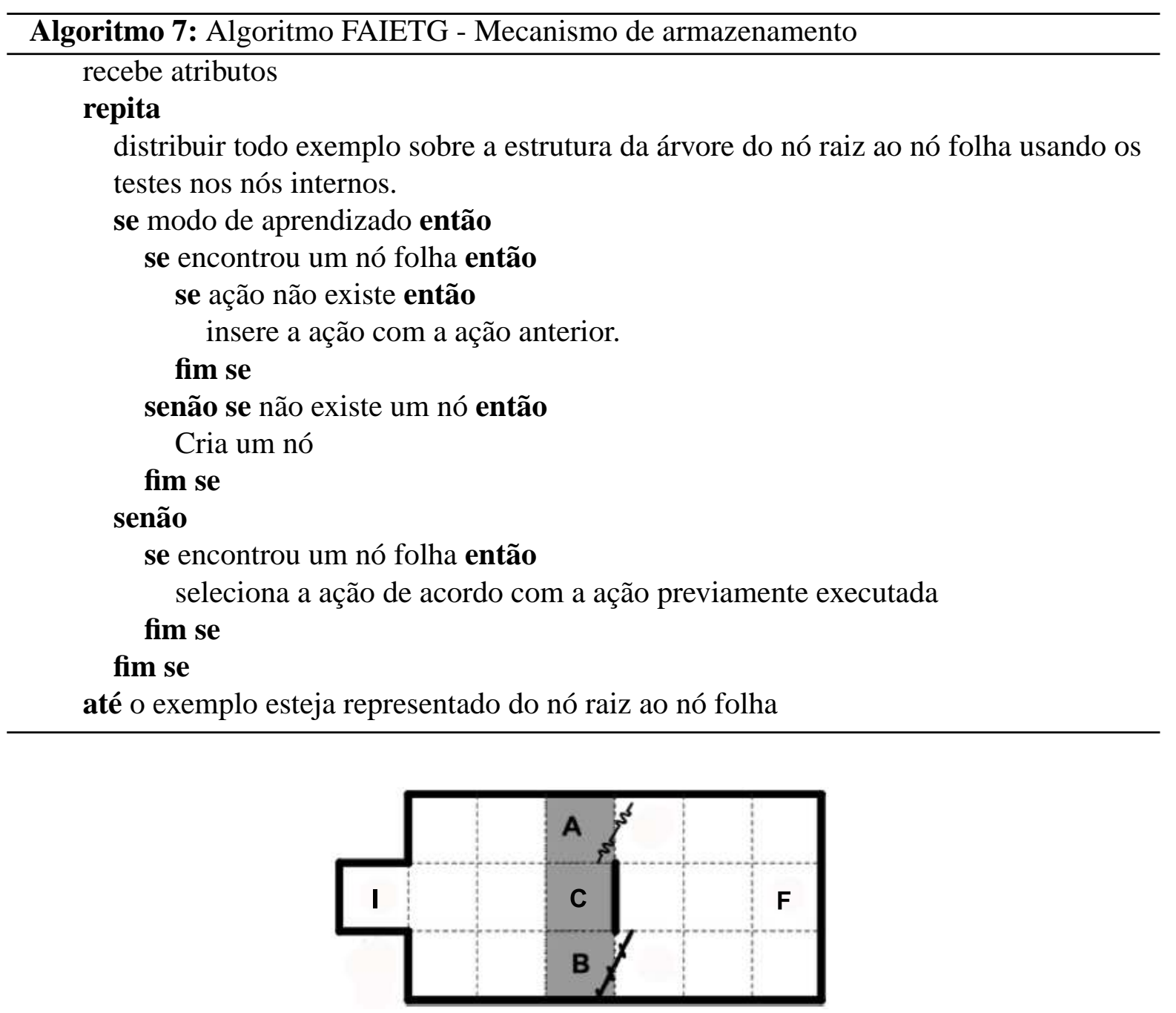

Figura 6.1: Problema do mundo da grade de luz. Figura adaptada de (Dung et al., 2008).

estava aberta se fecha e a outra se abre.

A Figura 6.1 mostra o problema do mundo da grade de luz, onde o agente parte do estado inicial I e tem que atingir o estado final $\mathrm{F}$ se locomovendo pelo grid. $\mathrm{O}$ ambiente possue uma parede no centro com duas portas separando os ambientes. Os estados A, B e C são denominados estados ocultos (Dung et al., 2008).

Existem outros trabalhos de rede neural recorrente (RNN) sobre problemas como $E$ maze (Dung et al., 2008), T maze (Bakker, 2002), relativos a música (Franklin, 2006) ou com reconhecimento de escrita (Graves \& Schmidhuber, 2008).

O elemento básico em um LSTM é a célula de memória (Figure 6.2), que contém uma unidade linear recursiva auto conectada chamada de "Constant Error Carousel" (CEC) (Hochreiter \& Schmidhuber, 1997). Uma chave (unidade) multiplicativa de entrada é usada para proteger o conteúdo da memória de perturbações irrelevantes de entrada. De forma 


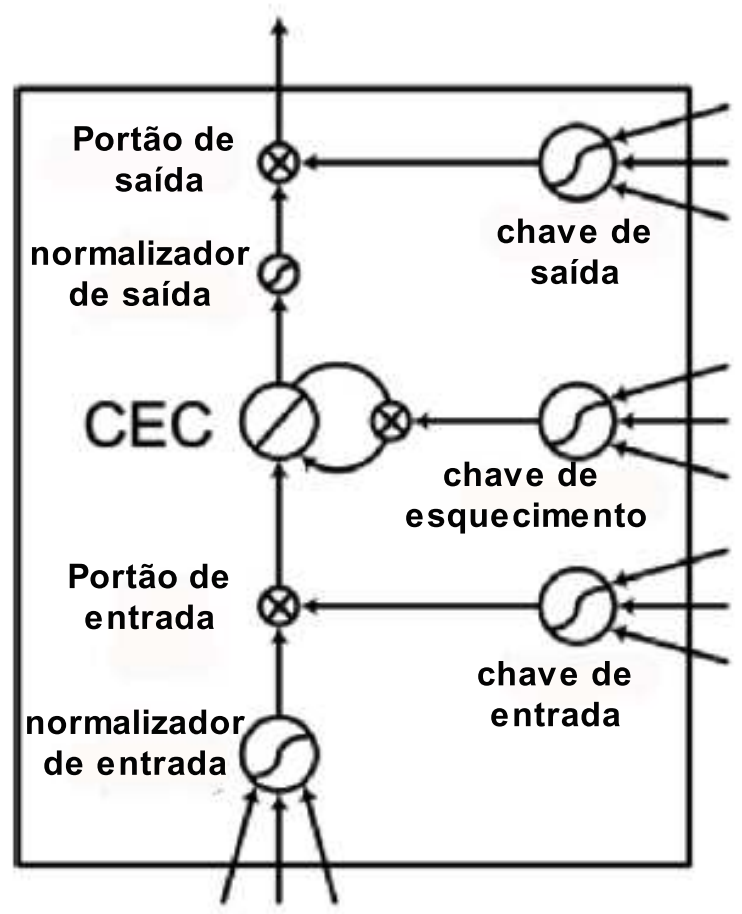

Figura 6.2: Célula de memória. Figura adaptada de Dung et al. (2008).

semelhante, uma chave de saída é usada para proteger o conteúdo da memória. Gers et al. (2000) utilizaram um limitador, chamado chave de esquecimento, para apagar conteúdo desatualizado.

Muitas topologias de redes LSTM são propostas para resolver um problema particular (Bakker et al., 2003; Gers et al., 2000). A Figura 6.3 mostra uma arquitetura típica com 4 neurônios de entrada, 5 neurônios na camada intermediaria, 3 células de memória e 3 neurônios de saída.

\section{RLSSAC}

De acordo com Dung et al. (2008), o RLSSAC é um método dividido em duas fases. $\mathrm{Na}$ primeira fase, é realizada a classificação dos estados, onde dois grupos são formados (estados completamente observáveis e estados obscuros) pela avaliação de cada estado dado um certo grau para cada tipo. Essa etapa é feita utilizando o algoritmo Q-learning padrão (Watkins, 1989). A segunda fase consiste na fase de aprendizado, na qual se utilizou-se a LSTM para atualizar a função Q dos estados obscuros.

Inicia-se o processamento classificando os estados em completos e obscuros. Dung 


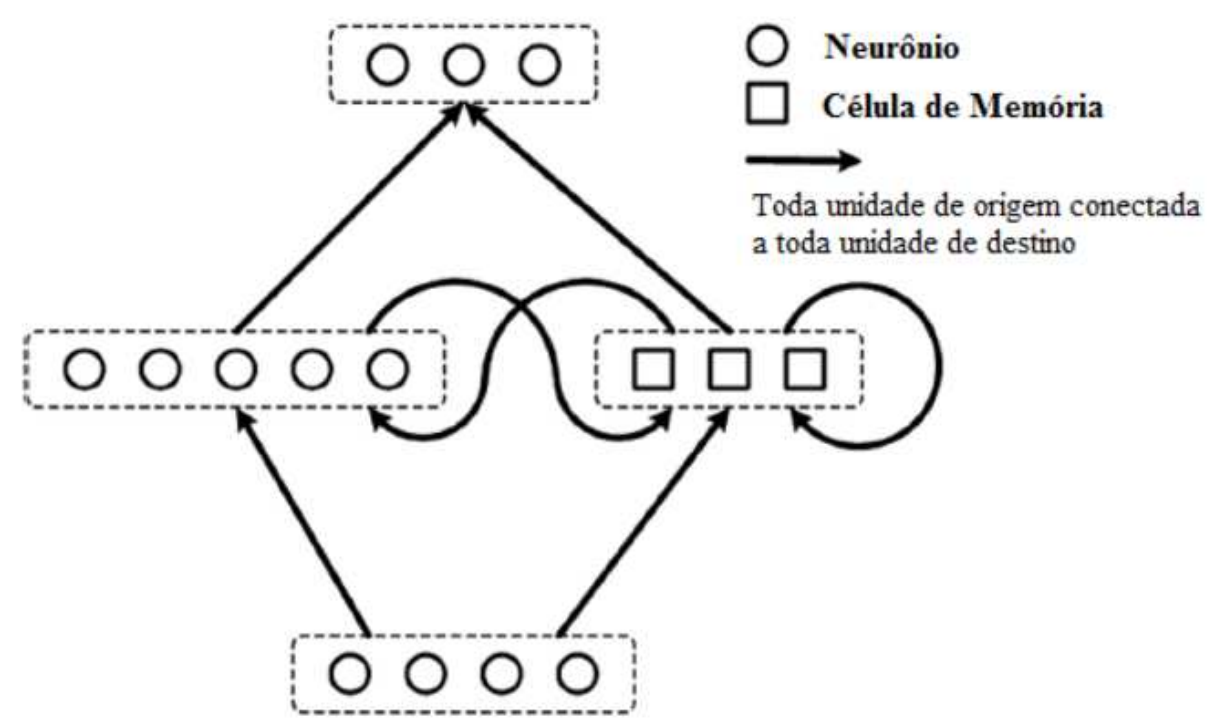

Figura 6.3: Topologia básica de uma LSTM. Figura adaptada de (Dung et al., 2008).

define estado obscuro como aquele que tem no mínimo duas escolhas ótimas, mas nenhuma delas tem uma recompensa estável positiva, ou seja, em certos momentos as recompensas são negativas. Para isso, foi determinado um valor de observação para definir os estados em seus grupos. Para estados obscuros, o valor deve ser baixo e para os outros, o valor deve ser alto.

Na primeira etapa, o agente explora o ambiente, utilizando o algoritmo Q-learning padrão, para identificar os estados em seus grupos. Para isso, ele calcula o erro crítico em cada estado:

$$
\delta(s, a)=r+\gamma \max _{a^{\prime}} Q\left(s^{\prime}, a^{\prime}\right)-\max _{a} Q(s, a)
$$

onde $\mathrm{Q}(\mathrm{s}, \mathrm{a})$ é o valor $\mathrm{Q}$ da ação a sobre o estado s e Q(s',a') é o valor Q da ação a' sobre o estado s'.

Caso o valor crítico seja positivo, é realizada a operação dada por:

$$
\delta^{+}(s, a)=\delta^{+}(s, a)+\delta(s, a)
$$

Caso contrário, a operação realizada é dada por:

$$
\delta^{-}(s, a)=\delta^{-}(s, a)-\delta(s, a)
$$


Após um longo período de tempo, o agente para a exploração. O valor definido para cada ação $a$ sobre o estado $s$ é definido como:

$$
v(s, a)=\left\{\begin{array}{lll}
\left|\frac{\delta^{+}(s, a)-\delta^{-}(s, a)}{\delta^{+}(s, a)+\delta^{-}(s, a)}\right| & \text { se } & n(s, a)>N_{t} \\
1 & \text { caso contrario }
\end{array}\right.
$$

onde $n(s, a)$ é o número de vezes que a ação $a$ foi realizada sobre o estado s e $N_{t}$ é um número grande.

Em seguida o grau de observação para um determinado estado $s$ pode ser verificado de acordo com:

$$
d(s)=\min _{a^{\prime}}(v(s, a))
$$

Para estados completos, o grau de observação é alto e pode ser estável positivo ou negativo. Para estados obscuros esse valor é sempre baixo, então:

$$
b(s)=\left\{\begin{array}{lll}
1 & \text { se } & d(s)>\tau \\
0 & & \text { caso contrario }
\end{array}\right.
$$

onde $\tau$ é um limiar e $\tau \in[0,1]$. Um estado é obscuro se o valor de $b(s)$ é 0 .

A fase do aprendizado é iniciada pelo armazenamento do valor Q na tabela de memória, para estados completos, e uma atualização da $L S T M$ para os casos de estados obscuros. O valor Q da ação $a$ no estado $s$ é definido por:

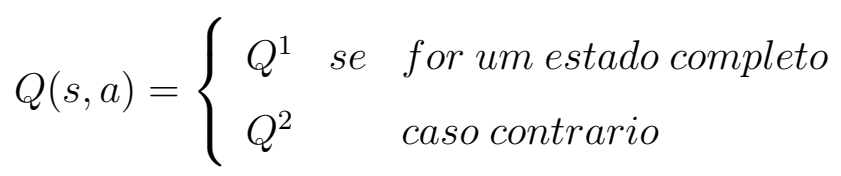

onde $Q^{1}(s, a)=Q^{1}(s, a)+\alpha\left(r+\gamma \max _{a^{\prime}} Q\left(s^{\prime}, a^{\prime}\right)-Q(s, a)\right)$. A equação $Q^{2}(s, a)=r+$ $\gamma \max _{a^{\prime}} Q\left(s^{\prime}, a^{\prime}\right)-Q(s, a)$ é utilizada para atualização da conexão da $\mathbb{R N N}$ para o nó de saída referente ao nó obscuro. Isto é possível, pois o ambiente já foi explorado na primeira etapa Dung et al. (2008). 


\section{RLSSACTG}

Com base no apresentado acima, foi proposto um algoritmo que utiliza $L S T M$ e o algoritmo FAIETGQ para o problema da atenção compartilhada. Devido a grande dificuldade de resolver todos os problemas com reforços diferentes para uma ação executada sobre um determinado estado, o algoritmo proposto foca na questão de retornar ao contato ocular com o ser humano quando o robô está observando um objeto ou um espaço vazio.

O algoritmo proposto utiliza a mesma $[L S T M$ da Figura 6.3 e a mecanismo de aprendizado por reforço é baseado no FAIETGQ. Assim inicia-se com a classificação dos estados. Para isso, foram utilizadas as 100 primeiras interações. A cada estado, o agente verifica a melhor ação a ser executada de acordo com o mecanismo utilizado para armazenamento. Caso o algoritmo não encontre o estado na estrutura de armazenamento, a ação é escolhida aleatoriamente. Após a ação ser executado pelo agente, um novo estado e reforço são percebidos pelo agente. Com os valores do estado, no qual a ação foi executada, da própria ação, o reforço e a ação que gerou o estado com reforço positivo são utilizados para atualizar a estrutura de armazenamento.

A estrutura de armazenamento recebe as informações e verifica se o estado já existe. Caso seja negativo, o estado é inserido na árvore com a ação e o valor Q calculado utilizando a equação 3.9. No entanto, caso o estado exista, o estado interno é percorrido e no nó folha é verificado se o tipo de reforço é diferente. Se o tipo de reforço for o mesmo, é verificado se a ação existe. Caso essa comparação seja positiva, o valor Q é atualizado, caso contrario, a ação é inserida, com seu respectivo valor Q e o tipo do reforço. Caso o tipo de reforço for diferente, o estado será tratado pela $L S T M$ Assim, os estados nas quais será utilizado a $L S T M$ serão marcado e utilizados como meio de seleção das ações. Caso contrário, a ação é selecionada como no FAIETGQ, ou seja, de acordo com a ação que resulta em reforço positivo.

Nas demais interações o tipo do estado não é alterado, somente é atualizado o mecanismo de armazenamento.

\subsubsection{Sem Informação Adicional Versão 2}

As técnicas citadas acima necessitam de um determinado período de tempo no início do processo, seja para aprender a retornar ao contato ocular ou para classificação de estados. O algoritmo FAIETGQ2 é uma melhoria no algoritmo FAIETGQ baseada na ideia de planos, 
onde o agente só seleciona uma ação quando existe uma mudança no estado do ambiente.

Leonetti \& Iocchi (2010) utilizaram uma representação através de planos reativos compostos por planos de estados e eventos utilizando grafos. Os planos de estados são os nós do grafo onde representam as ações que podem ser executadas. Nos vértices estão os eventos que refletem os estados do ambiente. Além disso, os vértices podem ter guardiões, que são condições que devem ser satisfeitas para atingir o outro estado. Dessa forma, o agente permanece em um nó até que exista modificação no estado. Caso exista um guardião, a condição deve ser satisfeita para que o agente mude de um nó para outro.

A situação descrita no sistema de Leonetti foi adaptada ao algoritmo FAIETGQ. Assim, o agente percebe o estado do ambiente e somente quando há alteração do estado o agente seleciona uma ação a ser executada. Além disso, o algoritmo FAIETGQ possui uma restrição na escolha da ação que é a ação previamente executada sobre o estado que gerou um reforço positivo.

Um problema é gerado na execução do novo algoritmo. Quando o agente, de forma errônea, olha para um local onde não existe um evento, o estado não vai se alterar se o agente não executar uma ação. Dessa forma, no momento que esse determinado estado acontece o agente não espera alteração do ambiente e passa buscar por uma ação que o leve ao contato ocular. Assim, esse problema inicial é resolvido e possibilita o agente a retornar ao contato ocular.

A vantagem desse algoritmo é a não obrigatoriedade de um período inicial para um aprendizado específico.

\subsubsection{Experimentos Realizados}

Nesta Seção, são apresentados os principais resultados dos experimentos executados para a avaliação da arquitetura proposta no contexto do aprendizado da atenção conjunta, empregando-se o simulador de interações sociais apresentado na seção 3.5, do Capítulo 3 . O propósito destes experimentos foi a determinação da capacidade de exibição de comportamentos apropriados e de aprendizagem da arquitetura durante o controle do robô, simulado em um ambiente social controlado.

Para este conjunto de experimentos, a configuração dos experimentos e os ajustes dos parâmetros seguem os apresentados na seção 3.6, do Capítulo 3 . 


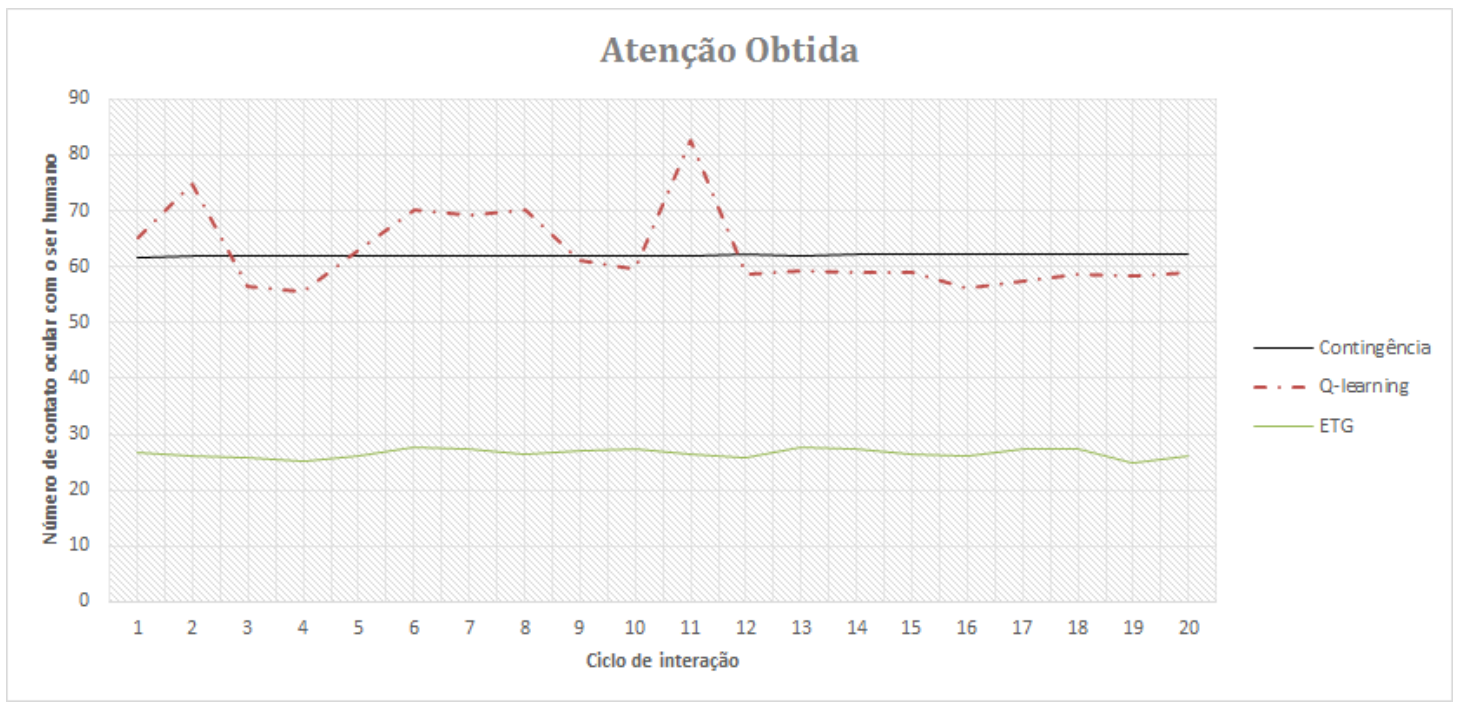

Figura 6.4: Média de atenção obtida pelo ser humano do robô durante a fase de avaliação.

Antes de analisar os resultados dos algoritmos apresentados nesse capítulo, os algoritmos utilizados anteriormente (Contingência, ETG e Q-learning) foram avaliados sem a utilização do módulo de controle de consequência. Os resultados dessa avaliação podem ser vistos na Figura 6.4 e 6.5

A Figura 6.4 mostra a média do número de vezes que o robô estabeleceu o contato ocular com o ser humano em cada etapa do aprendizado, sendo o máximo de 125 possibilidades. O resultado mostra que os valores alcançados por todas as técnicas, na maioria das vezes, não atinge $50 \%$. Além disso, o comportamento do algoritmo Q-learning mostra a instabilidade do mesmo quanto a manter o contato ocular.

A Figura 6.5 mostra o desempenho no aprendizado da atenção conjunta de três diferentes algoritmos da aprendizado usados como mecanismo de aprendizado: Contingência, ETG e Q-learning. Eles foram utilizados pela arquitetura para capacitar o robô com a atenção conjunta. O resultado mostra que o algoritmo de contingência atingiu, na média, $40 \%$ de desempenho e os algoritmos ETG e Q-learning atingiram valores próximos a $90 \%$.

A comparação feita entre os resultados obtidos acima e os apresentados na seção 3.6.4 do Capítulo 3, mostra que a performance dos algoritmos de aprendizado diminui sem o módulo de controle de consequência. A maior diferença está relacionada à capacidade de manter o contato ocular.

Após apresentar e analisar os resultados dos algoritmos de contingência, Q-learning e ETG sem a influência do módulo de controle de consequência, as Figuras 6.6 e 6.8 contém os 


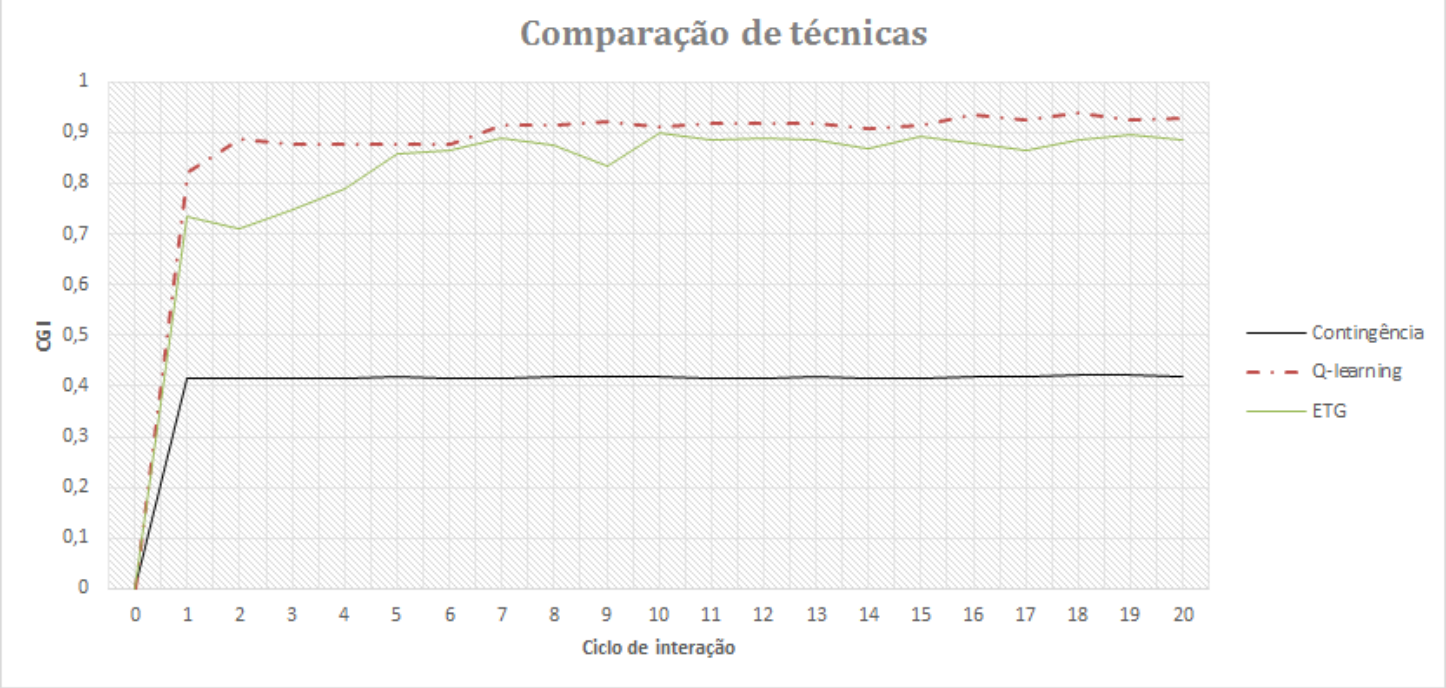

Figura 6.5: Evolução do aprendizado da atenção conjunta pelo robô durante o experimento.

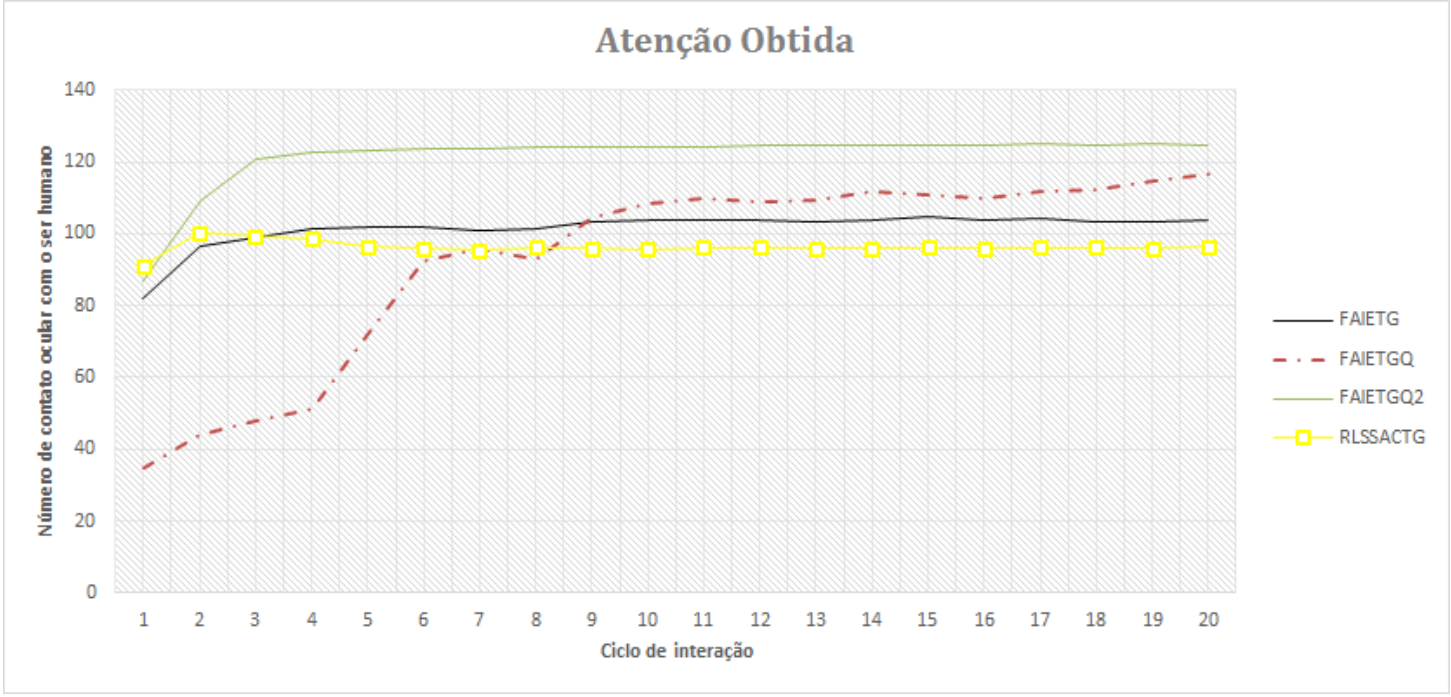

Figura 6.6: Média de atenção obtida pelo ser humano do robô durante a fase de avaliação.

resultados obtidos nos experimentos com os algoritmos FAIETG, FAIETGQ, FAIETGQ2 e o RLSSACTG.

A Figura 6.6 mostra que os algoritmos atingiram um valor satisfatório, visto que o pior deles (RLSSACTG) atinge valor próximo aos 100. Por outro lado, o algoritmo que apresentou melhor resultado (FAIETGQ2), se aproxima do valor máximo após o terceiro ciclo de interação, se mantendo estável após esse ciclo. Além disso, todos os algoritmos foram melhores se for feito um comparativo com os métodos apresentados na Figura 6.4

Ademais, a Figura 6.7 insere os valores do desvio padrão para cada técnica durante a evolução da média da atenção obtida pelo ser humano, apresentado na Figura 6.6. Segundo a 


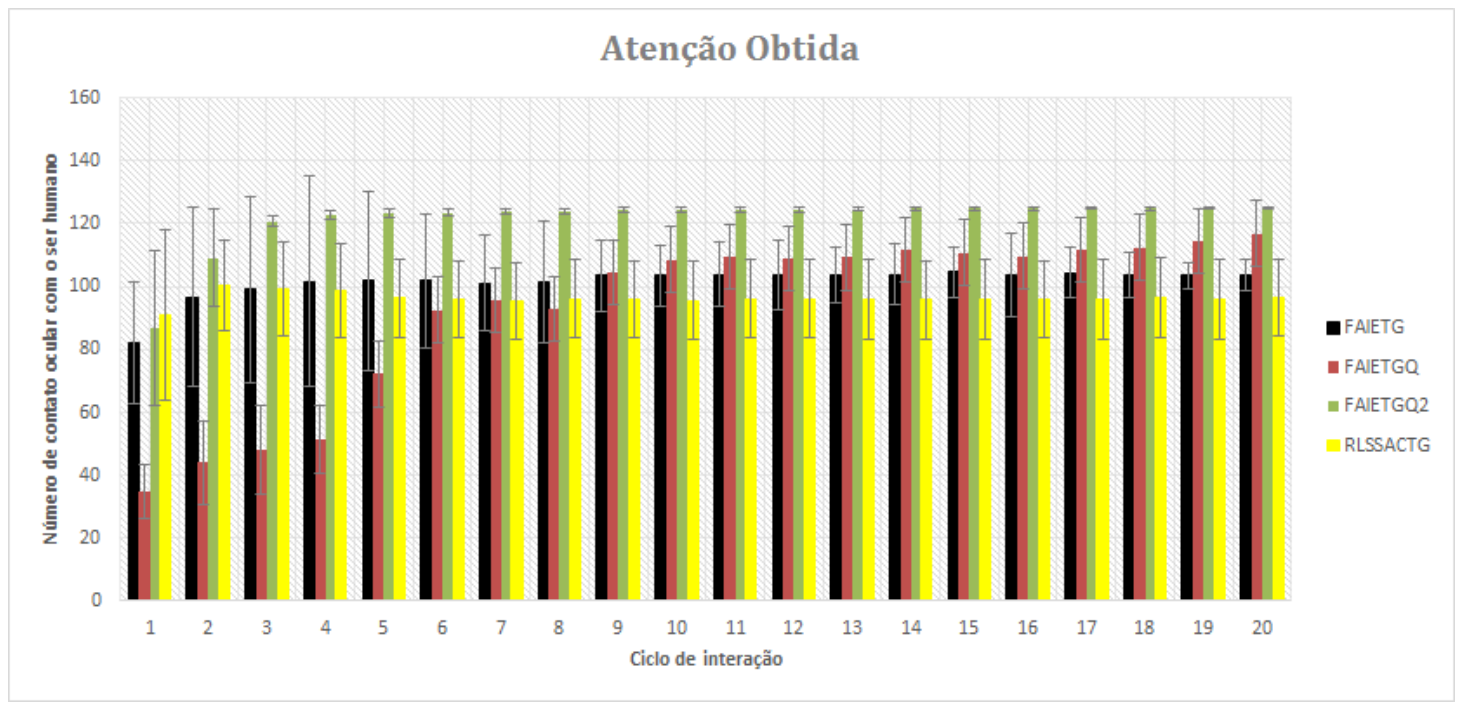

Figura 6.7: Média e desvio Padrão da atenção obtida pelo ser humano do robô durante a fase de avaliação.

Figura 6.7, os valores iniciais do desvio padrão são altos, mas a medidida que as interações acontencem esse valor reduz de forma diferente para cada algoritmo. Além disso, o melhor desempenho é apresentado pelo algoritmo FAIETGQ2.

Um comparativo entre o desenvolvimento do aprendizado da atenção conjunta é apresentado na Figura 6.8 e 6.9. Na Figura 6.8 mostra a evolução dos valores da média do CGI durante a interação e a Figura 6.9 é inserida os valores do desvio padrão da Figura 6.8. Os algoritmos seguem um padrão, com um início onde o robô adquire grande conhecimento e com alguns ciclos depois, o nível de conhecimento se estabiliza. Com um diferencial, o algoritmo FAIETGQ se inicia com um nível menor de aprendizado mas se sobrepõem aos outros, após alguns ciclos e atinge o melhor resultado, com valores próximos ao máximo, ao final dos 20 ciclos de interação. No entanto, os outros algoritmo têm um aprendizado mais rápido e após o terceiro ciclo apresentam um comportamento constante, com pequenas variações.

Uma análise mais profunda do desempenho dos algoritmos apresentada no capítulo pode ser feita considerando a Figura 6.6 e a Figura 6.8, O algoritmo FAIETGQ atingiu os melhores resultados na análise, por ter alcançado o melhor CGI e próximo ao melhor resultado de atenção obtida. No entanto, o algoritmo não atingiu uma estabilidade em nenhum dos dois fatores e a necessidade de vários ciclos para atingir a melhor performance pode ser considerado um ponto negativo. Nesse caso, o algoritmo FAIETGQ2 consegue atingir um bom resultado em apenas três ciclos. Esses dois algoritmos obtiveram os melhores resultados e podem ser considerados na implantação de sistemas robóticos para capacitar um robô em aprender a 


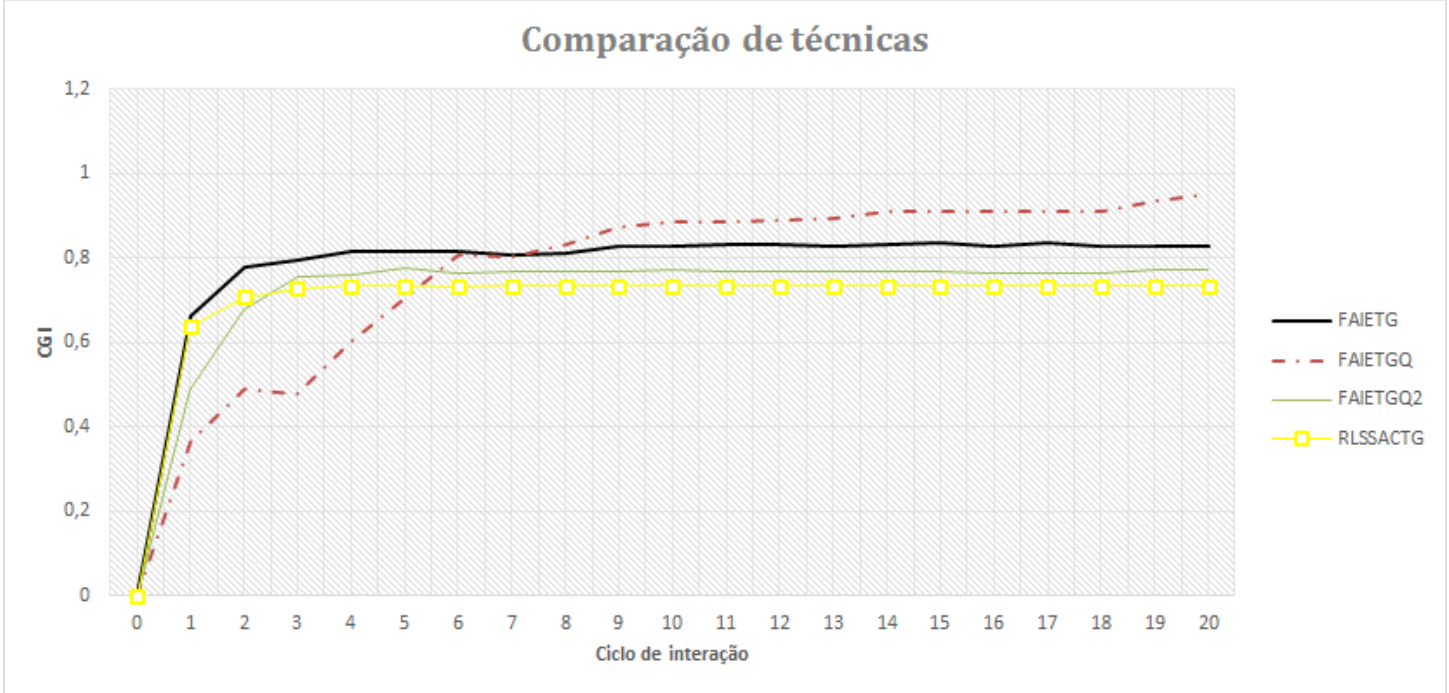

Figura 6.8: Média do CGI durante a evolução do aprendizado da atenção conjunta pelo robô durante o experimento.

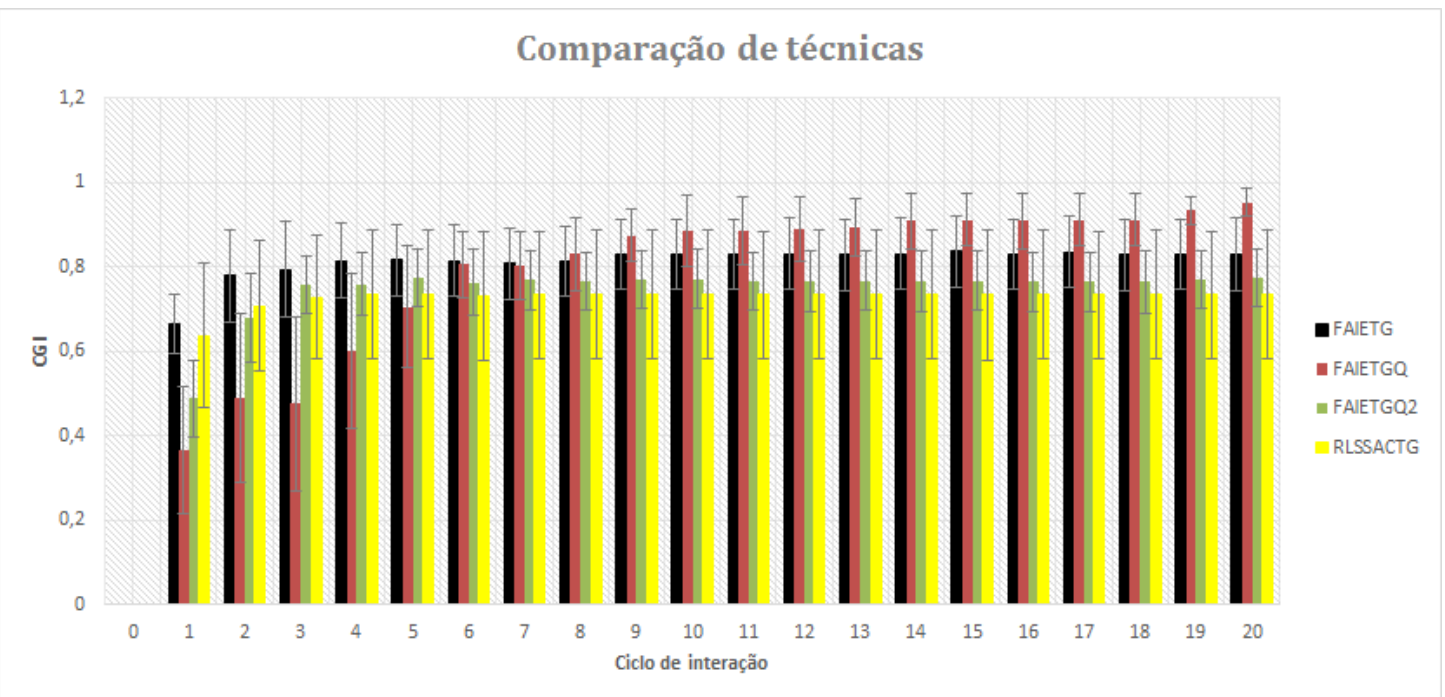

Figura 6.9: Média e desvio padrão do CGI durante a evolução do aprendizado da atenção conjunta pelo robô durante o experimento.

atenção compartilhada.

\subsection{Considerações Finais}

O capítulo apresentou três algoritmos desenvolvidos utilizando duas concepções diferentes para o aprendizado da atenção conjunta. Os algoritmos foram baseados em técnicas para resolver o problema de um reforço diferente para uma ação tomada sobre um estado em diferentes espaços de tempo. Eles foram avaliados em um simulador de interações sociais. 
Os resultados mostraram que todos os algoritmos apresentados nesse capítulo são capazes de capacitar um robô a aprender a atenção conjunta durante uma simples interação de forma satisfatória. Além disso, os algoritmos FAIETGQ e FAIETGQ2 apresentaram melhores resultados que os outros algoritmos. 



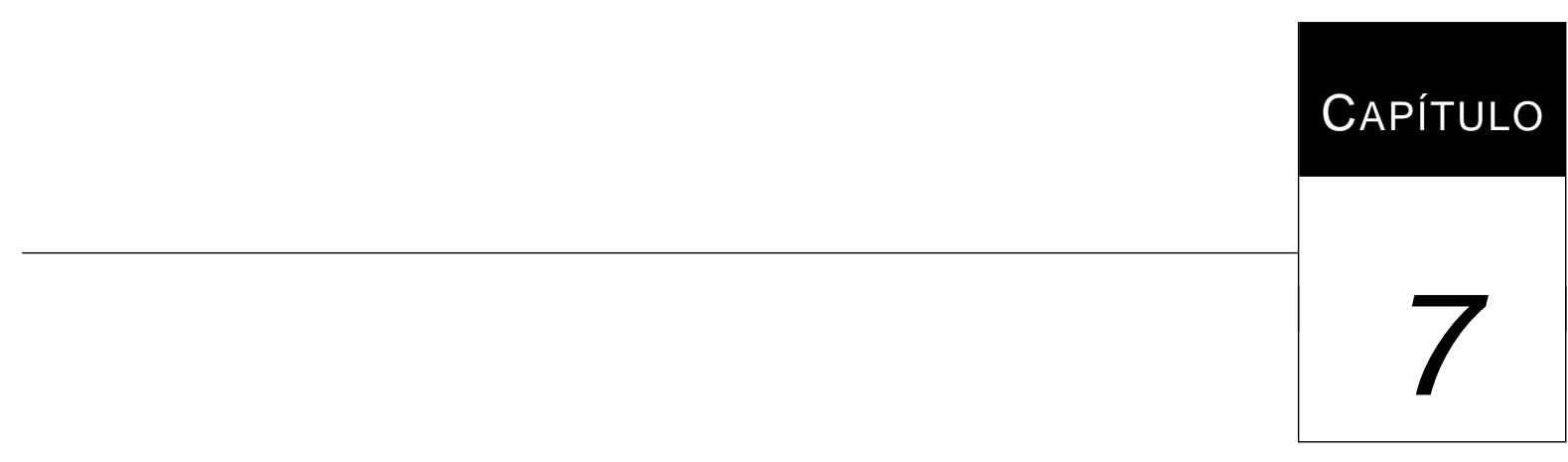

\section{Conclusões e Trabalhos Futuros}

O foco da pesquisa desenvolvida durante este doutorado foi o desenvolvimento dos módulos constituintes da arquitetura robótica para torná-la mais flexível à inserção de novos módulos e melhorar a interação entre o robô e o ser humano. As contribuições originais oriundas deste trabalho são destacadas a seguir.

\subsection{Contribuições}

No primeiro momento, uma análise mais profunda da arquitetura utilizada e a revisão bibliográfica de sistemas propostos na literatura para capacitar um robô a aprender ou somente exercer a habilidade da atenção compartilhada, formam o marco inicial do trabalho. A análise teve como ponto principal o funcionamento da arquitetura utilizando o algoritmo ETG, mostrando passo a passo o funcionamento e uma análise de complexidade. Além disso, a revisão bibliográfica foi importante para delimitar os avanços no desenvolvimento de sistemas e as aplicações existentes. O estudo trouxe contribuições relevantes e foram responsáveis por artigos científicos citados abaixo: 
- Silva, R. R., Reis, M. J. D., Romero, R. A. F., Robots Learning Shared Attention: a survey. International Journal of Social Robotics. Em análise.

- Silva, R. R., Romero, R. A. F., Computer Vision for learning to interact socially with humans. Robotic Vision: Technologies for Machine Learning and Vision Applications. IGI Global. Capítulo de Livro a ser publicado.

- Silva, R. R., Romero, R. A. F., Modelling Shared Attention Through Relational Reinforcement Learning. Journal of Intelligent \& Robotic Systems., v. 66, p. 167 - 182, 2012.

- Silva, R. R., Policastro, C. A., Zuliani, G., Pizzolato, E., Romero, R. A. F., Concept Learning by Human Tutelage for Social Robots. Learning and Nonlinear Models., v. 6, p. $44-67,2008$.

Em um segundo momento, o enfoque foi no desenvolvimento de estratégias em algoritmos de aprendizado que não dependam de informação adicional para capacitar o robô a aprender a habilidade da atenção compartilhada. Para que isso fosse possível, a abordagem assumida está relacionada à associação dos valores correntes com a ação anteriormente executada, além da adição de uma rede neural recorrente em uma das propostas. Esse pressuposto foi possível pois o problema não requer uma vasta exploração do ambiente, mas apenas a identificação do ponto de origem do resultado positivo, ou seja, do objetivo ou estado final. $\mathrm{O}$ êxito dessa estratégia simples e eficiente foi divulgado em fóruns internacionais por meio de artigos científicos:

- Silva, R. R., Romero, R. A. F. Improvements on Relational Reinforcement Learning to Solve Joint Attention. In: The Third International Conference on Advanced Cognitive Technologies and Applications (COGNITIVE 2011), Roma, 2011. p. 63 - 69.

- Silva, R. R., Romero, R. A. F. Relational Reinforcement Learning and Recurrent Neural Network with State Classification to Solve Joint Attention. In: The 2011 International Joint Conference on Neural Networks (Proceedings of IJCNN'2011), 2011, San Jose, CA, USA. Los Alamos : IEEE Press, 2011. p. 1222-1229.

- Silva, R. R., Romero, R. A. F. Using only Aspects of Interaction to Solve Shared Attention. In: 3rd International Workshop on Evolutionary and Reinforcement Learning 
for Autonomous Robot Systems (ERLARS 2010) on The 19th European Conference on Artificial Intelligence (ECAI 2010), 2010, Lisboa, Portugal. p. 43 - 51.

Com o desenvolvimento de um algoritmo de aprendizado que não necessita mais de informação do modulo de controle de consequência para capacitar um robô a aprender a atenção compartilhada, tornou-se possível o desenvolvimento de um novo módulo capaz de simular alguns reflexos encontrados nos seres humanos. O modelo proposto é baseado na psicologia evolutiva das emoções e desenvolvido de forma simples, abrindo a possibilidade de personalizar os robôs de acordo com as interações realizadas durante a vida. Este estudo proporcionou a escrita de dois artigos: um foi aceito e apresentado em um congresso internacional e o outro foi submetido a um periódico da área:

- Silva, R. R., Reis, M. J. D., Romero, R. A. F. Interaction history affecting personal emotion qualities of a robot. IEEE Transactions on Robotics, submetido

- Silva, R. R., Reis, M. J. D., Romero, R. A. F. Personal Identity Module Using Psychoevolutionary Emotion Theory for Social Robots. In: 21 IEEE International Symposium on Robot and Human Interactive Communication (Ro-man 2012), Paris, 2012. p.551-558.

A última contribuição desta tese está relacionada ao desenvolvimento de um novo módulo de percepção de estímulos baseados em técnicas de visão computacional para identificar o estado do ambiente. Dessa forma, foi adotada uma abordagem que identifica a presença do ser humano e utiliza um histograma de orientação com classificadores $S V M$ s para classificar o estado do ambiente entre onze estados possíveis. O algoritmo proposto nesse trabalho além de estimar a posição da cabeça, verifica se existe uma pessoa no seu foco de visão. Dessa forma, a presença ou não do ser humano é considerada nos estados a ser classificados, fato não considerado em outros trabalhos. A contribuição desse trabalho foi submetida para a melhor conferência internacional de robótica, segundo o ranking elaborado pela qualis da CAPES:

- Silva, R. R., Romero, R. A. F. Understanding of the Environment by a Robot during Interactions with a Human Being. In: 2013 IEEE International Conference on Robotics and Automation (ICRA 2013), submetido. 


\subsection{Trabalhos Futuros}

Como continuidade, pretende-se estudar e analisar melhorias a serem inseridas no módulo de percepção de estímulos que proporcione uma acurácia e estabilidade maior na classificação dos estados. Os estudos devem incorporar também a classificação desses estados independente do ambiente que está sendo considerado, ou seja, com um plano de fundo que seja dinâmico. Além disso, adicionar a este módulo, capacidades como a de identificar objetos em cenas e a pessoa com quem está interagindo.

Em relação ao módulo de identidade pessoal, deseja-se aperfeiçoar o modelo utilizado. Para isso, um estudo mais aprofundado sobre os reflexos humanos e as suas relações se faz necessário. A relação entre os elementos constituintes do módulo MIP e os efeitos que esse módulo podem acarretar na arquitetura merecem ser analisados. Além disso, a adição de tipos de personalidade que influenciará no desenvolvimento do módulo e do robô, tais como a personalidade introvertida que pode inibir mais a interação ou extrovertido que necessite de mais interação também faz parte dos trabalhos futuros.

Outro ponto relevante a ser pesquisado é como a arquitetura analisará cada tipo de interação e a influência de cada um na arquitetura. Uma interação simples, como uma conversa sobre um assunto, uma interação mais complexa, como uma ajuste de conduta dos pais ou outra que tenha valor na formação do robô, uma diversão, um trabalho, etc. Esses fatores são importantes para se criar um robô com personalidade única.

Por fim, com algumas melhorias citadas no módulo de visão será possível utilizar a arquitetura no robô NAO. A expansão dessa arquitetura para utilizar toda a estrutura do humanoide em uma situação real, onde o robô tem uma função definida, é considerada importante para inserção do mesmo em um ambiente social. 


\section{Referências Bibliográficas}

Bakker, B. (2002). Reinforcement learning with long short-term memory. In Neural information processing systems (nips) (pp. 1475-1482). MIT Press.

Bakker, B., Zhumatiy, V., Gruener, G., \& Schmidhuber, J. (2003). A robot that reinforcement-learns to identify and memorize important previous observations. In Proceedings of the 2003 ieee/rsj international conference on intelligent robots and systems.

Baldwin, D. A. (1995). Understanding the link between joint attention and language. Joint attention Its origins and role in development, 131-158.

Bartneck, C., \& Forlizzi, J. (2004). A design-centred framework for social human-robot interaction. In 13th ieee international workshop on robot and human interactive communication.

Belkin, M., \& Niyogi, P. (2003, June). Laplacian eigenmaps for dimensionality reduction and data representation. Neural Computation, 15(6), 1373-1396.

Beymer, D. (1994, jun). Face recognition under varying pose. In Ieee computer society conference on computer vision and pattern recognition (p. 756 -761).

Blockeel, H., \& De Raedt, L. (1998). Top-down induction of first-order logical decision trees. Artificial Intelligence, 101(1-2), 285-297.

Böckler, A., Knoblich, G., \& Sebanz, N. (2011). Observing shared attention modulates gaze following. cognition. Cognition, 120, 292-298. 
Boucenna, S., Gaussier, P., \& Hafemeister, L. (2011, aug.). Development of joint attention and social referencing. In 2011 ieee international conference on development and learning (icdl) (Vol. 2, p. 1-6).

Bradski, G., \& Kaehler, A. (2008). Learning opencv. O’Reilly Media.

Bradski, G. R. (1998). Computer vision face tracking for use in a perceptual user interface.

Bräuer, J., Call, J., \& Tomasello, M. (2005, May). All great ape species follow gaze to distant locations and around barriers. Journal of Comparative Psychology, 119(2), 145-154.

Breazeal, C. (2002). Designing sociable robots. Cambridge, MA, USA: MIT Press.

Breazeal, C. (2003, July). Emotion and sociable humanoid robots. International Journal of Human-Computer Studies, 59(1-2), 119-155.

Breazeal, C., Edsinger, A., Fitzpatrick, P., \& Scassellati, B. (2001, September). Active vision for sociable robots. IEEE Transactions on Systems, Man, and Cybernetics, Part A: Systems and Humans, 31(5), 443-453.

Brooks, R., \& Meltzoff, A. N. (2005). The development of gaze following and its relation to language. Developmental Science, 6(8), 535-543.

Brown, L. M., \& Tran, Y. L. (2002). Comparative study of coarse head pose estimation. In Proceedings of the workshop on motion and video computing (pp. 125-130). Washington, DC, USA: IEEE Computer Society.

Bugnyar, T., Stöwe, M., \& Heinrich, B. (2004). Ravens, corvus corax, follow gaze direction of humans around obstacles. The Royal Society, 271, 1331-1336.

Carlson, E., \& Triesch, J. (2003). A computational model of the emergence of gaze following. In Connectionist models of cognition and perception ii (pp. 105-114). World Scientific.

Carpenter, M., Nagell, K., Tomasello, M., Butterworth, G., \& Moore, C. (1998). Social cognition, joint attention, and communicative competence from 9 to 15 months of age. Monographs of the Society for Research in Child Development, 63(4), 1-143.

Chang, C.-C., \& Lin, C.-J. (2011, May). Libsvm: A library for support vector machines. ACM Trans. Intell. Syst. Technol., 2(3), 27:1-27:27. 
Clifford, S., \& Dissanayake, C. (2008). The early development of joint attention in infants with autistic disorder using home video observations and parental interview. Journal of Autism and Developmental Disorders, 38(5), 791-805.

Cortes, C., \& Vapnik, V. (1995, sep). Support-vector networks. Mach. Learn., 20(3), 273-297.

Cosmides, L., \& Tobby, J. (2000). Evolutionary psychology and the emotions. Handbook of emotions, 91-115.

Dalal, N. (2006). Finding people in images and videos. Doctoral dissertation, Institut National Polytechnique de Grenoble.

Deák, G. O., Fasel, I., \& Movellan, J. (2001). The emergence of shared attention: Using robots to test developmental theories. In Proceedings of the international workshop on epigenetic robotics (pp. 95-104).

Deák, G. O., \& Triesch, J. (2005). Origins of shared attention in human infants. In K. Fuzita \& S. Itakura (Eds.), Diversity of cognition (p. 67-74). Kyoto University Press.

Delaunay, F., Greeff, J., \& Belpaeme, T. (2010). A study of a retro-projected robotic face and its effectiveness for gaze reading by humans. In 5 proceeding of the acm/ieee international conference on human-robot interaction (pp. 39-44). Piscataway, NJ, USA: IEEE Press.

Delinicolas, E. K., \& Young, R. L. (2007). Joint attention, language, social relating, and stereotypical behaviors in children with autistic disorder. Autism, 11(5), 425-436.

Doniec, M. W., Sun, G., \& Scassellati, B. (2006). Active learning of joint attention. In Humanoids (p. 34-39). IEEE.

Driessens, K. (2004, Maio). Relational reinforcement learning. Doctoral dissertation, Katholieke Universiteit Leuven.

Dube, W., McDonald, R., Mansfield, R., Holcomb, W., \& Ahearn, W. (2004). Toward a behavioral analisys of joint attention. The Behavior Analyst, 27(2), 197-207.

Duffy, B. R. (2000, November). The social robot. Doctoral dissertation, Department of Computer Science, University College Dublin.

Dung, L. T., Komeda, T., \& Takagi, M. (2008, Agosto). Reinforcement learning for pomdp using state classification. Applied Artificial Intelligence, 22, 761-779. 
Fasel, I., Deák, G. O., Triesch, J., \& Movellan, J. (2002). Combining embodied models and empirical research for understanding the development of shared attention. In 2 proceedings of the international conference on development and learning (pp. 21-27). Washington, DC, USA: IEEE Computer Society.

Ferrara, M., \& Gennaro, L. D. (2001). How much sleep do we need? Sleep Medicine Reviews, $5(2), 155-179$.

Ferrari, P., Kohler, E., Fogassi, L., \& Gallese, V. (2000). The ability to follow eye gaze and its emergence during development in macaque monkeys. Proceedings of the National Acadamy of Sciences of the United State of America, 97(25), 3997-4002.

Fong, T. W., Nourbakhsh, I., \& Dautenhahn, K. (2003). A survey of socially interactive robots. Robotics and Autonomous Systems.

Franklin, J. A. (2006). Recurrent neural networks for music computation. INFORMS J. on Computing, 18(3), 321-338.

Gallery, L. P. (2012). Plutcking wheel of emotions. Available from http://launchpadgallery.org/byte-me-2012/plutchiks_wheel/

Gee, A. H., \& Cipolla, R. (1994). Determining the gaze of faces in images. Image and Vision Computing, 12, 639-647.

Gers, F. A., Schmidhuber, J., \& Cummins, F. (2000). Learning to forget: Continual prediction with 1stm. Neural Computation, 12, 2451-2471.

Goldberg, D. (1989). Genetic algorithm in search, optimization and machine learning. Massachusetts: Addison-Wesley Publishing Company, Inc.

Gosavi, A. (2009, April). Reinforcement learning: A tutorial survey and recent advances. INFORMS J. on Computing, 21(2), 178-192.

Graves, A., \& Schmidhuber, J. (2008). Offline handwriting recognition with multidimensional recurrent neural networks. In D. Koller, D. Schuurmans, Y. Bengio, \& L. Bottou (Eds.), Neural information processing systems (nips). MIT Press.

Haykin, S. (1999). Neural networks - a comprehensive foundation. Prentice Hall. 
Hegel, F., Krach, S., Kircher, T., Wrede, B., \& Sagerer, G. (2008, aug.). Understanding social robots: A user study on anthropomorphism. In Robot and human interactive communication, 2008. ro-man 2008. the 17th ieee international symposium on (p. 574 $-579)$.

Hochreiter, S., \& Schmidhuber, J. (1997). Long short-term memory. Neural Computation, 9(8), 1735-1780.

Hoffman, M. W., Grimes, D. B., Shon, A. P., \& Rao, R. P. N. (2006). A probabilistic model of gaze imitation and shared attention. Neural Networks, 19(3), 299-310.

Horprasert, T., Yacoob, Y., \& Davis, L. (1996, oct). Computing 3-d head orientation from a monocular image sequence. In 2 international conference on automatic face and gesture recognition (p. 242 -247).

Houghton. (2001). The american heritage dictionary of the english language (4th ed.). Houghton Mifflin Company.

Huang, C., \& Thomaz, A. (2010). Joint attention in human-robot interaction. AAAI Fall Symposium Series, 32-37.

Huang, H., Chen, J., \& Jian, H. (2002). Development of the joint attention with a new face tracking method for multiple people. In Ieee workshop on advanced robotics and its social impacts (arso) (pp. 32-37). IEEE.

Huang, J., Shao, X., \& Wechsler, H. (1998). Face pose discrimination using support vector machines (svm). In 14 international conference on pattern recognition (pp. 154-156). Washington, DC, USA: IEEE Computer Society.

Ikegami, T., \& Iizuka, H. (2003). Joint attention and dynamics repertoire in coupled dynamical recognizers. In 2 proceedings of the international symposium on imitation in animals and artifacts (p. 125-130).

Itti, L. (2000, Jan). Models of bottom-up and top-down visual attention. Doctoral dissertation, Department of Computer Science, University College Dublin.

Ivanov, T., Matthies, L., \& Vasilescu, M. (2009, oct.). Head pose estimation using multilinear subspace analysis for robot human awareness. In 12 ieee international conference on computer vision workshops (p. 227 -233). 
Jasso, H. (2007). A reinforcement learning model of gaze following. Doctoral dissertation, University of California, San Diego, California.

Jimenez, P., Nuevo, J., Bergasa, L., \& Sotelo, M. (2009, june). Face tracking and pose estimation with automatic three-dimensional model construction. Computer Vision, IET, $3(2), 93-102$.

Kaelbling, L., Littman, M., \& Moore, A. (1996). Reinforcement learning: A survey. Journal of Artificial Intelligence Research, 4, 237-285.

Kaminski, J., Riedel, J., Call, J., \& Tomasello, M. (2001). Domestic goats (capra hircus) follow gaze direction and use social cues in an object choice task. Animal behaviour, 69, $11-18$.

Kaplan, F., \& Hafner, V. (2004). The challenges of joint attention. Interaction Studies, 7, $67-74$.

Kim, H., Jasso, H., Deak, G., \& Triesch, J. (2008, aug.). A robotic model of the development of gaze following. In 7 ieee international conference on development and learning (pp. 238-243). IEEE.

Kirby, R., Simmons, R., \& Forlizzi, J. (2006, September). Modeling affect in socially interactive robots. In 15 ieee international symposium on robot and human interactive communication (ro-man06) (p. 558-563).

Kozima, H. (2002). Infanoid. Socially Intelligent Agents, 157-164.

Kozima, H., Michalowski, M. P., \& Nakagawa, C. (2009). Keepon: A playful robot for research, therapy, and entertainment. International Journal of Social Robotics, 1(1), 3-18.

Kozima, H., \& Yano, H. (2001). A robot that learns to communicate with human caregivers. In Proceedings of the first international workshop on epigenetic robotics.

Kwisthout, J., Vogt, P., Haselager, P., \& Dijkstra, T. (2008). Joint attention and language evolution. Connection Science - Social Learning in Embodied Agents, 20(2-3), 155-171.

Lau, B., \& Triesch, J. (2004). Learning gaze following in space: a computational model. In 3 proceedings of international conference for development and learning (pp. 1-8). 
Leonetti, M., \& Iocchi, L. (2010). Improving the performance of complex agent plans through reinforcement learning. In 9 proceedings of the international conference on autonomous agents and multiagent systems (Vol. 1, pp. 723-730). Richland, SC: International Foundation for Autonomous Agents and Multiagent Systems.

Lienhart, R., \& Maydt, J. (2002). An extended set of haar-like features for rapid object detection. In Proceedings of international conference on image processing. (Vol. 1, p. I-900 - I-903).

Lowe, D. G. (2004, November). Distinctive image features from scale-invariant keypoints. International Journal on Compututer Vision, 60(2), 91-110.

Marin-Urias, L., Sisbot, E., Pandey, A., Tadakuma, R., \& Alami, R. (2009, dec.). Towards shared attention through geometric reasoning for human robot interaction. In 9 proceedings of the ieee-ras international conference on humanoid robots (p. 331 -336).

Mataric, M. J. (2007). The robotics primer. MIT Press.

Matsuda, G., \& Omori, T. (2001). Learning of joint visual attention by reinforcement learning. In Proceedings of the international conference on cognitive modeling (iccm) (pp. 157-162).

Matthews, J. T., Almeida, G. J. M., Simmons, R., Silva, R., \& Schlenk, E. (2012a). Usability of a virtual coach system for therapeutic exercise for osteoarthritis of the knee. In Proceedings of ieee/rsj international conference on intelligent robots and systems.workshop on motivational aspects of robotics in physical therapy. IEEE.

Matthews, J. T., Almeida, G. J. M., Simmons, R., Silva, R., \& Schlenk, E. (2012b, april). Using a virtual coach for therapeutic exercise for knee osteoarthritis. Poster.

Meltzoff, A. N., Brooks, R., Shon, A. P., \& Rao, R. P. N. (2010). "social"robots are psychological agents for infants: A test of gaze following. Neural Networks, 23(8-9), 966-972.

Mitchell, T. M. (1997). Machine learning. New York: McGraw-Hill.

Moore, C., \& Dunham, P. J. (1995). Joint attention: Its origins and role in development. Hillsdale, NJ: Erlbaum. 
Moral, S., Pardo, D., \& Angulo, C. (2009). Social robot paradigms: An overview. In Proceedings of the 10th international work-conference on artificial neural networks: Part $i$ : Bio-inspired systems: Computational and ambient intelligence (pp. 773-780). Berlin, Heidelberg: Springer-Verlag.

Morency, L., Whitehill, J., \& Movellan, J. (2010, May). Monocular head pose estimation using generalized adaptive view-based appearance model. Image Vision Computation, 28(5), 754-761.

Morency, L.-P., Sundberg, P., \& Darrel, T. (2003). Pose estimation using 3d view-based eigenspaces. In Proceedings of analysis and modeling of faces and gestures (p. 45-52). IEEE.

Mundy, P., \& Jarrold, W. (2010). Infant joint attention, neural networks and social cognition. Neural Networks, 23(8-9), 985-997.

Murphy-Chutorian, E., \& Trivedi, M. (2008, june). Hyhope: Hybrid head orientation and position estimation for vision-based driver head tracking. In Ieee intelligent vehicles symposium (p. 512 -517).

Murphy-Chutorian, E., \& Trivedi, M. M. (2009, April). Head pose estimation in computer vision: A survey. IEEE Trans. Pattern Anal. Mach. Intell., 31(4), 607-626. Available from http://dx.doi.org/10.1109/TPAMI.2008.106

Mutlu, B., Hodgins, J. K., \& Forlizzi, J. (2006, December). A storytelling robot: Modeling and evaluation of human-like gaze behavior. In Proceedings of ieee-ras international conference on humanoid robots. IEEE.

Nagai, Y. (2004). Understanding the development of joint attention from a viewpoint of cognitive developmental robotics. Doctoral dissertation, Department of Adaptive Machine Systems, Graduate School of Engeneering, Osaka University.

Nagai, Y. (2005, April). The role of motion information in learning human-robot joint attention. In Robotics and automation, 2005. icra 2005. proceedings of the 2005 ieee international conference on (pp. 2069-2074).

Nagai, Y., Hosoda, A., \& Asada, M. (2003). A constructive model for the development of joint attention. Connection Science, 15(4), 211-229. 
Niyogi, S., \& Freeman, W. T. (1996). Example-based head tracking. In Proceedings of the 2nd international conference on automatic face and gesture recognition (fg '96) (pp. 374-378). Washington, DC, USA: IEEE Computer Society.

Nuance. (2001). Introduction to the nuance system (Tech. Rep.). Nuance Communications.

Perez, C. H., Escribano, G. S., \& Sanz, R. (2012). The morphofunctional approach to emotion modelling in robotics. Adaptive Behavior.

Plutcking, R. (2002). Emotions and life: Perspectives from psychology, biology, and evolution. American Psychological Association.

Policastro, C. (2008, Outubro). Arquitetura robótica inspirada na análise do comportamento. Doctoral dissertation, Universidade de São Paulo.

Raytchev, B., Yoda, I., \& Sakaue, K. (2004). Head pose estimation by nonlinear manifold learning. In 17 international conference on pattern recognition (pp. 462-466). Washington, DC, USA: IEEE Computer Society.

Roweis, S. T., \& Saul, L. K. (2000). Nonlinear dimensionality reduction by locally linear embedding. SCIENCE, 290, 2323-2326.

Scassellati, B. (1996). Mechanisms of shared attention for a humanoid robot.

Scassellati, B. (1999). Imitation and mechanisms of joint attention: A developmental structure for building social skills on a humanoid robot. In (pp. 176-195). Springer-Verlag.

Schilbach, L., Wilms, M., Eickhoff, S. B., Romanzetti, S., Tepest, R., Bente, G., et al. (2010). Minds made for sharing: Initiating joint attention recruits reward-related neurocircuitry. $J$. Cognitive Neuroscience, 22(12), 2702-2715.

Serio, T., Andery, M., Gioia, P., \& Micheleto, N. (2004). Controle de estímulos e comportamento operante: uma (nova) introdução. EDUC - Editora da PUC - SP.

Shepherd, S. V., Hosoda, A., \& Asada, M. (2010). Following gaze: gaze-following behavior as a window into social cognition. Frontiers in integrative neuroscience, 4, 1-13.

Shon, A., Grimes, D., Baker, C., Hoffman, M., Zhou, S., \& Rao, R. (2005, April). Probabilistic gaze imitation and saliency learning in a robotic head. In Proceedings of the ieee international conference on robotics and automation. (p. 2865-2870). 
Silva, R. R., Policastro, C. A., \& Romero, R. A. F. (2009). Relational reinforcement learning applied to shared attention. In Proceedings of 2009 international joint conference on neural networks (p. 2943-2949). Atlanta, Georgia, USA: IEEE.

Silva, R. R., Policastro, C. A., Zuliani, G., Pizzolato, E., \& Romero, R. A. F. (2008). Concept learning by human tutelage for social robots. Learning and Nonlinear Models, 6(4), 44-67.

Silva, R. R., \& Romero, R. A. F. (n.d.). Modelling shared attention through relational reinforcement learning. Journal of Intellingent and Robotic Systems.

Staudte, M., \& Crocker, M. (2011). Investigating joint attention mechanisms through spoken human-robot interaction. Cognition, 120(2), 268-291.

Sumioka, H., Yoshikawa, Y., \& Asada, M. (2008). Learning of joint attention from detecting causality based on transfer entropy. Journal of Robotics and Mechatronics, 20, 378-385.

Sumioka, H., Yoshikawa, Y., \& Asada, M. (2010). Reproducing interaction contingency toward open-ended development of social actions: Case study on joint attention. IEEE Transactions on autonomous mental development, 2, 40-50.

Sutton, R., \& Barto, A. (1998). Reinforcement learning: An introduction. MIT Press.

Tan, P., Steinbach, M., \& Kumar, V. (2005). Introduction to data mining,. Boston, MA, USA: Addison-Wesley Longman Publishing Co.

Team, R. C. (2012). R: A language and environment for statistical computing [Computer software manual]. Vienna, Austria. Available from http://www.R-project.org (ISBN 3-900051-07-0)

Tenenbaum, J. B., Silva, V. d., \& Langford, J. C. (2000). A global geometric framework for nonlinear dimensionality reduction. Science, 290(5500), 2319-2323.

Thomaz, A., Berlin, M., \& Breazeal, C. (2005, aug.). An embodied computational model of social referencing. In Proceedings of international workshop on robot and human interactive communication. IEEE.

Tomasello, M. (1995). Joint attention as social cognition. Joint attention Its origins and role in development, 5(16), 103-130. 
Tomasello, M., Carpenter, M., Call, J., Behne, T., \& Moll, H. (2005). Understanding and sharing intentions: The origins of cultural cognition. Behavioral and Brain Sciences, 28, $376-735$.

Trafton, J. G., Harrison, A. M., Fransen, B., \& Bugajska, M. (2009). An embodied model of infant gaze-following. In Proceedings of international conference of cognitive modeling.

Triesch, J., Teuscher, C., Deák, G., \& Carlson, E. (2006). Gaze following: why (not) learn it? Developmental Science, 9(2), 125 - 147.

Viola, P. A., \& Jones, M. J. (2001). Rapid object detection using a boosted cascade of simple features. In $C v p r(1)$ (p. 511-518). IEEE Computer Society. Available from http://dblp.uni-trier.de/db/conf/cvpr/cvpr2001-1.html\#ViolaJ01

Voit, M., Nickel, K., \& Stiefelhagen, R. (2007). Neural network-based head pose estimation and multi-view fusion. In Proceedings of the 1st international evaluation conference on classification of events, activities and relationships (pp. 291-298). Berlin, Heidelberg: Springer-Verlag.

Wang, J.-G., \& Sung, E. (2007, December). Em enhancement of 3d head pose estimated by point at infinity. Image Vision Comput., 25(12), 1864-1874.

Watkins, C. J. C. H. (1989). Learning from delayed rewards. Doctoral dissertation, University of Cambridge.

Whalen, C., \& Schreibman, L. (2003). Joint attention training for children with autism using behavior modification procedures. Journal of Child Psychology and Psychiatry, 44(3), $456-468$.

Yao, P., Evans, G., \& Calway, A. D. (2001). Using affine correspondence to estimate 3-d facial pose. In International conference on image processing (Vol. 13, p. 919-922). IEEE.

Yoshikawa, Y., Shinozawa, K., Ishiguro, H., Hagita, N., \& Miyamoto, T. (2006). Responsive robot gaze to interaction partner. In Proceedings of robotics: Science and systems.

Yucel, Z., Salah, A., Merigli, C., \& Mericli, T. (2009, sept.). Joint visual attention modeling for naturally interacting robotic agents. In 24 proceedings of the international symposium on computer and information sciences (p. 242 -247). 
Zhang, Z., Hu, Y., Liu, M., \& Huang, T. (2007). Head pose estimation in seminar room using multi view face detectors. In Proceedings of the 1st international evaluation conference on classification of events, activities and relationships (pp. 299-304). Berlin, Heidelberg: Springer-Verlag.

Zhao, L., Pingali, G., \& Carlbom, I. (2002). Real-time head orientation estimation using neural networks. In International conference on image processing (Vol. 1, p. I-297 - I-300). 


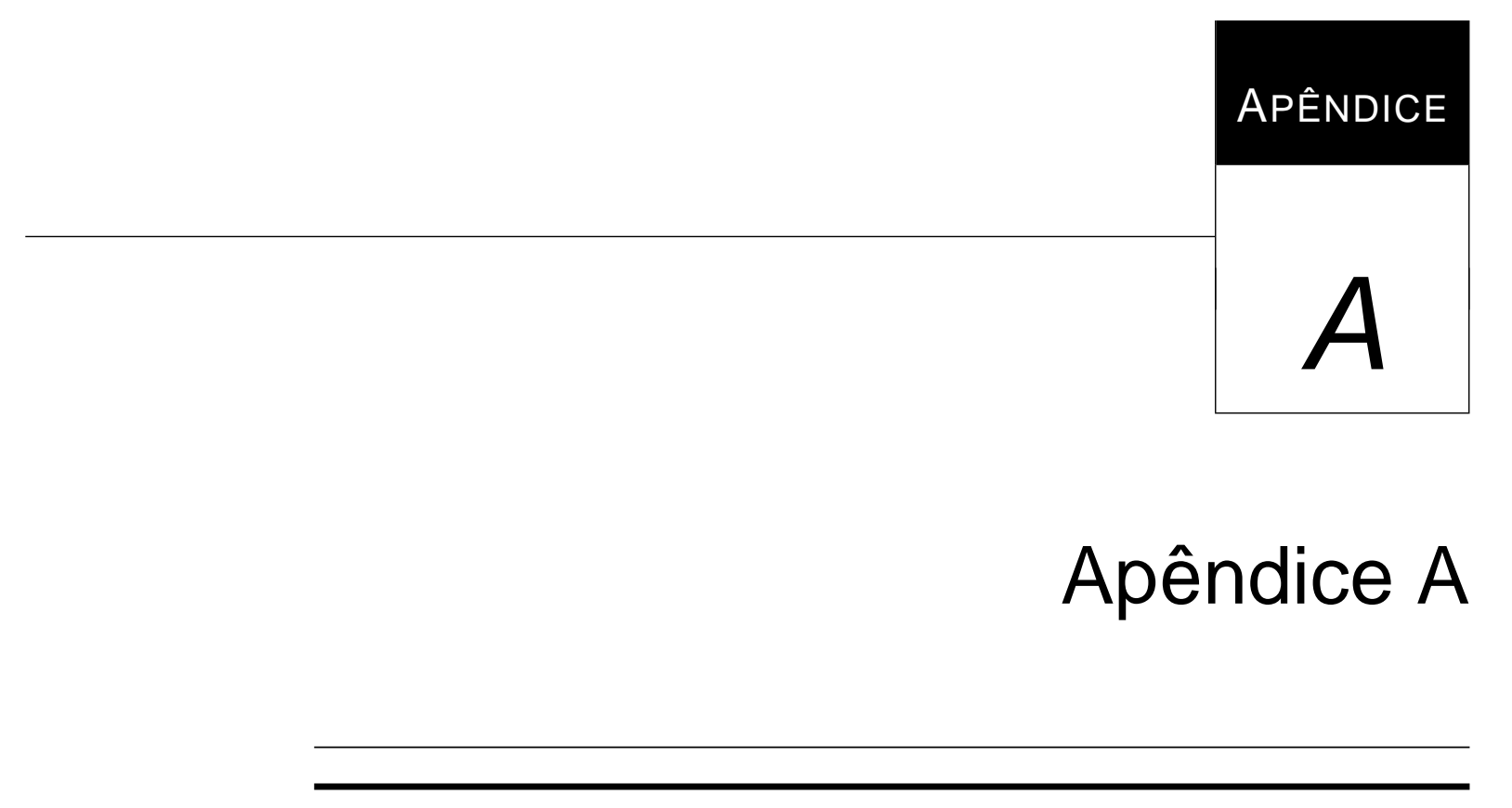

\section{A.1 Resultado dos testes sobre o módulo de identidade pes- Soal}

\section{A.1.1 Experimento 1}

As Figuras A.1, A.2, A.3 e A.4 mostram de forma separada cada uma das curvas da Figura 5.5. Elas representam as curvas da variação dos níveis de antecipação-surpresa, medo-raiva, alegria-tristeza e confiança-desgosto, respectimanente.

As Figuras A.5, A.6 e A.7 mostram o que acontece na parte intermediaria dos experimentos.

O fluxo do nível energia permanece o mesmo e o humor tem uma flutuação de acordo com a história de interação. O nível de atenção e diversão segue o mesmo padrão, porque possui uma dependência dos fatores externos. Nesse caso, com uma sequencia padrão de situações adotada durante todo o experimento, sem adoção de nenhuma aleatoriedade, os resultados apresentados já eram esperados. 


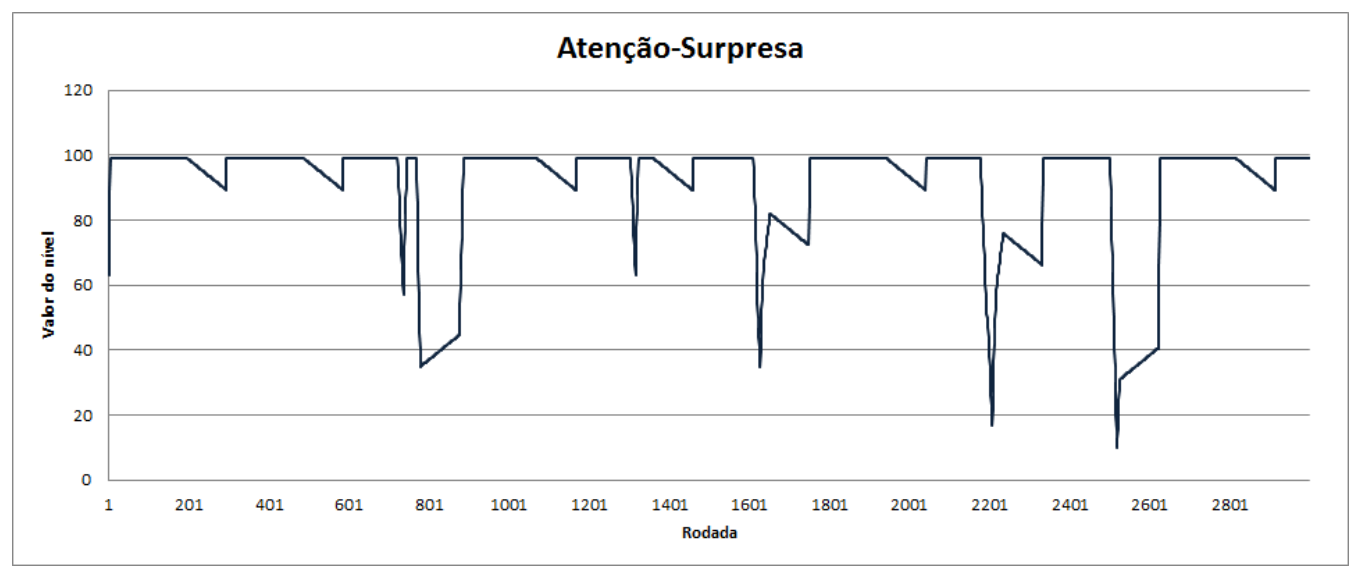

Figura A.1: Resultado obtido das primeiras 3000 rodadas da barra antecipação-surpresa. Ele representa a variação do nível da barra.

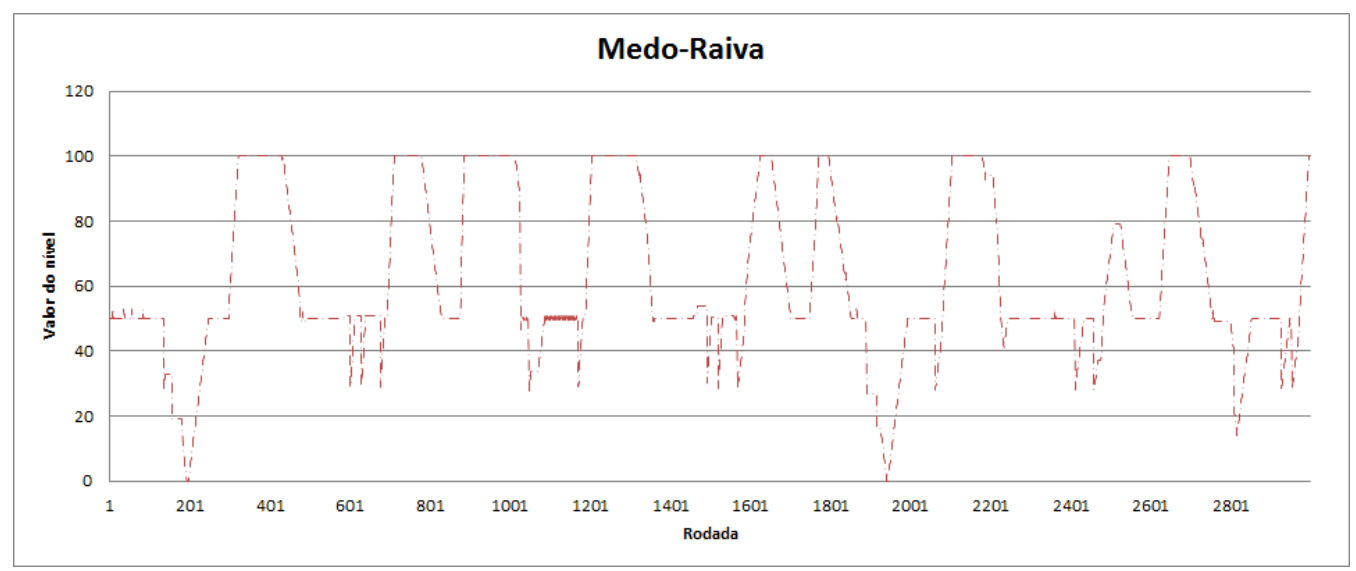

Figura A.2: Resultado obtido das primeiras 3000 rodadas da barra medo-raiva. Ele representa a variação do nível da barra.

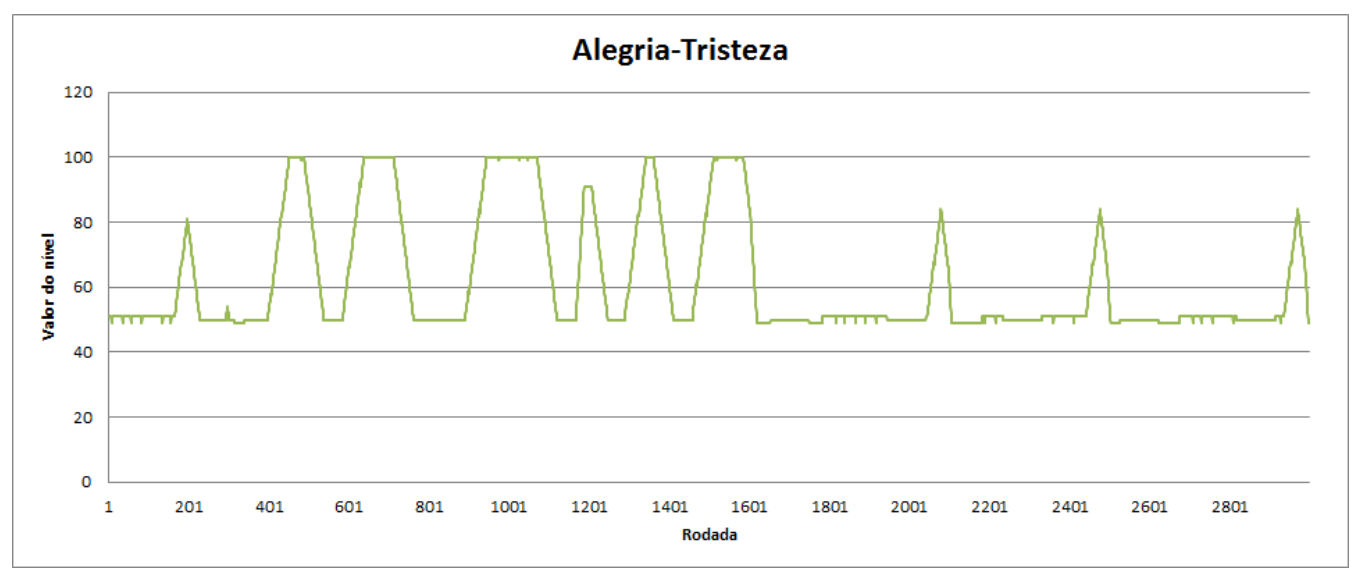

Figura A.3: Resultado obtido das primeiras 3000 rodadas da barra alegria-tristeza. Ele representa a variação do nível da barra.

Os níveis que compõem a emoção são mantidos na mesma base, com uma flutuação dos componentes, tal como apresentado na Figura A.7. O nível da barra AS se mantem na 


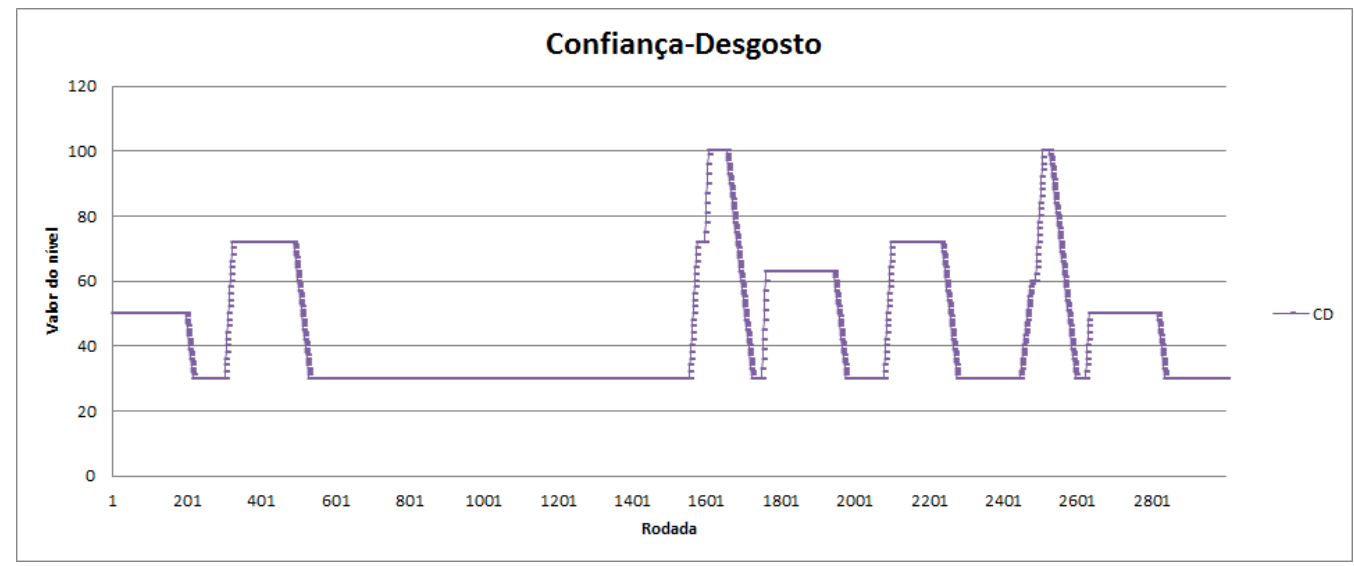

Figura A.4: Resultado obtido das primeiras 3000 rodadas da barra confiança-desgosto. Ele representa a variação do nível da barra.

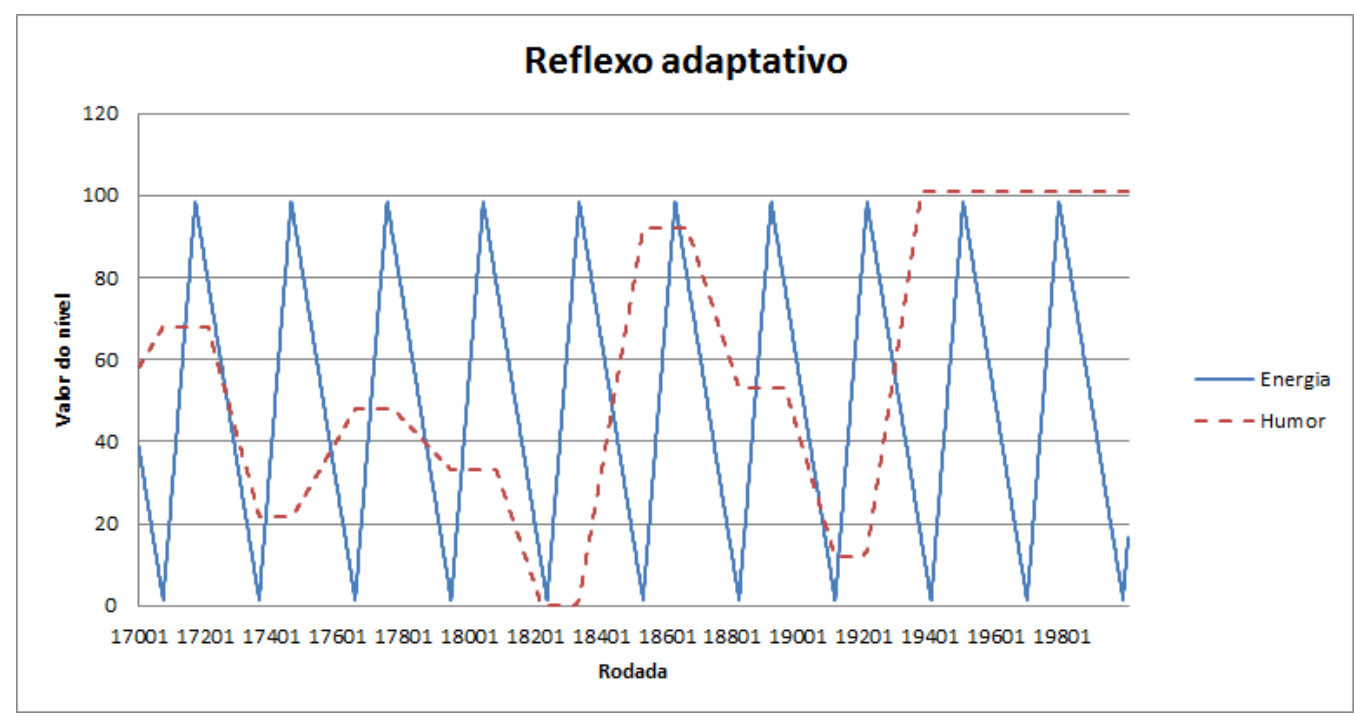

Figura A.5: Resultado da parte intermediaria dos experimentos dos elementos energia e humor. As rodadas que foram consideradas estão entre 17001 e 20000.

maior parte do período com valores máximos de antecipação, mas com um pouco mais de tempo no nível da barra surpresa e, em alguns casos, atinge ou permanece próximo ao valor máximo de surpresa. O nível da barra AT permanece mais tempo no sentimento de tristeza e obtém o valor máximo de tristeza uma vez, mas na maior parte do tempo o nível permanece no valor intermediário e na parte da alegria. As variações dos níveis da barra $\mathrm{MR}$ e $\mathrm{CD}$ não apresentaram grandes mudanças, apenas o fato de que, somente uma vez, o nível da barra confiança chegou perto de valor máximo.

As Figuras A.8, A.9, A.10 e A.11 mostram de forma separada cada uma das curvas da Figura A.7 Elas representam as curvas da variação dos níveis de antecipação-surpresa, medo-raiva, alegria-tristeza e confiança-desgosto, respectimanente. 


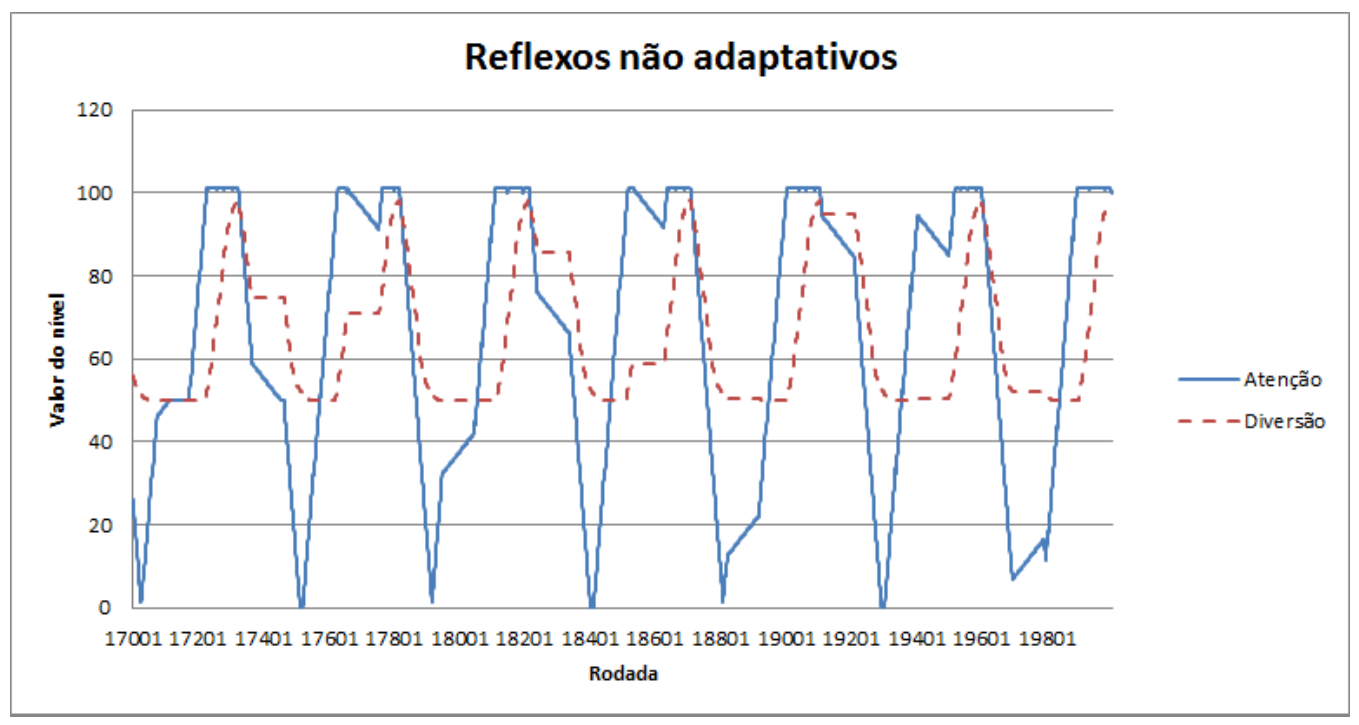

Figura A.6: Resultado da parte intermediaria dos experimentos dos elementos atenção e diversão. As rodadas que foram consideradas estão entre 17001 e 20000.

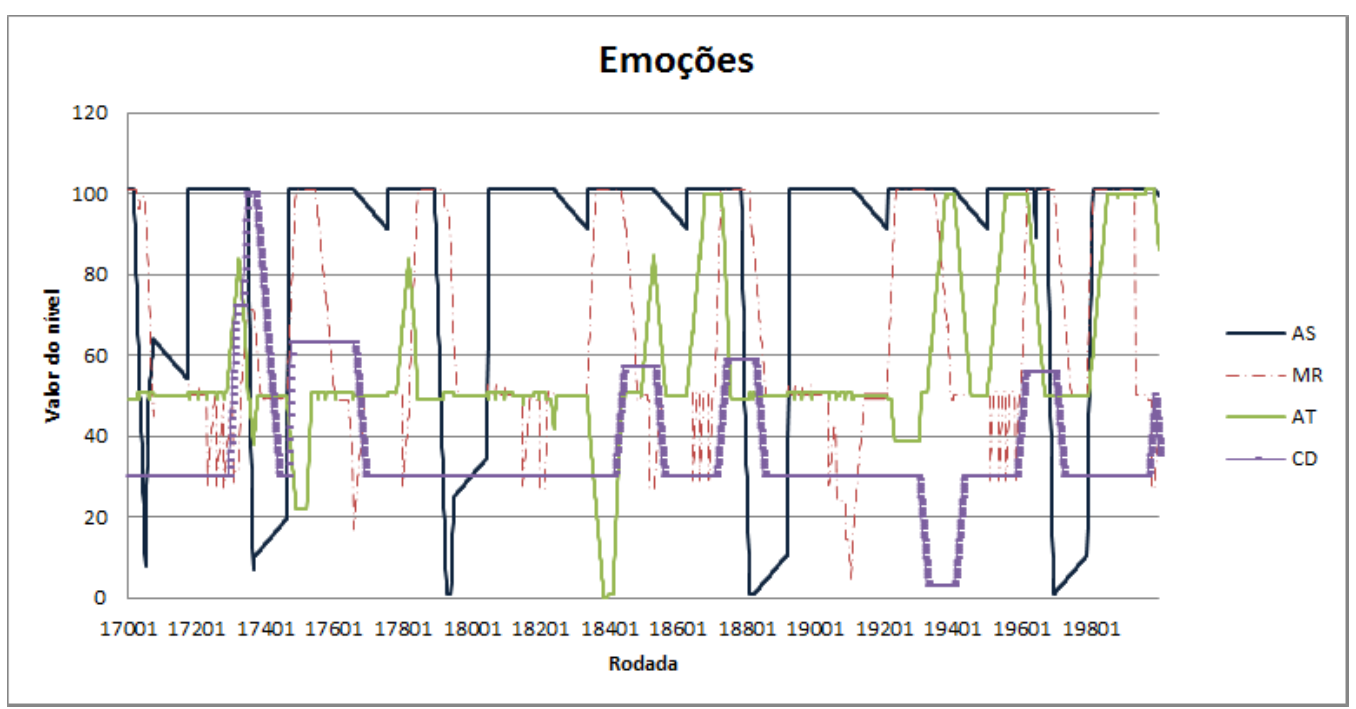

Figura A.7: Resultado da parte intermediaria dos experimentos do elemento emoção. As rodadas que foram consideradas estão entre 17001 e 20000.

Nos últimos 3000 ciclos, os elementos de reflexo adaptativos e não-adaptativos seguem os padrões dos níveis obtidos nas iterações iniciais e outros partes subsequentes, como mostrado acima, e estão representados nas Figuras A.12 e A.13.

As Figuras A.14, A.15, A.16 A.17mostram de forma separada cada uma das curvas da Figura 5.6. Elas representam as curvas da variação dos níveis de antecipação-surpresa, medo-raiva, alegria-tristeza e confiança-desgosto, respectimanente. 


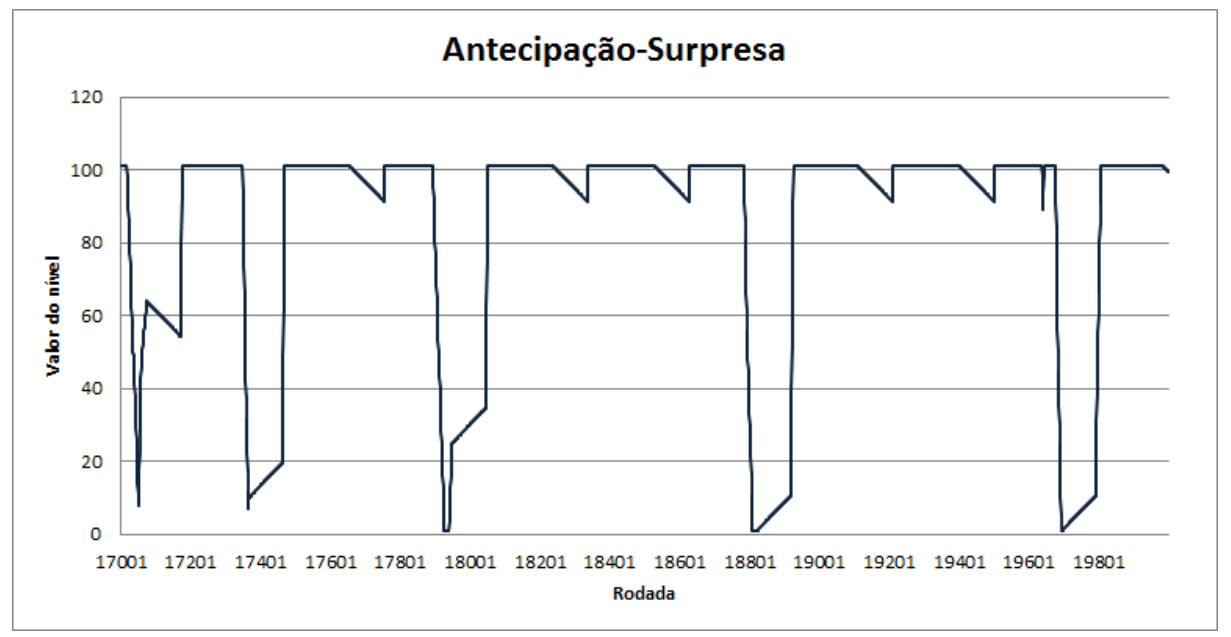

Figura A.8: Resultado da parte intermediaria dos experimentos da barra antecipação-surpresa. Ele representa a variação do nível da barra.

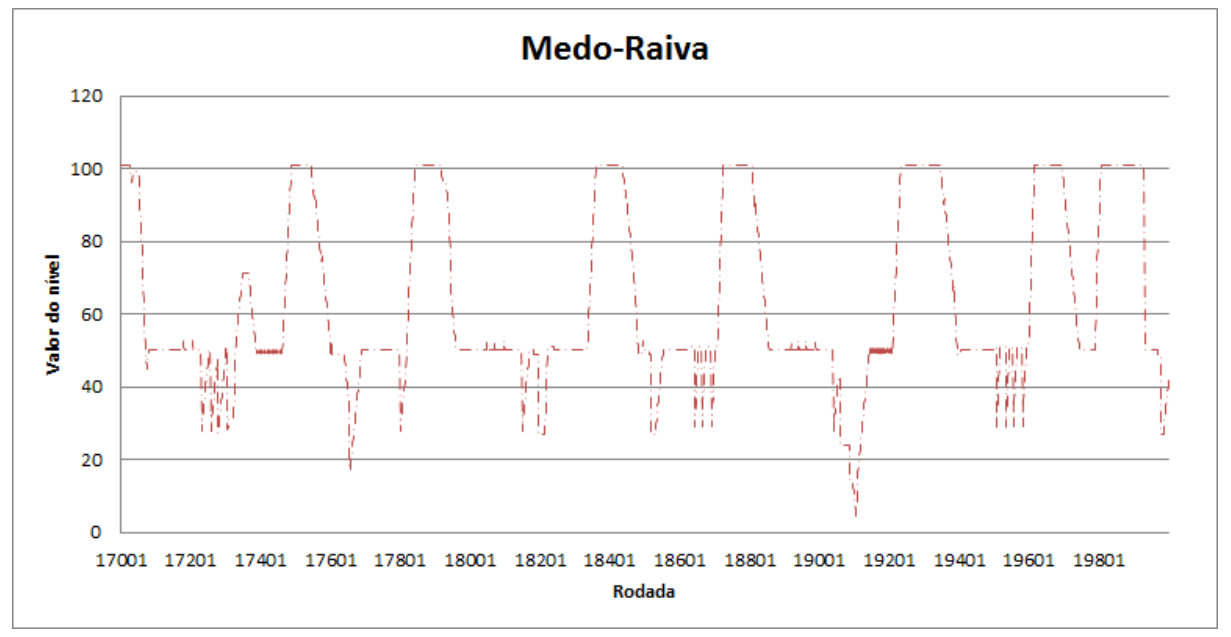

Figura A.9: Resultado da parte intermediaria dos experimentos da barra medo-raiva. Ele representa a variação do nível da barra.

\section{A.1.2 Experimento 2}

As Figuras A.18, A.19 A.20 e A.21 mostram de forma separada cada uma das curvas da Figura 5.9. Elas representam as curvas da variação dos níveis de antecipação-surpresa, medo-raiva, alegria-tristeza e confiança-desgosto, respectimanente.

Seguindo a mesma metodologia utilizada no Experimento 1, é apresentado os resultados dos valores intermediários. O humor permanece a maior parte do tempo no nível mais baixo, atingindo o valor nível mínimo com alguns picos no nível de bom humor, como pode ser visto na Figura A.22, O nível de atenção e diversão, na Figura A.23, continua com o mesmo padrão, refletindo a dependência dos fatores externos. 


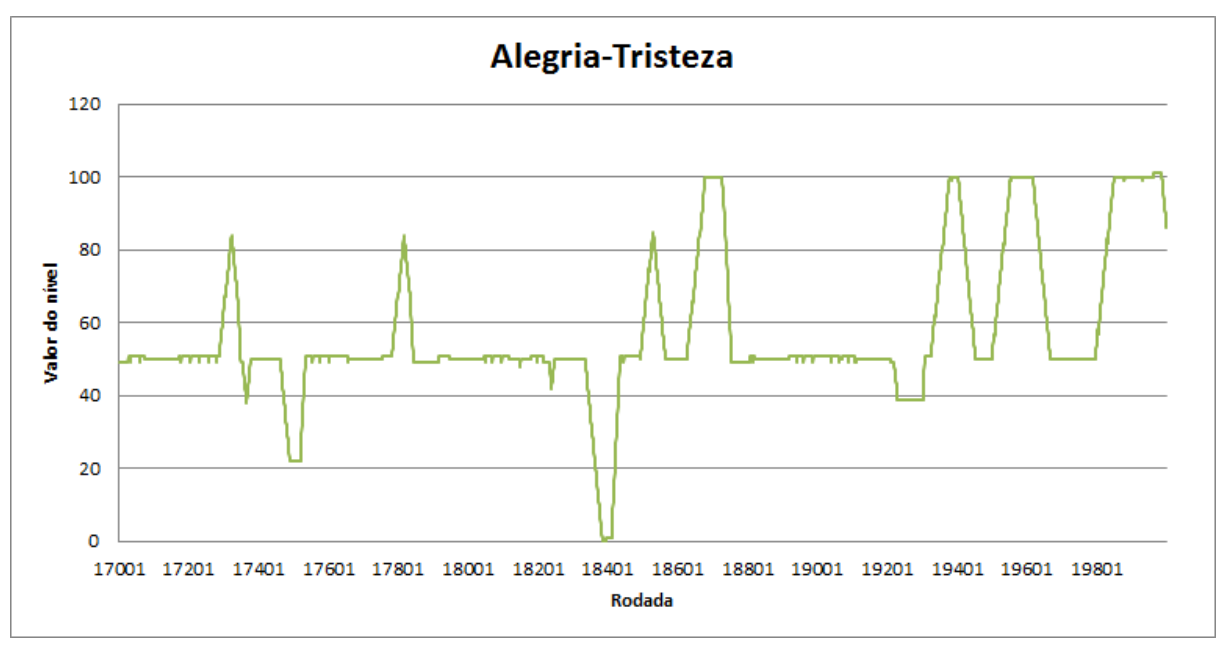

Figura A.10: Resultado da parte intermediaria dos experimentos da barra alegria-tristeza. Ele representa a variação do nível da barra.

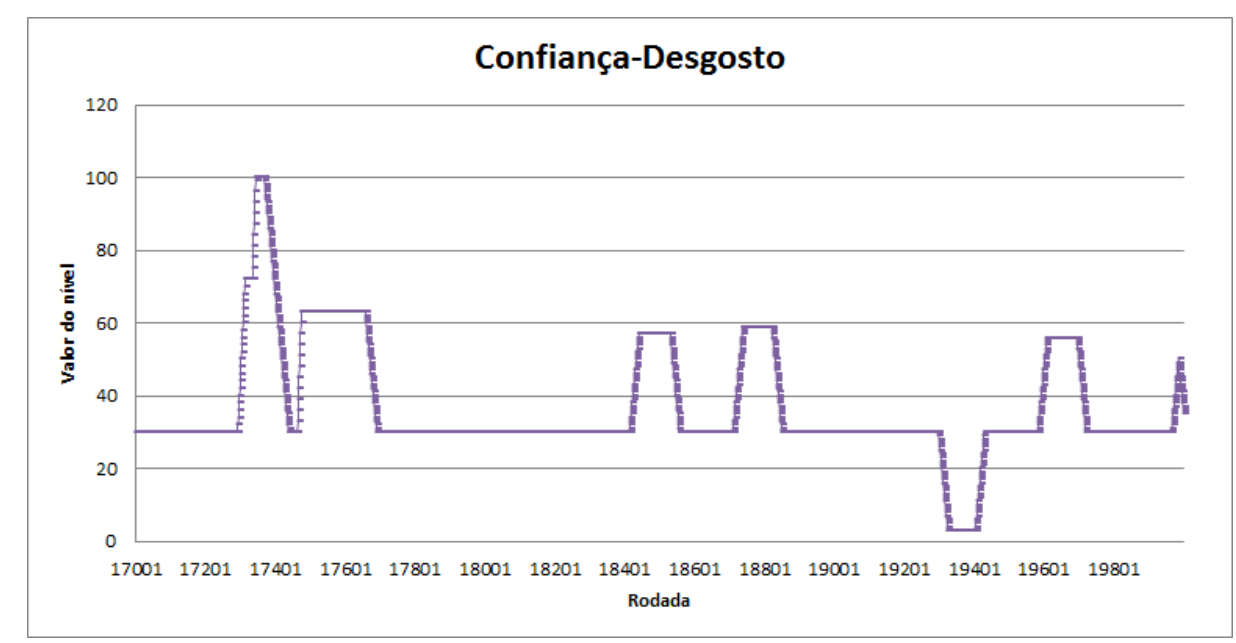

Figura A.11: Resultado da parte intermediaria dos experimentos da barra confiança-desgosto. Ele representa a variação do nível da barra.

O desempenho de todos os níveis que fazem parte de emoções nas posições intermediárias são apresentados na Figura A.24. O nível da barra AS tem desempenho semelhante ao das interações iniciais. O padrão de oscilação mantém um padrão e que pode ser confirmando nos resultados das últimas três mil rodadas, apresentados na Figura 5.10, No caso do nível da barra $\mathrm{MR}$, o nível continua atingindo o valor máximo de medo, mas com menor intensidade. Além disso, ao atingir valores próximos ao intermediário, a permanecia nessa região é maior. A maior diferença entre os valores obtidos no início e nas posições intermediárias, está no nível da barra AT O nível flutua entre o valor máximo de tristeza, sendo que em alguns momentos o valor máximo é atingido. No entanto, o nível permanece por mais tempo no valor intermediário. O nível da barra $\mathrm{CD}$ permanência na maior parte do tempo em nível de 


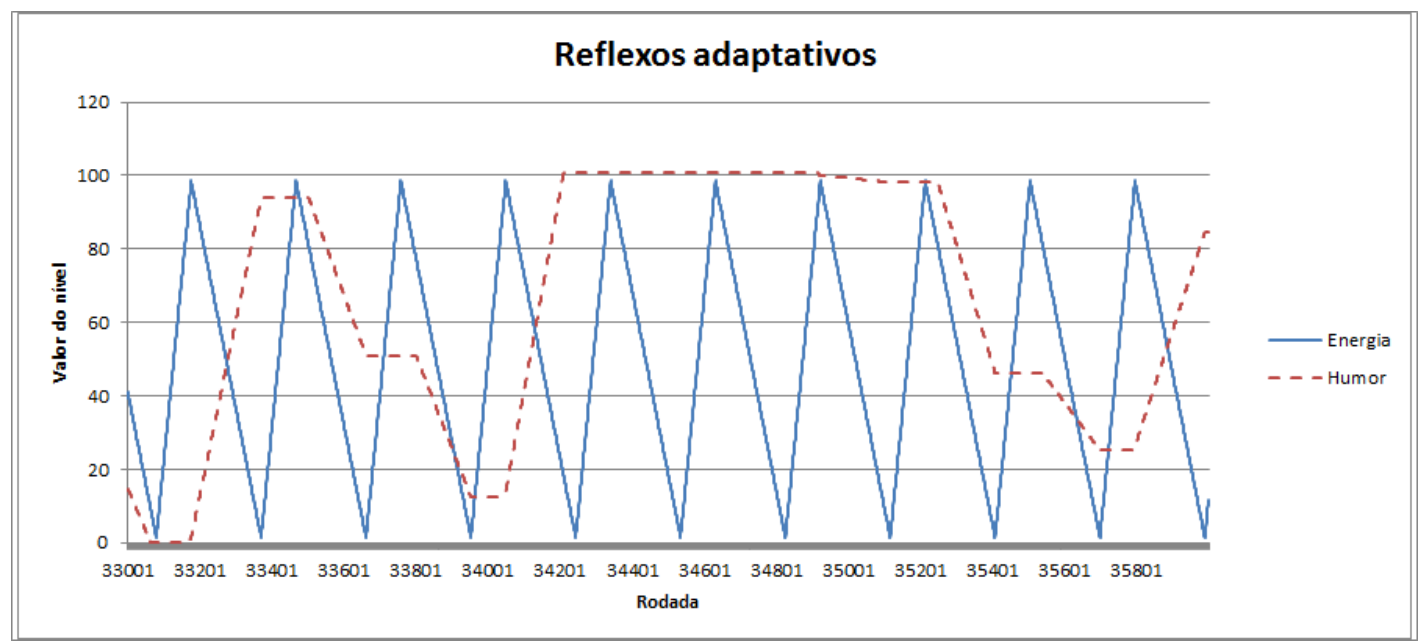

Figura A.12: Resultado das últimas 3000 rodadas dos elementos energia e humor.

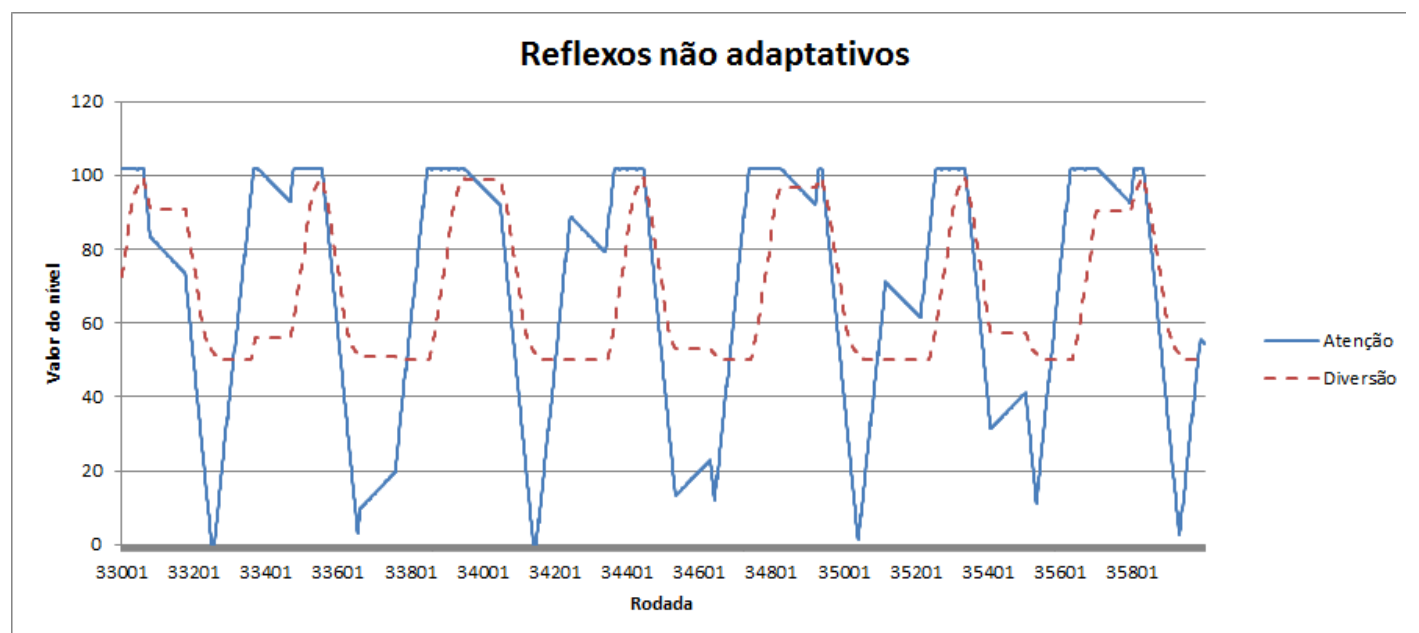

Figura A.13: Resultado das últimas 3000 rodadas dos elementos atenção e diversão.

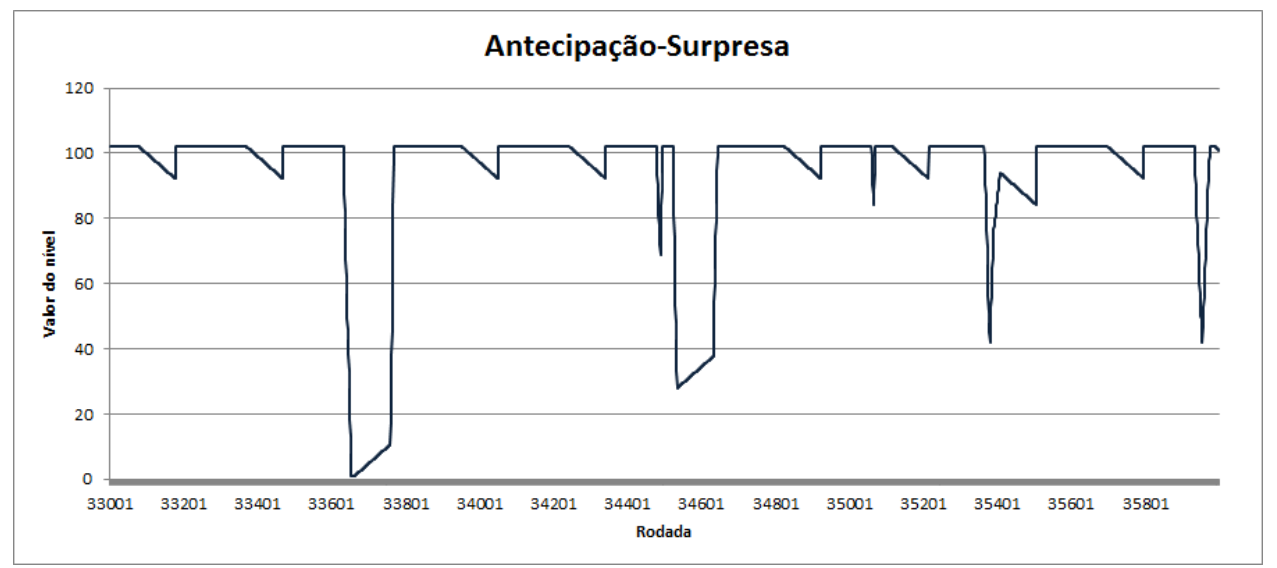

Figura A.14: Resultado das últimas 3000 rodadas da barra antecipação-surpresa. Ele representa a variação do nível da barra. 


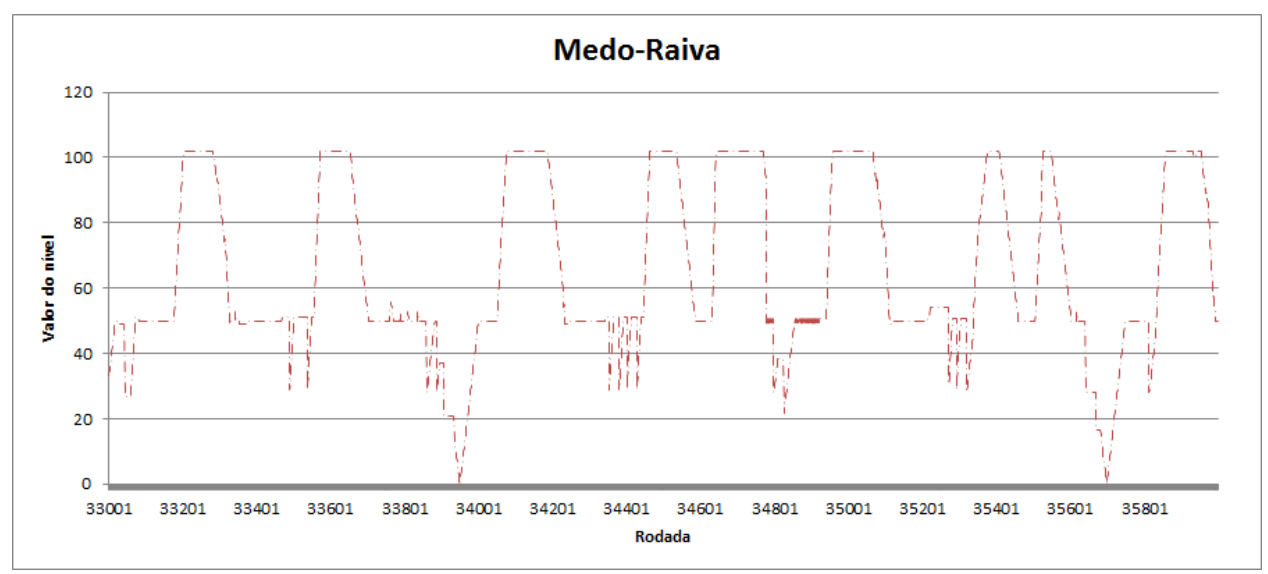

Figura A.15: Resultado das últimas 3000 rodadas da barra medo-raiva. Ele representa a variação do nível da barra.

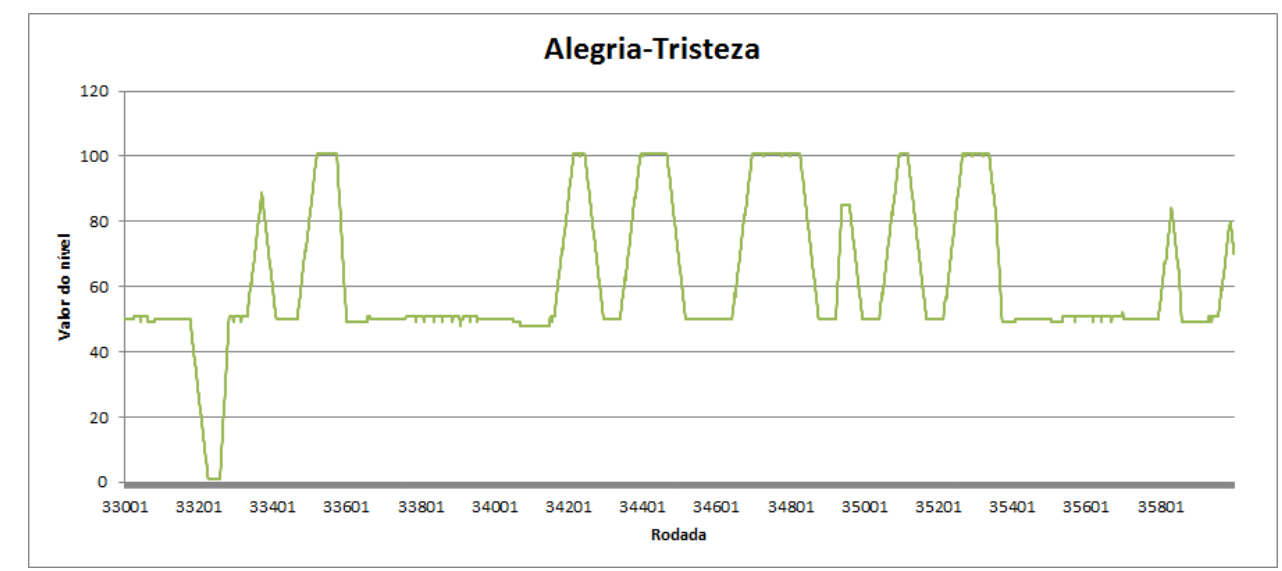

Figura A.16: Resultado das últimas 3000 rodadas da barra alegria-tristeza. Ele representa a variação do nível da barra.

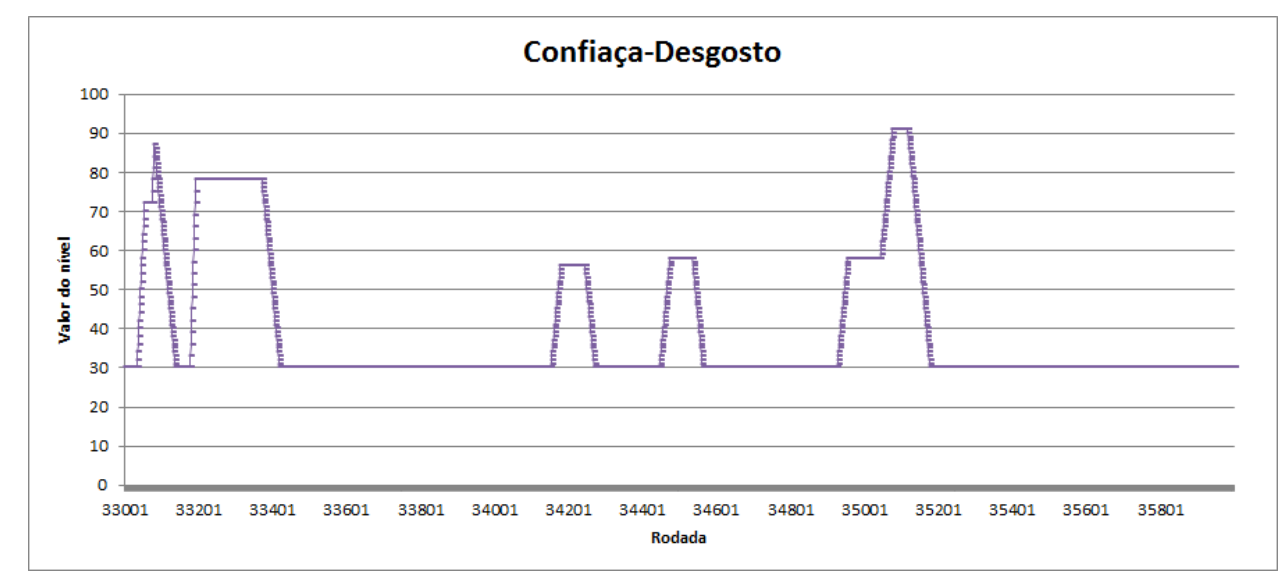

Figura A.17: Resultado das últimas 3000 rodadas da barra confiança-desgosto. Ele representa a variação do nível da barra.

desgosto próximo ao valor intermediário, com algumas pequenas flutuações sobre o mesmo atingindo níveis pequenos de confiança. 


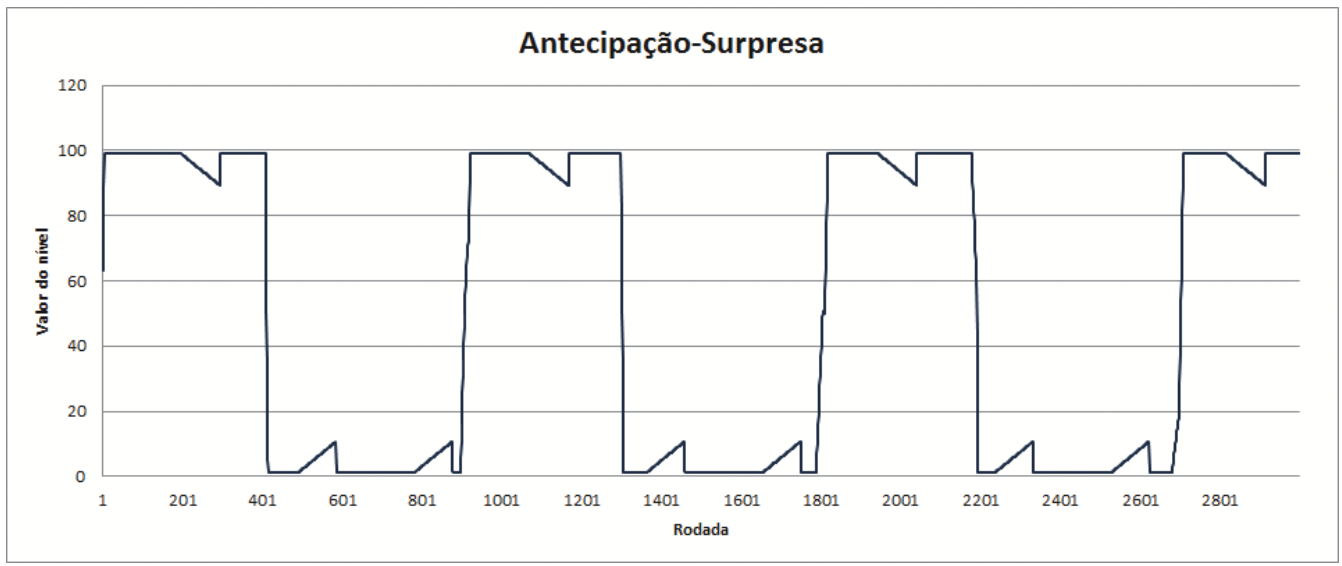

Figura A.18: Resultado obtido das primeiras 3000 rodadas da barra antecipação-surpresa. Ele representa a variação do nível da barra.

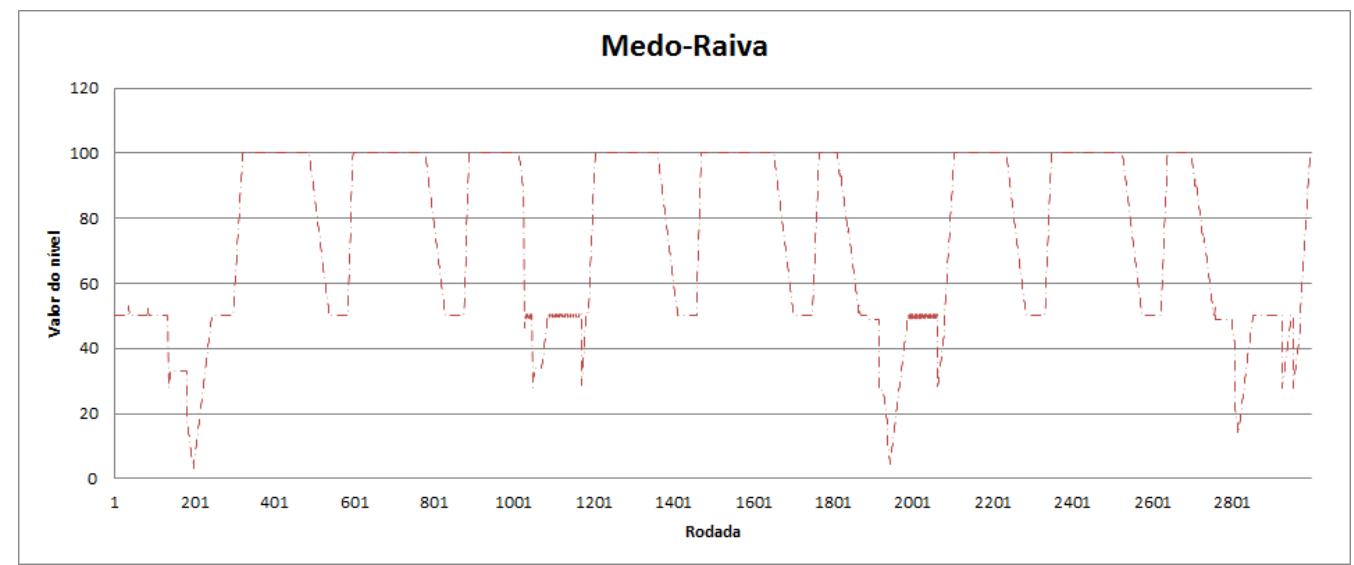

Figura A.19: Resultado obtido das primeiras 3000 rodadas da barra medo-raiva. Ele representa a variação do nível da barra.

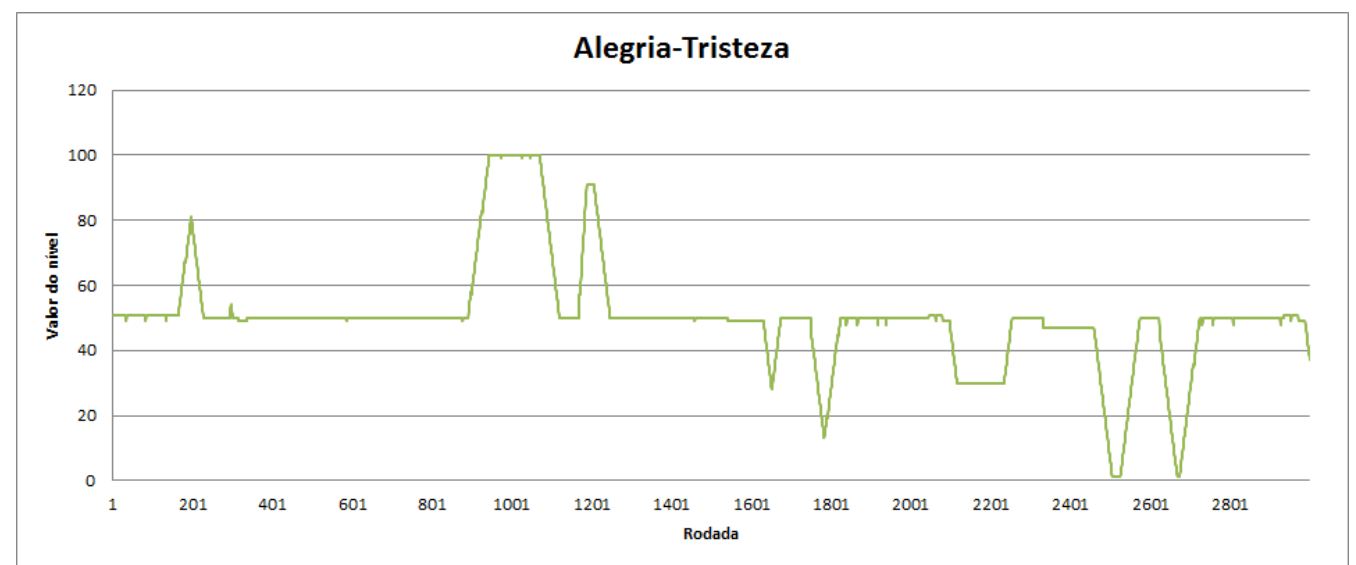

Figura A.20: Resultado obtido das primeiras 3000 rodadas da barra alegria-tristeza. Ele representa a variação do nível da barra.

As Figuras A.25, A.26, A.27 A.28 mostram de forma separada cada uma das curvas da Figura A.24. Elas representam as curvas da variação dos níveis de antecipação-surpresa, 


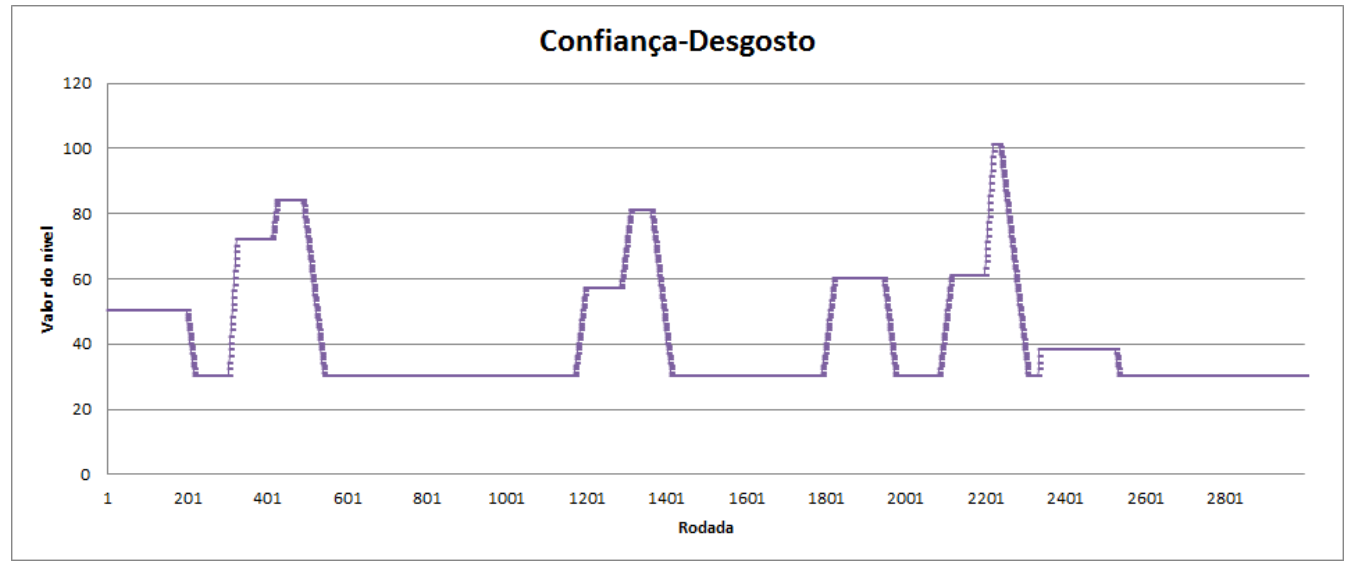

Figura A.21: Resultado obtido das primeiras 3000 rodadas da barra confiança-desgosto. Ele representa a variação do nível da barra.

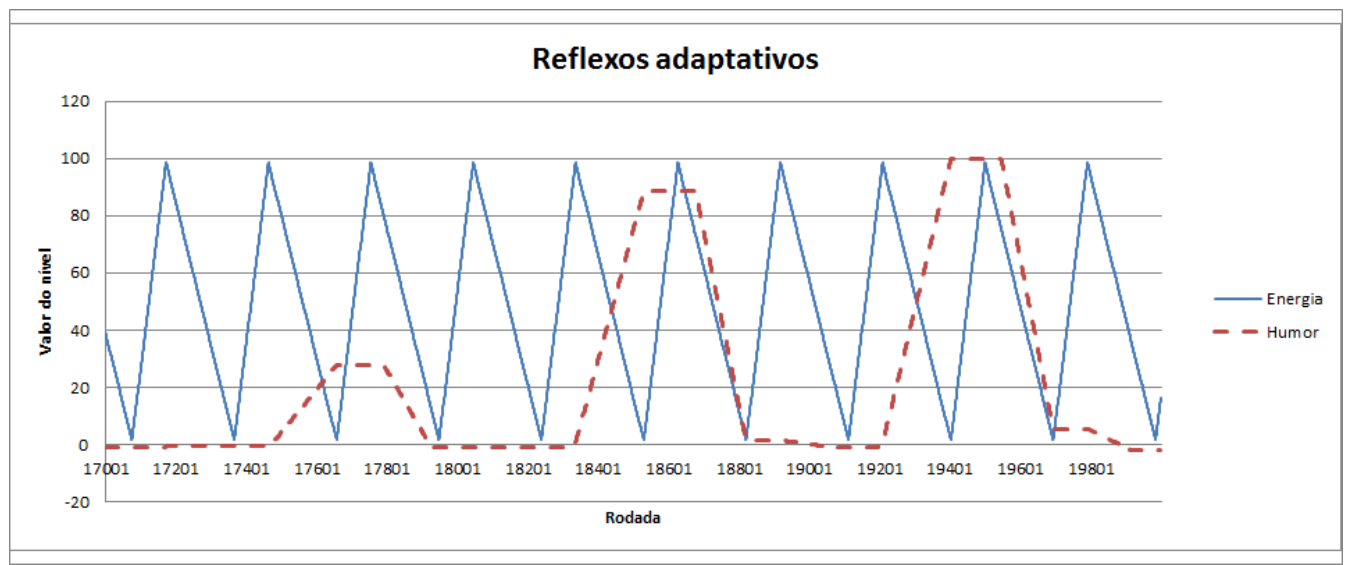

Figura A.22: Resultado da parte intermediaria dos experimentos dos elementos energia e humor. As rodadas que foram consideradas estão entre 17001 e 20000.

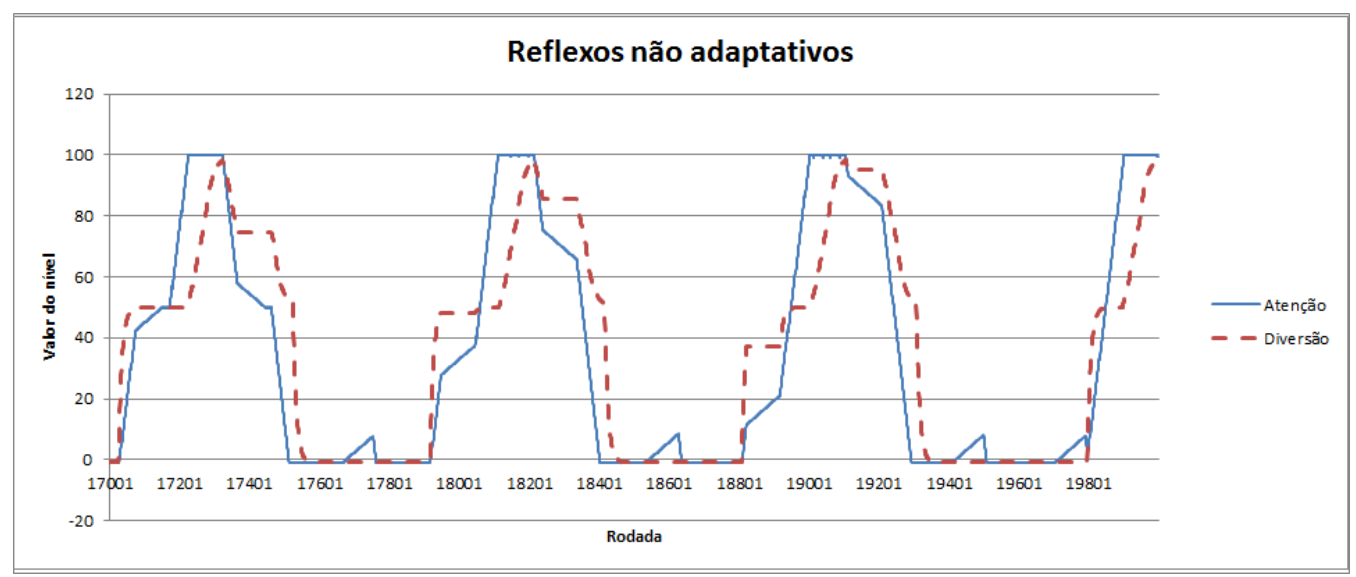

Figura A.23: Resultado da parte intermediaria dos experimentos dos elementos atenção e diversão. As rodadas que foram consideradas estão entre 17001 e 20000.

medo-raiva, alegria-tristeza e confiança-desgosto, respectimanente. 


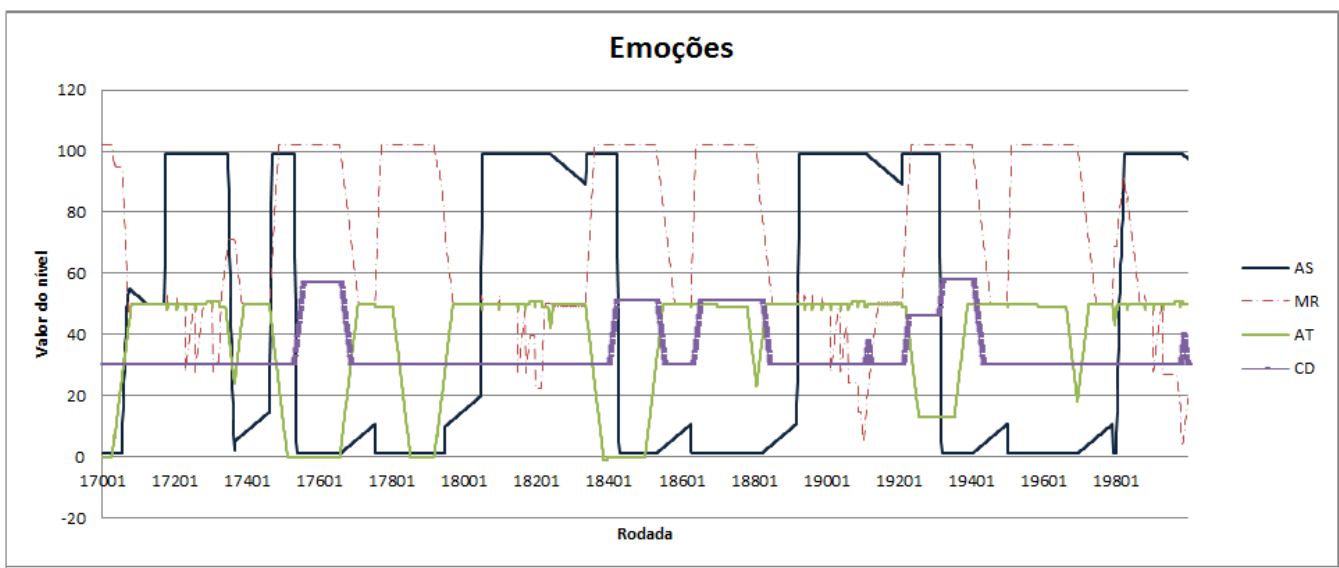

Figura A.24: Resultado da parte intermediaria dos experimentos do elemento emoção. As rodadas que foram consideradas estão entre 17001 e 20000.

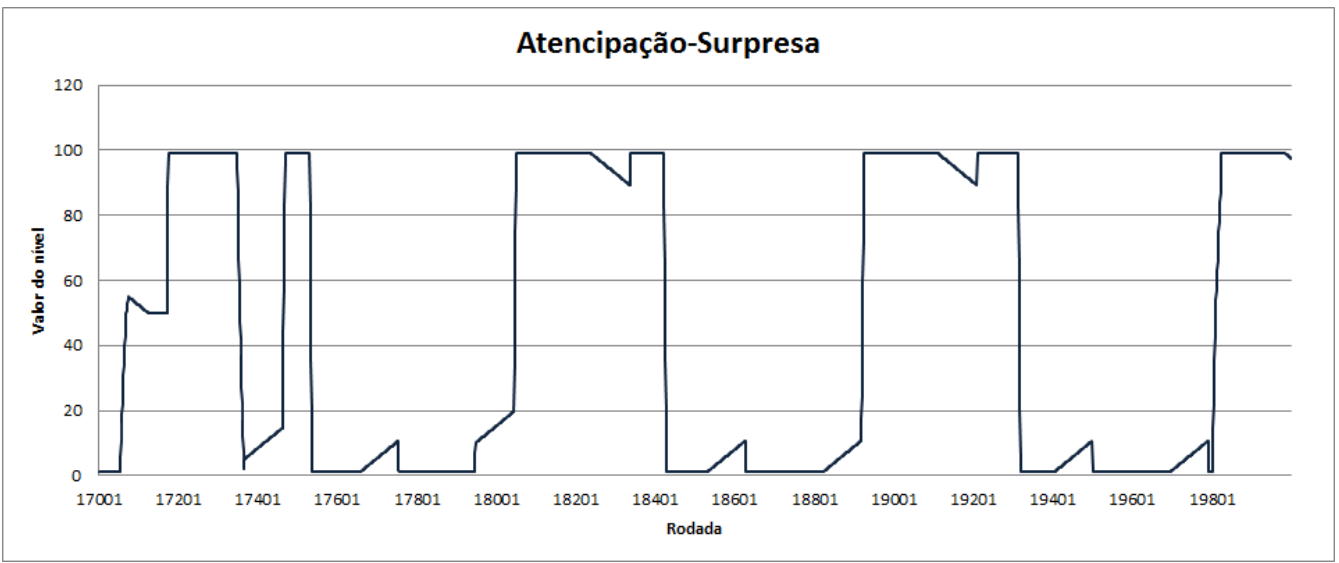

Figura A.25: Resultado da parte intermediaria dos experimentos da barra antecipação-surpresa. Ele representa a variação do nível da barra.

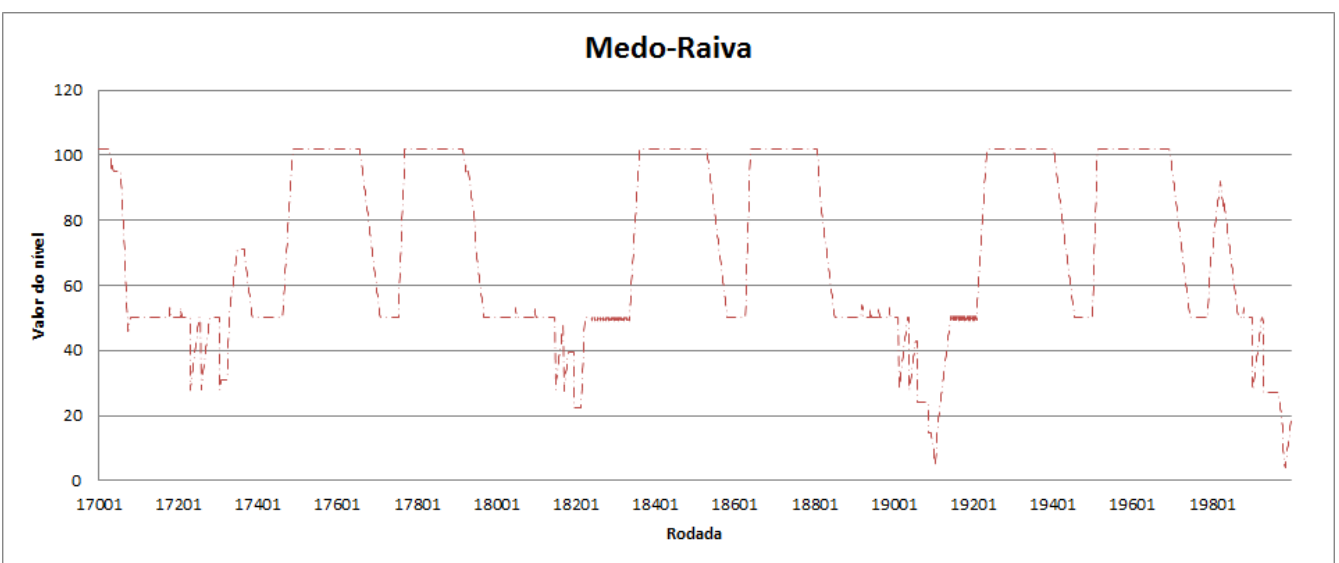

Figura A.26: Resultado da parte intermediaria dos experimentos da barra medo-raiva. Ele representa a variação do nível da barra.

Os resultados obtidos nos últimos três mil ciclos são apresentados nas Figuras A.29, A.30 e 5.10. 


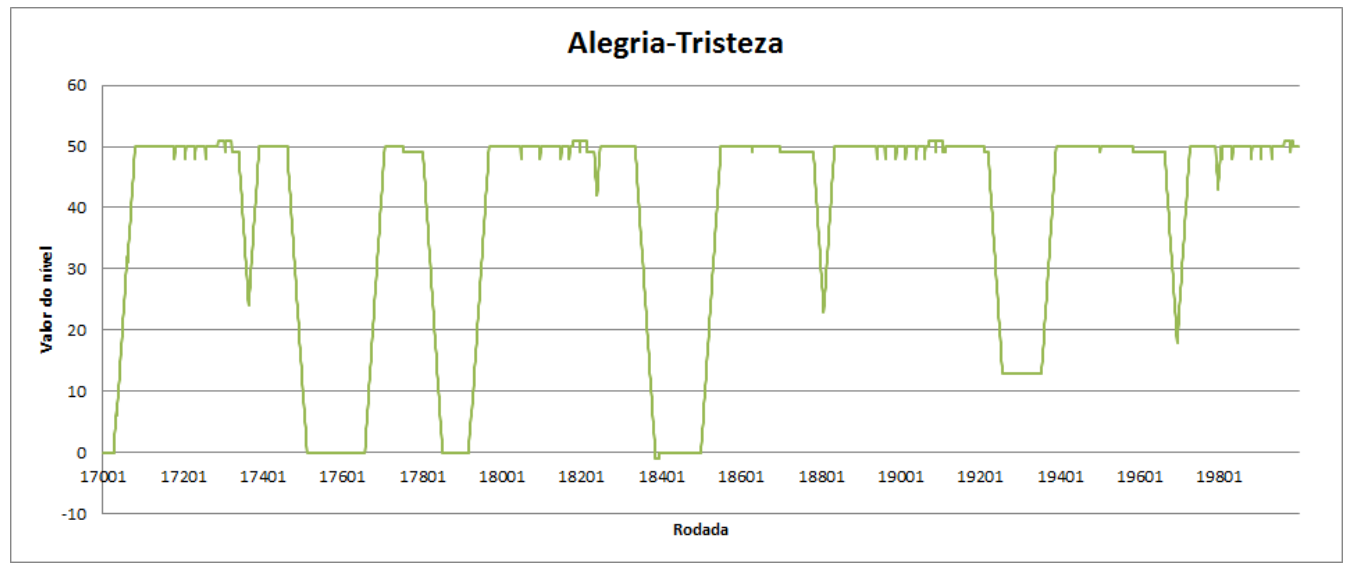

Figura A.27: Resultado da parte intermediaria dos experimentos da barra alegria-tristeza. Ele representa a variação do nível da barra.

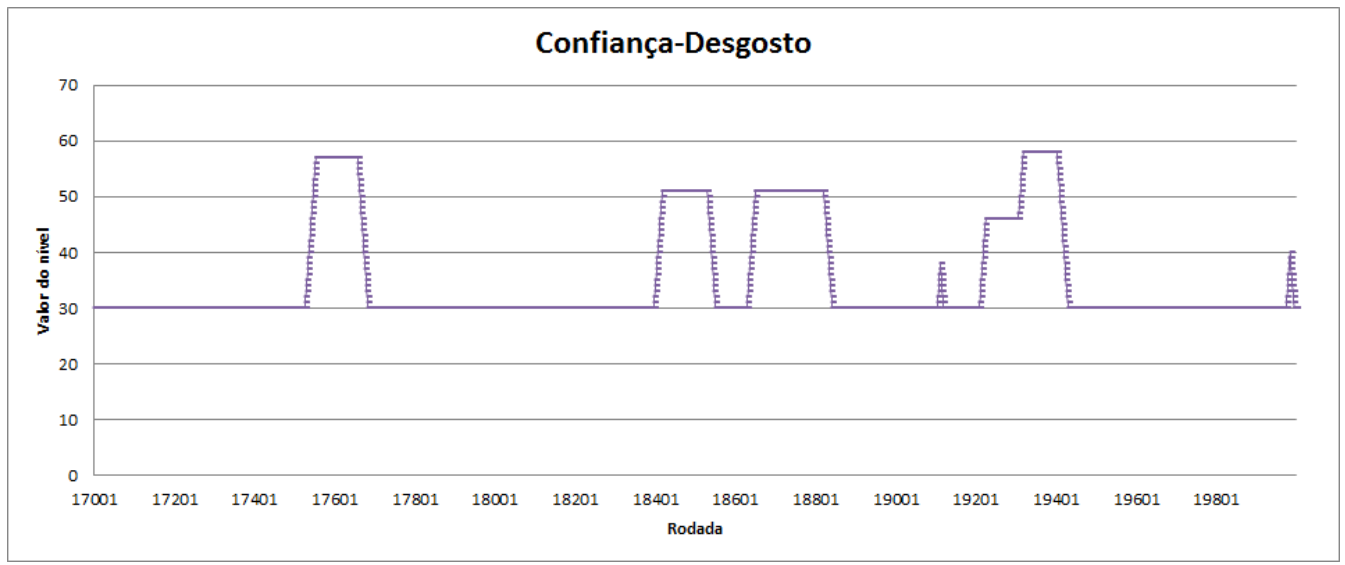

Figura A.28: Resultado da parte intermediaria dos experimentos da barra confiança-desgosto. Ele representa a variação do nível da barra.

A Figura A.29 apresenta uma grande alteração no nível do humor em relação aos demais. O nível permanece no valor mínimo na maior quantidade de tempo, com apenas uma pequena recuperação, e finaliza o experimento com o valor mínimo.

Os valores dos níveis de atenção e diversão seguem o mesmo padrão e não apresentam alterações, como mostra a Figura A.30.

As Figuras A.31, A.32, A.33 e A.34 mostram de forma separada cada uma das curvas da Figura 5.10. Elas representam as curvas da variação dos níveis de antecipação-surpresa, medo-raiva, alegria-tristeza e confiança-desgosto, respectimanente. 


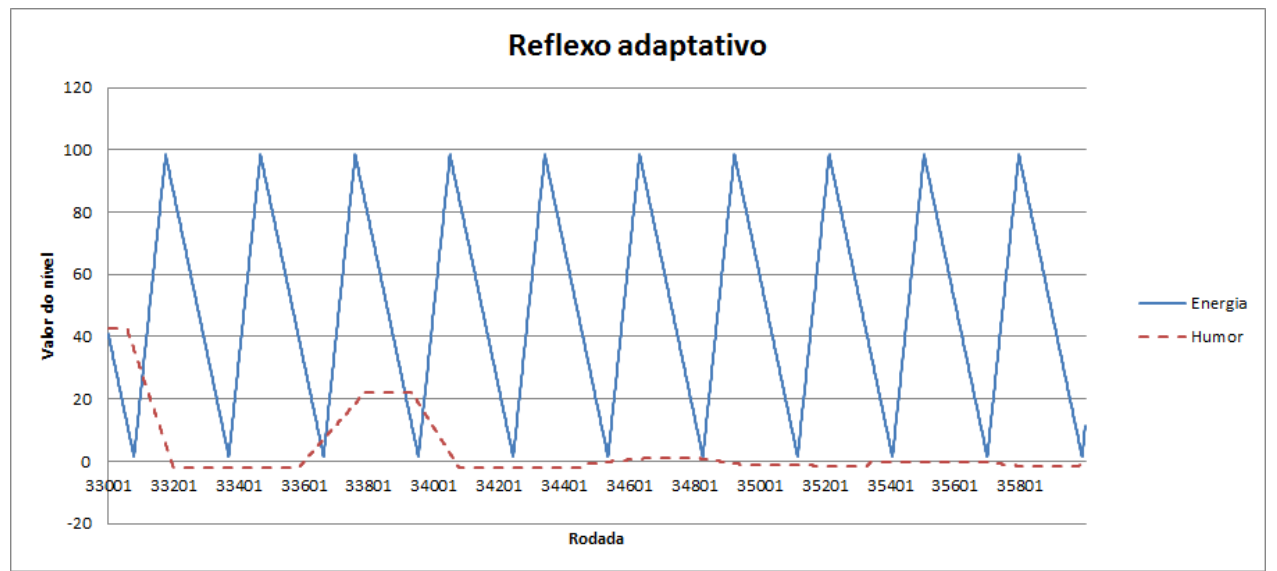

Figura A.29: Resultado das últimas 3000 rodadas dos elementos energia e humor.

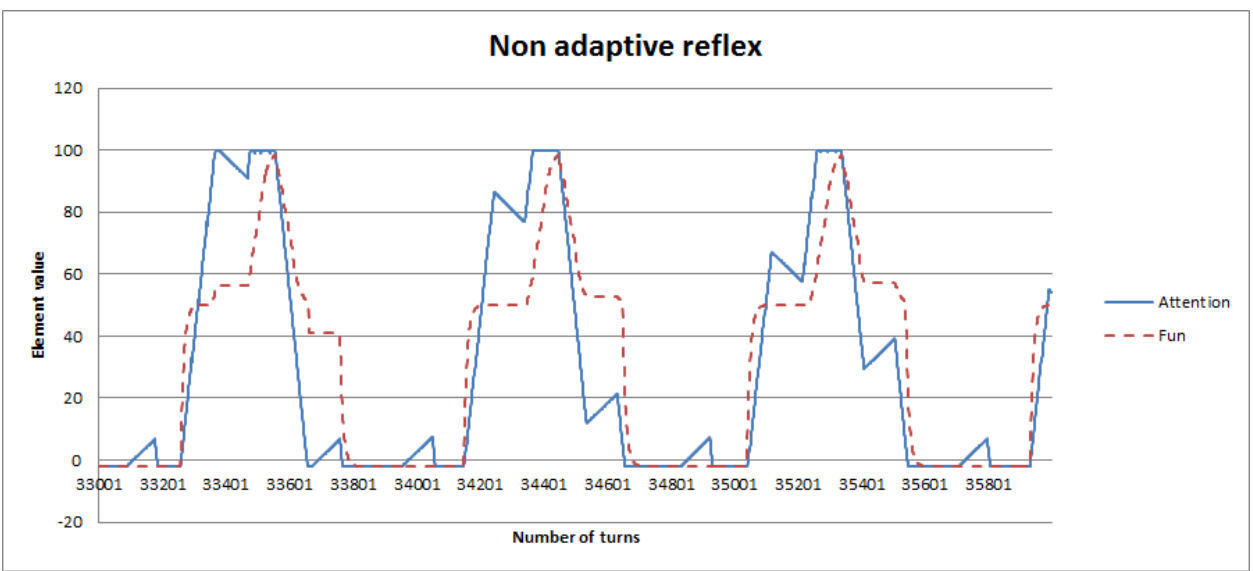

Figura A.30: Resultado das últimas 3000 rodadas dos elementos atenção e diversão.

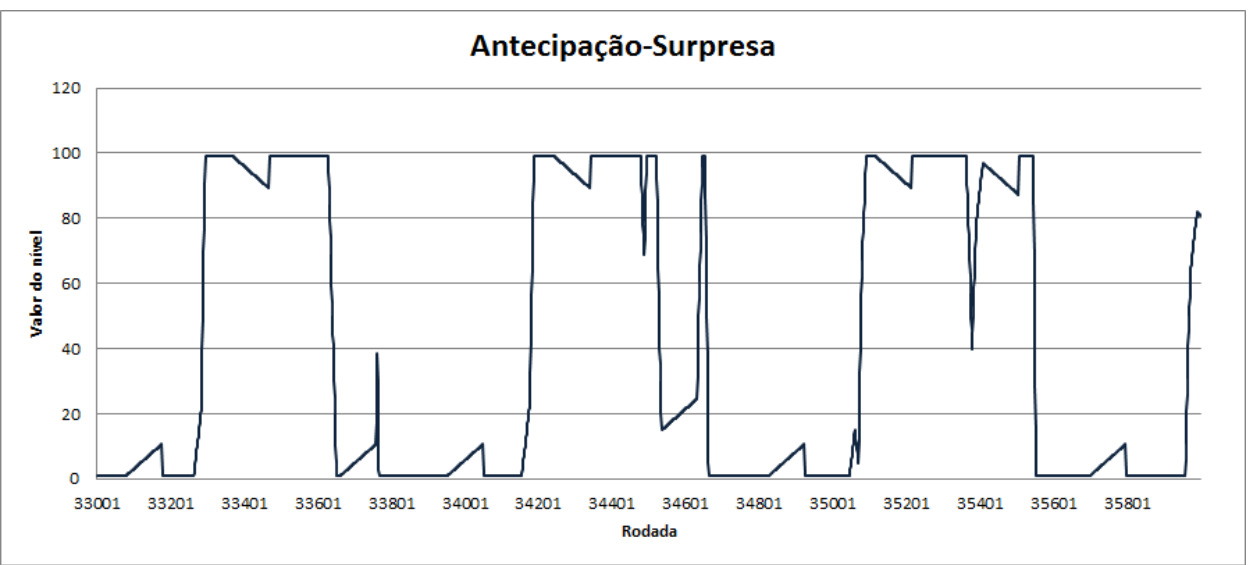

Figura A.31: Resultado das últimas 3000 rodadas da barra antecipação-surpresa. Ele representa a variação do nível da barra. 


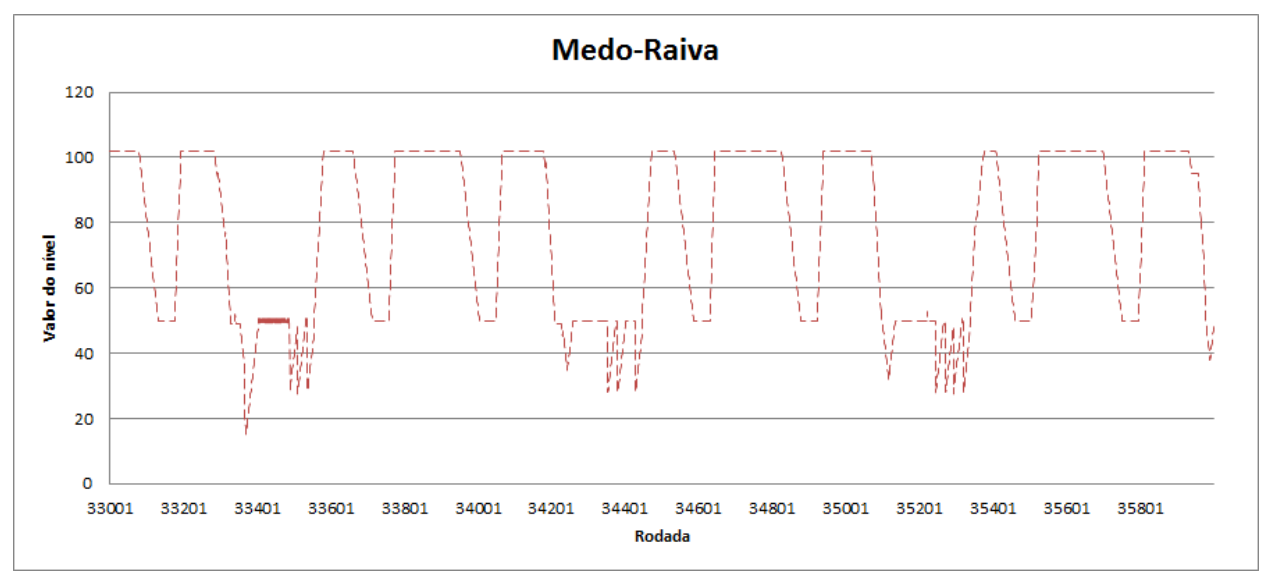

Figura A.32: Resultado das últimas 3000 rodadas da barra medo-raiva. Ele representa a variação do nível da barra.

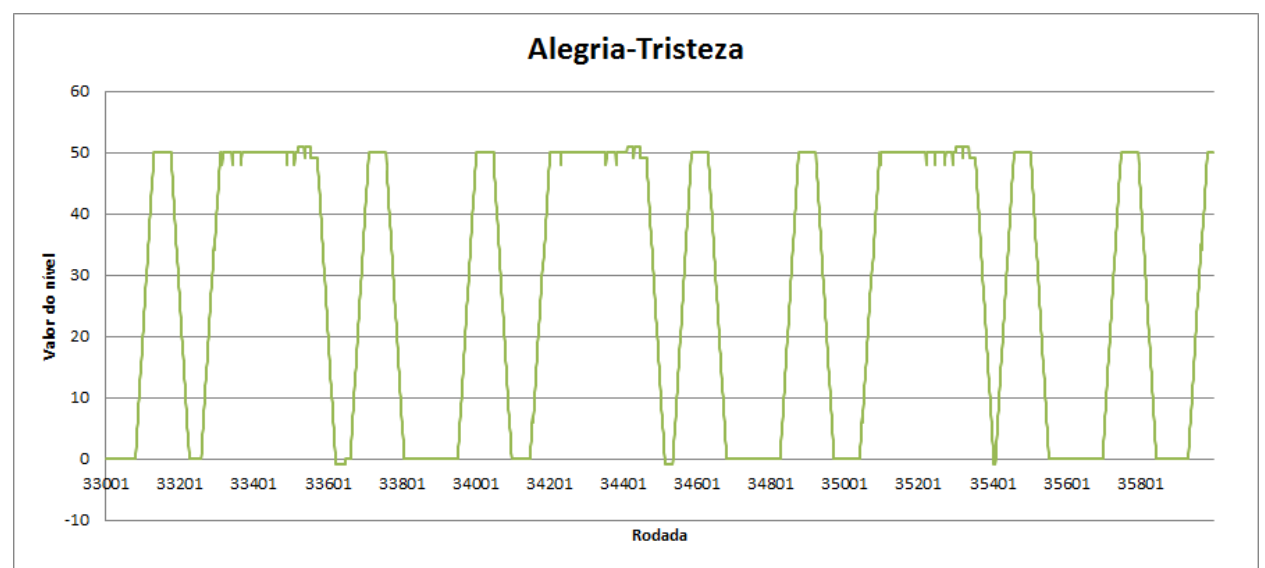

Figura A.33: Resultado das últimas 3000 rodadas da barra alegria-tristeza. Ele representa a variação do nível da barra.

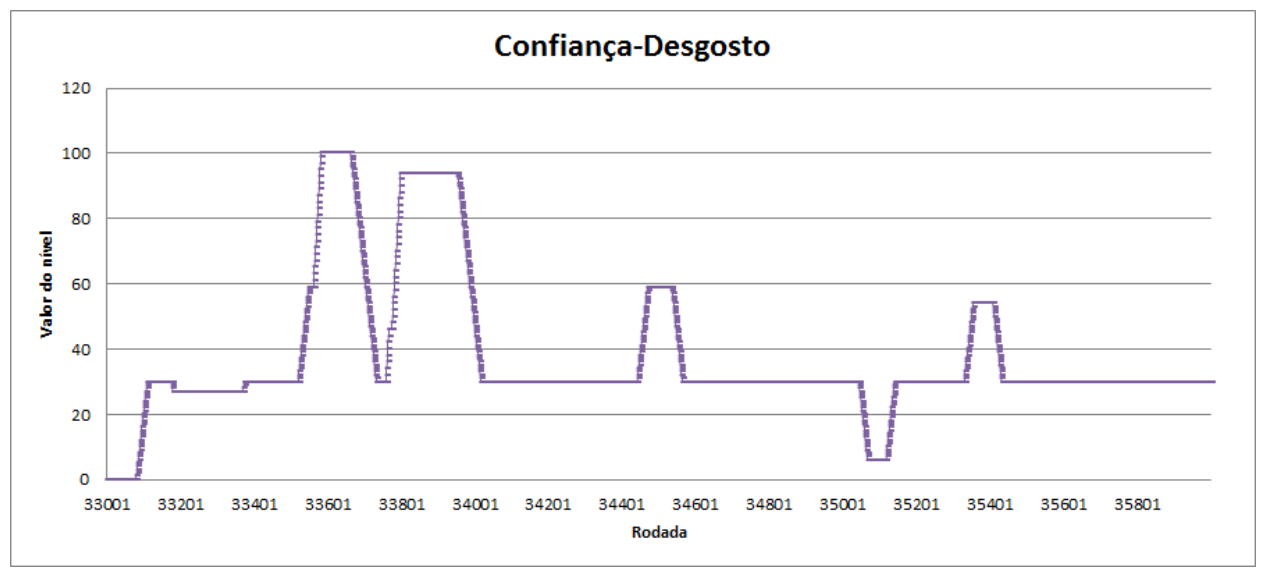

Figura A.34: Resultado das últimas 3000 rodadas da barra confiança-desgosto. Ele representa a variação do nível da barra. 